\title{
UNSAT-H Version 3.0: \\ Unsaturated Soil Water and Heat Flow Model \\ Theory, User Manual, and Examples
}

M. J. Fayer

June 2000

Prepared for

the U.S. Department of Energy

under Contract DE-AC06-76RLO 1830

Pacific Northwest National Laboratory

Richland, Washington 99352 


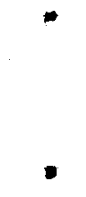




\section{DISCLAIMER}

This report was prepared as an account of work sponsored by an agency of the United States Government. Neither the United States Government nor any agency thereof, nor any of their employees, make any warranty, express or implied, or assumes any legal liability or responsibility for the accuracy, completeness, or usefulness of any information, apparatus, product, or process disclosed, or represents that its use would not infringe privately owned rights. Reference herein to any specific commercial product, process, or service by trade name, trademark, manufacturer, or otherwise does not necessarily constitute or imply its endorsement, recommendation, or favoring by the United States Government or any agency thereof. The views and opinions of authors expressed herein do not necessarily state or reflect those of the United States Government or any agency thereof. 


\section{DISCLAIMER}

Portions of this document may be illegible in electronic image products. Images are produced from the best available original document. 


\section{Summary}

The UNSAT-H model was developed at Pacific Northwest National Laboratory (PNNL) to assess the water dynamics of arid sites and, in particular, estimate recharge fluxes for scenarios pertinent to waste disposal facilities. During the last 4 years, the UNSAT-H model received support from the Immobilized Waste Program (IWP) of the Hanford Site's River Protection Project. This program is designing and assessing the performance of on-site disposal facilities to receive radioactive wastes that are currently stored in single- and double-shell tanks at the Hanford Site (LMHC 1999). The IWP is interested in estimates of recharge rates for current conditions and long-term scenarios involving the vadose zone disposal of tank wastes. Simulation modeling with UNSAT-H is one of the methods being used to provide those estimates (e.g., Rockhold et al. 1995; Fayer et al. 1999).

To achieve the above goals for assessing water dynamics and estimating recharge rates, the UNSAT-H model addresses soil water infiltration, redistribution, evaporation, plant transpiration, deep drainage, and soil heat flow as one-dimensional processes. The UNSAT-H model simulates liquid water flow using Richards' equation (Richards 1931), water vapor diffusion using Fick's law, and sensible heat flow using the Fourier equation.

This report documents UNSAT-H.Version 3.0. The report includes the bases for the conceptual model and its numerical implementation, benchmark test cases, example simulations involving layered soils and plants, and the code manual. Version 3.0 is an enhanced-capability update of UNSAT-H Version 2.0 (Fayer and Jones 1990). New features include hysteresis, an iterative solution of head and temperature, an energy balance check, the modified Picard solution technique, additional hydraulic functions, multiple-year simulation capability, and general enhancements.

This report includes eight example problems. The first four are verification tests of UNSAT-H capabilities, three of which are repeats of the tests used for previous versions of UNSAT-H. The first test examines the ability of UNSAT-H to simulate infiltration compared to separate analytical and numerical solutions. This test was repeated using the modified Picard solution technique. The second test examines the ability of UNSAT-H to simulate drainage compared to measurements and a numerical solution. The third test examines the ability of UNSAT-H to simulate heat conduction compared to an analytical solution. The fourth test is new for UNSAT-H and examines the ability of UNSAT-H to simulate hysteresis compared to measurements and a numerical solution. The results of all four tests showed that the tested processes were correctly implemented in UNSAT-H. The repeat of the first test with the modified Picard solution technique successfully demonstrated a $10^{4}$ to $10^{5}$ reduction in mass balance errors.

The second four example problems are demonstrations of real-world situations. The first three are repeat problems from previous versions of UNSAT-H. The first demonstration involves a 1-year simulation of the water dynamics of a layered soil without heat flow or plants. The second demonstration repeats the first for a 3-day period but with the addition of heat flow. This demonstration was repeated 
with the new energy balance check; a $4 \mathrm{x}$ reduction in the heat balance error was obtained. The third demonstration involves a 1-year simulation of the water dynamics of a sandy soil with plants. The fourth and final demonstration is a 35-year simulation of the water dynamics of a sandy loam soil without plants to highlight the new multiyear capability. 


\section{Acknowledgments}

Before acknowledging those who helped with this document, I want to express my appreciation to those who worked with me on previous versions of UNSAT-H, primarily Tim Jones and Glendon Gee. UNSAT-H Version 3.0 was built on the work of folks like these. For help specifically on Version 3.0, I want to thank Bob Lenhard for his help incorporating his hysteresis model. I want to thank Gary Streile of PNNL for providing a technical review of the report. I am grateful to the editor, Jan Tarantino, and the text processing team for their help transforming my initial rough draft into a polished final report.

Finally, my appreciation goes to all those who sent in suggestions for changes and improvements to the code. Many of the suggestions were excellent and some were implemented in Version 3.0. For those suggestions that did not make it into Version 3.0, I will consider them for implementation in future versions. 


\section{Glossary}

\section{Roman Symbols}

c Fractional cloud cover, unitless

$c_{e} \quad$ Unit conversion factor, $\mathrm{cm} \mathrm{s} \mathrm{m}^{-1} \mathrm{hr}^{-1}$

C Soil water capacity (i.e., $\partial \theta / \partial h), 1 / \mathrm{cm}$

$C_{h} \quad$ Volumetric heat capacity of moist soil, $\mathrm{J} \mathrm{m}^{-3} \mathrm{~K}^{-1}$

$C_{h a} \quad$ Volumetric heat capacity of air, $\mathrm{J} \mathrm{m}^{-3} \mathrm{~K}^{-1}$

$C_{h s} \quad$ Volumetric heat capacity of dry soil particles, $\mathrm{J} \mathrm{m}^{-3} \mathrm{~K}^{-1}$

$C_{h v} \quad$ Volumetric heat capacity of water vapor, $\mathrm{J} \mathrm{m}^{-3} \mathrm{~K}^{-1}$

$C_{h w} \quad$ Volumetric heat capacity of liquid water, $\mathrm{J} \mathrm{m}^{-3} \mathrm{~K}^{-1}$

d Zero plane displacement, $\mathrm{m}$

D Drainage, $\mathrm{cm}$

D Water vapor diffusivity in soil, $\mathrm{cm}^{2} \mathrm{hr}^{-1}$

$D_{a} \quad$ Water vapor diffusivity in air, $\mathrm{cm}^{2} \mathrm{~s}^{-1}$

E Evaporation, cm

$E_{p} \quad$ Potential evaporation, $\mathrm{cm}$

$e \quad$ Evaporation flux density, $\mathrm{cm} / \mathrm{hr}$

$e_{a} \quad$ Saturation vapor pressure at the mean air temperature, mb

$e_{d} \quad$ Actual vapor pressure of air, $\mathrm{mb}$

$g$ Gravitational acceleration, $\mathrm{cm} / \mathrm{s}^{2}$

$G \quad$ Soil surface heat flux density, $\mathrm{J} \mathrm{s}^{-1} \mathrm{~m}^{-2}$ 

Soil water matric suction, $\mathrm{cm}$
$h_{c} \quad$ Matric suction at which the modified van Genuchten retention function is equal to $\theta_{s}, \mathrm{~cm}$
$h_{d} \quad$ Matric suction at which the water content is zero in the Rossi and Nimmo retention functions, $\mathrm{cm}$
$h_{e} \quad$ Air-entry matric suction, $\mathrm{cm}$
$h_{i} \quad$ Coefficient of the Rossi and Nimmo soil water retention functions, $\mathrm{cm}$
$h_{m} \quad$ Matric suction at which the water content is zero in the modified Brooks-Corey and van Genuchten functions, $\mathrm{cm}$
$h_{o} \quad$ Coefficient of the Rossi and Nimmo soil water retention functions, $\mathrm{cm}$
$H \quad$ Hydraulic head, $\mathrm{cm}$
$H \quad$ Soil surface sensible heat flux density, $\mathrm{J} \mathrm{s}^{-1} \mathrm{~m}^{-2}$
$H_{R} \quad$ Relative humidity, unitless
I Infiltration, $\mathrm{cm}$
$I_{L A} \quad$ Leaf area index, unitless
$J \quad$ Day of the year from 1 to 366
$k \quad$ von Karman's constant, unitless
$k_{h} \quad$ Thermal conductivity of soil, $\mathrm{J} \mathrm{s}^{-1} \mathrm{~cm}^{-1} \mathrm{~K}^{-1}$
$K_{L} \quad$ Hydraulic conductivity, $\mathrm{cm} / \mathrm{hr}$
$K_{s} \quad$ Saturated hydraulic conductivity, $\mathrm{cm} / \mathrm{hr}$
$K_{T} \quad$ Total hydraulic conductivity relative to a matric suction gradient and represented by the sum of $K_{L}$ and $K_{v h}, \mathrm{~cm} / \mathrm{hr}$
$K_{v h} \quad$ Equivalent hydraulic conductivity of water vapor in response to a matric suction gradient, $\mathrm{cm} / \mathrm{hr}$
$K_{v T} \quad$ Equivalent hydraulic conductivity of water vapor in response to a temperature gradient, $\mathrm{cm} / \mathrm{hr}$
$\ell \quad$ Pore interaction term, unitless




\begin{tabular}{|c|c|}
\hline$L_{o}$ & Volumetric latent heat of vaporization of water, $\mathrm{J} \mathrm{cm}^{-3}$ \\
\hline$L E$ & Latent heat flux density, $\mathrm{J} \mathrm{s}^{-1} \mathrm{~m}^{-2}$ \\
\hline$M$ & Molecular weight of water, $g$ mole $^{-1}$ \\
\hline$q_{h}$ & Heat flux density, $\mathrm{J} \mathrm{hr}^{-1} \mathrm{~cm}^{-2}$ \\
\hline$q_{L}$ & Flux density of liquid water, $\mathrm{cm} / \mathrm{hr}$ \\
\hline$q_{v}$ & Flux density of water vapor (the sum of $q_{v h}$ and $q_{v T}$ ), cm/hr \\
\hline$q_{v h}$ & Flux density of water vapor due to the matric suction gradient, $\mathrm{cm} / \mathrm{hr}$ \\
\hline$q_{v T}$ & Flux density of water vapor due to the temperature gradient, $\mathrm{cm} / \mathrm{hr}$ \\
\hline$Q_{o}$ & Potential daily solar radiation, $\mathrm{J} \mathrm{s}^{-1} \mathrm{~m}^{-2}$ \\
\hline$r_{h}$ & Boundary layer resistance to heat transfer, $\mathrm{s} / \mathrm{m}$ \\
\hline$r_{v}$ & Boundary layer resistance to water vapor transfer, $\mathrm{s} / \mathrm{m}$ \\
\hline$R$ & Gas constant, erg mole ${ }^{-1} \mathrm{~K}^{-1}$ \\
\hline$R_{n}$ & Net radiation, $\mathrm{J} \mathrm{s}^{-1} \mathrm{~m}^{-2}$ \\
\hline$R_{n i}$ & Isothermal net radiation, $\mathrm{J} \mathrm{s}^{-1} \mathrm{~m}^{-2}$ \\
\hline$R_{o f f}$ & Runoff, $\mathrm{cm}$ \\
\hline$s$ & Slope of the saturation vapor pressure-temperature curve, $\mathrm{mb} \mathrm{K}^{-1}$ \\
\hline$S$ & Sink term that represents plant water uptake, $1 / \mathrm{hr}$ \\
\hline$S_{\text {ext }}$ & $\begin{array}{l}\text { Solar constant, i.e., the flux density of solar radiation at the outside edge of the earth's } \\
\text { atmosphere on a plane normal to the flux of solar radiation, } \mathrm{J} \mathrm{s}^{-1} \mathrm{~m}^{-2}\end{array}$ \\
\hline$S_{h}$ & Heat storage relative to $T_{o}, \mathrm{~J} \mathrm{~cm}^{-3}$ \\
\hline${ }^{i} S_{n r}$ & $\begin{array}{l}\text { Maximum volumetric air content that becomes trapped as the soil is wetted from an air dry } \\
\text { condition to satiation, } \mathrm{cm}^{3} \mathrm{~cm}^{-3}\end{array}$ \\
\hline$S_{p o t}$ & Potential plant water uptake \\
\hline
\end{tabular}




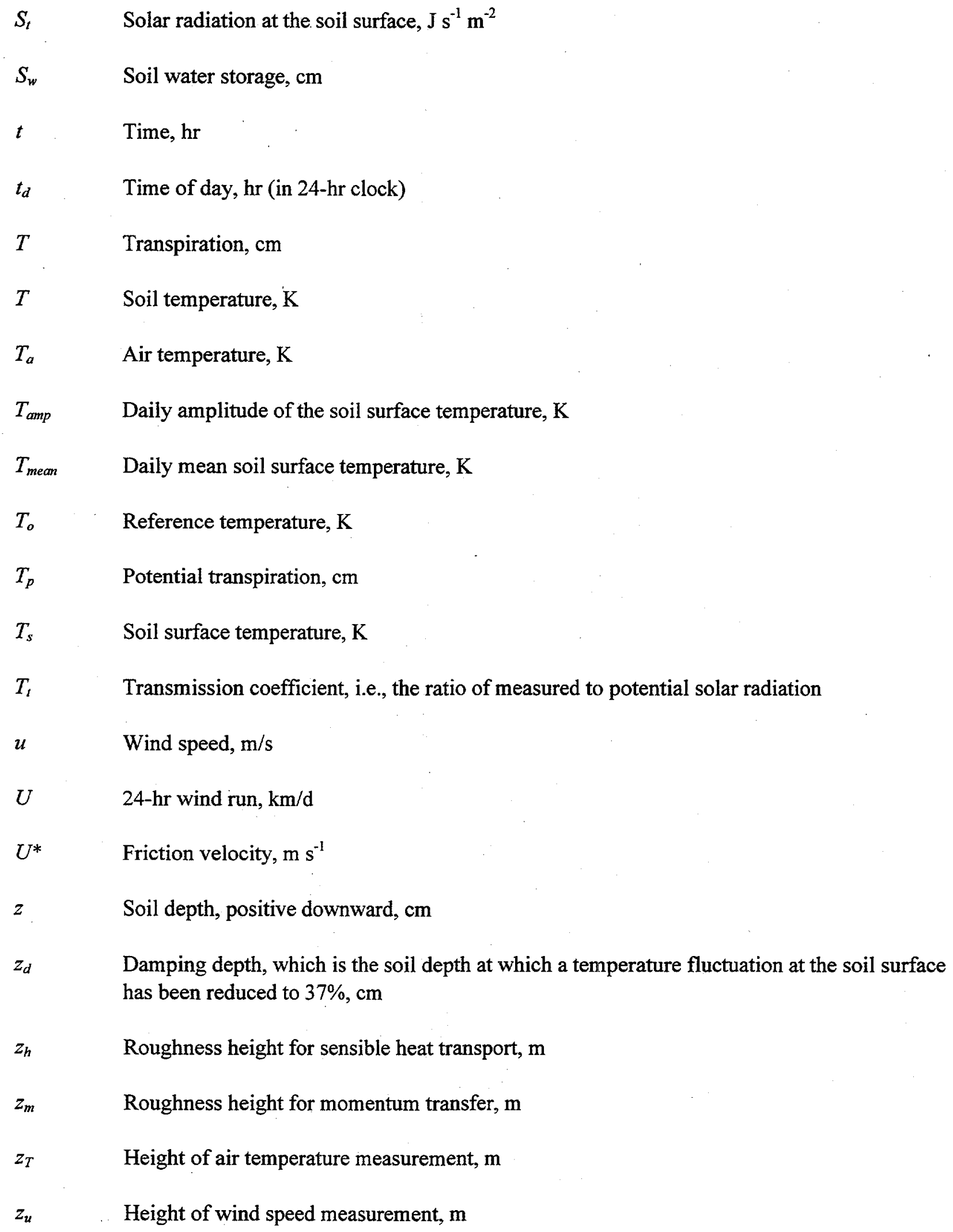




\section{Greek Symbols}

$\alpha$

$\alpha_{d}$

$\alpha_{f}$

$\alpha_{i}$

$\alpha_{s}$

$\beta$

$\chi$

$\delta$

$\varepsilon_{\alpha}$

$\varepsilon_{a c}$

$\mathcal{E}_{s}$

$\gamma$

$\eta$

$\varphi$

$\lambda$

$\pi$

$\theta$

$\theta_{a}$

$\theta_{d}$

Soil hydraulic property coefficient, units are model dependent

van Genuchten $\alpha$ coefficient for the drainage path in the hysteresis model, $1 / \mathrm{cm}$

Plant water uptake factor that relates actual uptake to potential uptake, unitless

van Genuchten $\alpha$ coefficient for the imbibition path in the hysteresis model, $1 / \mathrm{cm}$

Soil surface albedo, unitless

Soil hydraulic property coefficient, units are model dependent

Soil hydraulic property coefficient for describing vapor adsorption, unitless

Solar declination, radians

Clear-sky emissivity, unitless

Cloudy-sky emissivity, unitless

Soil surface emissivity, unitless

Psychrometric constant, $\mathrm{mb} \mathrm{K}^{-1}$

Enhancement factor for thermal vapor diffusion, unitless

Latitude, radians

Coefficient of the Rossi and Nimmo (1994) soil hydraulic property models

Mathematical symbol "pi"

Volumetric water content, $\mathrm{cm}^{3} \mathrm{~cm}^{-3}$

Coefficient of the modified Brooks-Corey and modified van Genuchten hydraulic property functions, $\mathrm{cm}^{3} \mathrm{~cm}^{-3}$

Volumetric water content above which plant water withdrawal is at the optimal rate and below which plant water withdrawal is increasingly less than the potential withdrawal rate, $\mathrm{cm}^{3} \mathrm{~cm}^{-3}$ 
$\theta_{n} \quad$ Volumetric water content above which plants can no longer extract water because of anaerobic conditions, $\mathrm{cm}^{3} \mathrm{~cm}^{-3}$

$\theta_{r} \quad$ Residual volumetric soil water content, $\mathrm{cm}^{3} \mathrm{~cm}^{-3}$

$\theta_{s} \quad$ Saturated volumetric soil water content, $\mathrm{cm}^{3} \mathrm{~cm}^{-3}$

$\theta_{v} \quad$ Water vapor content expressed as an equivalent volumetric soil water content, $\mathrm{cm}^{3} \mathrm{~cm}^{-3}$

$\theta_{w} \quad$ Volumetric water content below which plants can no longer extract water, $\mathrm{cm}^{3} \mathrm{~cm}^{-3}$

$\rho_{r} \quad$ Root density function, $1 / \mathrm{cm}$

$\rho_{r L} \quad$ Root length density, unitless

$\rho_{v} \quad$ Water vapor density in soil pore space, $\mathrm{g} \mathrm{cm}^{-3}$

$\rho_{v a} \quad$ Atmospheric water vapor density, $\mathrm{g} \mathrm{cm}^{-3}$

$\rho_{v s} \quad$ Saturated water vapor density, $\mathrm{g} \mathrm{cm}^{-3}$

$\rho_{v s s} \quad$ Water vapor density at the soil surface, $\mathrm{g} \mathrm{cm}^{-3}$

$\rho_{w} \quad$ Liquid water density, $\mathrm{g} \mathrm{cm}^{-3}$

$\sigma \quad$ Stephan-Boltzmann constant, $\mathrm{J} \mathrm{s}^{-1} \mathrm{~m}^{-2} \mathrm{~K}^{-4}$

$\omega \quad$ Angular frequency of the soil surface temperature oscillation, $1 / \mathrm{hr}$

$\psi \quad$ Matric potential (the negative of matric suction), $\mathrm{cm}$

$\psi_{h} \quad$ Atmospheric stability correction factor for sensible heat transport, unitless

$\psi_{m} \quad$ Atmospheric stability correction factor for momentum transport, unitless

$\zeta \quad$ Atmospheric stability parameter, unitless 


\section{Contents}

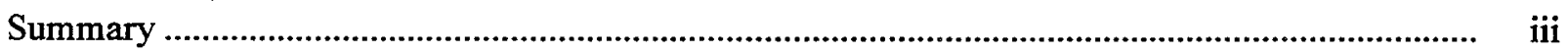

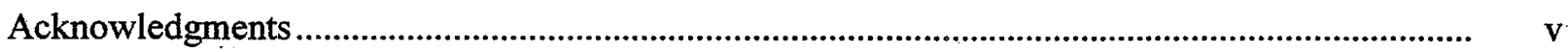

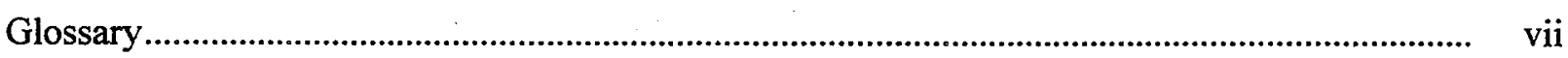

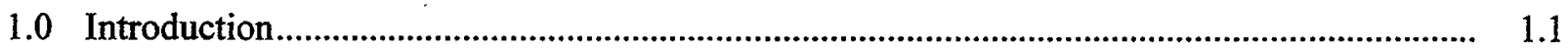

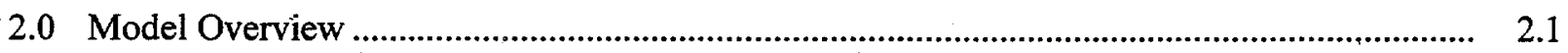

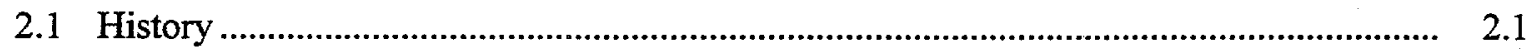

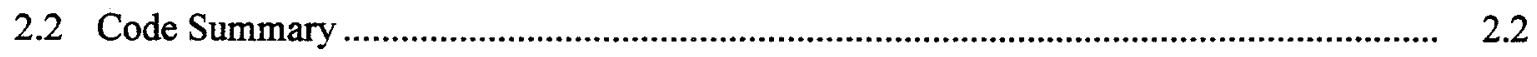

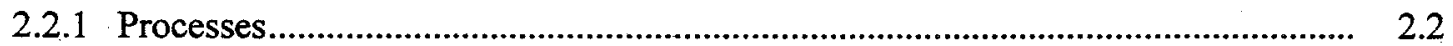

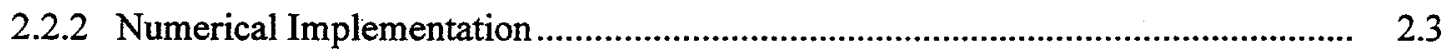

2.2.3 Input Requirements............................................................................... 2.3

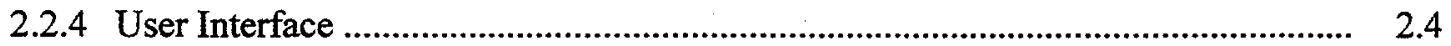

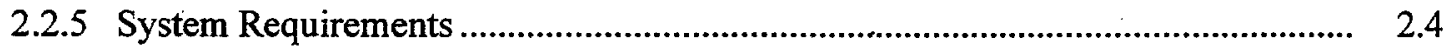

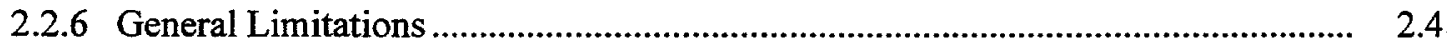

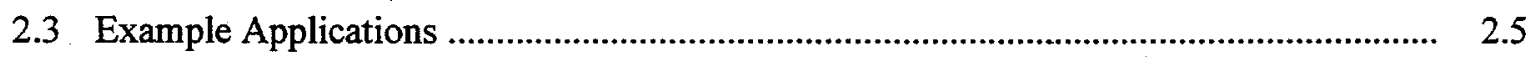

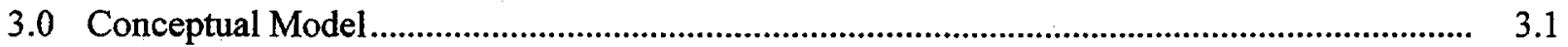

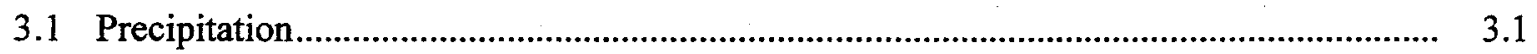

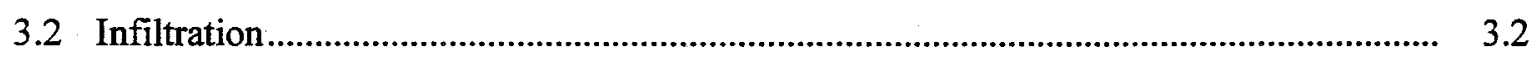

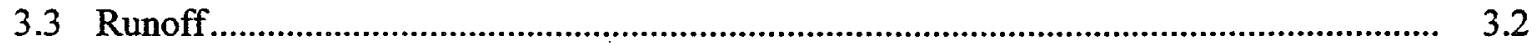

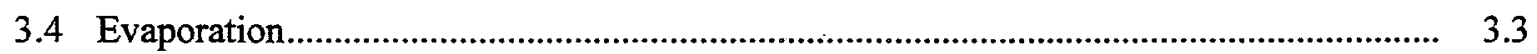

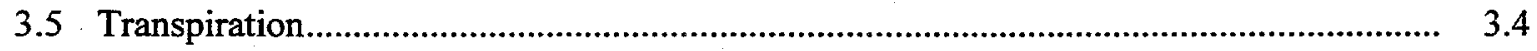

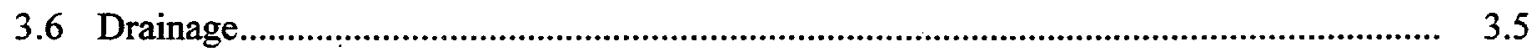

4.0 Mathematical Model ..........................................................................................

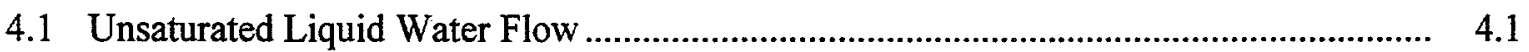




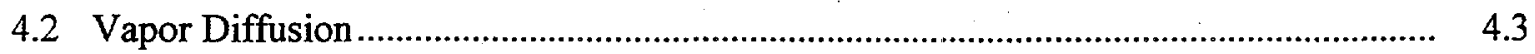

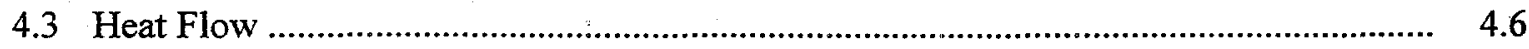

4.4 Constitutive Relationships........................................................................................... 4.7

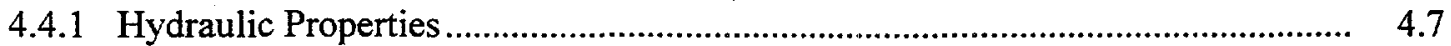

4.4.2 Vapor Properties ........................................................................................... 4.13

4.4.3 Thermal Properties ................................................................................. 4.13

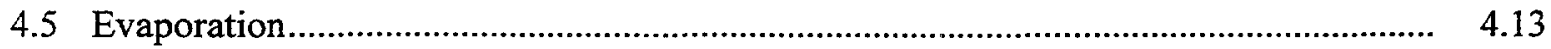

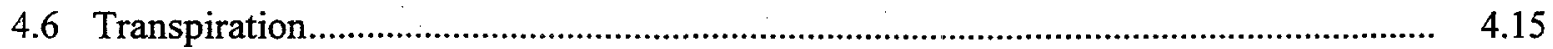

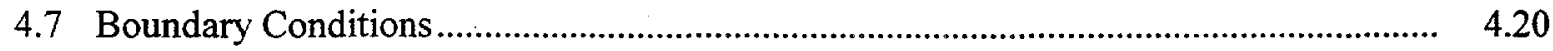

5.0 Numerical Implementation .......................................................................................

5.1 Finite Difference Approximation of Water Flow ..................................................

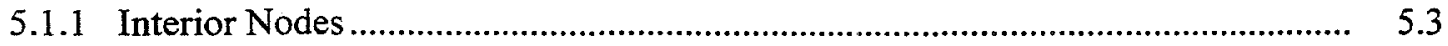

5.1.2 Surface Boundary Node.................................................................................. 5.4

5.1.3 Lower Boundary Node ......................................................................... 5.7

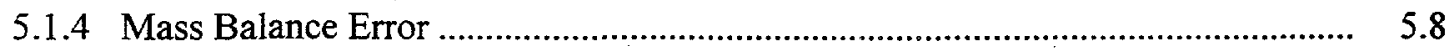

5.2 Finite Difference Approximation of Heat Flow ....................................................... 5.8

5.2.1 Interior Nodes .................................................................................... 5.10

5.2 .2 Surface Boundary Node .................................................................................... 5.11

5.2 .3 Lower Boundary Node .............................................................................. 5.13

5.2.4 Heat Balance Error ................................................................................... 5.14

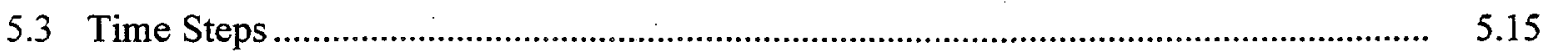

6.0 Code Design, Problem Formulation, and Code Operation ................................................. 6.1

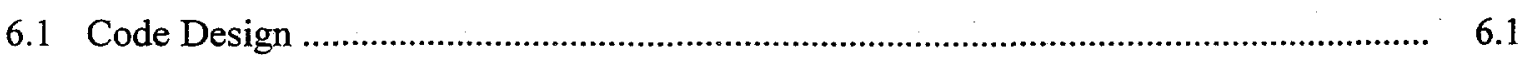

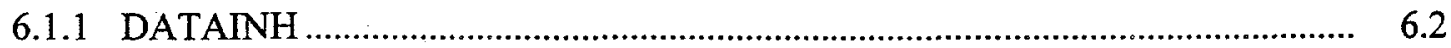

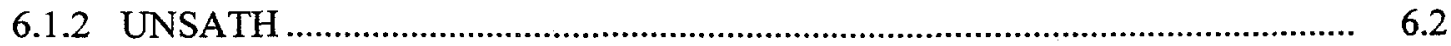

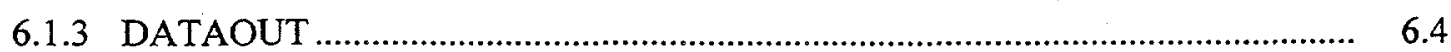

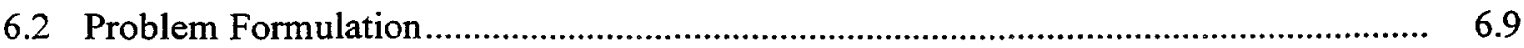


6.3 Code Operation

7.0 Example Simulations

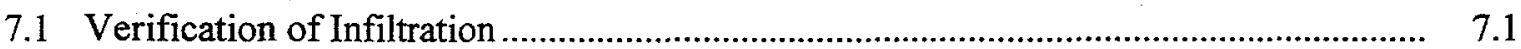

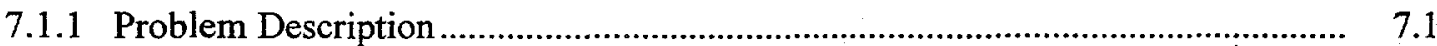

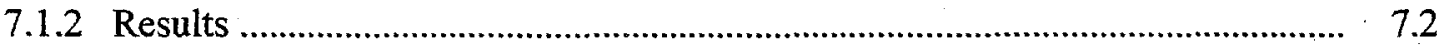

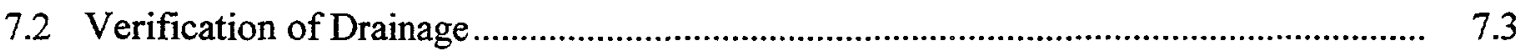

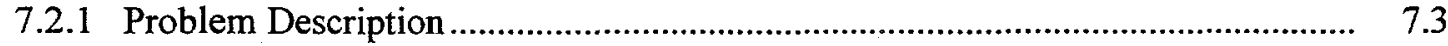

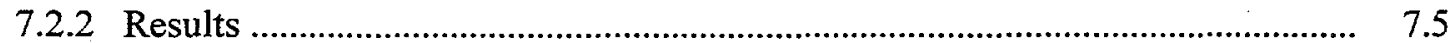

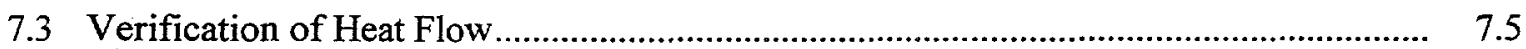

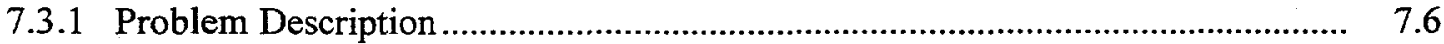

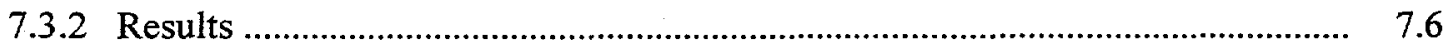

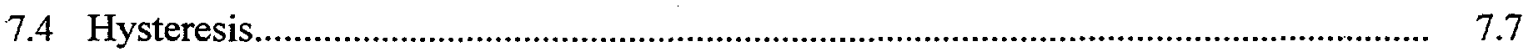

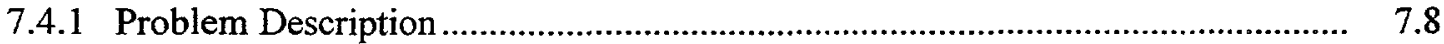

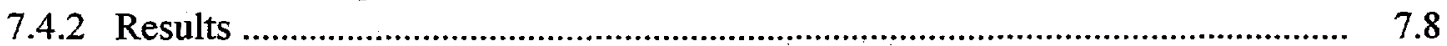

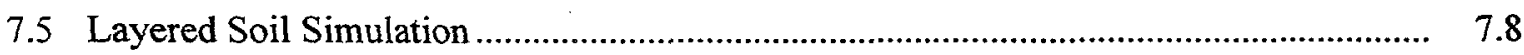

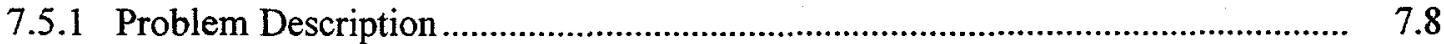

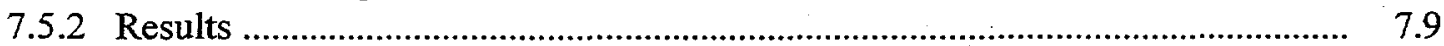

7.6 Layered Soil Simulation with Heat Flow ................................................................

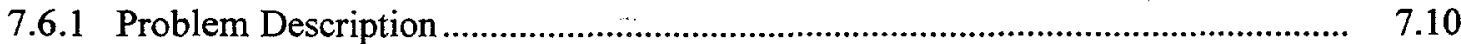

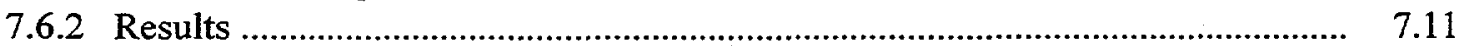

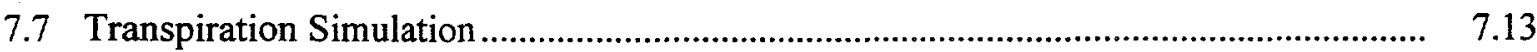

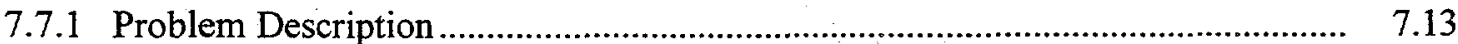

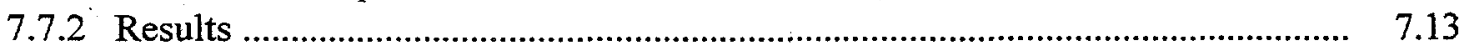

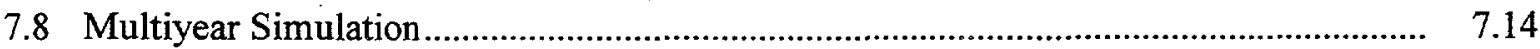

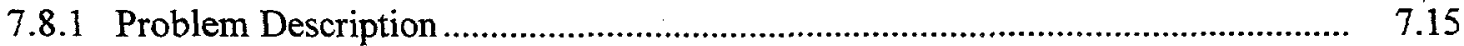

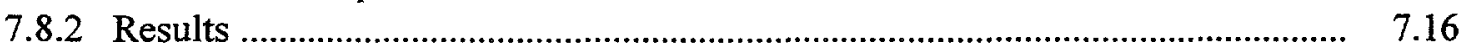




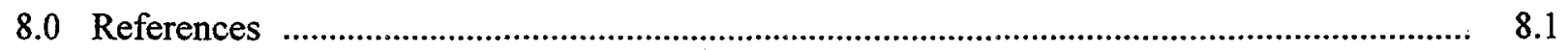

Appendix A - UNSAT-H Version 3.0 Input Manual ........................................................... A.1

Appendix B - Input and Output Files for Example Simulations ......................................... B.1 


\section{Figures}

4.1 Effect of Hysteresis on Water Retention During Drying and Wetting of Silt Loam................ $\quad 4.10$

4.2 The Ratio of Potential Transpiration to Potential Evapotranspiration as a Function of Leaf Area Index

4.3 Relationship Between the Ratio of Transpiration to Net Radiation and Day of the Year

4.4 Root Mass at the End of the 1974 Growing Season Cheatgrass and Bluebunch Wheatgrass Communities of the Hanford Site

4.5 The Sink Term Reduction Factor $a_{f}$ as a Function of Water Content.

6.1 Format of the *.bin File Created by DATAINH for Input to UNSATH

6.2 Operations Flow of UNSATH

6.3 Operations Flow of DELSUB Loop in UNSATH

6.4 Format of the *.res Output File Created by UNSATH

6.5 Example Problem Formulation: a) Site Description, b) Model Representation

6.6 Parameter Dimensions Associated with UNSAT-H Version 3.0

7.1 Infiltration Rate and Cumulative Infiltration Versus Time as Determined Using the Philip Solution, the Numerical Code of Haverkamp et al., and UNSAT-H.

7.2 Cumulative Drainage Versus Time as Determined by Kool et al. and UNSAT-H

7.3 Soil Temperature as a Function of Time (a) and Depth (b) as Determined Using an Analytic Solution and UNSAT-H.

7.4 Degree of Saturation Measured, Predicted by Lenhard et al., and Predicted by UNSAT-H

7.5 Water Content Profiles Within a Layered Soil

7.6 Simulation Results for Water and Heat Flow in a Layered Soil

7.7 Soil Hydraulic Properties for the 200 Area Lysimeter 


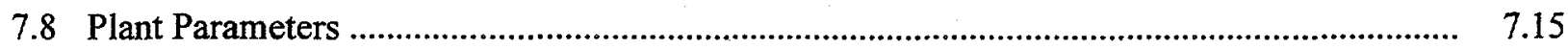

7.9 Variation in Annual Deep Drainage for the Multiyear Simulation Example ........................... 7.16

\section{Tables}

4.1 Cheatgrass Root-Biomass Data, Root-Length Density, and Root Density Function

6.1 Data Flow, Program Tasks, and Subroutines.

6.2 Definition of Computer Variables Used in Section 6

6.3 Subroutines in DATAINH

6.4 Subroutines in UNSATH 6.5

6.5 Subroutines in DATAOUT

6.6 Logical Unit Assignments

7.1 Parameters Used in the Infiltration Simulations.

7.2 Impact of Using the Modified Picard Solution Technique

7.3 Hydraulic Property Parameters for Silt Loam Soil and Ceramic Plate 7.4

7.4 Parameters Used in the Multiyear Simulation. 


\subsection{Introduction}

The accelerating pace of development throughout the world places increasing demands on the vadose zone, which is that portion of the earth's surface that encompasses the soil and unsaturated sediments that lie above the water table. On a site-specific basis, the vadose zone affects the movement of water, nutrients, chemicals, pathogens, and contaminants to (and sometimes from) the water table. Of special importance from a vadose-zone perspective are contaminants (e.g., low-level, mixed, transuranic [TRU] wastes) that have been buried in or released to the vadose zone, or the contaminants that have been or will be disposed in special vadose zone facilities (e.g., lined landfills, vaults). In most cases, the dominant mechanism for movement is the liquid water flux, and to some extent in drier regions, the vapor flux (exceptions include nonaqueous phase liquids and gases). Thus, the successful assessment of the quantity and quality of groundwater resources depends, in part, on the ability to predict the flux of water that moves into and through the vadose zone. These fluxes, loosely called recharge rates, are the primary mechanism for transporting vadose zone contaminants to the groundwater. The acceptability of contaminants in the vadose zone is contingent on a credible demonstration that recharge rates to the water table are less than those that would transport sufficient quantities of soluble contaminants to create an environmental or risk hazard.

Numerical modeling is one of the methods used to estimate the flux of water moving through the vadose zone. Field measurements of recharge rates are ideal but often expensive and of limited spatial and temporal scope. For example, the data do not exist for many of the disposal scenarios under consideration and the data certainly do not exist for the disposal time frame of 1000 years or more. In lieu of actual data, a recharge model can be used to assess any scenario or cover design and to make predictions of future recharge rates given estimates of future climate and vegetation conditions.

The UNSAT-H model was developed at Pacific Northwest National Laboratory (PNNL) for assessing the water dynamics of arid sites and, in particular, estimating recharge fluxes for scenarios pertinent to waste disposal facilities at the Hanford Site. The UNSAT-H model accomplishes this goal by simulating soil water infiltration, redistribution, evaporation, plant transpiration, deep drainage, and soil heat flow.

The UNSAT-H model was developed during the last several years to support the Immobilized Waste Program (IWP) of the Hanford Site's River Protection Project. This program is designing and assessing the performance of on-site disposal facilities to receive radioactive wastes that are currently stored in single- and double-shell tanks at the Hanford Site (LMHC 1999). Specifically, the wastes in the tanks will be separated into high- and low-activity fractions. The high-activity fraction will be vitrified and sent to a national repository. The low-activity fraction will be vitrified, renamed immobilized low-activity waste (ILAW), and stored in a disposal facility at Hanford. PNNL assists the IWP in performance assessment (PA) activities associated with the ILAW disposal facility. One of the PNNL tasks is to provide estimates of recharge rates for current conditions and long-term scenarios involving the vadose zone disposal of ILAW. Simulation modeling with UNSAT-H is one of the methods being used to provide those estimates (e.g., Rockhold et al. 1995; Fayer et al. 1999). 
This report documents UNSAT-H Version 3.0. The report includes the bases for the conceptual model and its numerical implementation, benchmark test cases, example simulations involving layered soils and plants, and the code manual. Version 3.0 is an enhanced-capability update of UNSAT-H Version 2.0 (Fayer and Jones 1990). New features include hysteresis, an iterative solution of head and temperature, an energy balance check, the modified Picard solution technique, additional hydraulic functions, multiple year simulation capability, and general enhancements. As UNSAT-H Version 3.0 is used and evaluated, the documentation represented by this report will provide the basis for further evaluations and potential enhancements. 


\subsection{Model Overview}

The two major objectives of UNSAT-H are to estimate deep drainage rates (which can then be used in contaminant transport and water resources analyses) and assist in optimizing barrier design. To accomplish these objectives, the model must be able to predict the near-surface water dynamics at the pertinent sites for current and postulated future climatic conditions.

\subsection{History}

The history of UNSAT-H begins with the UNSAT model (Gupta et al. 1978). The purpose of the UNSAT model was to predict the water dynamics of agricultural land. In 1979, the UNSAT model was brought to the Hanford Site and modified for waste management. The result was UNSAT-H Version 1.0, with the " $\mathrm{H}$ " being added to signify Hanford (Fayer et al. 1986). Although most of the mathematical and numerical formulations of the UNSAT model that related to liquid water flow were retained in UNSAT-H Version 1.0, the model was changed to include isothermal vapor flow, an empirical cheatgrasstranspiration algorithm, and additional hydraulic property functions.

In 1990, new capabilities were added to UNSAT-H to create Version 2.0 (Fayer and Jones 1990). These new capabilities allowed the model user to simulate soil heat flow, thermal vapor flow, and actual evaporation directly, as well as represent soil hydraulic properties with the van Genuchten water retention function and the Mualem conductivity function.

Subsequent to publication of UNSAT-H Version 2.0, several revisions of the code were released to reflect error corrections and capability additions. Version 2.03 , which was available for several years, was the last version to use single-precision REAL variables. Starting with Version 2.04, which was made available in July 1998, double-precision REAL variables were used to achieve greater accuracy, particularly when fluxes were very low. Version 2.04 also allowed the user to modify the equation used to partition potential evapotranspiration (PET) to reflect more accurately the transpiration rate of plant communities with a low leaf area index. Version 2.05 was released in April 1999 to include a couple of minor updates and to fix a rare time-step error that led to an infinite loop. Version 2.05 represents the last release prior to the release of Version 3.0.

For Version 3.0 (this report), the UNSAT-H code was modified to include hysteresis, an iterative solution of head and temperature, an energy balance check, the modified Picard solution technique, additional hydraulic functions, multiple year simulation capability, and general enhancements. For the remainder of this report, comments concerning UNSAT-H will refer to Version 3.0, unless stated otherwise. 


\subsection{Code Summary}

The UNSAT-H code is designed to simulate water and heat flow processes in one dimension (typically vertical). UNSAT-H can simulate the isothermal flow of liquid water and water vapor, the thermal flow of water vapor, the flow of heat, the surface energy balance, soil-water extraction by plants, and deep drainage. Information about where to find the code, updates, and lessons learned can be found at http://hydrology.pnl.gov/.

\subsubsection{Processes}

Infiltration. The UNSAT-H model simulates infiltration in a two-step process. First, infiltration is set equal to the precipitation rate during each time step. Second, if the surface soil saturates, the solution of that time step is repeated using a Dirichlet boundary condition (with the surface node saturated). The resulting flux from the surface into the profile is the infiltration rate.

Runoff. The UNSAT-H model does not simulate runoff explicitly. Instead, it equates runoff to the precipitation rate that is in excess of the infiltration rate. There is no provision for run-on or surface detention.

Soil Water and Heat Flow. The UNSAT-H model simulates liquid water flow using the Richards equation, water vapor diffusion using Fick's law, and sensible heat flow using the Fourier equation. Convective airflow is not considered. Options for describing soil water retention include linked polynomials, the Haverkamp function, the Brooks and Corey function, the van Genuchten function, and several special functions that account for water retention of very dry soils. In addition, the van Genuchten function can also be treated hysteretically. Options for describing hydraulic conductivity include linked polynomials, the Haverkamp model, the Mualem model, and the Burdine model.

Drainage and Lower Boundary Heat Flow. The UNSAT-H model has several options for the boundary conditions. For water flow, the user can specify Dirichlet or Neumann conditions, or a unit hydraulic gradient condition. For heat flow, the user can specify Dirichlet or Neumann conditions, or a temperature gradient.

Evaporation. The UNSAT-H model simulates evaporation in two ways. In the isothermal mode, UNSAT-H uses the PET concept. The user supplies either daily values of PET or daily weather data, with which the code calculates daily PET values using the Penman equation. During each time step, the code attempts to apply the potential evaporation rate. If the soil surface dries to or above a user-defined matric potential limit, the time step is re-solved using a Dirichlet condition at the surface. In this situation, the surface potential is held constant at the matric potential limit and evaporation is set equal to the flux from below.

In the thermal mode, UNSAT-H calculates evaporation as a function of the vapor density difference between the soil and the reference height (the height at which air temperature and wind speed are measured) and the resistance to vapor transport. The resistance to vapor transport is a function of several factors, including air temperature, wind speed, and atmospheric stability. 
Transpiration. The UNSAT-H model simulates the effects of plant transpiration using the PET concept. There is no provision to simulate both water and heat flow in a plant canopy. Plant information is supplied to the code to partition the PET into potential evaporation and potential transpiration. The potential transpiration is applied to the root zone using the root distribution to apportion it among the computational nodes that have roots. The withdrawal of water from a particular node is dependent on the suction head of the node. The user provides suction head values that define how the potential transpiration rate applied to a particular node is reduced. Below the minimum value, sometimes known as the wilting point, transpiration is unable to remove any water. When all nodes with roots reach this level of suction head, transpiration is reduced to zero.

\subsubsection{Numerical Implementation}

The mathematical equations that describe the state and dynamics of the modeled system are written in an implicit finite-difference form. The user must specify an averaging scheme for internodal hydraulic and vapor conductivities; choices include arithmetic (and arithmetic-weighted), geometric, and harmonic. Heat internodal conductances are calculated as arithmetic means. The resulting equations are solved using an iteration technique (either standard or modified Picard) with the Thomas algorithm. The solution strategy for each iteration is to solve the water flow equations, then solve the heat flow equations. After the second and subsequent iterations, the convergence criteria are checked.

The user controls the spatial detail of the solution by specifying the node spacing in the input file. The user also controls the temporal detail by specifying the minimum and maximum time step size. The user can control the solution accuracy by specifying acceptance criteria for the solution to a particular time step. The available criteria include change in water content, mass balance error, absolute change in head, relative change in head, and heat balance error.

\subsubsection{Input Requirements}

The following list is a subset of the information needed to run UNSAT-H (see Appendix A for a complete list). Not all of these inputs are needed for every simulation. Instructions for formulating a problem to be solved and running the code are given in Section 6.0. The format for entering the data is listed in Appendix A.

Simulation Information. This information includes simulation options. Simulation options include number of nodes (up to 250 nodes in the compiled version), node depths and associated material types (up to 10 materials in the compiled version), boundary condition choices, output frequencies, and maximum and minimum time step size.

Constitutive Relationships. This information includes the parameters needed to describe the hydraulic, hysteretic, and thermal properties of each material, depending on the options chosen.

Initial Conditions. This information includes the initial suction head profiles and soil temperature profiles (if simulating heat flow). 
Plant Parameters. This information includes details about the seasonal variation of leaf area index and maximum rooting depth, root density variations with depth, and suction head limits that impact the withdrawal efficiency of plants. UNSAT-H also has a specific function for partitioning PET into evaporation and transpiration for Bromus tectorum (cheatgrass).

Boundary Conditions. This information includes daily PET values; daily weather conditions (e.g., temperature, wind speed, solar radiation, precipitation); and lower boundary condition choices (e.g., water fluxes, temperature gradient).

\subsubsection{User Interface}

The UNSAT-H code comprises three programs. DATAINH is used to read the text input file, process the information, and create a binary input file. UNSATH is the main program; it reads the binary input file, performs the simulation, and creates a binary output file. The user runs DATAOUT to read the binary output file. The output file contains daily (and less-than-daily if selected by the user) summaries of water content, suction head, water flow, temperature, heat flow, and plant water use as a function of depth. The file also contains cumulative totals of the water and heat balance components (e.g., storage, precipitation, evaporation, transpiration, drainage, net radiation, and the sensible, latent, and soil heat fluxes). The user can then view the output on screen or write the output to a text file for manipulation with a spreadsheet or graphics program.

\subsubsection{System Requirements}

The UNSAT-H code is written in Compaq Visual Fortran, ${ }^{(a)}$ which is based on American National Standard FORTRAN 77 (ANSI X3.9-1978) and FORTRAN 90 (ANSI X3.198-1992). Although extensions to FORTRAN 77 are available, limited use has been made of them to keep UNSAT-H close to standard FORTRAN 77 form. The UNSAT-H code may not compile cleanly with other compilers. The removal of this restriction may be considered in the next revision of UNSAT-H.

The executable images for a PC require a total of 1.5 megabytes of storage. The storage required for a given output file depends on the number of nodes and length of time simulated. For the 250 -node CLAY example in Section 7.1, the output file required 537 kilobytes of storage for the 41-day simulation using daily output.

\subsubsection{General Limitations}

Features of UNSAT-H that may limit its application include one dimensionality, the use of empirical plant transpiration algorithms, and the lack of algorithms for snowmelt, freezing soil, and the temperature dependence of soil properties. Use of UNSAT-H is considered valid where flow is assumed to be strictly vertical, such as in fairly level terrain or the central portion of a landfill surface cover. For steeper terrain or the edge of an elevated surface cover with sideslopes, lateral flow could be significant and thus not be amenable to analysis with a one-dimensional model. Although the one-dimensional nature of UNSAT-H

(a) Compaq Computer Corporation, P. O. Box 692000, Houston, Texas 77269-2000. 
constitutes a well-defined limitation on the types of problems that can be solved, the other limitations listed above do not. The severity of each of these limitations with respect to the intended uses of the code is being evaluated by validation testing, which is the process by which model predictions are objectively compared to field or laboratory data. Testing by Fayer et al. (1992), Fayer and Gee (1997), and Khire et al. (1997) has begun to demonstrate the reliability of UNSAT-H predictions.

\subsection{Example Applications}

UNSAT-H can be used to solve a variety of water and heat flow problems in unsaturated soils and sediments. With proper accounting for site-specific features, recharge can be estimated as a function of variations in soil type or layering, plant cover and type, and climate. The applications described below represent a small sample of those available. These examples are intended to give the reader a sense of what has been accomplished.

The first major use of UNSAT-H was for the cover analyses used to support the Hanford Defense Waste Environmental Impact Statement (DOE 1987). The simulations illustrated the impact of soil type and layer thickness, the presence of plants, and weather variations on drainage through the cover. For all of these simulations, the precipitation rate was increased to twice normal $(30.1 \mathrm{~cm} / \mathrm{yr})$ to evaluate what was then considered a worst-case situation. The results showed that coarse-textured soils such as sands were ineffective at preventing drainage under these conditions whereas fine-textured soils were effective. The results also showed that a coarse-textured layer was needed beneath the fine-textured layer to create a capillary break. If this "break" was too deep (e.g., $3.0 \mathrm{~m}$ ) or not present at all, the fine-textured soil could not prevent significant drainage from occurring.

Baca and Magnuson (1990) conducted verifications and benchmark tests of UNSAT-H. In addition to repeating the tests reported by Fayer and Jones (1990), they conducted additional tests that included horizontal infiltration, imposition of a constant heat flux at the surface, infiltration into a stratified vadose zone, and coupled heat and water flow in a field test plot. Baca and Magnuson judged UNSAT-H to be fully operational.

Fayer and Gee (1992) used UNSAT-H to demonstrate the sensitivity of predicted drainage to hydraulic property descriptions and vapor flow. They used drainage and water content data collected from a sand-filled lysimeter at the Hanford Site for comparison. They found that, of the 10 hydraulic property cases evaluated, 9 cases yielded drainage predictions within $10 \%$ of the measured value when vapor flow was included. Without vapor flow, only one case yielded a drainage prediction within $10 \%$ of measured value. Fayer and Gee (1992) concluded that vapor flow was a necessary process to be included in simulations of drainage in sandy soil in semiarid climates.

Fayer et al. (1992) tested the UNSAT-H model using data from a 1.7-m deep lysimeter containing a specific cover design. They found that the model reproduced much of the observed water balance changes. The largest discrepancies occurred in winter (when evaporation was overpredicted) and summer (when evaporation was underpredicted). Fayer et al. (1992) demonstrated the model sensitivity to the saturated hydraulic conductivity $\left(K_{s}\right)$, the pore interaction term, PET, and the presence of a snow cover (mimicked by setting PET to zero). When optimal values of these parameters were used in a single 
simulation, i.e., the calibrated model, the root-mean-square error was reduced by $63 \%$ from that determined with the uncalibrated model. Additional simulations were performed that indicated that hysteresis is also important to modeling of covers.

Magnuson (1993) used UNSAT-H simulations to evaluate two landfill cover designs for a disposal facility in Idaho. He examined the sensitivity of UNSAT-H to changes in the hydraulic property parameters of the cover soil and the underlying gravel and cobble layers. In most cases, the changes were factors of 0.5 and 2.0 about the base value. Drainage through this cover during the 10 -year simulations was nil, so he used the maximum predicted storage as a surrogate measure of performance, reasoning that drainage was most likely under those conditions when storage was at a maximum. Magnuson found that the hydraulic properties of the surface soil layer had the greatest impact on maximum storage. Changing the saturated water content $\left(\theta_{s}\right)$ by $0.1 \mathrm{~cm}^{3} / \mathrm{cm}^{3}$ yielded a $10 \%$ change in maximum storage. Increasing the air-entry suction head $\left(h_{c}\right)$ of the surface soil decreased maximum storage, whereas increasing the value for the gravel or cobble layers increased maximum storage slightly. Changing the $K_{s}$ value of the surface soil decreased maximum storage. Apparently, precipitation could infiltrate the soil more deeply, but it was easier for evaporation to extract that water later. Changes to the $K_{s}$ of the gravel and cobble layers had no discernible effect on maximum storage.

Magnuson (1993) also evaluated the sensitivity to the same parameters for the case where the cover was a single soil material with no layering. For these simulations, drainage was detectable so it was used as the performance measure. Magnuson found that drainage changed inversely with changes in $\theta_{s}$. For example, as $\theta_{s}$ was changed from 0.5 to 0.4 , drainage increased by $89 \%$ (from 1.36 to $2.58 \mathrm{~cm} / \mathrm{yr}$ ). Changing the residual water content ( $\theta_{r}$ ) from 0.007 to 0.056 increased drainage by $36 \%$. Increasing $h_{c}$ from 21 to $60 \mathrm{~cm}$ reduced drainage by $91 \%$. Magnuson looked at a second soil type and found that the model responses to the changes were sometimes different. For example, increasing the $K_{s}$ of the second soil type increased drainage, in contrast to the first soil type in which drainage decreased with increasing $K_{s}$. The importance of this result is that parameter sensitivities can be dependent on the conceptual model and so should be determined on a case-by-case basis.

Fayer and Gee (1997) used a 6-year record of water storage, suction, and drainage data to test UNSAT-H. This comparison was an extension of the work by Fayer et al. (1992). The data were collected from a non-vegetated weighing lysimeter containing $1.5 \mathrm{~m}$ of silt loam over sand and gravel. This capillary-break layering configuration was designed to promote water storage in the upper layer for easier removal by evapotranspiration. Four simulations were conducted: 1) standard parameters, 2) calibrated parameters, 3) heat flow, and 4) hysteresis. The water storage results showed little difference among the four simulations; the root mean square (RMS) errors were all between 23.4 and $23.7 \mathrm{~mm}$. Fayer et al. (1992) reported an RMS error of $8.1 \mathrm{~mm}$ for the calibrated simulation during the first 1.5 years. Beyond the calibration period, however, the calibrated model was not much more successful than the other models in predicting total water storage.

The standard parameters, heat flow, and hysteresis simulations had the largest maximum storage difference $(75$ to $80 \mathrm{~mm})$; the calibrated simulation had the smallest $(59.3 \mathrm{~mm})$. This result may be one benefit of the calibration, the goal of which was to match the peak water storage in winter. In contrast, 
the calibrated simulation had the largest mean and median differences (19.6 and $16.4 \mathrm{~mm}$, respectively). The other simulations had values between -6.0 and $3.0 \mathrm{~mm}$.

All of the simulations almost always overpredicted suction heads, more so in the summer than the winter. The hysteresis simulation gave the best qualitative match of suction heads throughout the 6-year period. At times, the predictions coincided with the measurements, most importantly during the one and only drainage event observed in 6 years. The other three simulations predicted suction heads that were generally at least a factor of 3 greater than the measured values.

The hysteresis simulation was the only one to predict drainage. The predicted cumulative drainage was within $52 \%$ of the measured amount and the timing matched the observations. Fayer and Gee (1997) attributed the success of the drainage prediction to the ability to simulate suction heads at the interface. They suggested that suction head is better than water storage as an indicator of conditions at the silt loamsand interface that control drainage.

Based on the comparisons, Fayer and Gee (1997) reached several conclusions. First, UNSAT-H can reasonably predict the water balance components of a capillary-break type cover. The predictions improve if the hysteresis phenomenon is included. Second, the inclusion of heat flow has only a minor effect on surface evaporation and vapor flow within the soil. The impacts of heat flow on snow accumulation and melt and on soil freezing were not evaluated, but Fayer and Gee (1992) speculated that these impacts could be important. Finally, a calibrated model will not necessarily apply well outside of the calibration period. Fayer and Gee (1997) offered suggestions for improving the calibration process: 1) include a more complete conceptual model (e.g., including hysteresis), 2) use multiple performance measures, and 3) calibrate with a period of time sufficiently long to encompass the range of conditions envisioned for the design life of the cover.

Khire et al. (1997) applied the UNSAT-H and HELP models to resistive barrier test cells at the Greater Wenatchee Regional Landfill in Washington and the Live Oak Landfill in Georgia. The Wenatchee landfill is in a semiarid climate; the Live Oak landfill is in a humid climate. The authors tested the models using a 3-year record of data that included overland flow, soil water storage, evapotranspiration, and percolation. The results, in the form of time series plots, showed that the models generally mimicked the seasonal trends. The authors stated that the UNSAT-H predictions tended to be more accurate that those using HELP. With respect to UNSAT-H, the authors noted several conceptual features that were important to the Wenatchee site but were not included in the model: snow cover, snow melt, and freezing soil. Based on their experience with simulating these two landfills, Khire et al. (1997) suggested that practitioners use a simpler model (e.g., HELP) during the iterative design phase and a more complex model (e.g., UNSAT-H) for final checks.

Fayer et al. (1999) conducted a set of simulations to estimate recharge rates for scenarios pertinent to the 2001 ILAW PA. The scenarios included the surface cover ( $1 \mathrm{~m}$ of silt loam over sand and gravel) and two surrounding soil types, as well as two types of surface cover degradation. The simulations were conducted using a 41-year sequence of weather collected at the Hanford Site from 1957 to 1997 . The simulation results indicated that the surface cover would limit drainage to $<0.1 \mathrm{~mm} / \mathrm{yr}$, which is lower than the cover design goal of $0.5 \mathrm{~mm} / \mathrm{yr}$. The cover maintained this performance level for almost all 
scenarios evaluated, including plant removal, wetter and cooler climate, and erosion of $20 \mathrm{~cm}$ of the silt loam layer. The cover also maintained this performance when $20 \mathrm{~cm}$ of windblown sand was deposited on the cover under current climate conditions. Under 7 of the 8 future climate scenarios, the predicted drainage rates continued to be $<0.1 \mathrm{~mm} / \mathrm{yr}$. Only under the future climate scenario of wetter and cooler weather was significant drainage $(16.9 \mathrm{~mm} / \mathrm{yr})$ simulated, even though shrub-steppe vegetation was

present. This simulation was intended to stress the system. While the record indicates periods of cooler weather and periods of wetter weather, the record does not indicate their concurrent occurrence. Instead, cooler weather appears to result in drier conditions. Additional simulations highlighted model sensitivities to further variations in climate, soil hydraulic properties, plant parameters, and irrigation. 


\subsection{Conceptual Model}

A conceptual model of the near-surface water dynamics of a site identifies the features and processes that are thought to significantly influence the flow of water in soil. The development of a site-specific conceptual model for water flow in unsaturated soil begins by formulating a site-specific water balance equation to partition the water at a site into three categories: input, output, and storage. On the soil surface, precipitation $(P)$ represents the input and infiltration $(I)$ and runoff $\left(R_{o f f}\right.$; the amount that runs off the surface) represent the outputs. Overland flow that runs onto a site (i.e., run-on) would be an input to the system, but this process is not included in the UNSAT-H conceptual model. Precipitation could collect in depressions on the soil surface or on the surfaces in the plant canopy, but these water storage mechanisms are not included in the UNSAT-H conceptual model. With no water storage allowed, the equation for the water balance above the soil surface becomes

$$
0=P-I-R_{o f f}
$$

Once water has infiltrated the soil, the soil water balance equation that forms the basis of the UNSAT-H conceptual model is

$$
\Delta S_{w}=I-E-T-D
$$

where $\Delta S_{w}$ is the change in soil water storage during an interval of time. Water storage is the average volumetric water content of the soil multiplied by the depth of soil. The water balance equation simply states that the change in the amount of water stored in the soil profile is equal to the total infiltration minus the amount of water that is lost to evaporation, $E$; transpiration, $T$; and drainage, $D$.

The second step in developing the conceptual model is to identify the environmental processes and physical principles controlling each term in Equation (3.2). For example, the flow of heat to the soil surface affects the rate of evaporation. Based on the interrelationships among terms in Equation (3.2), any attempt to solve for the value of one term will be limited by the accuracy of the other terms.

\subsection{Precipitation}

Annual precipitation at the Hanford Site has averaged about $17.3 \mathrm{~cm}$ since 1946, ranging from less than $7.6 \mathrm{~cm}$ to $31.3 \mathrm{~cm}$ (Hoitink et al. 1999). In addition to low annual rates, precipitation at the Hanford Site is highly seasonal, with an average of $60 \%$ of the annual total coming between October and February. During these months, a significant percentage of precipitation may occur as snow. In fact, snow typically accounts for $22 \%$ of the annual precipitation and $37 \%$ of the winter total.

The seasonal character of precipitation and the significant proportion as snow raise two issues that must be addressed by the conceptual model. The first issue is whether to explicitly account for snowfall and snowmelt, or to treat snow as an equivalent amount of rain. Snow covers the ground at the Hanford Site an average of 22 days per year, but may range from 0 to 60 days. The presence of a snow cover may 
both delay the entry of water into the soil and affect evaporation rates. The present conceptual model incorporated into UNSAT-H, however, views snow as an equivalent amount of rain. The UNSAT-H model does not attempt to simulate snowmelt or the effects of snow cover on evaporation, nor does it account for sublimation.

The second issue related to winter precipitation is how frozen soil affects infiltration, redistribution, evaporation, and runoff. If the climate at the Hanford Site were such that precipitation were negligible during winter months; then the effects of soil freezing would likely be small. However, the presence of significant precipitation during winter months means that frozen soil may need to be considered. The monthly weather records for the Hanford Site indicate that average temperatures at the $38-\mathrm{cm}$ depth have been as low as $-3.6^{\circ} \mathrm{C}$. The need for future modifications of UNSAT-H (e.g., to simulate snowmelt and frozen soil) is being investigated.

\subsection{Infiltration}

Infiltration is the process of water entry into soil. The instantaneous infiltration rate, called the soil infiltrability, is a function of several factors, including the time from the onset of precipitation (or irrigation), the initial water content, the hydraulic properties of the surface soil, and the hydraulic properties of layers deeper within the profile (Hillel 1980). At the start of an infiltration event, the instantaneous infiltration rate is maximal. In time, the rate decreases asymptotically to a value approaching the saturated conductivity of the surface soil. As the wetted depth of soil increases, the infiltration rate decreases asymptotically and approaches the saturated conductivity of the most impeding layer within the wetted portion of the profile. The process can be viewed in two stages. In the first stage, infiltration is controlled by the supply of water (i.e., supply-controlled or flux-controlled). This situation is typical of nearly all precipitation events at the Hanford Site. In the second stage, infiltration is controlled by the soil profile conditions. Many algebraic equations have been developed to estimate infiltration rates during this second stage. However, the UNSAT-H conceptual model does not use an infiltration equation. Instead, infiltration is determined directly by calculating the ability of the soil profile to transmit water downward. Section 3.6 describes the conceptual model for soil water redistribution within the profile.

\subsection{Runoff}

When the precipitation rate exceeds the infiltration rate, water begins to accumulate on the soil surface. Overland flow occurs when the soil's water-detention capacity is exceeded and the surface is slightly sloped. Overland flow is unlikely to occur during rainfall at the Hanford Site because the infiltration capacities of most of the soils exceed several centimeters per hour, in contrast to the 1000-year storm intensity of less than $3 \mathrm{~cm} / \mathrm{hr}$ for $1 \mathrm{hr}$ (Hoitink et al. 1999). Higher storm intensities are probable, but for shorter periods of time. Regardless of precipitation intensity, overland flow may occur when a snow cover melts quickly and the soil beneath is frozen (such that the soil's infiltrability is severely restricted). Localized overland flow has been observed at the Hanford Site under such conditions.

Overland flow is not addressed by the UNSAT-H conceptual model, partly because the process occurs so rarely, but mostly because UNSAT-H is a one-dimensional model. When overland flow does 
occur, it is caused, in part, by variable surface topography. Overland flow is a multidimensional process that a one-dimensional model cannot describe. For a one-dimensional model to be applicable, the problem must be formulated such that water is applied uniformly over the surface. Therefore, UNSAT-H can be applied only to areas for which local run-on/runoff processes can be represented by a uniform precipitation rate over the entire area of interest, or to areas in which overland flow is prevented, such as in lysimeters.

\subsection{Evaporation}

Evaporation is the process of water loss from soil and/or plant surfaces to the atmosphere. Evaporation of water from the soil surface is controlled by the flow of heat to and from the soil surface, the flow of water to the soil surface from below, and the transfer of water vapor from the soil surface to the atmosphere (Hillel 1980). If any of these processes is altered, evaporation will change accordingly.

An integrated form of Fick's law of diffusion (the equation used to model vapor flow within the soil profile) addresses the interrelationships of these three processes and, therefore, has the structure necessary to predict evaporation. This form of Fick's law simply states that the evaporation rate is equal to the deficit in vapor density between the soil surface and the atmosphere divided by the atmospheric boundary-layer resistance. The atmospheric boundary layer is defined as the region of the atmosphere that is directly affected by the shearing forces originating at the surface. Rosenberg et al. (1983) refer to this layer as the turbulent surface layer. Air temperature, vapor density, and wind speed are measured within the atmospheric boundary layer.

The integrated form of Fick's law accounts for the potential effects that each of the three processes identified above may have on evaporation. For the first process, heat flow, a rising soil-surface temperature causes the vapor density at the soil surface to increase. This increased vapor density, in turn, increases the vapor density deficit between the soil surface and the atmosphere, and a higher evaporation rate thus ensues. Falling surface temperature has the opposite effect of reducing the deficit, thus lowering the evaporation rate.

In the second process, water flow, a decrease in the supply of water to the surface leads to surface drying. A drier surface has a lower vapor density; hence, the vapor density deficit is smaller and evaporation is reduced. An increased supply of water to the soil surface would have the opposite effect.

The third process, transporting water vapor from the soil surface to the atmosphere, is controlled by both the atmospheric vapor density and the atmospheric boundary-layer resistance. Generally, the soil surface is wetter (higher vapor density) than the air. If the atmosphere is moist, however, such as during the early morning when temperatures approach the dew point or following precipitation, the increased atmospheric vapor density decreases the surface-air vapor deficit and, therefore, decreases evaporation. Another way that the transfer of water vapor from the soil surface to the atmosphere can be reduced is by decreased wind speed or reduced eddy diffusion caused by high atmospheric stability.

UNSAT-H has an alternate conceptual model for evaporation in which the soil is isothermal. For this conceptual model, the diffusion equation for evaporation can be shown to be equivalent to Penman-type 
equations. The Penman equation and its derivatives (Monteith 1980) are attempts to rewrite the diffusion equation to exclude the explicit dependence of the rate of diffusion on soil-surface temperature. Penmantype equations attempt to replace the need for data on soil surface temperature with information on net radiation and soil heat flux.

When the soil surface is very wet, as immediately after a heavy rainfall, the evaporation rate will be at a maximum. This maximum rate, termed potential evaporation $\left(E_{p}\right)$, is determined largely by atmospheric parameters that control the supply of energy to and from the surface and the transport of water vapor away from the surface. The isothermal conceptual model in UNSAT-H assumes that $E_{p}$ can be calculated solely based on atmospheric parameters, thus ignoring the effects of soil surface temperature and water content on the evaporation rate.

Given this conceptual model, the actual evaporation rate from a soil surface is equal to $E_{p}$ for only the few hours immediately following rainfall. More often, the evaporation rate is much lower than $E_{p}$ because, as water evaporates from the soil, the soil profile begins to dry, particularly near the surface. Dry soil is a poor conductor of water and cannot readily transmit water from the moist, deeper layers to the evaporating surface at a rate sufficient to maintain the $E_{p}$ rate. Thus, drying of the soil limits actual evaporation to a rate that is generally a small fraction of $E_{p}$. Because of the dryness of Hanford Site soils, an important concept in this evaporation model is that the evaporation rate is limited primarily by soil conditions, rather than atmospheric conditions.

At times, usually nighttime, the atmospheric vapor density can exceed the soil surface vapor density and result in the formation of dew. This form of water addition to the soil is not part of the current UNSAT-H conceptual model.

\subsection{Transpiration}

Transpiration is the evaporation of water from plants. When the soil surface is well vegetated with active plants, transpiration is usually the dominant mode of water loss from the soil profile. Even when the surface is only sparsely vegetated, transpiration can rival evaporation as the primary source of water loss from the soil. Exceptions to the above may occur during certain times of the year when plants are dormant or reacting to extreme water stress.

In their Hanford Site characterization report to satisfy the requirements of the National Environmental Policy Act, Neitzel et al. (1999) identified shrublands as the areally predominant vegetation community at the Hanford Site. This community, commonly called shrub-steppe, includes big sagebrush, three-tip sagebrush, bitterbrush, gray rabbitbrush, and spiny hopsage. Grasses and forbs typically make up the understory in these communities. Grasslands are another areally extensive community. Bluebunch wheatgrass dominates at the upper elevations and shares space with Sandberg's bluegrass and cheatgrass (an alien species) at the lower elevations. At many locations, particularly those that have been disturbed, cheatgrass has become the dominant species. This change is important because cheatgrass, which has shallow roots, tends to crowd out the native species, some of which can have deep roots. Gee and Heller (1985) reported that rooting depths range from less than $100 \mathrm{~cm}$ for cheatgrass to $200 \mathrm{~cm}$ for sagebrush, 
$220 \mathrm{~cm}$ for rabbitbrush, and $300 \mathrm{~cm}$ for bitterbrush. Gee (1987) reported that this rooting-depth difference can lead to increased recharge under cheatgrass communities.

Annual water loss by transpiration at the Hanford Site is less than potential transpiration $\left(T_{p}\right)$, just as annual evaporation is less than $E_{p}$. The reduction of transpiration below the potential rate is caused primarily by two mechanisms. The first mechanism involves a decrease in plant biomass, primarily leaf area; the second mechanism involves stomatal closure.

When plants are stressed by lack of water, they may lose leaves, shoots, and roots. This reduction in plant tissue means that less water is necessary to maintain the remaining biomass. Reduction of plant biomass is a relatively slow mechanism that responds to climatic conditions averaged over weeks or months. On a short-term (e.g., hourly) basis, water loss can be reduced by stomatal closure. Closing of stomata (small openings in the leaves) drastically reduces plant water loss. In addition, closure of the stomata reduces carbon dioxide uptake, which limits photosynthesis and reduces overall plant metabolism.

The UNSAT-H conceptual model of transpiration relies on estimates of a potential evapotranspiration rate (PET) that is calculated from climate data. That potential rate is then modified by a "crop" coefficient that is a function of either leaf area or time of year. The resulting $T_{p}$ is applied to specific depths within the soil profile in proportion to the fraction of roots at these respective depths.

UNSAT-H currently allows for a fixed distribution of roots in the profile throughout the year and a variable maximum depth of root penetration. This conceptual model of transpiration offers some flexibility to vary transpiration during the simulation, but only in a predetermined way, and never solely in response to the conditions of the specific simulation. Some of the plant communities at the Hanford Site are mixed. That is, they include perennial as well as annual species, each with its own life cycle and rooting characteristics that influence the composite annual transpiration distribution. Caution should be exercised when the UNSAT-H model is applied to such plant communities until more information is available on the behavior of mixed plant communities.

\subsection{Drainage}

The final term of Equation (3.2) is drainage, which is the movement of water downward through the bottom of the zone being simulated. Of particular interest is the drainage water that reaches the water table. This specific type of drainage is known as groundwater recharge. As a practical matter, once water drains below the root zone, there is little chance of it being drawn upward again. Therefore, recharge is often defined as drainage below the root zone. Recharge is perhaps the water balance term of most interest for waste management because of its potential to move contaminants out of waste-disposal sites. A primary objective of any waste-disposal facility is to reduce recharge, and thus reduce the potential for drainage of water through the waste material.

Drainage results from the redistribution of water through a soil system in response to gradients in the energy state of the water. Other mechanisms that might induce water redistribution, such as geothermal gradients and barometric pressure fluctuations, have been shown to be minor contributors to water flow in 
soils at the Hanford Site (Reisenauer et al. 1975; Jones 1978; Gee and Simmons 1979). The energy state of water is expressed as a potential energy, commonly assumed to consist of a gravitational potential, pressure or matric potential, and solute potential. All of these potentials are expressed relative to the energy state of pure water at atmospheric pressure and a reference elevation.

Pressure or matric potential describes the water pressure difference from atmospheric pressure. When the water pressure is greater than the atmospheric pressure, the soil is saturated and the term pressure potential is used. When the water pressure is less than the atmospheric pressure, the soil is unsaturated and the term matric potential is used. Nearly all applications of UNSAT-H will be for unsaturated problems; consequently, the convention is to use matric potential.

The solute potential, which is the drop in potential energy caused by the presence of solutes, is effective in contributing to water flow only when there is a differential restriction of solute movement relative to water. In the absence of a semipermeable membrane, the solute potential is commonly neglected. In the conceptual model, therefore, the energy state of water is described by the sum of the gravitational and matric potentials; the sum is usually called the hydraulic potential. Water continually redistributes from areas of high hydraulic potential to areas of low hydraulic potential, regardless of direction.

A question that must be addressed by the conceptual model is whether to include the flow of water vapor in the redistribution and drainage calculations. The above discussion of water redistribution in response to potential gradients applies mainly to water in the liquid phase. In unsaturated soils, water is also present in the vapor phase. Water vapor moves and redistributes within the soil in response to vapor pressure gradients. These vapor pressure gradients can arise from matric and osmotic potential gradients in the liquid phase and from temperature gradients within the soil. In the absence of a semipermeable membrane that could produce osmotic potential gradients, osmotic potential is not part of the UNSAT-H conceptual model. Water vapor flow induced by matric potential gradients is known as isothermal vapor flow. Vapor flow induced by thermal gradients is known as thermal flow.

Analyses like that of Campbell (1985) imply that isothermal vapor flow can affect the near-surface (top $10 \mathrm{~cm}$ ) water-content profile, although it is unclear how this would affect long-term simulations of the water balance. Thermal vapor flow affects evaporation when the surface soil is dry and steep thermal gradients are present, a condition that occurs frequently at the semiarid Hanford Site. Hammel et al. (1981) reported that exclusion of thermal vapor flow resulted in a higher predicted evaporative loss and poorer agreement between measured and predicted moisture profiles in a seed zone. Therefore, UNSAT-H can recognize that vapor flow has a thermal component.

Water redistribution (and thus drainage) is dependent on the soil hydraulic properties, which are described using mathematical functions. In some cases, a property is significantly affected by its prior values in addition to the current state of the system. This non-uniqueness of a property is called hysteresis. Soil hydraulic properties that are hysteretic have been shown to affect soil water flow in some situations (Gillham et al. 1979; Kool and Parker 1987; Lenhard et al. 1991). One of the available 
hydraulic functions (the van Genuchten function) is implemented in a hysteresis model within UNSAT-H. The remaining soil hydraulic property functions in the UNSAT-H conceptual model are unique (i.e., they exhibit no hysteresis).

Soil hydraulic properties and the diffusion coefficient of water vapor through air are somewhat dependent on temperature. Nimmo and Miller (1986) determined that the temperature dependence of water potential is much greater than that which would result from just the dependence of surface tension on temperature. Currently, however, the soil properties of the UNSAT-H conceptual model are assumed to be independent of temperature.

Deep below the soil surface, temperature gradients are assumed to have a negligible effect on redistribution of water. Near the soil surface, however, steep temperature gradients can exist and be the dominant cause of water vapor diffusion. Heat flow near the surface also plays a major role in determining the evaporation rate. Heat may be transferred within the soil by different mechanisms. Heat transported by conduction or by convection within moving liquid, vapor, or air is known as sensible heat. Heat associated with a phase change is known as latent heat. The latent heat associated with the phase change between liquid and vapor may be transported convectively or diffusively by water vapor. The latent heat associated with melting ice can be transported convectively by moving liquid water. Heat can also be transmitted through radiative transfer. All materials at a temperature above absolute zero radiate energy in the form of heat.

The current conceptual model of heat flow within the soil includes the conduction and convection of sensible heat and the diffusive transport of latent heat of vaporization. The UNSAT-H conceptual model does not address the convective transport of latent heat associated with soil freezing or thawing, radiative heat transfer within the soil profile, or ice formation. The contribution from these processes to the soil energy balance is assumed to be small. At the soil surface, convective and radiative heat flow processes between the soil and atmosphere are considered in the conceptual model. 


\subsection{Mathematical Model}

The mathematical model consists of a set of differential equations and boundary conditions that quantify the conceptual model by describing the processes depicted in Equation (3.2). In this section, the mathematical models for unsaturated liquid water flow, vapor flow, heat flow, evaporation, and transpiration are presented.

In discussions of soil water flow for unsaturated conditions, hydraulic potential is calculated as the sum of the gravitational and matric potentials. The fundamental expression of potential is in terms of energy per unit mass. It is much more convenient and common, however, to replace the term potential with head, which is energy per unit weight and has units of centimeters. Therefore, the total potential is given as the hydraulic head, $H$; the gravitational potential as the gravitational head, $Z$; and the matric potential as the matric head, $\dot{\psi}$.

\subsection{Unsaturated Liquid Water Flow}

The differential equation for liquid water flow is a modified form of Richards' equation (Richards 1931). This equation describes the change in water storage, redistribution, and plant water uptake at every point within the soil profile. The flow of water across either boundary of the profile is represented by specifying a flux (e.g., precipitation, evaporation, or drainage) or by calculating a flux either directly (e.g., evaporation as a diffusive flux) or indirectly (e.g., holding the value of the boundary-node head constant for such boundary conditions as a ponded surface, evaporation, or a water table).

The development of the modified Richards' equation begins with Darcy's law. In its original form, Darcy's law represented an empirical relationship between the rate of flow in saturated sand and the hydraulic head gradient. The one-dimensional differential form of Darcy's law (Hillel 1980) is

$$
q_{L}=-K_{s} \frac{\partial H}{\partial z}
$$

where $q_{L}$ is flux density of water, $\mathrm{cm} \mathrm{hr}^{-1} ; K_{s}$ is saturated hydraulic conductivity, $\mathrm{cm} \mathrm{hr}^{-1}$; and $z$ is depth below the soil surface, $\mathrm{cm}$. Darcy's law can be extended to unsaturated flow by replacing the saturated conductivity term with liquid conductivity, $K_{L}$, as a function of matric head, yielding

$$
q_{L}=-K_{L}(\psi) \frac{\partial H}{\partial z}
$$

Equation (4.2) must be combined with the continuity equation to describe transient flow. The continuity equation states that the change in water content of a volume of soil must equal the difference between flux into and out of the soil volume. For one-dimensional flow, the continuity equation is 


$$
\frac{\partial \theta}{\partial t}=-\frac{\partial q_{L}}{\partial z}
$$

where $\theta$ is the volumetric water content, $\mathrm{cm}^{3} \mathrm{~cm}^{-3}$; and $t$ is time, hr. Combining Equations (4.2) and (4.3) yields

$$
\frac{\partial \theta}{\partial t}=\frac{\partial}{\partial z}\left[K_{L}(\psi) \frac{\partial H}{\partial z}\right]
$$

UNSAT-H has two sign conventions that relate to heads. The first convention concerns gravitational head. With the soil surface as the reference elevation, the gravitational head at a point in the soil is the elevation of the point with respect to the soil surface and thus is negative. Because depth measured from the surface is positive, the gravitational head equals the negative of soil depth. Therefore, in UNSAT-H, $z$ is replaced with $-z$. The second convention concerns matric head, which is a negative number for unsaturated soil conditions. In UNSAT-H, matric head is replaced with suction head, $h$, which is the negative of matric head. Thus, a positive suction head represents a matric head, and a negative.suction head represents a pressure head. The calculation of hydraulic head then changes from $H=\psi+Z$ to the UNSAT-H form

$$
H=-(h+z)
$$

Using the chain rule of differentiation, $\partial \theta / \partial t$ in Equation (4.4) can be replaced by $C(h)(\partial h / \partial t)$, where $C(h)$ represents $\partial \theta / \partial h$ (i.e., the negative of the specific moisture capacity). With this manipulation and the incorporation of the identity $h=-\psi$, Equation (4.4) becomes

$$
C(h) \frac{\partial h}{\partial t}=\frac{\partial}{\partial z}\left[K_{L}(h) \frac{\partial H}{\partial z}\right]
$$

Combining Equations (4.5) and (4.6) and adding a sink term, $S$, for water uptake by plants gives

$$
C(h) \frac{\partial h}{\partial t}=-\frac{\partial}{\partial z}\left[K_{L}(h)\left(\frac{\partial h}{\partial z}+1\right)\right]-S(z, t)
$$

where $S(z, t)$ indicates that the sink term is a function of depth and time. With slight rearrangement, Equation (4.7) is the same as that in Gupta et al. (1978), Gee and Simmons (1979), and Simmons and Gee (1981).

The assumptions that led to Equation (4.7) are

- fluid is incompressible

- air phase is continuous 
- air phase is at constant pressure

- flow is one-dimensional

- liquid water flow is isothermal

- vapor flow is negligible.

The first three assumptions are routinely made for modeling of soil water under unsaturated conditions and are considered valid for the Hanford Site. The fourth assumption, one-dimensional flow, is considered valid for most near-surface modeling efforts, provided the surface is uniform and nearly level, no overland flow exists, and soil properties are homogeneous and isotropic within each defined soil layer. The fifth assumption, isothermal liquid flow, is considered valid for the Hanford Site. The final assumption, that vapor flow in negligible, is not considered valid. Soils at the Hanford Site dry out significantly during the summer and liquid-water conductivities decrease dramatically, to a point at which diffusion of water vapor from the soil to the atmosphere can be the dominant mode of water loss. Vapor flow is considered in the next section.

\subsection{Vapor Diffusion}

The fundamental equation used to calculate the diffusion of water vapor in soils is Fick's law of diffusion, which can be written as

$$
q_{v}=-\frac{D}{\rho_{w}} \frac{\partial \rho_{v}}{\partial z}
$$

where $q_{v}=$ flux density of water vapor, $\mathrm{cm} \mathrm{hr}^{-1}$

$\rho_{w}=$ density of liquid water, $\mathrm{g} \mathrm{cm}^{-3}$

$D=$ vapor diffusivity in soil, $\mathrm{cm}^{2} \mathrm{hr}^{-1}$

$\rho_{v}=$ vapor density, $\mathrm{g} \mathrm{cm}^{-3}$.

When applying Fick's law to soils, adjustments must be made to account for the tortuous diffusion path and the reduced cross-sectional area available for flow. The need for both adjustments arises from the three-phase nature of soils. The usual way these adjustments are included in Equation (4.8) is to write the diffusivity term as

$$
D=\alpha\left(\theta_{s}-\theta\right) D_{a}
$$

where $\alpha$ is the tortuosity factor; $D_{a}$ is the diffusivity of water vapor in air, $\mathrm{cm}^{2} \mathrm{~s}^{-1}$; and the quantity $\left(\theta_{s}-\theta\right)$ represents the air-filled porosity. Many variations of Equation (4.9) exist (Marshall 1959; Currie 1965; Troeh et al. 1982); however, they generally treat $\alpha$ as a constant or as a function of air-filled porosity. The most common formulation is to set $\alpha$ equal to 0.66 (Penman 1940; van Bavel 1952). 
Fick's law can be written to explicitly include gradients for suction head and temperature by using the chain rule of differentiation to rewrite the vapor density gradient. Equation (4.8) becomes

$$
q_{v}=-\frac{D}{\rho_{w}} \frac{\partial \rho_{v}}{\partial h} \frac{\partial h}{\partial z}-\frac{D}{\rho_{w}} \frac{\partial \rho_{v}}{\partial T} \frac{\partial T}{\partial z}
$$

where $T$ is the temperature, $\mathrm{K}$.

The vapor density at a specific point in the soil can be related to the saturated vapor density, $\rho_{v s}$, and relative humidity, $H_{R}$, by

$$
\rho_{v}=\rho_{v s} H_{R}
$$

Because water vapor density is a function of relative humidity and temperature, Equation (4.10) can be rewritten. Combining Equations (4.10) and (4.11), using the product rule for differentiation and assuming $\partial H_{R} / \partial T=0$ (Philip and deVries 1957), Fick's law can be written as

$$
q_{v}=-\frac{D}{\rho_{w}} \rho_{v s} \frac{\partial H_{R}}{\partial z}-\frac{D}{\rho_{w}} H_{R} \frac{\partial \rho_{v s}}{\partial T} \frac{\partial T}{\partial z}
$$

Equation (4.12) explicitly includes the effect of soil temperature on vapor diffusion. The first term represents isothermal vapor diffusion. The second term represents thermal vapor diffusion. From the soil suction head, the relative humidity can be determined using (Campbell 1985)

$$
H_{R}=\exp \left[-\frac{h M g}{R T}\right]
$$

where $M$ is the molecular weight of water, $g$ mole $^{-1} ; g$ is the gravitational constant, $\mathrm{cm} \mathrm{s}^{-2}$; and $R$ is the gas constant, erg mole $\mathrm{K}^{-1}$.

Much work has been published that evaluates the validity of Equation (4.12), particularly the thermal vapor diffusion term. Experimental measurements show that Equation (4.12) underpredicts water vapor flow. This deficiency is particularly apparent when temperature gradients are present (Gurr et al. 1952; Taylor and Cavazza 1954; Philip and de Vries 1957; Cassel et al. 1969; Cass et al. 1984). Most researchers have assumed that the problem is with the thermal vapor diffusion term of Equation (4.12); however, Scotter (1976) presents evidence that the isothermal term is also incomplete.

The most widely accepted explanation of why Equation (4.12) fails was proposed by Philip and de Vries (1957). They suggest two features that could be responsible for vapor diffusion greater than that predicted by Fick's law. The first is that the measured temperature gradient in a soil underestimates the temperature gradient within the air phase of the soil pores, and this "microscopic" temperature gradient is the more appropriate value to use in Fick's law. Second, Philip and de Vries (1957) propose that vapor is effectively transported through the liquid phase by condensation and evaporation processes operating 
within individual pores. These processes would have the effect of increasing the cross-sectional area available for vapor diffusion to a value larger than that for air-filled porosity and of decreasing the tortuosity or path length for diffusion. Philip and deVries (1957) proposed adding an enhancement factor, $\eta$, to the thermal vapor diffusion term in Equation (4.12) to account for these two processes.

Substituting the enhancement factor into Equation (4.12) and expressing the $H_{R}$ gradient in terms of the gradient in $h$ gives the following formulation of Fick's law:

$$
q_{v}=\left(\frac{D}{\rho_{w}} \rho_{v s} \frac{M g}{R T} H_{R} \frac{\partial h}{\partial z}\right)-\left(\frac{D}{\rho_{w}} \eta H_{R} \frac{d \rho_{v s}}{d T} \frac{\partial T}{\partial z}\right)
$$

This law explicitly accounts for the effect of temperature gradients and enhanced vapor diffusion in soil.

The first term on the right-hand side of Equation (4.14) is referred to as the isothermal vapor flux density, $q_{v h}$. Although considered the isothermal flux, it does allow for the saturated vapor density throughout the soil to vary according to the simulated soil temperature, rather than being a constant based on a fixed value of soil temperature. The second term on the right-hand side of Equation (4.14) is referred to as the thermal vapor flux density, $q_{v r}$.

The $q_{v h}$ and $q_{v T}$ terms in Equation (4.14) are similar to the flux equation for liquid flow. As such, most of the parameters can be combined to yield vapor conductivity terms. The isothermal vapor conductivity term, $K_{v h}$, is

$$
K_{v h}=\frac{D \rho_{v s} M g}{\rho_{w} R T} H_{R}
$$

The thermal vapor conductivity term, $K_{v T}$, is

$$
K_{v T}=\frac{D \eta H_{R}}{\rho_{w}} \frac{d \rho_{v s}}{d T}
$$

Equation (4.7) can now be rewritten to include the contribution of vapor flow

$$
C(h) \frac{\partial h}{\partial t}=-\frac{\partial}{\partial z}\left[K_{T}(h) \frac{\partial h}{\partial z}+K_{L}(h)+q_{v T}\right]-S(z, t)
$$

where $K_{T}$ is $K_{L}+K_{v h}$. Equation (4.17) is the modified Richards' equation that serves as the primary differential equation solved by UNSAT-H; it describes changes in water storage, isothermal redistribution of liquid water, nonisothermal redistribution of water vapor, and water uptake by plants. This equation is applied at every point in the interior of the soil profile. 


\subsection{Heat Flow}

Calculation of soil temperature requires solving the energy balance equations in much the same manner that the soil water-balance equations are solved to obtain soil water potential. The constitutive equation describing the conduction of sensible heat is Fourier's law of heat conduction

$$
q_{h}=-k_{h} \frac{\partial T}{\partial z}
$$

where $q_{h}$ is the heat flux density, $\mathrm{J} \mathrm{cm}^{-2} \mathrm{hr}^{-1}$; and $k_{h}$ is the thermal conductivity of soil, $\mathrm{J} \mathrm{cm}^{-1} \mathrm{hr}^{-1} \mathrm{~K}^{-1}$.

The latent heat transported by vapor flow is equal to the product of the latent heat of vaporization and the flux density of water vapor, which is calculated using Equation (4.14). The heat convected by water flow is equal to the product of the heat capacity of water, the flux density of water, and the soil temperature. Adding latent and convective heat transport to Equation (4.18) gives the steady-state heat flux density (Jury 1973):

$$
q_{h}=-k_{h} \frac{\partial T}{\partial z}+L_{o} q_{v}+C_{h v}\left(T-T_{o}\right) q_{v}+C_{h w}\left(T-T_{o}\right) q_{L}
$$

where $L_{o}$ is the volumetric latent heat of vaporization of water, $\mathrm{J} \mathrm{cm}^{-3}$, at the reference temperature $T_{o}$, and $C_{h v}$ and $C_{h w}$ are the volumetric heat capacities of water vapor and liquid, $\mathrm{J} \mathrm{cm}^{-3} \mathrm{~K}^{-1}$.

Relative to the reference temperature, the storage of heat $\left(S_{h}\right)$ in the soil is

$$
S_{h}=C_{h s}\left(T-T_{o}\right)+L_{o} \theta_{v}+C_{h v}\left(T-T_{o}\right) \theta_{v}+C_{h w}\left(T-T_{o}\right) \theta
$$

where $C_{h s}$ is the volumetric heat capacity of dry soil particles, $\mathrm{J} \mathrm{cm}^{-3} \mathrm{~K}^{-1}$, and $\theta_{v}$ is the volumetric vapor content expressed as an equivalent water content. The continuity equation for the conservation of energy in one dimension is (Jury 1973)

$$
\frac{\partial S_{h}}{\partial t}=-\frac{\partial q_{h}}{\partial z}
$$

Combining the continuity equation with Equation (4.19) gives the soil temperature equation to be solved by UNSAT-H:

$$
\begin{aligned}
& C_{h} \frac{\partial T}{\partial t}+L_{o} \frac{\partial \theta_{v}}{\partial t}+C_{h v}\left(T-T_{o}\right) \frac{\partial \theta_{v}}{\partial t}+C_{h w}\left(T-T_{o}\right) \frac{\partial \theta}{\partial t}= \\
& -\frac{\partial}{\partial z}\left[-k_{h} \frac{\partial T}{\partial z}+L_{o} q_{v}+C_{h v}\left(T-T_{o}\right) q_{v}+C_{h w}\left(T-T_{o}\right) q_{L}\right]
\end{aligned}
$$


where $C_{h}=C_{h s}+C_{h v} \theta_{v}+C_{h w} \theta$ and represents the volumetric heat capacity of moist soil, $\mathrm{J} \mathrm{cm}^{-3} \mathrm{~K}^{-1}$. The contributions of air and organic matter to $C_{h}$ are considered negligible.

As stated previously, Equations (4.19) and (4.22) describe soil heat flow by accounting for conduction and convection of sensible heat and transfer of latent heat of vaporization by diffusion of water vapor. Heat balance processes that are assumed by Equation (4.22) to be negligible include 1) convective transfer of the latent heat of melting ice by liquid water, 2) convective transfer of sensible heat by the soil gas phase, 3) heat transfer by radiation, and 4) heat of wetting effects.

\subsection{Constitutive Relationships}

The UNSAT-H code must have mathematical descriptions of the hydraulic, vapor, and thermal properties of the soil and air.

\subsubsection{Hydraulic Properties}

To solve the flow equation for liquid water, UNSAT-H must be supplied with relationships for both water content and hydraulic conductivity as functions of suction head. The water content relationship is known as the soil water retention function [its derivative is the capacity term in Equation (4.7)]. The hydraulic conductivity relationship is known as the hydraulic conductivity function. Together, these two functions constitute the set of hydraulic properties required by UNSAT-H.

The UNSAT-H code contains eight options for describing the soil hydraulic properties: polynomials (Bond et al. 1984), Haverkamp functions (Haverkamp et al. 1977), Brooks-Corey functions (Corey 1977), van Genuchten functions (van Genuchten 1978), modified Brooks-Corey and van Genuchten functions (Fayer and Simmons 1995), and the Rossi-Nimmo sum and junction models (Rossi and Nimmo 1994). A special hysteretic version of the van Genuchten function is also available.

Polynomials. The first option allows up to four polynomials of the forms

$$
\theta=a+b \log (h)+c \log ^{2}(h)+d \log ^{3}(h)+e \log ^{4}(h)
$$

and

$$
\log \left(K_{L}\right)=a+b \log (h)+c \log ^{2}(h)+d \log ^{3}(h)+e \log ^{4}(h)
$$

to be used to describe each soil property for different ranges of $h$. Note that the coefficients in Equations (4.23) and (4.24) are different and unrelated. The polynomials must be equivalent at each matching point. For the water retention polynomial, the derivatives must also be equivalent at each matching point. Two major advantages of this option are that the user can easily fit polynomials to any data set and can extend the polynomials into the high suction-head range. The disadvantages of this option are that it requires many parameters and consumes slightly more computer time for representing soil properties than the other options. 
Haverkamp Functions. The second option uses the Haverkamp functions (Haverkamp et al. 1977) to describe soil properties by equations of the forms

$$
\begin{array}{cc}
\theta=\theta_{r}+\left(\theta_{s}-\theta_{r}\right)\left[\frac{\alpha}{\alpha+h^{\beta}}\right] & h>h_{e} \\
\theta=\theta_{s} & h \leq h_{e}
\end{array}
$$

and

$$
\begin{array}{cc}
K_{L}=K_{s}\left[\frac{A}{A+h^{B}}\right] & h>h_{e} \\
K_{L}=K_{s} & h \leq h_{e}
\end{array}
$$

where $\theta_{r}$ is the residual water content measured in $\mathrm{cm}^{3} \mathrm{~cm}^{-3}, \theta_{s}$ is the saturated water content measured in $\mathrm{cm}^{3} \mathrm{~cm}^{-3}, h_{e}$ represents the air-entry suction head (the point at which the soil begins to desaturate), and $\alpha$, $\beta, A$, and $B$ are curve-fitting parameters. The option exists in UNSAT-H to replace the $h$ term in Equation (4.25) with $\ln (h)$.

Brooks-Corey Functions. The third option uses the Brooks-Corey function (Corey 1977) to describe soil properties with equations of the forms

$$
\begin{array}{cc}
\theta=\theta_{r}+\left(\theta_{s}-\theta_{r}\right)\left(\frac{h_{e}}{h}\right)^{1 / b} & h>h_{e} \\
\theta=\theta_{s} & h \leq h_{e}
\end{array}
$$

and

$$
\begin{array}{cc}
K_{L}=K_{s}+\left(\frac{h_{e}}{h}\right)^{2+b^{\prime} / b} & h>h_{e} \\
K_{L}=K_{s} & h \leq h_{e}
\end{array}
$$

where $b$ is a curve-fitting parameter (which is the inverse of the original Brooks-Corey parameter $\lambda$ ). For the Burdine conductivity model (Burdine 1953), $b$ ' represents $1+\ell$, where $\ell$ is the exponent (usually 2) of the pore interaction term. For the Mualem model (Mualem 1976), $b$ ' represents $2+\ell$, where $\ell$ is usually 0.5 .

van Genuchten Function. The fourth option uses the van Genuchten (1978) function to describe soil water retention as 


$$
\theta=\theta_{r}+\left(\theta_{s}-\theta_{r}\right)\left[1+(\alpha h)^{n}\right]^{-m}
$$

where $\alpha, n$, and $m$ are curve-fitting parameters. When this function is combined with the Burdine conductivity model (Burdine 1953),

$$
K_{L}=K_{s} \frac{\left\{1-(\alpha h)^{n-2}\left[1+(\alpha h)^{n}\right]^{-m}\right\}}{\left[1+(\alpha h)^{n}\right]^{j m}}
$$

where it is usually assumed that $m=1-1 / n$. When the van Genuchten function is combined with the Mualem conductivity model (Mualem 1976)

$$
K_{L}=K_{s} \frac{\left\{1-(\alpha h)^{n m}\left[1+(\alpha h)^{n}\right\}^{-m}\right\}^{2}}{\left[1+(\alpha h)^{n}\right]^{e m}}
$$

where it is usually assumed that $m=1-1 / n$.

The UNSAT-H code allows use of the van Genuchten function to describe non-hysteretic hydraulic properties. In addition, for the van Genuchten function option, UNSAT-H also allows a hysteretic description of the hydraulic properties. The hysteresis model described by Lenhard et al. (1991) was added to UNSAT-H (Fayer 1993). The basis for this hysteresis model is that the internal scanning curves can be scaled from either the primary drainage curve or the primary imbibition curve. The scanning curves and the primary imbibition curve are further scaled according to the amount of entrapped air.

The Lenhard et al. (1991) hysteresis model was chosen for its simplicity: only two parameters are required. The first parameter is ${ }^{i} S_{n r}$ (superscript $i$ refers to imbibition) the maximum amount of air that becomes entrapped when the soil is wetted from an air dry condition to satiation, a condition whereby the sediment has a suction head of zero but is not necessarily completely saturated. The other parameter is $\alpha_{i}$ (subscript $i$ refers to imbibition), one of the parameters used to describe the primary imbibition curve.

The only restriction on the parameter $\alpha_{i}$ is that it must be greater than or equal to the value of $\alpha_{d}$, a similar parameter but associated with the primary drainage curve.

Figure 4.1 shows how saturation can vary depending on the history of wetting and drying. Starting from complete effective saturation $\left(S_{e}=1.0\right)$, the soil saturation decreases along the primary drainage path until the suction head reaches $200 \mathrm{~cm}$. At this point, the soil switches from draining to wetting and begins to imbibe water. The effective saturation increases until the suction head is $50 \mathrm{~cm}$. At this point, the soil switches from wetting to drying. Saturation begins to decrease until the suction head is about $140 \mathrm{~cm}$. Once again, the soil switches from drying to wetting and saturation begins to increase. As the soil reaches the $50-\mathrm{cm}$ suction-head value, note that the saturation value is equal the earlier value when there was a reversal at this suction head. This feature is very important because it demonstrates that the hysteretic 


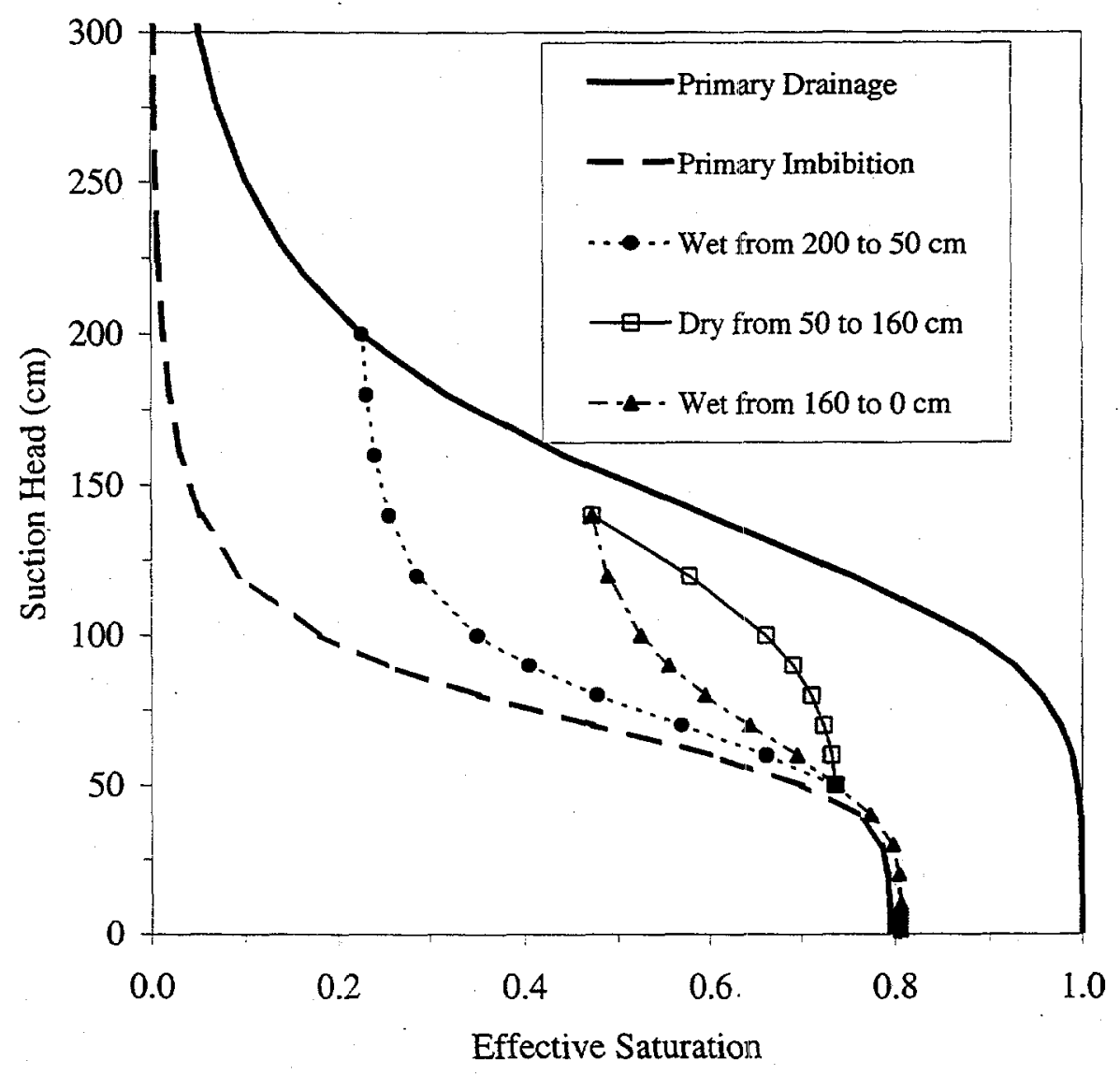

Figure 4.1. Effect of Hysteresis on Water Retention During Drying and Wetting of Silt Loam (after Fayer 1993). The retention and hysteresis parameters are $\alpha_{d}=0.007, \alpha_{i}=0.014, n=5$, and ${ }^{i} S_{n r}=0.206$.

loops are closed. Lenhard et al. (1991) noted that earlier hysteresis models had loops that did not close and thus suffered from instability and mass balance problems.

As the soil continues to wet from a suction head of 50 to $0 \mathrm{~cm}$, the effective saturation increases to about 0.8 . Normally, the saturation at this point would be 1.0, but the Lenhard et al. (1991) hysteresis model allows for air entrapment. Note that the amount of air entrapped at this time is a function of ${ }^{i} S_{n r}$ and the $S_{e}$ value at the reversal point on the primary drainage path.

For the hysteresis model, hydraulic conductivity is determined using a modified form of the Mualem conductivity model (Mualem 1976). The entrapped air component of the hysteresis model can impact hydraulic conductivity. Therefore, corrections for entrapped air that were proposed by Lenhard et al. (1991) have been implemented. 
Modified Brooks-Corey Function. The fifth option uses the modified Brooks-Corey retention function proposed by Fayer and Simmons (1995):

$$
\begin{array}{cc}
\theta=\chi \theta_{a}+\left(\theta_{s}-\chi \theta_{a}\right)\left(\frac{h}{h_{e}}\right)^{-1 / b} & h_{m} \geq h>h_{e} \\
\theta=\theta_{s} & h \leq h_{e}
\end{array}
$$

The parameter $h_{m}$ represents the suction head at the oven-dry water content (which is zero). Although generally fixed at $10^{7} \mathrm{~cm}$, the parameter $h_{m}$ may be much higher for very fine-textured porous media and thus could be considered a curve-fitting parameter. In Equation (4.32), the parameter $\chi$ is defined as

$$
\chi=1-\frac{\ln h}{\ln h_{m}}
$$

Campbell and Shiozawa (1992) used $\chi$ to describe soil water retention at very high values of suction head, where water retention is essentially an adsorption phenomenon. Their adsorption equation (in a slightly different form) is

$$
\theta=\chi \theta_{a}
$$

The parameter $\theta_{\alpha}$ that occurs in Equations (4.32) and (4.34) is unique to each equation; it is essentially a curve-fitting parameter for the respective equations. The hydraulic conductivity function (not shown, Fayer and Simmons 1995) is based on the Mualem conductivity model.

Modified van Genuchten Function. The sixth option uses the modified van Genuchten retention function proposed by Fayer and Simmons:

$$
\begin{array}{cc}
\theta=\chi \theta_{a}+\left(\theta_{s}-\chi \theta_{a}\right)\left[1+(\alpha h)^{n}\right]^{-m} & h_{m} \geq h>h_{c} \\
\theta=\theta_{s} & h \leq h_{c}
\end{array}
$$

The lower limit of (4.35) is the suction head, $h_{c}$, at which $\theta$ equals $\theta_{s}$. The value of $h_{c}$ is a function of the other parameters; typical values range from $10^{-7}$ to $10^{-20} \mathrm{~cm}$. The hydraulic conductivity function (not shown, Fayer and Simmons 1995) is based on the Mualem conductivity model.

Rossi-Nimmo Sum Model. The seventh option uses the Rossi and Nimmo (1994) "sum" model to describe soil water retention. Using their nomenclature, the model is 


$$
\begin{array}{cc}
\frac{\theta}{\theta_{s}}=1 & h<0 \\
\frac{\theta}{\theta_{s}}=1-c\left(\frac{h}{h_{o}}\right)^{2} & 0 \leq h \leq h_{i} \\
\frac{\theta}{\theta_{s}}=\left(\frac{h_{o}}{h}\right)^{\lambda}-\left(\frac{h_{o}}{h_{d}}\right)^{\lambda}+\alpha \ln \left(\frac{h_{d}}{h}\right) & h_{i} \leq h \leq h_{d}
\end{array}
$$

where $h_{o}, h_{i}$, and $\lambda$ are the curve-fitting parameters. The parameter $h_{d}$ is the suction head at which the water content is zero (the oven-dry water content). It is equivalent to the parameter $h_{m}$ used in the modified Brooks-Corey and van Genuchten functions. The two parameters $\alpha$ and $c$ are functions of the other parameters and are calculated internally. The hydraulic conductivity function (not shown, Fayer and Simmons 1995) is based on the Mualem conductivity model.

Rossi-Nimmo Junction Model. The eighth option uses the Rossi and Nimmo (1994) "junction" model to describe soil water retention. Using their nomenclature, the model is

$$
\begin{array}{cc}
\frac{\theta}{\theta_{s}}=1 & h<0 \\
\frac{\theta}{\theta_{s}}=1-c\left(\frac{h}{h_{o}}\right)^{2} & 0 \leq h \leq h_{i} \\
\frac{\theta}{\theta_{s}}=\left(\frac{h_{o}}{h}\right)^{\lambda} & h_{i} \leq h \leq h_{j} \\
\frac{\theta}{\theta_{s}}=\alpha \ln \left(\frac{h_{d}}{h}\right) & h_{j} \leq h \leq h_{d}
\end{array}
$$

where $h_{o}$ and $\lambda$ are the curve-fitting parameters. The four parameters $\alpha, c, h_{i}$, and $h_{j}$ are functions of the other parameters and are calculated internally. The hydraulic conductivity function (not shown) is based on the Mualem conductivity model.

\subsubsection{Vapor Properties}

Doorenbos and Pruitt (1977) provided an empirical equation to calculate saturated vapor pressure as a function of temperature. The pressure units were millibars. Their equation was modified for UNSAT-H to provide saturated vapor density in units of $\mathrm{g} \mathrm{cm}^{-3}$. The modified empirical equation is

$$
\rho_{v s}=\exp \left[46.440973-\frac{6790.4985}{T}-6.02808 \ln T\right]
$$


The derivative of $\rho_{v s}$ with respect to temperature is

$$
\frac{d \rho_{v s}}{d T}=\rho_{v s}\left[\frac{6790.4985}{T}-6.02808\right] \frac{1}{T}
$$

\subsubsection{Thermal Properties}

In Equation (4.22), the thermal conductivity of soil, $k_{h}$, is a function of water content. Cass et al. (1984) measured values of $k_{h}$ for a soil from the Hanford Site. They used the relationship

$$
k_{h}=A+B \frac{\theta}{\theta_{s}}-(A-D) \exp \left[-\left(C \frac{\theta}{\theta_{s}}\right)^{E}\right]
$$

to express $k_{h}, \mathrm{~J} \mathrm{~s}^{-1} \mathrm{~m}^{-1} \mathrm{~K}^{-1}$, as a function of water content. Cass et al. (1984) also measured the enhancement factor [ $\eta$ in Equation (4.14)] for the same soil. They then used Equation (4.40) to represent $\eta$ as a function of water content, substituting $\eta$ for $k_{h}$ in Equation (4.40). Equation (4.40) is the only option available in UNSAT-H for describing these two soil properties.

\subsection{Evaporation}

An equation that integrates the three processes of heat and water flow to the soil surface and transport of water vapor to the atmosphere is an integrated form of Fick's law of diffusion (Campbell 1977)

$$
e=\frac{c_{e}\left(\rho_{v s s}-\rho_{v a}\right)}{\rho_{w} r_{v}}
$$

where $e=$ evaporation flux density, $\mathrm{cm} \mathrm{hr}^{-1}$

$c_{e}=$ units conversion factor, $\mathrm{cm} \mathrm{s} \mathrm{m}^{-1} \mathrm{hr}^{-1}$

$\rho_{\text {vss }}=$ vapor density at soil surface, $\mathrm{g} \mathrm{cm}^{-3}$

$\rho_{v a}=$ atmospheric vapor density, $\mathrm{g} \mathrm{cm}^{-3}$

$r_{v}=$ boundary layer resistance to vapor transport, $\mathrm{s} \mathrm{m}^{-1}$.

Equation (4.41) is an integrated form of Fick's law because it is the result of integrating the differential equation form of Fick's law (Equation 4.8) over the atmospheric boundary-layer distance. The result is a vapor density difference divided by a resistance, rather than a diffusivity times a vapor density gradient. This approach is advantageous in that the thickness of the atmospheric boundary layer does not appear explicitly in the equation, but rather is contained implicitly in the resistance term. In its representation of evaporation, Equation (4.41) does not treat the atmospheric boundary layer as a separate region by applying the differential form of Fick's law to that region. Instead, the assumption supporting 
Equation (4.41) is that diffusive transport of water vapor in the atmospheric boundary layer is sufficiently rapid (compared to that in the soil) that a quasi-steady-state water vapor profile exists within the layer, dependent only on $\rho_{v s s}$ and $\rho_{v a}$.

Solution of Equation (4.41) requires that the values of three parameters be known. The vapor density at the soil surface is obtained from the suction head and temperature of the soil surface. The atmospheric water vapor density is obtained from meteorological data. The third parameter, the atmospheric boundary-layer resistance, is calculated as detailed in Campbell (1985). For bare soil, it is assumed that the exchange surface for heat and water are the same (i.e., the soil surface), and that heat and water are exchanged between the soil surface and the atmosphere by the same eddy-diffusion process. Therefore, the atmospheric boundary-layer resistance to water vapor and heat transport is

$$
r_{v}=r_{h}=\frac{\ln \left[\left(z_{T}-d+z_{h}\right) / z_{h}\right]+\psi_{h}}{k U^{*}}
$$

where $r_{v}=$ boundary layer resistance to water vapor transfer, $\mathrm{s} \mathrm{m}^{-1}$

$r_{h}=$ boundary layer resistance to heat transfer, $\mathrm{s} \mathrm{m}^{-1}$

$z_{T}=$ height of air temperature measurement, $\mathrm{m}$

$d=$ zero plane displacement, $\mathrm{m}$

$z_{h}=$ roughness height for sensible heat transport, $\mathrm{m}$

$\psi_{h}=$ atmospheric stability correction factor for sensible heat transport

$k=$ von Karman's constant

$U^{*}=$ friction velocity, $\mathrm{m} \mathrm{s}^{-1}$.

The friction velocity in Equation (4.42) is calculated using

$$
U^{*}=\frac{k u}{\ln \left[\left(z_{u}-d+z_{m}\right) / z_{m}\right]+\psi_{m}}
$$

where $u=$ wind speed, $\mathrm{m} \mathrm{s}^{-1}$

$z_{u}=$ height of wind speed measurement, $\mathrm{m}$

$z_{m}=$ roughness height for momentum transfer, $m$

$\psi_{m}=$ atmospheric stability correction factor for momentum transfer.

The atmospheric stability correction factors required for Equations (4.42) and (4.43) are calculated differently, depending on the direction of the sensible heat flux (Bussinger 1975; Campbell 1985). For stable conditions, when the surface temperature is lower than the air temperature and sensible heat flux is from the atmosphere to the soil

$$
\psi_{m}=\psi_{h}=4.7 \zeta
$$

where $\zeta$ is the atmospheric stability parameter. Atmospheric stability is determined using 


$$
\zeta=\frac{-k z_{T} g H}{C_{h a} T_{a} U^{* 3}}
$$

where $H$ is the sensible heat flux, $\mathrm{J} \mathrm{m}^{-2} \mathrm{~s}^{-1} ; C_{h a}$ is the volumetric heat capacity of air, $\mathrm{J} \mathrm{m}^{-3} \mathrm{~K}^{-1}$; and $T_{a}$ is the air temperature, $\mathrm{K}$.

For unstable conditions when the surface temperature is higher than the air temperature and the sensible heat flux is from the soil to the atmosphere, there is a greater potential for eddy diffusion and atmospheric turbulence. For these conditions, the stability correction factors are calculated using

$$
\psi_{h}=-2 \ln \left[\frac{1+(1-16 \zeta)^{1 / 2}}{2}\right]
$$

and

$$
\psi_{m}=0.6 \psi_{h}
$$

Note that the atmospheric boundary-layer resistance (Equation 4.42) depends on the stability parameters, which depend on the sensible heat flux, which, in turn, depends on the boundary-layer resistance. Therefore, the atmospheric boundary-layer resistance is calculated using the iterative technique described by Campbell (1985).

When heat flow is not being modeled, evaporation is calculated using the $E_{p}$ concept. The daily $E_{p}$ is estimated or derived from daily weather parameters (see Section 4.7). As long as the suction head of the surface node does not exceed the maximum suction head (a value that corresponds to air-dry soil), evaporation will proceed at the $E_{p}$ rate. When the maximum suction head is exceeded, the simulation continues with a constant head boundary in which the suction head of the surface node is equal to the maximum head. For such conditions, the evaporation rate is always less than the $E_{p}$ rate and is calculated as the sum of the change in storage of the surface node and the flux between the surface node and the node below it.

\subsection{Transpiration}

The mathematical model of transpiration is based on the concept of potential evapotranspiration. Thus, its use is constrained to problems that do not require heat flow to be modeled.

The removal of soil water by transpiring plants is modeled as a sink term in Equation (4.17). The calculation of the sink term is accomplished in three steps. First, PET is partitioned into $T_{p}$ and $E_{p}$, subject to the constraint that PET $=E_{p}+T_{p}$. In the second step, $T_{p}$ is distributed over the root zone in proportion to the relative root density at each depth. This effectively establishes a potential sink term for 
each depth. The final step is to modify the potential sink term of each node, based on water content, to arrive at the actual sink term. Calculation of the sink term in this manner was proposed by Feddes et al. (1978).

Two methods are used to partition PET in the UNSAT-H code. In the first method, $T_{p}$ is calculated from the leaf area index $\left(I_{L A}\right)$ using the equation

$$
T_{p}=\operatorname{PET}\left[a+b\left(I_{L A}\right)^{c}\right] d \leq I_{L A} \leq e
$$

with the following parameter values: $a=-0.21, b=0.7, c=0.5, d=0.1$, and $e=2.7$. Equation (4.48) was developed by Ritchie and Burnett (1971) for cotton and grain sorghum. Ritchie (1972) noted that PET in Equation (4.48) is actually net radiation and not PET in the sense of that calculated by the Penman combination equation (Doorenbos and Pruitt 1977). Figure 4.2 shows the data and equation from Ritchie and Burnett (1971). Note that Equation (4.48) does not fit the data as well as portrayed by Ritchie and Burnett (1971). Reanalysis of the data resulted in a better set of parameter values: $a=0.0, b=0.52$, $c=0.5, d=0.0$, and $e=3.7$. $^{\text {(a) }}$ Seasonal $I_{L A}$ data are not currently available for the plant communities at the Hanford Site; hence, this option has not been tested using Hanford Site data.

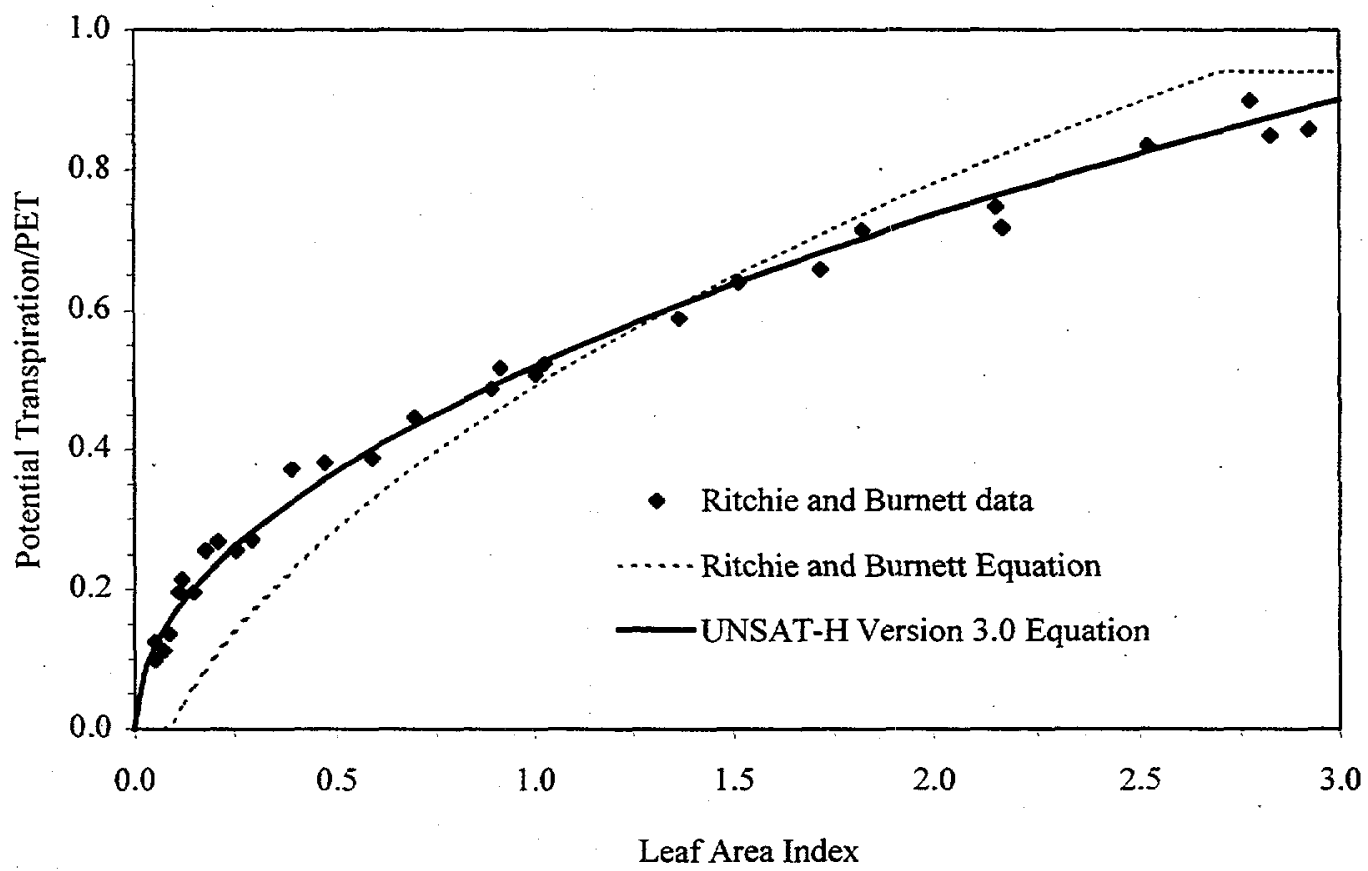

Figure 4.2. The Ratio of Potential Transpiration to Potential Evapotranspiration as a Function of Leaf Area Index

(a) Personal communication from Mark Ankeny, DB Stephens and Assoc., Albuquerque, New Mexico. 
The second method for partitioning PET uses local cheatgrass data. Hinds (1975) conducted field experiments with cheatgrass growing in microlysimeters in the Fitzner/Eberhardt Arid Lands Ecology (ALE) Reserve of the Hanford Site. During April and May 1972, Hinds measured total and net shortwave radiation, soil heat flux, evaporation, and transpiration; and calculated net long-wave radiation with an empirical equation. Hinds then related transpiration to the total net radiation and computed a ratio that could be termed a "crop coefficient." The ratio of transpiration to net radiation applies to the 2 months of Hinds' experiment. The shaded portion of Figure 4.3 represents this ratio for the 2-month period.

According to Klemmedson and Smith (1964), cheatgrass usually germinates in the fall, remains dormant during the winter, resumes growth in early spring, and flowers and dies of either maturity or lack of soil moisture by early June. To use UNSAT-H to simulate the phenology of cheatgrass, the transpiration/net radiation relationship (shown as a cross-hatched area in Figure 4.3) has been extended throughout the growing season. The code user can do this by choosing two dates. The first date is assigned as the day cheatgrass seeds germinate. The second date is assigned as the day cheatgrass plants cease transpiring because of senescence. Because the dates for these two parameters depend on the conditions of the simulation, they are left as variables for the code user. As seen in Figure 4.3, the ratio of transpiration to net radiation increases linearly between germination and the first day of maximum transpiration (day of the year 90), and then decreases linearly from the last day of maximum transpiration (day of the year 151) to zero as the plant senesces.

From year to year, plant biomass production (and thus transpiration) varies because of weather conditions and water and nutrient availability. The exact relationship between biomass and transpiration has not yet been established for cheatgrass or other common plant species at the Hanford Site. Therefore, an empirical relationship is used to estimate the effect of increased biomass on transpiration. Hinds (1975)

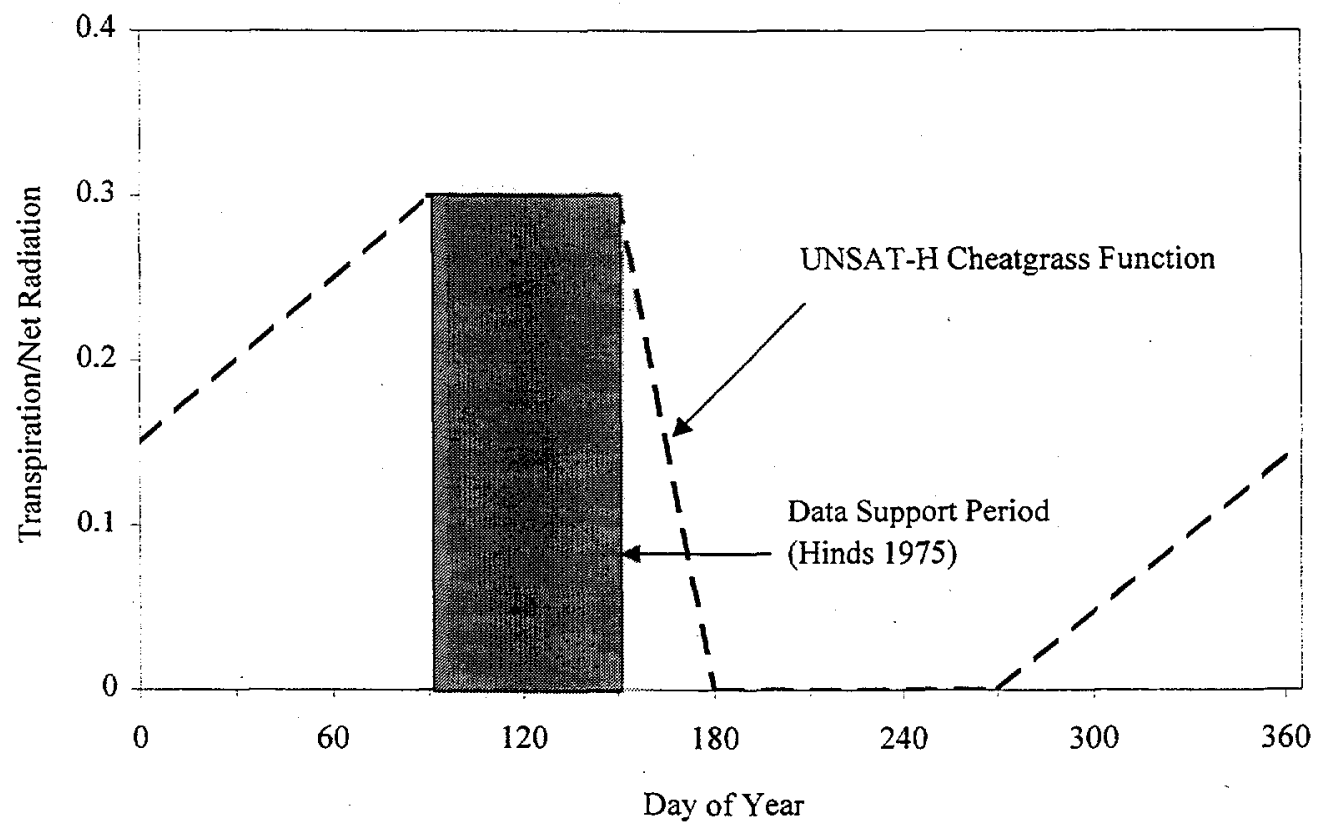

Figure 4.3. Relationship Between the Ratio of Transpiration to Net Radiation and Day of the Year 
measured $220 \mathrm{~g} / \mathrm{m}^{2}$ of plant biomass during the course of his experiment. If a direct relationship between biomass and transpiration is assumed, the transpiration ratio within UNSAT-H can be altered by specifying a value for biomass other than 220 . For example, specifying a biomass of $440 \mathrm{~g} / \mathrm{m}^{2}$ results in doubling the transpiration/net radiation ratio, with the constraint that the ratio must be between 0.0 and 1.0 .

Once $T_{p}$ is determined, the transpiration demand is applied to the root zone using the volumetric sink term of Equation (4.17). The sink term of each node in the model domain is assigned a fraction of the transpiration demand, with the fraction calculated as the root-length density of the node divided by the total root length within the soil profile. Cline et al. (1977) measured end-of-growing-season distributions of belowground biomass (both living and dead tissue) in two plant communities on the ALE Reserve.

Figure 4.4 shows the total root biomass distributions for an annual grass community (mostly cheatgrass) at the $305-\mathrm{m}(1000-\mathrm{ft})$ elevation, and for a perennial grass community (mostly bluebunch wheatgrass) at the $366-\mathrm{m}(1200-\mathrm{ft})$ elevation. The cheatgrass root biomass was mostly in the top $30 \mathrm{~cm}(0$ to $3 \mathrm{dm})$ of soil, in contrast to the deeper distribution for the bluebunch wheatgrass.

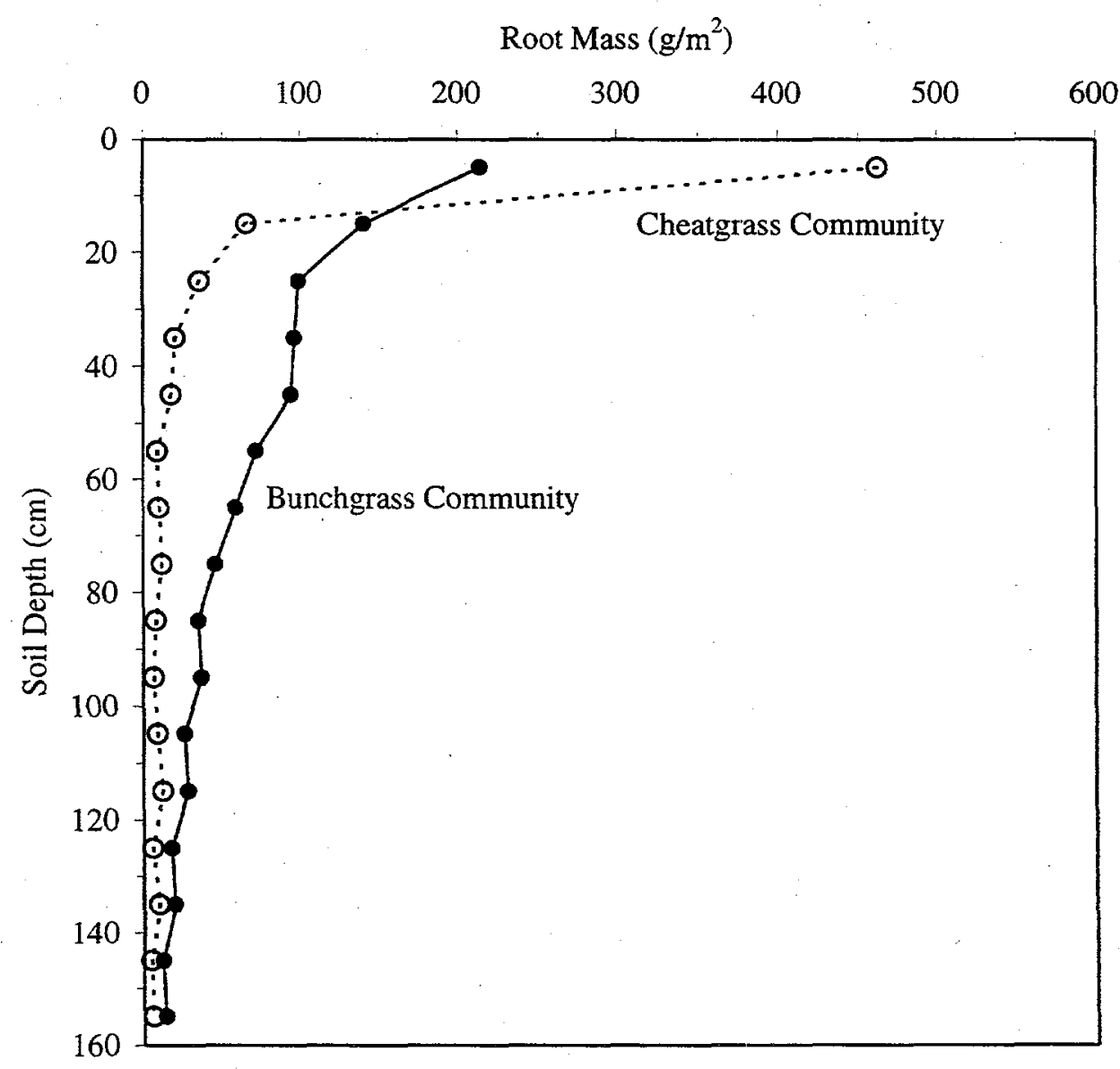

Figure 4.4. Root Mass at the End of the 1974 Growing Season for Cheatgrass and Bluebunch Wheatgrass Communities of the Hanford Site 
The cheatgrass root biomass data of Figure 4.4 were normalized for biomass found between 0 and $80 \mathrm{~cm}$ (Table 4.1). Assuming that the normalized total root biomass is directly related to root-length density $\left(\rho_{r L}\right)$, the $\rho_{r L}$ can be related to the depth, $z$, below the surface by

$$
\rho_{r L}=a \exp (-b z)+c
$$

where $a, b$, and $c$ are coefficients that optimize the fit to the normalized biomass data $(a=1.163$, $b=0.129$, and $c=0.020$ ). The units of $\rho_{r L}$ are $\mathrm{cm}$ roots $/ \mathrm{cm}$ soil. To calculate the root-density function $\left(\rho_{r}\right)$, the values of $\rho_{r L}$ are multiplied by their respective depth intervals to obtain the total root length. Each $\rho_{r L}$ value is then divided by the total root length to obtain the $\rho_{r}$ value for each depth. Table 4.1 contains the $\rho_{r}$ values calculated for two depths of root penetration.

After $T_{p}$ is distributed throughout the root zone, the final step is to calculate the actual transpiration or sink term at each depth. This is done by multiplying the potential sink term, $S_{\text {pot }}$, of each node by the sink term reduction factor, $\alpha_{f}$, a factor that is less than or equal to 1.0 and is a function of the soil water content of the respective node. The factor $\alpha_{f}$ relates the transpiration rate to the water status in the root zone. The relationship between $\alpha_{f}$ and water content is shown in Figure 4.5. When the soil water content of a node is greater than $\theta_{n}, \alpha_{f}$ equals zero (because anaerobic conditions prevail and the plant ceases withdrawal of water from that node). When the soil water content is between $\theta_{d}$ and $\theta_{n}, \alpha_{f}$ is 1.0 and the rate of withdrawal is equal to $S_{p o r}$. If the soil water content is between $\theta_{w}$ and $\theta_{d}$, the rate of withdrawal is reduced linearly from 1.0 to 0.0 as the water content decreases. When the soil water content is less than $\theta_{w}, \alpha_{f}$ equals zero to indicate that the plant has stopped withdrawing water from that node.

Table 4.1. Cheatgrass Root-Biomass Data, Root-Length Density $\left(\rho_{r L}\right)$, and Root-Density Function $\left(\rho_{r}\right)$

\begin{tabular}{|c|c|c|c|c|c|}
\hline \multirow{3}{*}{$\begin{array}{c}\text { Depth } \\
\text { Interval, } \\
\text { cm }\end{array}$} & \multirow{3}{*}{$\begin{array}{c}\text { Root } \\
\text { Biomass } \\
\text { g/m }\end{array}$} & \multirow{3}{*}{$\begin{array}{l}\text { Normalized } \\
\text { Biomass }\end{array}$} & \multirow{3}{*}{$\begin{array}{c}\rho_{r L} \\
\text { cm roots/ } \\
\text { cm soil }\end{array}$} & \multirow{2}{*}{\multicolumn{2}{|c|}{$\frac{\rho_{r}(1 / \mathrm{cm})}{\text { Roots Penetrate to... }}$}} \\
\hline & & & & & \\
\hline & & & & $80 \mathrm{~cm}$ & $20 \mathrm{~cm}$ \\
\hline $0-10$ & 499.4 & 0.630 & 0.630 & 0.0629 & 0.0770 \\
\hline $10-20$ & 145.5 & 0.184 & 0.188 & 0.0188 & 0.0230 \\
\hline $20-30$ & 51.1 & 0.065 & 0.066 & 0.0066 & - \\
\hline $30-40$ & 31.5 & 0.040 & 0.033 & 0.0033 & -- \\
\hline $40-50$ & 25.6 & 0.032 & 0.024 & 0.0024 & -- \\
\hline $50-60$ & 15.7 & 0.020 & 0.021 & 0.0021 & -- \\
\hline $60-70$ & 11.8 & 0.015 & 0.020 & 0.0020 & -- \\
\hline $70-80$ & 11.8 & 0.015 & 0.020 & 0.0020 & -- \\
\hline Total $=$ & 792.4 & & & & \\
\hline
\end{tabular}




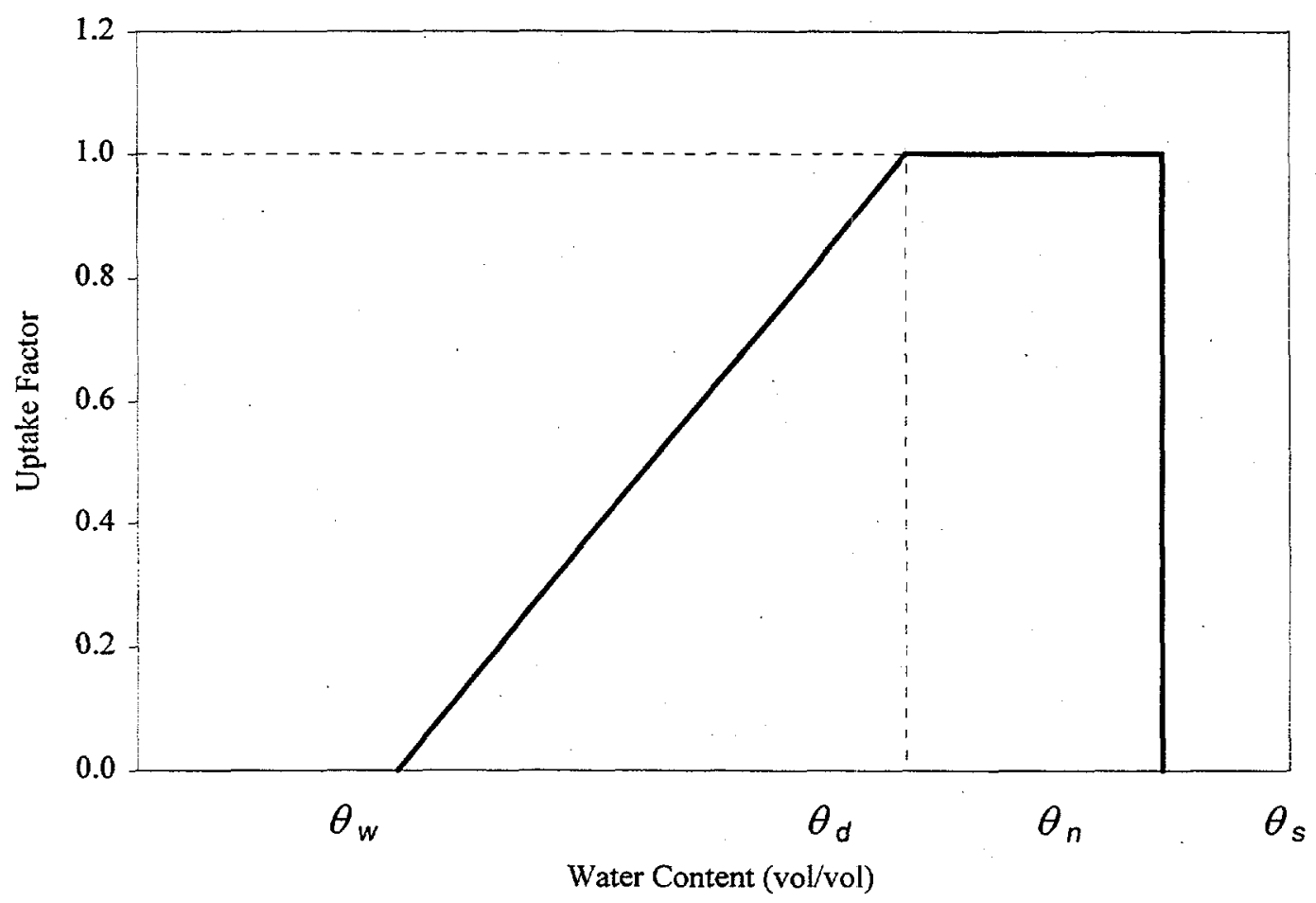

Figure 4.5. The Sink Term Reduction Factor $a_{f}$ as a Function of Water Content

\subsection{Boundary Conditions}

The flow of water and heat across the surface and lower boundary of the soil column of interest is determined by boundary condition specifications. Section 4.5 described evaporation (the movement of water vapor from the soil surface to the atmosphere). This section describes the remaining boundary conditions, including liquid water flow; weather variables that affect evaporation, transpiration, and heat flow; heat exchange; and water and heat fluxes at the bottom boundary.

For infiltration events, the upper boundary condition for water flow can be either a flux or constant head. The flux boundary can be specified as an hourly flux that is equivalent to a precipitation rate. If the suction head of the surface node should become less than the minimum suction head, the upper boundary becomes a constant head that is equivalent to the minimum suction head. During this condition, infiltration is calculated as the sum of the change in storage of the surface node and the flux between the surface node and the node below it. The constant head condition continues until the precipitation rate becomes less than the potential infiltration rate, and the suction head of the surface node exceeds the minimum suction head. At that time, the upper boundary of the domain reverts to being a flux boundary. The second surface-boundary option is to specify a constant suction head, such as a depth of ponding. The surface water flux then becomes equivalent to the flux between the first and second nodes. 
Similarly, the surface boundary condition during evaporation is either a flux or a constant suction head. The input required for the evaporative-flux boundary condition is either daily weather data or daily PET values. The daily weather data consist of

- daily maximum and minimum air temperatures

- daily average dewpoint temperature

- total daily solar radiation

- average daily wind speed

- daily average cloud cover.

The maximum and minimum air temperatures are used to calculate a sinusoidal variation in air temperature, $T_{a}$, throughout the day, using

$$
T_{a}=T_{\text {mean }}+T_{a m p} \cos \left[\frac{2 \pi}{24}\left(t_{d}-15\right)\right]
$$

where $T_{\text {mean }}$ is the average of maximum and minimum air temperatures, $\mathrm{K} ; T_{\text {amp }}$ is the air temperature amplitude, $\mathrm{K}$; and $t_{d}$ is the time of day, hr. Equation (4.50) assumes the daily minimum temperature occurs at $0300 \mathrm{hr}$ and the daily maximum temperature occurs at $1500 \mathrm{hr}$.

Before $0300 \mathrm{hr}$, the maximum air temperature from the previous day is used in Equation (4.50). After $1500 \mathrm{hr}$, the minimum air temperature from the next day is used in Equation (4.50). This arrangement ensures that air temperature has no discontinuity at midnight.

The dewpoint temperature (and thus the atmospheric vapor density) are assumed to remain constant during the day. When heat flow is being modeled, solar radiation is distributed during the day as outlined later in this section. Wind speed and cloud cover remain constant throughout the day.

When heat flow is not being modeled, the boundary condition for evapotranspiration will be a function of the PET rate. The PET rate can be either input directly as a daily value or calculated as a daily value using the form of the Penman equation reported by Doorenbos and Pruitt (1977)

$$
\mathrm{PET}=\frac{s R_{n i}}{s+\gamma}+\frac{\gamma}{s+\gamma} 0.27\left(1+\frac{U}{100}\right)\left(e_{a}-e_{d}\right)
$$

where $s=$ slope of the saturation vapor pressure-temperature curve, $\mathrm{mb} \mathrm{K}^{-1}$

$R_{n i}=$ isothermal net radiation, $\mathrm{mm} \mathrm{d}^{-1}$

$\gamma=$ psychrometric constant, $\mathrm{mb} \mathrm{K}^{-1}$

$U=24-\mathrm{hr}$ wind run, $\mathrm{km} \mathrm{d}^{-1}$ 
$e_{a}=$ saturation vapor pressure at the mean air temperature, $\mathrm{mb}$

$e_{d}=$ actual vapor pressure, $\mathrm{mb}$.

The units used by Doorenbos and Pruitt (1977) were retained for this option.

Whether input or calculated, the PET value is distributed during the day according to the input of the code user or a sine function. The sine function approximates the daily variation of solar radiation, with the maximum value occurring at $1200 \mathrm{hr}$. This option allows $88 \%$ of the daily PET to be applied sinusoidally between 0600 and $1800 \mathrm{hr}$. During the remaining time, hourly PET rates are $1 \%$ of the daily value.

When heat flow is modeled, the surface boundary condition for heat flow can be a calculated heat flux, constant temperature, variable temperature, or constant flux. With the first option, the heat flux results from normal exposure of the soil surface to the atmosphere. For this condition, the flux of heat into or out of the surface node is

$$
G=R_{n}-H-L E
$$

where $G=$ surface heat flux density, $\mathrm{J} \mathrm{s}^{-1} \mathrm{~m}^{-2}$

$R_{n}=$ net radiation, $\mathrm{J} \mathrm{s}^{-1} \mathrm{~m}^{-2}$

$H=$ sensible heat flux density, $\mathrm{J} \mathrm{s}^{-1} \mathrm{~m}^{-2}$

$L E=$ latent heat flux density, $\mathrm{J} \mathrm{s}^{-1} \mathrm{~m}^{-2}$.

In Equation (4.52), the net radiation, $R_{n}$, is calculated from Campbell (1985) using

$$
R_{n}=\left(1-\alpha_{s}\right) S_{t}+\varepsilon_{a} \sigma T_{a}^{4}-\varepsilon_{s} \sigma T_{s}^{4}
$$

where $\alpha_{s}=$ surface albedo

$S_{t}=$ solar radiation, $\mathrm{J} \mathrm{s}^{-1} \mathrm{~m}^{-2}$

$\varepsilon_{a}=$ atmospheric emissivity

$\sigma=$ Stephan-Boltzmann constant, $\mathrm{J} \mathrm{s}^{-1} \mathrm{~m}^{-2} \mathrm{~K}^{-4}$

$T_{a}=$ air temperature, $\mathrm{K}$

$\varepsilon_{s}=$ soil emissivity

$T_{s}=$ soil surface temperature, $\mathrm{K}$.

The calculation of net radiation requires estimates of the surface albedo, the atmospheric and soil emissivities, and solar radiation. Representative estimates of surface albedo are found in Campbell (1977); however, Hillel (1977) concluded that simulating the change in surface albedo during surface drying was important. Therefore, the relationship (van Bavel and Hillel 1976)

$$
\alpha_{s}=0.1+\left(0.25-\theta_{1}\right)
$$


was incorporated in which $\theta_{I}$ is the water content at the surface. The albedo value thus calculated is constrained to between 0.1 and 0.25 .

Campbell (1985) recommends that atmospheric emissivity be calculated based on cloud cover. For clear skies, Campbell recommends the formula of Brutsaert (1975)

$$
\varepsilon_{a}=4.174\left(\rho_{v a}\right)^{1 / 7}
$$

where $\rho_{v a}$ is the atmospheric vapor density. For cloudy skies, Campbell recommends the formula of Monteith (1975)

$$
\varepsilon_{a c}=(1-0.84 c) \varepsilon_{a}+0.84 c
$$

where $\varepsilon_{a}$ is the clear-sky emissivity and $c$ is the fractional cloud cover. Under cloudy-sky conditions, $\varepsilon_{a c}$ replaces $\varepsilon_{a}$ in Equation (4.53).

Although the emissivity of the soil surface could be estimated as a constant (Campbell 1977), $\varepsilon_{s}$ is dependent to some degree on the wetness of the soil surface. Therefore, the relationship (van Bavel and Hillel 1976)

$$
\varepsilon_{s}=0.9+0.18 \theta_{1}
$$

is included in which the emissivity is not allowed to exceed unity.

The daily solar radiation is converted into fluxes that are a function of the time of day. The first step is to calculate the transmission coefficient, $T_{t}$, which is the ratio of measured solar radiation to potential solar radiation. Potential daily solar radiation, $Q_{0}$, is a function of latitude, $\phi$, and the solar declination angle, $\delta$, which varies throughout the year. The potential daily solar radiation is calculated from (Campbell 1985)

$$
Q_{o}=\frac{117.5}{\pi}\left[h_{s} \sin (\phi) \sin (\delta)+\cos (\phi) \cos (\delta) \sin \left(h_{s}\right)\right]
$$

where $h_{s}$ is $\cos ^{-1}[-\tan (\phi) \tan (\delta)]$. The sine of the solar declination angle is calculated as

$$
\sin (\delta)=0.3985 \sin [4.869+0.0172 J+0.03345 \sin (6.224+0.0172 J)]
$$

where $J$ is the day of the year from 1 to 365 . The arguments of the trigonometric functions are in radians. If cloud data are unavailable, the fractional cloud cover, $c$, of Equation (4.56) is that of Campbell (1985)

$$
c=2.33-3.33 T_{t}
$$


The value of $c$ is constrained to be within the values of zero and one.

The measured daily solar radiation is converted to fluxes throughout the day using the transmission coefficient and

$$
S_{t}=S_{\text {ext }} T_{t} \sin (e)
$$

where $S_{e x t}$ is the solar constant (i.e., the flux density of solar radiation at the outside edge of the earth's atmosphere on a plane normal to the flux of solar radiation). The last term, $\sin (e)$, is the sine of the solar elevation angle, sometimes referred to as the solar altitude. The solar elevation angle is a function of latitude and time of day and year. The sine of the solar elevation angle is

$$
\sin (e)=\sin (\phi) \sin (\delta)+\cos (\phi) \cos (\delta) \cos \left[\frac{2 \pi}{24}\left(t_{d}-t_{o}\right)\right]
$$

where $t_{d}$ is the hour of the day, and $t_{o}$ is solar noon, specified in UNSAT-H to be $1200 \mathrm{hr}$.

The sensible heat flux is the loss or gain of heat by conduction and convection through the atmospheric boundary layer. The equation of choice is an integrated form of Fourier's law of conduction that closely resembles the integrated form of Fick's law used to calculate evaporation (Equation 4.41)

$$
H=\frac{C_{h a}}{r_{h}}\left(T_{s}-T_{a}\right)
$$

In a manner similar to that of the evaporation model, Equation (4.63) is used to represent the sensible heat flux such that the atmospheric boundary layer is not treated as a separate region in which the differential form of Fourier's law applies. Rather, Equation (4.63) assumes that the heat flux across the boundary layer is sufficiently rapid (compared to that in the soil) that a quasi-steady-state temperature profile exists within the layer and is dependent only on $T_{s}$ and $T_{a}$.

The latent heat term in Equation (4.52) is the product of the latent heat of vaporization, $L$, and the evaporation rate, $E$. The evaporation rate is calculated from Equation (4.41). Using Equations (4.53), (4.63), and (4.41), heat flux, $G$, at the soil surface can be calculated using Equation (4.52).

When the surface boundary condition for heat flow is constant temperature, the heat flux at the surface is equated to the heat flux between the surface node and the node below it. When the surface temperature is allowed to vary sinusoidally during the course of a day, the heat flux at the surface is equivalent to the flux between the surface node and the node below it, plus the change in heat storage at the surface node. For the last option, a constant heat flux is specified.

The second boundary to be specified is the lower boundary. The four options for flow of water across this boundary are 1) unit gradient, 2) constant suction head, 3) specified daily flux, and 4) impermeable boundary (i.e., zero flux). The unit gradient option corresponds to gravity-induced drainage and is most 
appropriate when applied to soil profiles that extend below the root zone and in which drainage is not impeded. With the unit gradient condition, the calculated drainage flux depends on the liquid water conductivity of the lower boundary node. The constant suction head option is most often chosen when the soil profile being simulated extends to a static water table, in which case the constant suction head value would be zero. Whenever drainage fluxes are known, they can be input directly using the flux option. Finally, the impermeable lower boundary condition can be used when drainage is restricted (e.g., in closed-bottom lysimeters).

For heat flow, the three options for the lower boundary condition are 1) constant gradient, 2) constant temperature, and 3) constant flux. For the constant gradient option, the heat flux across the lower boundary is a function of the chosen gradient, the thermal conductivity of the lower boundary node, and the thermally induced vapor flux. For the constant temperature option, the heat flux across the lower boundary is equal to the flux between the lower boundary node and the node above it. For the third option, a constant heat flux is specified. A value of zero can be used to model a boundary impermeable to heat flow. 


\subsection{Numerical Implementation}

The equations used to represent the conceptual model are solved numerically with a Crank-Nicholson finite difference scheme. In this scheme, the mathematical equations are approximated with finite difference equations in which a finite grid represents both the space and time derivatives. Some error is associated with this approximation, but the error can be minimized by decreasing the size of the space and/or time grid intervals. The finite difference equations can be formed into a matrix that is amenable to an iterative solution scheme using either standard or modified Picard iteration (Celia et al. 1990).

A new feature of UNSAT-H Version 3.0 is the strategy of solving for suction head and temperature in alternating steps while iterating a time step. This strategy represents a departure from the strategy used in Version 2.0, in which the suction head solution was obtained first, followed by the temperature solution. The new strategy of alternating the suction head and temperature solution per iteration produces much more stable results.

\subsection{Finite Difference Approximation of Water Flow}

With the Crank-Nicholson method, the time derivatives are evaluated at the midpoint of the time step. Thus, Equation (4.17) is approximated in the computer code as

$$
C_{i}^{j-1 / 2} \frac{h_{i}^{j}-h_{i}^{j-1}}{t^{j}-t^{j-1}}=\frac{-2}{z_{i+1}-z_{i-1}}\left[q_{i+1 / 2}^{j-1 / 2}-q_{i-1 / 2}^{j-1 / 2}\right]-S_{i}^{j-1 / 2}
$$

where

$$
C_{i}^{j-1 / 2}=\frac{C_{i}^{j}+C_{i}^{j-1}}{2}
$$

and

$$
q_{i \pm 1 / 2}^{j-1 / 2}=\frac{q_{i \pm 1 / 2}^{j}+q_{i \pm 1 / 2}^{j-1}}{2}
$$

The subscript $i$ denotes the node at depth $z_{i}$. The superscript $j$ denotes the time, $t_{j}$, for which the solution will be determined. The sink term, $S_{i}$, is directly calculated in the code as a function of the time of day and the water content, $\theta_{i}^{j-1 / 2}$.

The flux terms at the midpoints between nodes are approximated by 


$$
q_{i+1 / 2}^{j}=K_{T, i+1 / 2}^{j}\left(\frac{h_{i+1}^{j}-h_{i}^{j}}{z_{i+1}-z_{i}}\right)+G K_{L, i+1 / 2}^{j}-K_{\nu T, i+1 / 2}^{j}\left(\frac{T_{i+1}^{j}-T_{i}^{j}}{z_{i+1}-z_{i}}\right)
$$

and

$$
q_{i-1 / 2}^{j}=K_{T, i-1 / 2}^{j}\left(\frac{h_{i}^{j}-h_{i-1}^{j}}{z_{i}-z_{i-1}}\right)+G K_{L, i-1 / 2}^{j}-K_{v T, i-1 / 2}^{j}\left(\frac{T_{i}^{j}-T_{i-1}^{j}}{z_{i}-z_{i-1}}\right)
$$

During the first iteration of the water flow calculation, soil temperatures $T_{i}^{j}$ are equivalent to $T_{i}^{j-1}$. During subsequent iterations, soil temperatures $T_{i}^{j}$ are set to their values at the end of the previous successful iteration.

The $G$ term in Equations (5.4) and (5.5) is the gravity flow factor. When $G$ has a value of 0 , the gravity inducement to flow is neglected, thus allowing for simulation of horizontal flow. When $G$ is 1 , the gravity inducement to flow is included.

In Equations (5.4) and (5.5), the hydraulic conductivity between nodes can be calculated as the arithmetic mean (with an option for weighting the arithmetic mean to the upstream or downstream flow direction), the harmonic mean, or the geometric mean. The arithmetic equation is

$$
K_{L, i+1 / 2}^{j}=\omega_{u} K_{L, i}^{j}+\omega_{d} K_{L, i+1}^{j}
$$

where $\omega_{u}$ and $\omega_{d}$ represent upstream and downstream weighting options, with the constraint that $\omega_{u}+\omega_{d}$ $=1$. The equations for the harmonic and geometric means are

$$
\begin{aligned}
& K_{L, i+1 / 2}^{j}=2\left(\frac{1}{K_{L, i}^{j}}+\frac{1}{K_{L, i+1}^{j}}\right)^{-1} \\
& K_{L, i+1 / 2}^{j}=\left(K_{L, i}^{j} K_{L, i+1}^{j}\right)^{0.5}
\end{aligned}
$$

Values of $K_{L}$ are calculated from the input soil properties based on the head value of the corresponding node.

The isothermal vapor conductivity, $K_{v h}$, [which is part of $K_{T}$ in Equations (5.4) and (5.5)] is calculated according to 


$$
K_{v h, i}^{j}=\frac{\alpha D_{a} M g \rho_{v s, i}^{j-1}}{\rho_{w} R T_{i}^{j-1}}\left(\theta_{s}-\theta_{i}^{j}\right) \exp \left[\frac{-h_{i}^{j} M g}{R T_{i}^{j-1}}\right]
$$

based on Equations (4.9), (4.13), and (4.15). The value of $K_{v h}$ for the midpoint is calculated in the same manner as the liquid conductivity at the midpoint [i.e., using equations similar to Equations (5.6), (5.7), and 5.8)]. In Equations (5.4) and (5.5), the total conductivity applicable to a suction head gradient at a midpoint is thus

$$
K_{T, i+1 / 2}^{j}=K_{L, i+1 / 2}^{j}+K_{v h, i+1 / 2}^{j}
$$

The thermal vapor conductivity, $K_{v T}$, is calculated according to

$$
K_{v T, i}^{j}=\frac{\alpha D_{a}}{\rho_{w}}\left(\theta_{s}-\theta_{i}^{j}\right) \eta_{i}^{j} \exp \left[\frac{-h_{i}^{j} M g}{R T_{i}^{j-1}}\right] \frac{d \rho_{v s, i}^{j-1}}{d T_{i}^{j-1}}
$$

based on Equations (4.9), (4.13), and (4.16). The value of $K_{\mathrm{p} T}$ at the midpoint between nodes is calculated using the equally weighted arithmetic mean [Equation (5.6)].

\subsubsection{Interior Nodes}

Equation (5.1) is rearranged to solve for the suction head values at the end of a time step, with the general form of the rearranged equation being

$$
A_{i}^{*} h_{i-1}^{j}+B_{i}^{*} h_{i}^{j}+C_{i}^{*} h_{i+1}^{j}=D_{i}^{*}
$$

For the boundary nodes, the exact form of the coefficients in Equation (5.12) depends on the boundary conditions chosen. For all interior nodes, however, the coefficients for nodes $i=2, n-1$ are

$$
\begin{aligned}
& A_{i}^{*}=\frac{K_{T, i-1 / 2}^{j}}{\left(z_{i+1}-z_{i-1}\right)\left(z_{i}-z_{i-1}\right)} \\
& B_{i}^{*}=\frac{C_{i}^{j-1 / 2}}{t^{j}-t^{j-1}}-\frac{1}{\left(z_{i+1}-z_{i-1}\right)}\left[\frac{K_{T, i+1 / 2}^{j}}{\left(z_{i+1}-z_{i}\right)}+\frac{K_{T, i-1 / 2}^{j}}{\left(z_{i}-z_{i-1}\right)}\right]
\end{aligned}
$$




$$
\begin{aligned}
& C_{i}^{*}= \frac{K_{T, i+1 / 2}^{j}}{\left(z_{i+1}-z_{i-1}\right)\left(z_{i+1}-z_{i}\right)} \\
& D_{i}^{*}=\frac{C_{i}^{j-1 / 2} h_{i}^{j-1}}{t^{j}-t^{j-1}}-S_{i}^{j-1 / 2}-\frac{G}{\left(z_{i+1}-z_{i-1}\right)}\left(K_{L, i+1 / 2}^{j}-K_{L, i-1 / 2}^{j}\right) \\
&-\frac{1}{\left(z_{i+1}-z_{i-1}\right)}\left[\begin{array}{l}
K_{T, i+1 / 2}^{j-1}\left(\frac{h_{i+1}^{j-1}-h_{i}^{j-1}}{\left(z_{i+1}-z_{i}\right)}\right)-K_{T, i-1 / 2}^{j-1}\left(\frac{h_{i}^{j-1}-h_{i-1}^{j-1}}{\left(z_{i}-z_{i-1}\right)}\right) \\
+G\left(K_{L, i+1 / 2}^{j-1}-K_{L, i-1 / 2}^{j-1}\right)-K_{v T, i+1 / 2}^{j}\left(\frac{T_{i+1}^{j}-T_{i}^{j}}{z_{i+1}-z_{i}}\right) \\
-K_{v T, i+1 / 2}^{j-1}\left(\frac{T_{i+1}^{j-1}-T_{i}^{j-1}}{\left(z_{i+1}-z_{i}\right)}\right)+K_{v T, i-1 / 2}^{j}\left(\frac{T_{i}^{j}-T_{i-1}^{j}}{z_{i}-z_{i-1}}\right) \\
+K_{v T, i-1 / 2}^{j-1}\left(\frac{T_{i}^{j-1}-T_{i-1}^{j-1}}{\left(z_{i}-z_{i-1}\right)}\right)
\end{array}\right]
\end{aligned}
$$

When the modified Picard iteration technique is used, the $B^{*}$ and $D^{*}$ coefficients are modified. For $B^{*}$, the capacity in Equation (5.14) is changed from $C_{i}^{j-1 / 2}$ to $C_{i}^{j}$. For $D^{*}$, the entire term containing the capacity is replaced. The modification is

$$
D_{i}^{*}=D_{i}^{*} u-\frac{C_{i}^{j-1 / 2} h_{i}^{j-1}}{t^{j}-t^{j-1}}+\frac{\theta_{i}^{j-1}-\theta_{i}^{j, m}+C_{i}^{j, m} h_{i}^{j, m}}{t^{j}-t^{j-1}}
$$

where the superscript $u$ signifies the unmodified coefficient calculated in Equation (5.16), and the superscript $m$ is an iteration counter. Iteration $m$ represents the last completed iteration, while iteration $m+1$ represents the current iteration.

\subsubsection{Surface Boundary Node}

By convention, the surface boundary node in UNSAT-H is node 1 . The values of coefficients assigned to node 1 will depend on which surface boundary condition is chosen. One option in UNSAT-H is to specify a constant suction head for node 1 . The resulting solution equation for node 2 (the node below node 1) is

$$
B_{2}^{*} h_{2}^{j}+C_{2}^{*} h_{3}^{j}=D_{2}^{*}-A_{2}^{*} h_{1}^{j}
$$


In this case, the number of equations in the solution matrix is reduced by one because $h_{l}$ is already known.

Another surface boundary option in UNSAT-H specifies a surface flux, either as evaporation or precipitation. The special form of Equation (5.12) for this case looks like

$$
B_{1}^{*} h_{1}^{j}+C_{1}^{*} h_{2}^{j}=D_{1}^{*}
$$

where

$$
A_{1}^{*}=0
$$

$$
B_{1}^{*}=\frac{C_{1}^{j-1 / 2}}{t^{j}-t^{j-1}} \frac{K_{T, 3 / 2}^{j}}{\left(z_{2}-z_{1}\right)^{2}}
$$

$$
\begin{aligned}
& C_{1}^{*}=\frac{K_{T, 3 / 2}^{j}}{\left(z_{2}-z_{1}\right)^{2}} \\
& D_{1}^{*}=\frac{C_{1}^{j-1 / 2} h_{1}^{j-1}}{t^{j}-t^{j-1}}
\end{aligned}
$$

$$
-\frac{1}{\left(z_{2}-z_{1}\right)}\left[\begin{array}{l}
-2 q_{1 / 2}^{j-1 / 2}+G\left(K_{L, 3 / 2}^{j}\right)+K_{T, 3 / 2}^{j-1}\left(\frac{h_{2}^{j-1}-h_{1}^{j-1}}{\left(z_{2}-z_{1}\right)}\right) \\
+G\left(K_{L, 3 / 2}^{j-1}\right)-K_{v T, 3 / 2}^{j}\left(\frac{T_{2}^{j}-T_{1}^{j}}{\left(z_{2}-z_{1}\right)}\right)-K_{v T, 3 / 2}^{j-1}\left(\frac{T_{2}^{j-1}-T_{1}^{j-1}}{\left(z_{2}-z_{1}\right)}\right)
\end{array}\right]
$$

Note that plant water withdrawal from the surface node is not allowed. Also, the surface flux, $q_{1 / 2}^{j-1 / 2}$, is either specified by the user or calculated directly (e.g., the evaporative flux). The program checks during each time step to determine if the head value at the soil surface exceeds the range of values permitted (being either too wet or dry). If it does, then the suction head at the surface boundary is reset to the appropriate limit and the problem is re-solved for that time step for the remaining nodes. At the start of the next time step, the program will again assume a surface flux condition.

When evaporation and heat flow are simulated, the evaporation rate is calculated using Equation (4.41): 


$$
e=-c_{e}\left[\frac{\frac{1}{2}\left(\rho_{v s s}^{j}+\rho_{v s s}^{j-1}\right)-\rho_{v a}}{\rho_{w} r_{h}^{j-1 / 2}}\right]
$$

The negative sign was added to the beginning of Equation (5.24) to align the evaporation rate with the UNSAT-H convention that positive flux is downward.

The evaporation rate depends on $\rho_{v s s,}$ which is the product of the saturated vapor density at the soil surface temperature and the relative humidity (Equation 4.13) at the soil surface. Because of the dependence of $e$ on $\rho_{v s s}$, the evaporation rate is a nonlinear function of the suction head, $h_{1}$, of the surface node. A fraction of the dependence of $e$ on $h_{1}$ can be represented by expanding the exponential in Equation (4.13) and moving the linear $h_{1}$ term to the left-hand side of the matrix by modifying $B_{1}^{*}$ and $D_{1}^{*}$. The identity used to expand the exponential is

$$
\exp \left[f\left(h_{1}\right)\right]=1+f\left(h_{1}\right)+\frac{f\left(h_{1}\right)^{2}}{2 !}+\frac{f\left(h_{1}\right)^{3}}{3 !} \ldots=\left[\exp f\left(h_{1}\right)-f\left(h_{1}\right)\right]+f\left(h_{1}\right)
$$

where

$$
f\left(h_{1}\right)=\frac{-h_{1} M g}{R T}
$$

The modifications to the coefficients are

$$
\begin{aligned}
& B_{1}^{*}=B_{1}^{*} u-\frac{c_{e} \rho_{v s} h_{1}^{j} M g}{r_{h}^{j-1 / 2} \rho_{w} R T_{1}^{j-1}\left(z_{2}-z_{1}\right)} \\
& D_{1}^{*}=D_{1}^{* u}-\frac{c_{e} \rho_{v s} h_{1}^{j} M g}{r_{h}^{j-1 / 2} \rho_{w} R T_{1}^{j-1}\left(z_{2}-z_{1}\right)}
\end{aligned}
$$

where $B_{1}^{* u}$ and $D_{1}^{* u}$ on the right-hand side represent the unmodified version calculated previously.

When the modified Picard iteration technique is used, the $B^{*}$ and $D^{*}$ coefficients are modified. For $B^{*}$, the capacity in Equation (5.14) is changed from $C_{1}^{j-1 / 2}$ to $C_{1}^{j}$. For $D^{*}$, the entire term containing the capacity is replaced. The modification is 


$$
D_{1}^{*}=D_{1}^{* u}-\frac{C_{1}^{j-1 / 2} h_{1}^{j-1}}{t^{j}-t^{j-1}}+\frac{\theta_{1}^{j-1}-\theta_{1}^{j, m}+C_{1}^{j, m} h_{1}^{j, m}}{t^{j}-t^{j-1}}
$$

where the superscript $u$ signifies the unmodified coefficient calculated in Equation (5.16), and the superscript $m$ is an iteration counter. Iteration $m$ represents the last completed iteration, while iteration $m+1$ represents the current iteration.

\subsubsection{Lower Boundary Node}

Of the four options for determining the lower boundary condition, one is a fixed suction-head option. For this option, the user specifies in the initial conditions what the suction-head value of the node will be. The solution equation for node $n-1$ changes to

$$
A_{n-1}^{*} h_{n-2}^{j}+B_{n-1}^{*} h_{n-1}^{j}=D_{n-1}^{*}-C_{n-1}^{*} h_{n}^{j}
$$

and the number of equations to be solved is reduced by one. The user can specify a constant water table condition by using this fixed suction-head option and setting $h_{n}$ to zero.

The three other options are flux options. The general form of Equation (5.12) that is pertinent to all three options is

$$
A_{n}^{*} h_{n-1}^{j}+B_{n}^{*} h_{n}^{j}=D_{n}^{*}
$$

where

$$
\begin{aligned}
& A_{n}^{*}=\frac{K_{T, n-1 / 2}^{j}}{\left(z_{n}-z_{n-1}\right)^{2}} \\
& B_{n}^{*}=\frac{C_{n}^{j-1 / 2}}{t^{j}-t^{j-1}} \frac{K_{T, n-1 / 2}^{j}}{\left(z_{n}-z_{n-1}\right)^{2}} \\
& C_{n}^{*}=0
\end{aligned}
$$




$$
\begin{aligned}
D_{n}^{*}= & \frac{C_{n}^{j-1 / 2} h_{n}^{j-1}}{t^{j}-t^{j-1}}-S_{n}^{j-1 / 2} \\
& -\frac{1}{\left(z_{n}-z_{n-1}\right)}\left[\begin{array}{l}
2 q_{n+1 / 2}^{j-1 / 2}-G\left(K_{L, n-1}^{j}\right)-K_{T, n-1 / 2}^{j-1}\left(\frac{h_{n}^{j-1}-h_{n-1}^{j-1}}{\left(z_{n}-z_{n-1}\right)}\right) \\
\left.-G\left(K_{L, n-1}^{j-1}\right)+K_{v T, n-1 / 2}^{j}\left(\frac{T_{n}^{j}-T_{n-1}^{j}}{\left(z_{n}-z_{n-1}\right)}\right)+K_{v T, n-1 / 2}^{j-1} \cdot\left(\frac{T_{n}^{j-1}-T_{n-1}^{j-1}}{\left(z_{n}-z_{n-1}\right)}\right)\right]
\end{array}\right]
\end{aligned}
$$

For the impermeable boundary option, the time-averaged flux, $q_{n+1 / 2}^{j-1 / 2}$, is set equal to zero. For the specified flux boundary, $q_{n+1 / 2}^{j-1 / 2}$ is set equal to values specified by the code user. For the unit-gradient boundary condition, the flux is calculated as

$$
q_{n+1 / 2}^{j-1 / 2}=\frac{1}{2}\left(K_{L, n}^{j}+K_{L, n}^{j-1}\right)
$$

When the modified Picard iteration technique is used, the $B^{*}$ and $D^{*}$ coefficients are modified. For $B^{*}$, the capacity in Equation (5.14) is changed from $C_{n}^{j-1 / 2}$ to $C_{n}^{j}$. For $D^{*}$, the entire term containing the capacity is replaced. The modification is

$$
D_{n}^{*}=D_{n}^{* u}-\frac{C_{n}^{j-1 / 2} h_{n}^{j-1}}{t^{j}-t^{j-1}}+\frac{\theta_{n}^{j-1}-\theta_{n}^{j, m}+C_{n}^{j, m} h_{n}^{j, m}}{t^{j}-t^{j-1}}
$$

where the superscript $u$ signifies the unmodified coefficient calculated in Equation (5.16), and the superscript $m$ is an iteration counter. Iteration $m$ represents the last completed iteration, while iteration $m+1$ represents the current iteration.

\subsubsection{Mass Balance Error}

The first step in calculating the mass balance error is to calculate the soil-water storage at the end of a time step using

$$
S_{w}^{j}=\theta_{1}^{j}\left(\frac{z_{2}-z_{1}}{2}\right)+\theta_{n}^{j}\left(\frac{z_{n}-z_{n-1}}{2}\right)+\sum_{i=2}^{n-1} \theta_{i}^{j}\left(\frac{z_{i+1}-z_{i-1}}{2}\right)
$$

Then, the mass balance error $\left(E_{w}\right)$ for the time step can be obtained using

$$
E_{w}=I^{j}-E^{j}-T^{j}-D^{j}-\left(S_{w}^{j}-S_{w}^{j-1}\right)
$$


where the terms $I^{j}, E^{j}, T^{j}, D^{j}$ and $\left(S_{w}^{j}-S_{w}^{j-1}\right)$ refer to the amounts of infiltration, evaporation, transpiration, drainage, and change in storage, respectively, that have occurred during the time step.

\subsection{Finite Difference Approximation of Heat Flow}

In the Crank-Nicholson method, the time derivatives are evaluated at the midpoint of the time step. Thus, Equation (4.22) is approximated in the computer code as

$$
\begin{aligned}
& C_{h, i}^{j-1 / 2}\left(\frac{T_{i}^{j}-T_{i}^{j-1}}{t^{j}-t^{j-1}}\right)+C_{h v, i}^{j-1 / 2}\left(\frac{\theta_{v, i}^{j}-\theta_{v, i}^{j-1}}{t^{j}-t^{j-1}}\right)+C_{h w, i}^{j-1 / 2}\left(\frac{\theta_{i}^{j}-\theta_{i}^{j-1}}{t^{j}-t^{j-1}}\right) \\
& =\frac{-2}{z_{i+1}-z_{i-1}}\left[q_{h, i+1 / 2}^{j-1 / 2}-q_{h, i-1 / 2}^{j-1 / 2}\right]
\end{aligned}
$$

where

$$
\begin{aligned}
& C_{h, i}^{j-1 / 2}=\frac{1}{2}\left(C_{h, i}^{j}+C_{h, i}^{j-1}\right) \\
& C_{h v, i}^{j-1 / 2}=\frac{1}{2}\left[\left(L_{o}+C_{h v}\left(T_{i}^{j}-T_{o}\right)\right)+\left(L_{o}+C_{h v}\left(T_{i}^{j-1}-T_{o}\right)\right)\right] \\
& C_{h w, i}^{j-1 / 2}=\frac{1}{2}\left[C_{h w}\left(T_{i}^{j}-T_{o}\right)+C_{h w}\left(T_{i}^{j-1}-T_{o}\right)\right]
\end{aligned}
$$

and

$$
q_{h, i \pm 1 / 2}^{j-1 / 2}=\frac{1}{2}\left(q_{h, i \pm 1 / 2}^{j}+q_{h, i \pm 1 / 2}^{j-1}\right)
$$

The subscript $i$ denotes the node at depth $z_{i}$. The superscript $j$ denotes the time, $t_{j}$, for which the equations are solved.

The flux terms at the midpoints between nodes are approximated by

$$
\begin{aligned}
q_{h, i+1 / 2}^{j}= & -k_{h, i+1 / 2}^{j}\left(\frac{T_{i+1}^{j}-T_{i}^{j}}{z_{i+1}-z_{i}}\right)+\left[L_{o}+C_{h v}\left(\frac{T_{i+1}^{j}+T_{i}^{j}}{2}-T_{o}\right)\right] q_{v, i+1 / 2}^{j-1 / 2} \\
& +C_{h w}\left(\frac{T_{i+1}^{j}+T_{i}^{j}}{2}-T_{o}\right) q_{L, i+1 / 2}^{j-1 / 2}
\end{aligned}
$$


and

$$
\begin{aligned}
q_{h, i-1 / 2}^{j} & =-k_{h, i-1 / 2}^{j}\left(\frac{T_{i}^{j}-T_{i-1}^{j}}{z_{i}-z_{i-1}}\right)+\left[L_{o}+C_{h v}\left(\frac{T_{i}^{j}+T_{i-1}^{j}}{2}-T_{o}\right)\right] q_{v, i-1 / 2}^{j-1 / 2} \\
& +C_{h w}\left(\frac{T_{i}^{j}+T_{i-1}^{j}}{2}-T_{o}\right) q_{L, i-1 / 2}^{j-1 / 2}
\end{aligned}
$$

The thermal conductivity values in Equations (5.45) and (5.46) are calculated using an arithmetic mean. The $q_{v}$ term in Equations (5.45) and (5.46) is the sum of $q_{v h}$ and $q_{v r}$, and is obtained from solution of the water flow equation. Both $q_{L}$ and $q_{v}$ are updated with each iteration.

\subsubsection{Interior Nodes}

Equation (5.40) is rearranged to solve for the temperature values at the end of a particular time step, with the general form of the rearranged equation being

$$
A_{i}^{*} T_{i-1}^{j}+B_{i}^{*} T_{i}^{j}+C_{i}^{*} T_{i+1}^{j}=D_{i}^{*}
$$

For the boundary nodes, the exact form of the coefficients in Equation (5.47) depends on the boundary conditions chosen. For all interior nodes, however, the coefficients for nodes $i=2, n-1$ are

$$
\begin{aligned}
A_{i}^{*}= & \frac{1}{z_{i+1}-z_{i-1}}\left[\left(\frac{-k_{h, i-1 / 2}^{j}}{z_{i}-z_{i-1}}\right)-\frac{C_{h v}}{2} q_{v, i-1 / 2}^{j-1 / 2}-\frac{C_{h w}}{2} q_{L, i-1 / 2}^{j-1 / 2}\right] \\
B_{i}^{*}= & \frac{C_{h, i}^{j-1 / 2}}{t^{j}-t^{j-1}}+\frac{1}{z_{i+1}-z_{i-1}}\left[\left(\frac{k_{h, i+1 / 2}^{j}}{z_{i+1}-z_{i}}\right)+\left(\frac{k_{h, i-1 / 2}^{j}}{z_{i}-z_{i-1}}\right)\right] \\
& +\frac{C_{h v}}{2}\left[\frac{\theta_{v, i}^{j}-\theta_{v, i}^{j-1}}{t^{j}-t^{j-1}}+\frac{q_{v, i+1 / 2}^{j-1 / 2}-q_{v, i-1 / 2}^{j-1 / 2}}{z_{i+1}-z_{i-1}}\right] \\
& +\frac{C_{h w}}{2}\left[\frac{\theta_{i}^{j}-\theta_{i}^{j-1}}{t^{j}-t^{j-1}}+\frac{q_{L, i+1 / 2}^{j-1 / 2}-q_{L, i-1 / 2}^{j-1 / 2}}{z_{i+1}-z_{i-1}}\right] \\
C_{i}^{*} & =\frac{1}{z_{i+1}-z_{i-1}}\left[\left(\frac{-k_{h, i+1 / 2}^{j}}{z_{i+1}-z_{i}}\right)+\frac{C_{h v}}{2} q_{v, i+1 / 2}^{j-1 / 2}+\frac{C_{h w}}{2} q_{L, i+1 / 2}^{j-1 / 2}\right]
\end{aligned}
$$




$$
\begin{aligned}
& D_{i}^{*}=\frac{C_{h, i}^{j-1 / 2} T_{i}^{j-1}}{t^{j}-t^{j-1}}-\frac{1}{z_{i+1}-z_{i-1}}\left[-k_{h, i+1 / 2}^{j-1}\left(\frac{T_{i+1}^{j-1}-T_{i}^{j-1}}{z_{i+1}-z_{i}}\right)+k_{h, i-1 / 2}^{j-1}\left(\frac{T_{i}^{j-1}-T_{i-1}^{j-1}}{z_{i}-z_{i-1}}\right)\right] \\
& -\left[L_{o}+C_{h v}\left(\frac{T_{i}^{j-1}}{2}-T_{o}\right)\right] \frac{\theta_{v, i}^{j}-\theta_{v, i}^{j-1}}{t^{j}-t^{j-1}} \\
& -\frac{1}{z_{i+1}-z_{i-1}}\left[\begin{array}{l}
\left.\left(L_{o}-C_{h v} T_{o}\right)\left(q_{v, i+1 / 2}^{j-1 / 2}-q_{v, i-1 / 2}^{j-1 / 2}\right)+\left[L_{o}+C_{h v}\left(\frac{T_{i+1}^{j-1}+T_{i}^{j-1}}{2}-T_{o}\right)\right] q_{v, i+1 / 2}^{j-1 / 2}\right] \\
-\left[L_{o}+C_{h v}\left(\frac{T_{i}^{j-1}+T_{i-1}^{j-1}}{2}-T_{o}\right)\right] q_{v, i-1 / 2}^{j-1 / 2}
\end{array}\right] \\
& -C_{h w}\left(\frac{T_{i}^{j-1}}{2}-T_{o}\right) \frac{\theta_{i}^{j}-\theta_{i}^{j-1}}{t^{j}-t^{j-1}} \\
& -\frac{1}{z_{i+1}-z_{i-1}}\left[\begin{array}{l}
C_{h w}\left(\frac{T_{i+1}^{j-1}+T_{i}^{j-1}}{2}-T_{o}\right) q_{L, i+1 / 2}^{j-1 / 2}-C_{h w}\left(\frac{T_{i}^{j-1}+T_{i-1}^{j-1}}{2}-T_{o}\right) q_{L, i-1 / 2}^{j-1 / 2} \\
-C_{h w} T_{o}\left(q_{L, i+1 / 2}^{j-1 / 2}-q_{L, i-1 / 2}^{j-1 / 2}\right)
\end{array}\right]
\end{aligned}
$$

\subsubsection{Surface Boundary Node}

The values of the coefficients assigned to node 1 (the surface node) depend on the option chosen for the surface boundary condition for heat flow. Two of these options in UNSAT-H Version 2.0 permit specification of either a constant or variable temperature for node 1 . The resulting equation for heat flow at node 2 (the node below node 1 ) is

$$
B_{2}^{*} T_{2}^{j}+C_{2}^{*} T_{3}^{j}=D_{2}^{*}-A_{2}^{*} T_{1}^{j}
$$

In this case, the number of equations in the solution matrix is reduced by one because $T_{l}$ is already known.

The remaining two options for the surface boundary condition for heat flow in UNSAT-H are to treat the surface boundary as a heat flux. The special form of Equation (5.47) for this option looks like

$$
\begin{aligned}
& B_{1}^{*} T_{1}^{j}+C_{1}^{*} T_{2}^{j}=D_{1}^{*} \\
& A_{1}^{*}=0
\end{aligned}
$$




$$
\begin{aligned}
& B_{1}^{*}=\frac{C_{h, 1}^{j-1 / 2}}{t^{j}-t^{j-1}}+\frac{k_{h, 3 / 2}^{j}}{\left(z_{2}-z_{1}\right)^{2}} \\
& +\frac{C_{h v}}{2}\left[\frac{\theta_{v, 1}^{j}-\theta_{v, 1}^{j-1}}{t^{j}-t^{j-1}}+\frac{q_{v, 3 / 2}^{j-1 / 2}}{z_{2}-z_{1}}\right] \\
& +\frac{C_{h w}}{2}\left[\frac{\theta_{1}^{j}-\theta_{1}^{j-1}}{t^{j}-t^{j-1}}+\frac{q_{L, 3 / 2}^{j-1 / 2}}{z_{2}-z_{1}}\right] \\
& C_{1}^{*}=\frac{1}{\left(z_{2}-z_{1}\right)}\left[\frac{-k_{h, 3 / 2}^{j}}{\left(z_{2}-z_{1}\right)}+\frac{C_{h v}}{2} q_{v, 3 / 2}^{j-1 / 2}+\frac{C_{h w}}{2} q_{L, 3 / 2}^{j-1 / 2}\right] \\
& D_{1}^{*}=\frac{C_{h, 1}^{j-1 / 2} T_{1}^{j-1}}{t^{j}-t^{j-1}}-\frac{1}{z_{2}-z_{1}}\left[-k_{h, 3 / 2}^{j-1}\left(\frac{T_{2}^{j-1}-T_{1}^{j-1}}{z_{2}-z_{1}}\right)-2 q_{h, 1}^{j-1 / 2}\right] \\
& -\left[L_{o}+C_{h v}\left(\frac{T_{1}^{j-1}}{2}-T_{o}\right)\right] \frac{\theta_{v, 1}^{j}-\theta_{v, 1}^{j-1}}{t^{j}-t^{j-1}} \\
& -\frac{1}{z_{2}-z_{1}}\left[\left(L_{o}-C_{h v} T_{o}\right) q_{v, 3 / 2}^{j-1 / 2}+\left[L_{o}+C_{h v}\left(\frac{T_{2}^{j-1}+T_{1}^{j-1}}{2}-T_{o}\right)\right] q_{v, 3 / 2}^{j-1 / 2}\right] \\
& -C_{h w}\left(\frac{T_{1}^{j-1}}{2}-T_{o}\right) \frac{\theta_{1}^{j}-\theta_{1}^{j-1}}{t^{j}-t^{j-1}} \\
& -\frac{1}{z_{2}-z_{1}}\left[\begin{array}{l}
C_{h w}\left(\frac{T_{2}^{j-1}+T_{1}^{j-1}}{2}-T_{o}\right) q_{L, 3 / 2}^{j-1 / 2} \\
-C_{h w} T_{o}\left(q_{L, 3 / 2}^{j-1 / 2}\right)
\end{array}\right]
\end{aligned}
$$

According to the option chosen, the time-averaged flux, $q_{h}$, across the soil surface can be calculated [using Equation (4.52)] as a function of weather and soil parameters, or specified by the code user. When evaporation occurs, $q_{v, 1}<0$ and $q_{L, 1}=0$. When precipitation occurs, $q_{v, 1}=0$ and $q_{L, 1}>0$. 


\subsubsection{Lower Boundary Node}

Of the three options for determining the lower boundary condition, one is a constant temperature option. For this option, the user specifies in the initial conditions what the temperature value of the node will be. The solution equation for node $n-1$ changes to

$$
A_{n-1}^{*} T_{n-2}^{j}+B_{n-1}^{*} T_{n-1}^{j}=D_{n-1}^{*}-C_{n-1}^{*} T_{n}^{j}
$$

and the number of equations to be solved is reduced by one.

The two other options are flux options. The general form of Equation (5.47) pertinent to these two options is

$$
A_{n}^{*} T_{n-1}^{j}+B_{n}^{*} T_{n}^{j}=D_{n}^{*}
$$

where

$$
\begin{aligned}
A_{n}^{*} & =\frac{1}{\left(z_{n}-z_{n-1}\right)}\left[\frac{-k_{h, n-1 / 2}^{j}}{\left(z_{n}-z_{n-1}\right)}-\frac{C_{h v}}{2} q_{v, n-1 / 2}^{j-1 / 2}-\frac{C_{h w}}{2} q_{L, n-1 / 2}^{j-1 / 2}\right] \\
B_{n}^{*} & =\frac{C_{h, n}^{j-1 / 2}}{t^{j}-t^{j-1}}+\frac{k_{h, n-1 / 2}^{j}}{\left(z_{n}-z_{n-1}\right)^{2}} \\
& +\frac{C_{h v}}{2}\left[\frac{\theta_{v, n}^{j}-\theta_{v, n}^{j-1}}{t^{j}-t^{j-1}}+\frac{q_{v, n}^{j-1 / 2}-q_{v, n-1 / 2}^{j-1 / 2}}{z_{n}-z_{n-1}}\right] \\
& +\frac{C_{h w}}{2}\left[\frac{\theta_{n}^{j}-\theta_{n}^{j-1}}{t^{j}-t^{j-1}}+\frac{q_{L, n}^{j-1 / 2}-q_{L, n-1 / 2}^{j-1 / 2}}{z_{n}-z_{n-1}}\right] \\
C_{n}^{*} & =0
\end{aligned}
$$




$$
\begin{aligned}
D_{n}^{*} & =\frac{C_{h, n}^{j-1 / 2} T_{n}^{j-1}}{t^{j}-t^{j-1}}-\frac{1}{\left(z_{n}-z_{n-1}\right)}\left[2 q_{h, n}^{j-1}+k_{h, n-1 / 2}^{j-1}\left(\frac{T_{n}^{j-1}-T_{n-1}^{j-1}}{z_{n}-z_{n-1}}\right)\right] \\
& -\left[L_{o}+C_{h v}\left(\frac{T_{n}^{j-1}}{2}-T_{o}\right)\right] \frac{\theta_{v, n}^{j}-\theta_{v, n}^{j-1}}{t^{j}-t^{j-1}}\left[-\left[L_{o}+C_{h v}\left(\frac{2 T_{n}^{j-1}+\nabla T_{n}}{2}-T_{o}\right)\right] q_{v, n}^{j-1 / 2}\right] \\
& -\frac{1}{\left(z_{n}-z_{n-1}\right)}\left[\begin{array}{l}
{\left[L_{o}+C_{h v}\left(\frac{T_{n}^{j-1}+T_{n}^{j-1}}{2}-T_{o}\right) q_{v, n-1 / 2}^{j-1 / 2}\right.} \\
-\left(L_{o}-C_{h v} T_{o}\right)\left(q_{v, n}^{j-1 / 2}-q_{v, n-1 / 2}^{j-1 / 2}\right)
\end{array}\right] \\
& -C_{h w}\left(\frac{T_{n}^{j-1}}{2}-T_{o}\right) \theta_{t^{j}-\theta_{n}^{j-1}}^{j-1} \\
& -\frac{1}{\left(z_{n}-z_{n-1}\right)}\left[\begin{array}{l}
C_{h w}\left(T_{n}^{j-1}-T_{o}\right) q_{L, n}^{j-1 / 2}-C_{h w}\left(\frac{T_{n}^{j-1}+T_{n-1}^{j-1}}{2}-T_{o}\right) q_{L, n-1 / 2}^{j-1 / 2} \\
-C_{h w} T_{o}\left(q_{L, n}^{j-1 / 2}-q_{L, n-1 / 2}^{j-1 / 2}\right)
\end{array}\right]
\end{aligned}
$$

One of the two heat flux options for the lower boundary condition is a specified temperature gradient $\left(\nabla T_{n}\right)$. For this option, the flux is calculated as

$$
q_{h, n+1 / 2}^{j-1 / 2}=\frac{1}{2}\left(k_{h, n}^{j}+k_{h, n}^{j-1}\right) \nabla T_{n}
$$

If vapor flow is included, the temperature gradient at the bottom of the domain can induce a thermal vapor flux, represented by the second term on the right of Equation (4.14). The second flux option specifies a constant heat flux. With this option, the heat flux can be set equal to zero to simulate a boundary impermeable to heat flow. A thermally induced vapor flux across the bottom boundary is not permitted with this second heat flux option.

\subsubsection{Heat Balance Error}

Once a temperature solution has been obtained, a heat balance error $\left(E_{h}\right)$ is calculated. First, the heat storage $\left(S_{h}\right)$ of the soil during the time step is calculated using 


$$
\begin{aligned}
S_{h} & =\frac{z_{2}-z_{1}}{2} \Delta T_{1} C_{h, 1}^{j-1 / 2}+\left(L_{o}+C_{h v} \widetilde{T}_{1}\right)\left(\theta_{v, 1}^{j}-\theta_{v, 1}^{j-1}\right)+C_{h w} \widetilde{T}_{1}\left(\theta_{1}^{j}-\theta_{1}^{j-1}\right) \\
& +\frac{z_{n}-z_{n-1}}{2} \Delta T_{n} C_{h, n}^{j-1 / 2}+\left(L_{o}+C_{h v} \widetilde{T}_{n}\right)\left(\theta_{v, n}^{j}-\theta_{v, n}^{j-1}\right)+C_{h w} \widetilde{T}_{n}\left(\theta_{n}^{j}-\theta_{n}^{j-1}\right) \\
& +\sum_{i=2}^{n-1}\left[\frac{z_{i+1}-z_{i-1}}{2} \Delta T_{i} C_{h, i}^{j-1 / 2}+\left(L_{o}+C_{h v} \widetilde{T}_{i}\right)\left(\theta_{v, i}^{j}-\theta_{v, i}^{j-1}\right)+C_{h w} \widetilde{T}_{i}\left(\theta_{i}^{j}-\theta_{i}^{j-1}\right)\right]
\end{aligned}
$$

where

$$
\begin{aligned}
& \Delta T_{i}=T_{i}^{j}-T_{i}^{j-1} \\
& \widetilde{T}_{i}=\frac{1}{2}\left(T_{i}^{j}-T_{i}^{j-1}\right)-T_{o}
\end{aligned}
$$

Then, the heat balance error for the time step can be obtained using

$$
E_{h}^{j}=R_{n}^{j}-L E^{j}-H^{j}-Q H_{n}^{j}-\left(S_{h}^{j}-S_{h}^{j-1}\right)
$$

where the terms $R_{n}, L E, H, Q H_{n}$, and $\left(S_{h}^{j}-S_{h}^{j-1}\right)$ refer to the net radiation, latent heat, sensible heat, lower-boundary heat flows, and change in heat storage that have occurred during the time $\operatorname{step} j$. The calculated $E_{h}^{j}$ value is an informative index of the heat flow calculations and does not affect the calculation of water or heat flow or the time-step size. Individual $E_{h}^{j}$ values are summed during each output cycle.

\subsection{Time Steps}

Time steps must be kept small to solve the system of nonlinear equations with a minimum of error associated with the time discretization. Ideally, the optimal size of the time steps would be infinitesimally small. Practically, however, their size must be sufficiently large that a solution can be reached in a reasonable amount of computer time. In UNSAT-H, the time step is allowed to vary between specified minimum and maximum values. Within this range, the size of the time step will vary depending on userdefined criteria. Each criterion is evaluated relative to a user-defined acceptable value. If greater, the time step is reduced. If less, then the time step size is increased. The degree of decrease or increase is related to the size of the difference from the acceptable value.

A total of five criteria are available for controlling the size of the time step. Two of these criteria are the maximum relative change in water content $\left(\Delta \theta_{\text {rel }}\right)$ defined as 


$$
\Delta \theta_{r e l}=\operatorname{MAX}\left|\frac{\theta_{i}^{j}-\theta_{i}^{j-1}}{\theta_{i}^{j-1}}\right|
$$

and the mass balance error defined by Equation (5.39). One of these two criteria must be chosen, but they cannot be used simultaneously. The selected criterion is evaluated at the end of each time step.

The remaining three criteria are optional. The first optional criterion is to use the maximum relative change in suction head $\left(\Delta h_{r e l}\right)$ defined as

$$
\Delta h_{r e l}=\operatorname{MAX}\left|\frac{h_{i}^{j}-h_{i}^{j-1}}{h_{i}^{j-1}}\right|
$$

The second optional criteria is to monitor the maximum change in suction head, defined as

$$
\Delta h=\mathrm{MAX}\left|h_{i}^{j}-h_{i}^{j-1}\right|
$$

In both cases, the criterion is evaluated at the end of each iteration within a time step. The third optional criterion is to use the heat balance error defined by Equation (5.68). This criterion is evaluated at the end of a time step.

At the start of a simulation, the time step size is set to the minimum size. Thereafter, the time step size is governed by the time step criteria invoked. The only exception occurs at the start of an infiltration event, when the time step size is automatically reduced by a user-defined factor.

During simulations, time step adjustments are carried out as follows. After solving the water and heat (if necessary) flow equations to determine the matric suction and temperature solutions, the chosen criteria are calculated and compared to the allowable limits. If any of the limits are exceeded, the matric suction and temperature solutions are rejected, the time step is reduced by a factor between 0.5 and 1.0 (depending on the degree to which the criterion exceeds the assigned limit), the coefficient matrix is recalculated, and new solutions obtained. This process continues until either the criteria are within the allowable limits or the time step is reduced to the minimum allowable value. If an acceptable solution is not obtainable using the minimum time step, the program will terminate with an error message.

When all of the criteria are within the allowable limits, the next time step size is increased relative to the one just completed. The size of each successive time step can be increased until the maximum allowable time step, as defined by the user, is reached. From then on, as long as the criteria are satisfied, the time step size will be set to the maximum value. 


\subsection{Code Design, Problem Formulation, and Code Operation}

This section addresses the design and functioning of the UNSAT-H computer code. The topics include the structural design of the code, how to set up a problem conceptually and create an input file, and how to conduct a simulation with that input file.

\subsection{Code Design}

The UNSAT-H model consists of three programs: DATAINH, UNSATH, and DATAOUT. The relationships between these programs, as well as the file specifications and subroutine calls, are illustrated in Table 6.1. The symbol "*" in a file name (e.g., *.inp) is a "wildcard" character that can be replaced by any problem name. For example, the input file for a drainage problem might be called drain.inp. The three-character ending of the file names (e.g., bin, res) is called the "file name extension." The conventions in the UNSAT-H model are that bin indicates a binary input file, inp an ASCII input file, hri a hysteresis restart file, res a binary results file, and lis and out indicate ASCII results files. Several computer variables are used in the following sections to describe logic flow. These variables are defined in Table 6.2 .

Table 6.1. Data Flow, Program Tasks, and Subroutines

\begin{tabular}{|c|c|c|c|c|}
\hline $\begin{array}{l}\text { Input } \\
\text { Files }\end{array}$ & Program & Purpose & $\begin{array}{c}\text { Output Files } \\
\text { or Device }\end{array}$ & Subroutines and Functions \\
\hline $\begin{array}{l}{ }^{*} . i n p \\
\text { (ASCII } \\
\text { format) }\end{array}$ & DATANH & $\begin{array}{l}\text { Process input } \\
\text { data }\end{array}$ & $\begin{array}{l}\text { *.bin (binary } \\
\text { format), printer, } \\
\text { screen }\end{array}$ & $\begin{array}{l}\text { calpet, drain2p, dry2p, etbc, etpar, filbldr, } \\
\text { heatpar, hysini, hyspar, hysout, hysshp, } \\
\text { kcalcs, lowbc, myhrly, path, petpart, plantin, } \\
\text { polykh, precipbc, relhum, retent, rld, shppar, } \\
\text { thermk, timex, update, volvap, welcome, } \\
\text { wet2p }\end{array}$ \\
\hline $\begin{array}{l}\text { *.bin } \\
\text { (binary } \\
\text { format) }\end{array}$ & UNSATH & $\begin{array}{l}\text { Model } \\
\text { calculations }\end{array}$ & $\begin{array}{l}\text { *.res (binary } \\
\text { format) }\end{array}$ & $\begin{array}{l}\text { airtmp, blr, calpet, delchk, drain2p, dry2p, } \\
\text { etbc, filbldr, flux, heatflow, hysini, hysout, } \\
\text { hysshp, interk, kcalcs, kvcalc, lowbc, netrad, } \\
\text { path, petpart, polykh, precipbc, relhum, reset, } \\
\text { retent, rld, roots, therme, thermk, timex, } \\
\text { trsink, update, volvap, welcome, wet2p, } \\
\text { zeroa, zeroi, zeror }\end{array}$ \\
\hline $\begin{array}{l}\text { *.res } \\
\text { (binary } \\
\text { format) }\end{array}$ & DATAOUT & $\begin{array}{l}\text { Process output } \\
\text { data }\end{array}$ & $\begin{array}{l}{ }^{*} . \text { lis },{ }^{*} \text {.out, } \\
\text { toss.out (ASCII } \\
\text { format), printer, } \\
\text { screen }\end{array}$ & $\begin{array}{l}\text { ddsum, hardcopy, initsum, listdata, nodez, } \\
\text { profiler, readrec, reinit, scan, summary, } \\
\text { welcome }\end{array}$ \\
\hline
\end{tabular}


Table 6.2. Definition of Computer Variables Used in Section 6

\begin{tabular}{|l|l|}
\hline \multicolumn{1}{|c|}{ Variable } & \multicolumn{1}{c|}{ Definition } \\
\hline DELSUB & $\begin{array}{l}\text { Sub-daily calculation period; generally set to } 1 \mathrm{hr} \text { if PET and } \\
\text { precipitation are simulated. }\end{array}$ \\
\hline DELT & Time step size (hr) \\
\hline IDAY & Current simulation day \\
\hline IDEND & Last simulation day \\
\hline IYEAR & Current simulation year \\
\hline N & Current DELSUB period \\
\hline NPRINT & Activates output for each DELSUB period if NPRINT $=1$ \\
\hline NTOTAL & Total number of DELSUB periods \\
\hline NYEAR & Last simulation year \\
\hline
\end{tabular}

\subsubsection{DATAINH}

The purpose of DATAINH is to process the input data that are destined for the UNSATH program. Having DATAINH preprocess the data reduces the likelihood that UNSATH will fail to run because of input errors. Thus, jobs (program runs) submitted to run overnight have a greater likelihood of running successfully, given that the input data have already been checked by DATAINH.

The DATAINH program is run interactively. The program reads the data contained in the specified *.inp file, checks for errors, performs calculations (such as unit conversions), and then writes the data in binary form to a file with the same name as the input file, but with the extension bin. The error checking done by DATAINH consists mostly of determining whether the choices for various options exist (e.g., if option three was chosen when only two options exist), whether array dimensions are exceeded, and whether rainfall dates are listed in chronological order. Table 6.3 describes the subroutines that compose DATAINH.

All data required by UNSATH are output to a *.bin file in the format shown in Figure 6.1.

\subsubsection{UNSATH}

The UNSATH program is the heart of the UNSAT-H model. The *.bin file created by DATAINH serves as the input file for UNSATH. Table 6.4 describes the subroutines that compose UNSAT-H. The major steps executed within UNSATH are illustrated in Figures 6.2 and 6.3. The steps start with data input and end with the final summary output of the simulation to file *.res. 
Table 6.3. Subroutines in DATAINH

\begin{tabular}{|c|c|}
\hline Name & Purpose \\
\hline calpet.f & Calculates PET using the Penman equation \\
\hline datainh.f & Severs as the main program of DATAINH \\
\hline $\operatorname{drain} 2 p . f$ & $\begin{array}{l}\text { Calculates the apparent water saturation, entrapped air saturation, permeability, and apparent } \\
\text { saturation capacity for the primary drainage path with and without air entrapment }\end{array}$ \\
\hline$d r y 2 p \cdot f$ & Calculates water and air saturations, relative permeability, and capacity for drainage paths \\
\hline etbc.f & Reads in the PET and meteorological boundary conditions \\
\hline etpar.f & Reads in PET and meteorological parameters \\
\hline filbldr.f & Reads in list of filenames containing PET, meteorological, and precipitation data \\
\hline heatpar.f & Reads the soil parameters for heat flow \\
\hline hysini.f & Initializes variables for the hysteresis code \\
\hline hysout.f & Outputs final hysteresis variables from UNSAT-H to an external file for use in a possible restart \\
\hline hysparff & Reads soil parameters for hysteresis \\
\hline hysshp.f & $\begin{array}{l}\text { Passes the UNSAT-H parameters into the hysteresis routines in the correct units and converts the } \\
\text { output to UNSAT-H units }\end{array}$ \\
\hline kcalcs.f & Calculates hydraulic properties specific to modified Brooks-Corey and Van Genuchten functions \\
\hline lowbc.f & Reads in the lower boundary conditions \\
\hline myhrly.f & Calculates hourly distribution of PET based on the sine wave approach \\
\hline path.f & $\begin{array}{l}\text { Calculates the air-water capillary head, the amount of entrapped air, and the water saturation using } \\
\text { the input pressure heads of water and air }\end{array}$ \\
\hline petpart.f & Partitions PET into potential transpiration and evaporation \\
\hline plantinf & Reads in plant parameters \\
\hline polykh.f & Calculates the conductivity of each node as a function of the suction head value \\
\hline precipbc.f & Reads in precipitation data and writes meteorological and precipitation data to binary input file \\
\hline relhum.f & Calculates the relative humidity using suction head and temperature \\
\hline retent.f & $\begin{array}{l}\text { Calculates the water content and moisture capacity of each node as a function of the suction head } \\
\text { value }\end{array}$ \\
\hline rld.f & Calculates root density as a function of depth \\
\hline shppar.f & Reads in soil hydraulic property parameters \\
\hline thermk.f & Calculates soil thermal conductivity and volumetric heat capacity \\
\hline timex. $f$ & Queries the operating system and returns the time and date \\
\hline update.f & $\begin{array}{l}\text { Resets global variables after successful solution, and checks the index variables and sets them to } \\
\text { the proper saturation path }\end{array}$ \\
\hline volvap.f & Calculates volumetric vapor content \\
\hline welcome.f & Writes program header with version number and contact person \\
\hline wet $2 p . f$ & Calculates water and entrapped air saturations, relative permeability, and capacity for wetting paths \\
\hline
\end{tabular}




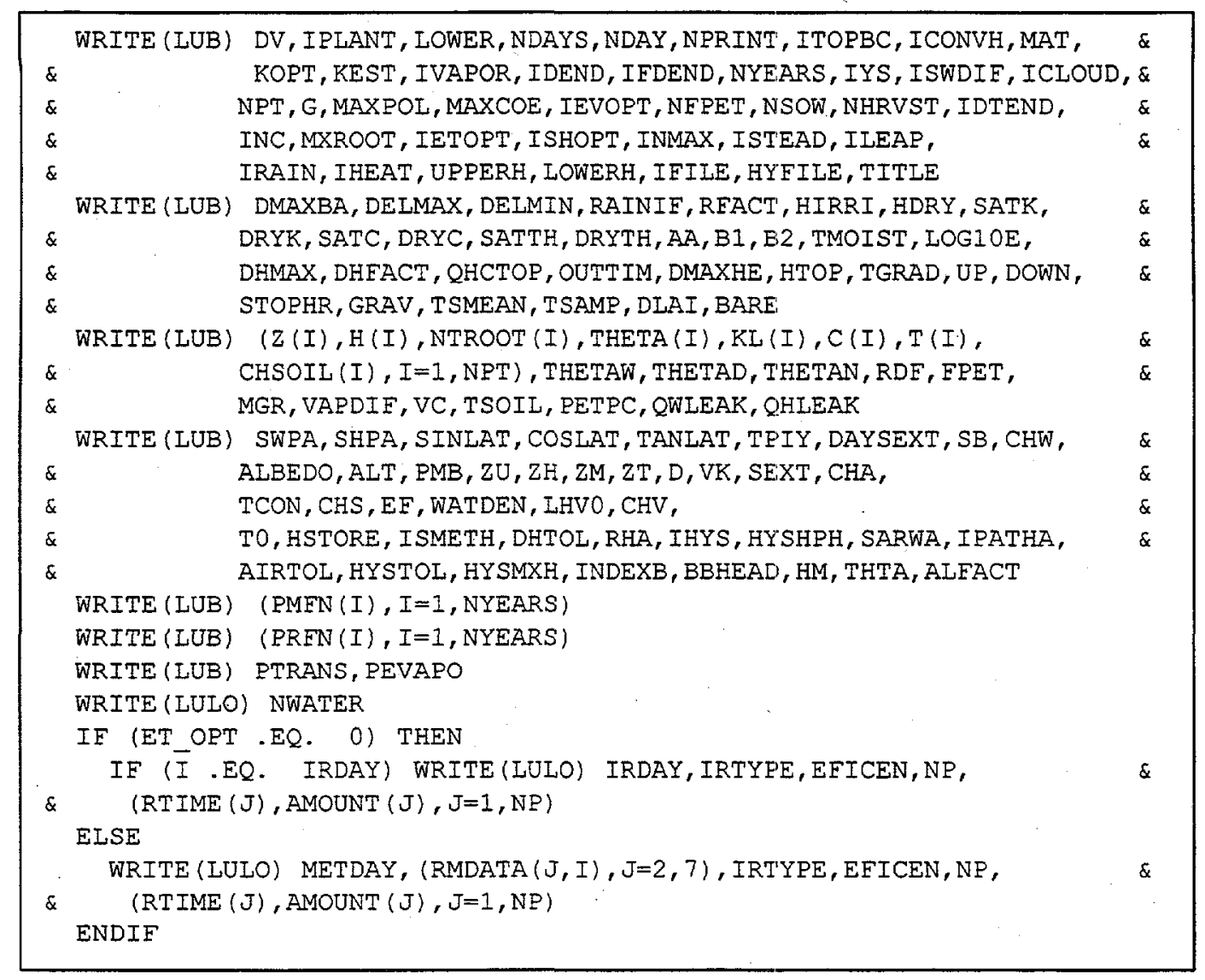

Figure 6.1. Format of the *.bin File Created by DATAINH for Input to UNSATH. LUB is the logical unit name for the binary output file. LULO is an alternate unit name that is equivalent to LUB.

Simulation data that are output to the *.res file include initial conditions, DELSUB and day-end values for head, water content, water and heat flow, temperatures, plant-sink terms, water and heatbalance terms, and at the end of the file, the simulation end results. The *.res format is shown in Figure 6.4.

\subsubsection{DATAOUT}

The purpose of DATAOUT is to process the UNSATH output data. Specifically, DATAOUT converts the binary output data found in a *.res file into ASCII format so that the results can be sent to either a screen for viewing or a printer or file for permanent record. Table 6.5 describes the subroutines that compose DATAOUT. 
Table 6.4. Subroutines in UNSATH

\begin{tabular}{|c|c|}
\hline Name & Purpose \\
\hline airtmp.f & Calculates the air temperature as a function of time of day \\
\hline blr.f & Calculates the boundary layer resistance to heat and vapor \\
\hline calpet.f & Calculates PET using the Penman Equation \\
\hline delckh.f & Adjusts the time step according to the mass and heat balance errors \\
\hline drain $2 p \cdot f$ & $\begin{array}{l}\text { Calculates the apparent water saturation, entrapped air saturation, permeability, and apparent } \\
\text { saturation capacity for the primary drainage path with and without air entrapment }\end{array}$ \\
\hline$d r y 2 p . f$ & Calculates water and air saturations, relative permeability, and capacity for drainage paths \\
\hline$e t b c . f$ & Reads in the PET and meteorological boundary conditions \\
\hline flux.f & Calculates liquid and vapor water fluxes between nodes \\
\hline hdrycalc.f & $\begin{array}{l}\text { Calculates a value for HDRY based on the temperature of the soil surface and the relative } \\
\text { humidity of the atmosphere }\end{array}$ \\
\hline heatflow.f & Solves the heat balance equations \\
\hline hysinif & Initializes variables for the hysteresis code \\
\hline hysout.f & Outputs hysteresis variables from UNSAT-H to an external file \\
\hline hysshp.f & $\begin{array}{l}\text { Passes the UNSAT-H parameters into the hysteresis routines in the correct units and converts the } \\
\text { output to UNSAT-H units }\end{array}$ \\
\hline interk.f & Calculates internodal liquid, vapor, and heat conductivities \\
\hline kcalcs.f & Calculates hydraulic properties specific to modified Brooks-Corey and Van Genuchten functions \\
\hline kvcalc.f & Calculates vapor conductivities \\
\hline netradff & $\begin{array}{l}\text { Calculates net radiation as a function of latitude, time of year, time of day, air and surface } \\
\text { temperature, atmospheric vapor density, albedo, cloud cover, surface and air emissivities, and } \\
\text { extraterrestrial solar flux }\end{array}$ \\
\hline path.f & $\begin{array}{l}\text { Calculates the air-water capillary head, the amount of entrapped air, and the water saturation using } \\
\text { the input suction heads of water and air }\end{array}$ \\
\hline petpart.f & Partitions PET into potential transpiration and evaporation \\
\hline polykh.f. & Calculates the conductivity of each node as a function of the suction head value \\
\hline precipbc.f & Reads in precipitation data and write meteorological and precipitation data to binary input file \\
\hline relhum.f & Calculates the relative humidity using suction head and temperature \\
\hline reset.f & $\begin{array}{l}\text { Copies } R \text { values into } A \text { to a) initialize parameters at start of iteration loop, and } b \text { ) reset parameters } \\
\text { after a time step reduction }\end{array}$ \\
\hline retent.f & $\begin{array}{l}\text { Calculates the water content and moisture capacity of each node as a function of the suction head } \\
\text { value }\end{array}$ \\
\hline rld.f & Calculates root density as a function of depth \\
\hline roots.f & Calculates maximum rooting depth and the root-density function \\
\hline therme.f & Calculates enhancement factor for soil vapor flow caused by thermal gradients \\
\hline thermk.f & Calculates soil thermal conductivity and vol. heat capacity \\
\hline timex.f & Queries the operating system and returns the time and date \\
\hline tridag. $f$ & Solves the tridiagonal solution matrix \\
\hline $\operatorname{trsink} f$ & Calculates the sink term at each node, and sums the sink terms to get transpiration \\
\hline unsath.f & Serves as the main program of UNSATH \\
\hline update.f & $\begin{array}{l}\text { Resets global variables after successful solution, and checks the index variables and sets them to } \\
\text { the proper saturation path }\end{array}$ \\
\hline volvap.f & Calculates volumetric vapor content \\
\hline
\end{tabular}


Table 6.4. (contd)

\begin{tabular}{||l|l|}
\hline \multicolumn{1}{|c|}{ Name } & \multicolumn{1}{|c|}{ Purpose } \\
\hline welcome.f & Writes program header with version number and contact person \\
\hline wet $2 p . f$ & Calculates water and entrapped air saturations, relative permeability, and capacity for wetting paths \\
\hline zeroa.f & Sets ARRAY variables to zero \\
\hline zeroi.f & Sets INTEGER variables to zero \\
\hline zeror. $f$ & Sets REAL variables to zero \\
\hline
\end{tabular}

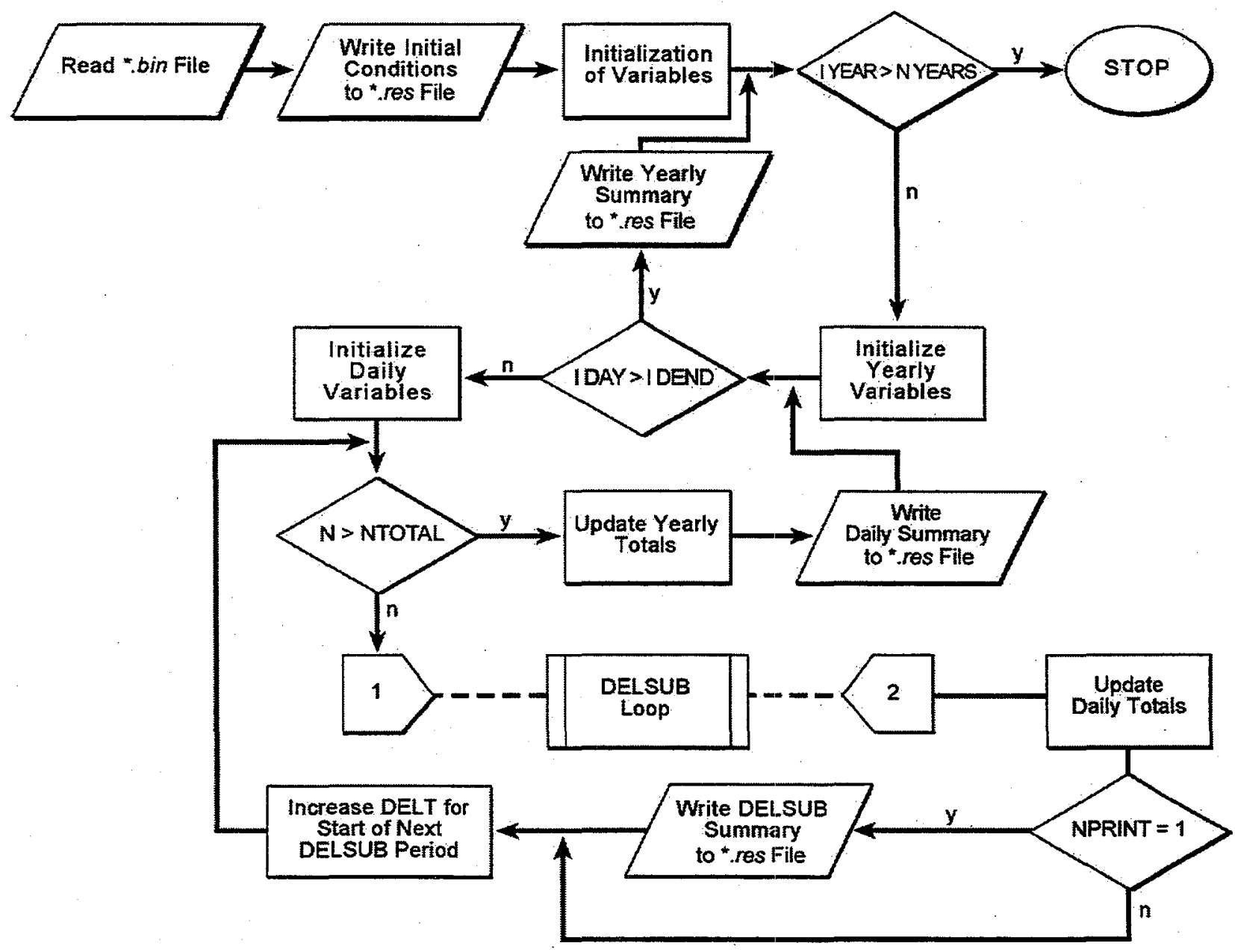

Figure 6.2. Operations Flow of UNSATH 


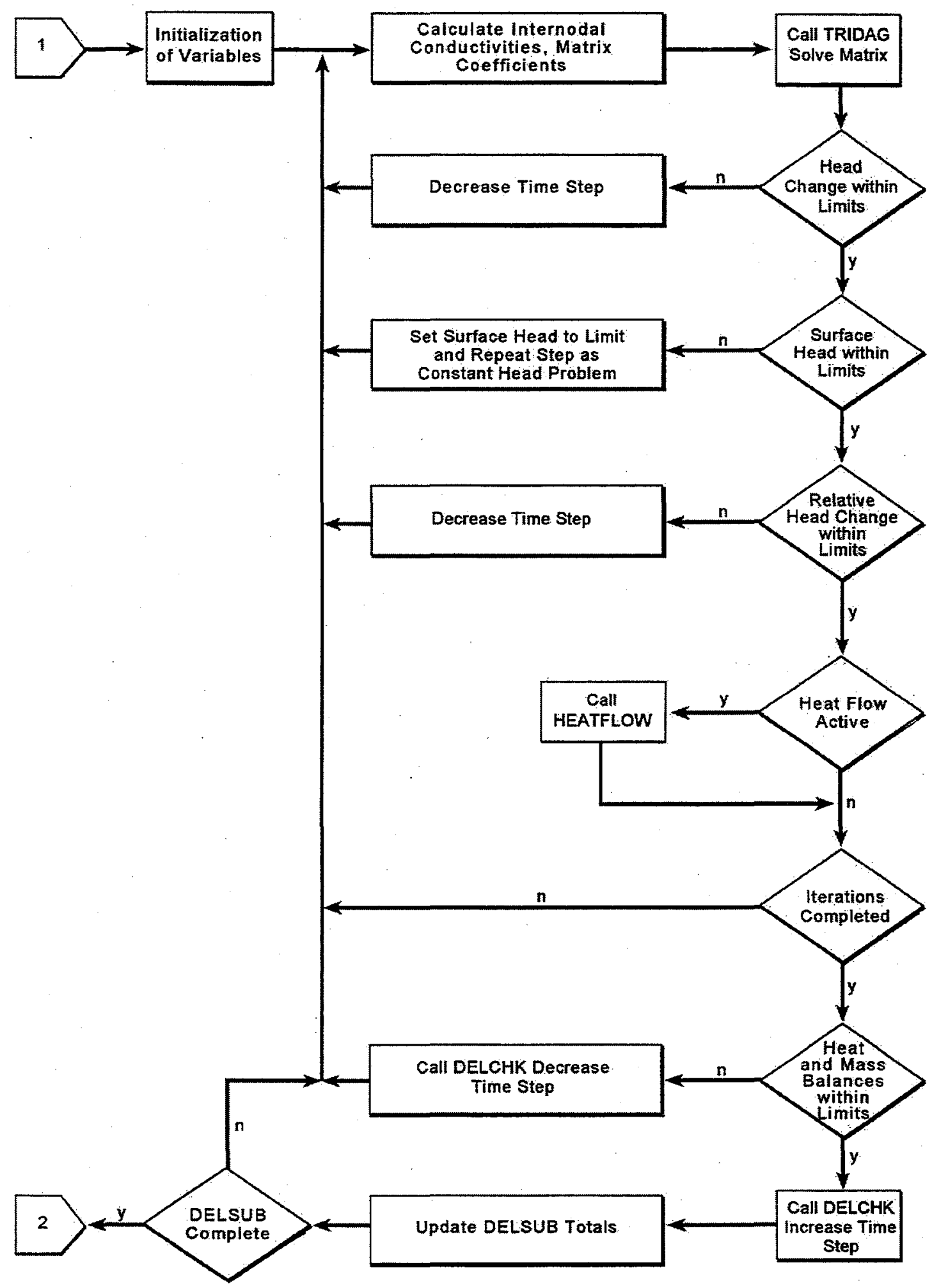

Figure 6.3. Operations Flow of DELSUB Loop in UNSATH 


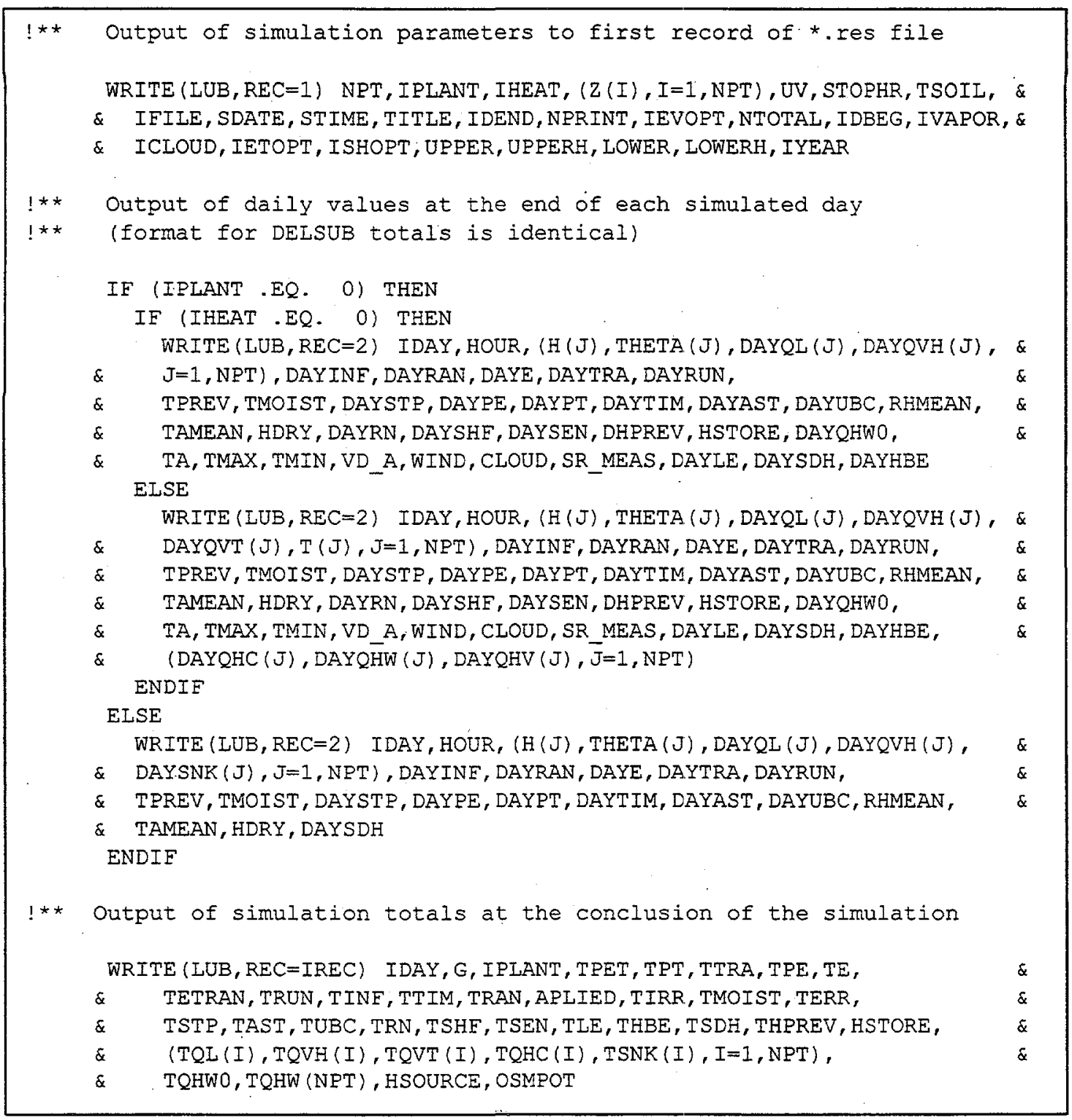

Figure 6.4. Format of the *.res Output File Created by UNSATH: LUB is a logical name for the binary output file.

Two conventions govern output from DATAOUT. First, state variables (e.g., suction head, water content, storage, temperature) are output at the end of the period under review. Thus, for a daily summary, the values of the state variables are the values at the end of the day. The second convention is that all flux variables are integrated for the period under review. Thus, for a DELSUB period, the reported flux is actually the cumulative amount for that period. Dividing this cumulative amount by the DELSUB period yields the average flux for that period. 
Table 6.5. Subroutines in DATAOUT

\begin{tabular}{|l|l|}
\hline \multicolumn{1}{|c|}{ Name } & \multicolumn{1}{c|}{ Purpose } \\
\hline dataout.f & Serves as the main program of DATAOUT \\
\hline ddsum.f & Outputs end-of-DELSUB and end-of-day summaries for any day of a simulation \\
\hline hardcopy.f & Creates a hard copy of the results of an UNSAT-H simulation using a pre-defined format \\
\hline initsum.f & Outputs the initial conditions \\
\hline listdata.f & $\begin{array}{l}\text { Outputs data lists, such as head values at the end of each day, for review on the screen or for } \\
\text { output to a separate file to be used for plotting purposes }\end{array}$ \\
\hline nodez.f & Allows user to enter node numbers for desired output \\
\hline profiler.f & $\begin{array}{l}\text { Creates lists of data (e.g., water content, head) versus depth that can be output to a screen or a } \\
\text { separate file to be used for plotting purposes }\end{array}$ \\
\hline readrec.f $f$ & Reads the *.res file (from UNSATH), either DELSUB or daily summary records \\
\hline reinit.f & Outputs a file (toss.out) with the suction head values for the end of the chosen time period \\
\hline scan.f & $\begin{array}{l}\text { Displays on the screen the end-of-DELSUB and end-of-day summaries for any day of a } \\
\text { simulation, including the initial conditions and the simulation-end summary }\end{array}$ \\
\hline summary.f & Reads and outputs the year-end summary data found in the last record of an UNSATH *.res file \\
\hline welcome.f & Writes program header with version number and contact person \\
\hline
\end{tabular}

\subsection{Problem Formulation}

Application of the UNSAT-H model to a particular problem requires the problem to be formulated in terms understood by the numerical model. Problem formulation entails specifying program control options, discretizing the spatial and temporal domain of interest, assigning soil and plant properties, and defining the boundary conditions.

The program control variables that can be adjusted include length of time to be simulated, frequency of data output, maximum and minimum time-step size, and the mass-balance and heat-balance error limits. Some of these choices affect the amount of computer time necessary to solve the problem. For instance, reducing the size of the maximum time step or using very small mass-balance error limits increases the computer time. However, such choices may yield a more accurate solution. Because of the tradeoff between benefits and their costs, program control variables should be chosen carefully. Several trial runs may be needed to optimize both solution accuracy and computer time. (See Section 5.3 for a discussion of time steps.)

To make the problem formulation more realistic, assume that the water-balance dynamics of the site illustrated in Figure 6.5a are to be simulated. The problem can be modeled in one dimension in the vertical direction and, therefore, requires discretization (i.e., nodal spacing) as shown in Figure 6.5b. The node spacing should be very small near the surface and become progressively larger downward through the profile. The smaller node spacing near the surface is necessary for a correct solution because very large and rapid changes in suction head are expected as the surface dries and wets in response to evaporation and precipitation. Therefore, nodal spacing of $0.1 \mathrm{~cm}$ near the surface is commonly used. For conditions in which head changes at the surface are less dramatic, such as for constant ponding, the node spacing can be increased. By convention, the first node (node 1) is at the surface and the last node is at the bottom of the soil profile to be simulated. 


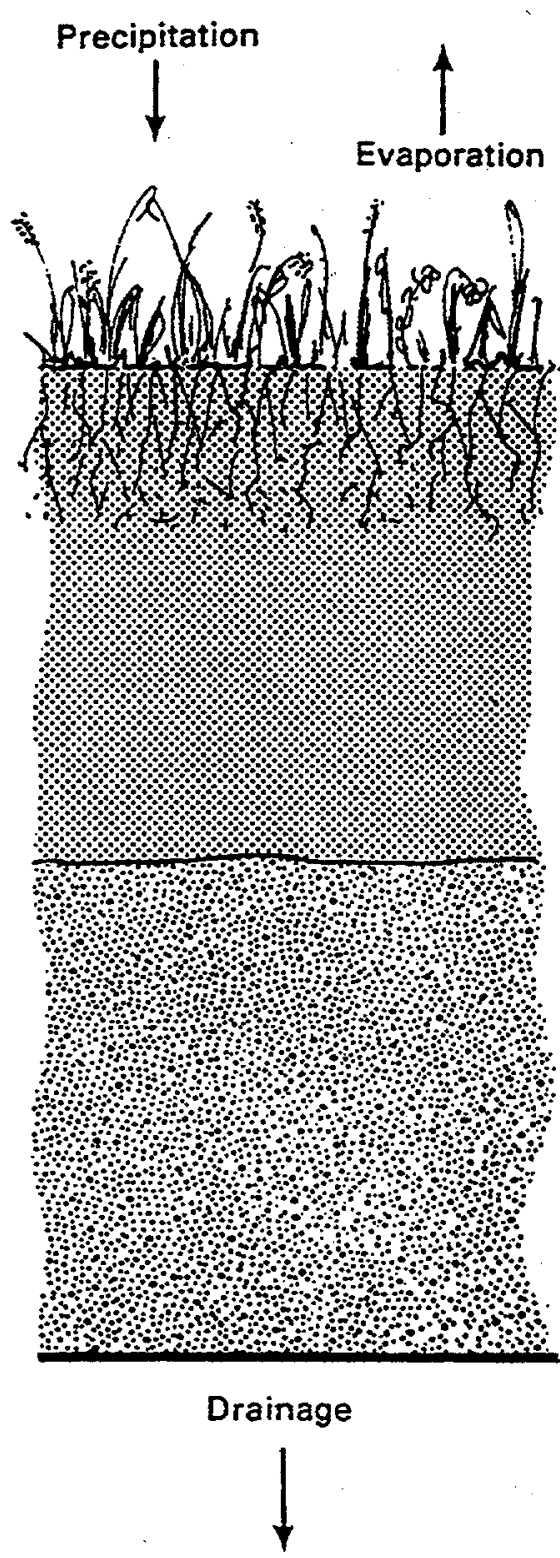

(a)
Hourly Rainfall

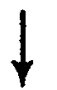<smiles>CC[As](C)(C)C</smiles>
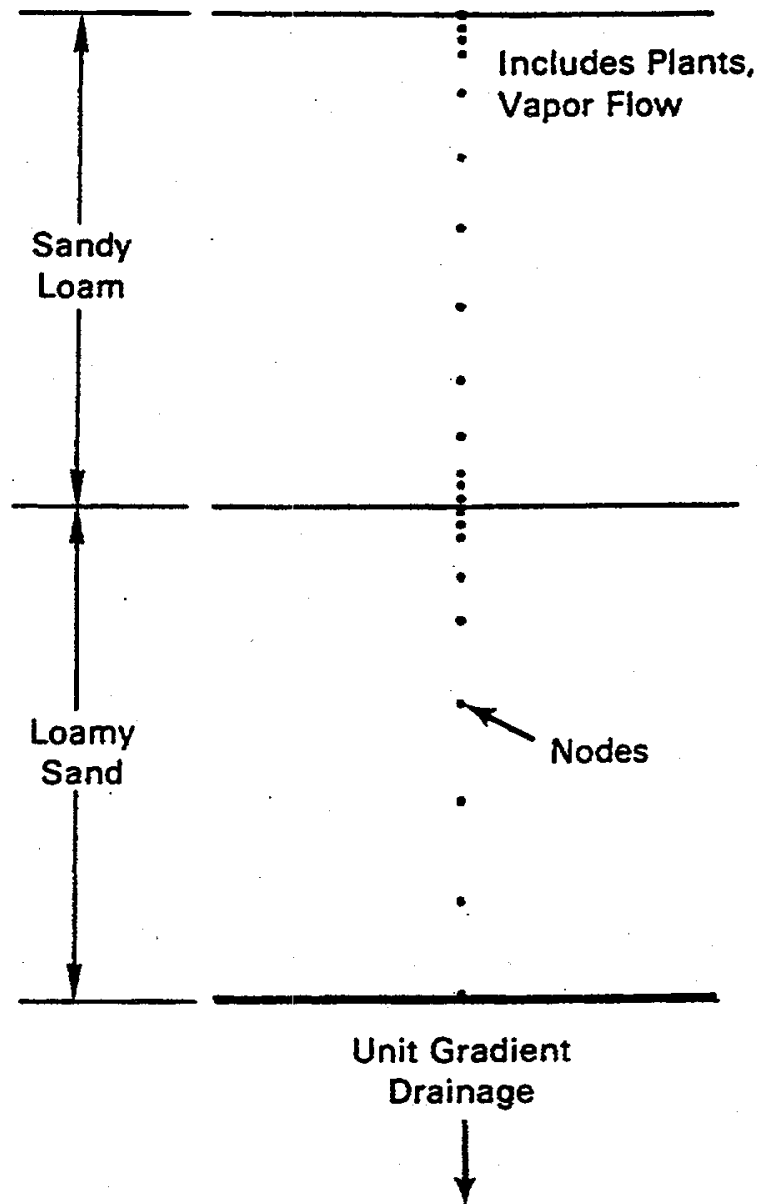

(b)

Figure 6.5. Example Problem Formulation: a) Site Description, b) Model Representation

Other things being equal, a larger number of nodes provides a more accurate solution, but requires more computer time. Uncertainties regarding the sufficiency of the number of nodes for a particular problem may require repetition of the simulation with more nodes to check the prior solution. If the solution remains essentially the same, additional nodes are not necessary. If the solution changes significantly, then the original number of nodes may have been insufficient (i.e., the node spacing was too large). In that case, repetition of the simulation with smaller node spacing is needed until the solution does not change appreciably. 
In the example shown in Figure 6.5a, the soil type changes at the midpoint of the profile. This kind of change may make the solution difficult if the hydraulic properties of the two soils are significantly different. Therefore, the node spacing near the interface of two soils should be decreased (i.e., more nodes in that vicinity), until the solution does not change.

After discretizing the spatial domain, the next step is to assign soil properties. In the example of Figure 6.5a, there are two soil types. Nodes within each soil are assigned the properties of that soil. In other instances, soil layering may be less clearly defined. In those cases, the dominant soil types are identified and soil properties assigned accordingly.

Once soil properties have been assigned, initial conditions must be specified. This step is accomplished for all simulations by specifying the head values at the start of the simulation period. If heat flow is being modeled, the temperature values must also be specified. In most instances, soil characterization data consists of neutron probe measurements of water content at several depths within the profile. Based on these measurements, water contents must be assigned to each node. Unfortunately, the measurement depths are unlikely to coincide with the nodal depths. Therefore, values must be interpolated. The nodal water contents must then be converted to head values (the initial conditions required by UNSAT-H) according to the soil hydraulic properties assigned to the respective node.

The next stage in problem formulation is to describe the plant community, if one is present. Required plant data include fraction of surface covered by plants, dates of germination and death, rooting depths, and responses to moisture-related stress.

The lower and upper boundary conditions must be identified next. In Figure 6.5b, the lower boundary is known to be permeable, but measurements of the drainage rate are not available, and the head at the lowest node is not likely to remain constant for long periods of time. As an approximation, a unit gradient can be assumed to exist at the lower boundary because the boundary is well below the root zone. In the absence of heat flow measurements, a rough estimate of the geothermal gradient can be used.

For the surface boundary, daily weather data must be provided if heat flow and evaporation are being modeled. Daily weather data must also be provided if evaporation is being modeled using the PET concept and the code is to calculate the daily PET. Otherwise, daily PET must be provided. These values are calculated external to the UNSAT-H code using programs such as FAOPET (Doorenbos and Pruitt 1977). Precipitation rates can be entered directly.

When a problem is to be solved using UNSAT-H, the necessary data must be collected into a *.inp file in the format required by the preprocessor program, DATAINH. That format is specified in Appendix A. 


\subsection{Code Operation}

The three programs that constitute UNSAT-H (DATAINH, UNSATH, and DATAOUT) read and create input and output files at several points in their operation. These operations involve particular logical units as specified in unsath.inc. The current assignments are listed in Table 6.6. Before running the model, the user must ensure that these logical units have not been redefined.

Table 6.6. Logical Unit Assignments

\begin{tabular}{||l|c|l||}
\hline $\begin{array}{c}\text { Logical } \\
\text { Unit }\end{array}$ & Variable & \multicolumn{1}{c|}{ Description } \\
\hline 1 & LUI & Binary input file unit (input to UNSATH and DATAOUT) \\
\hline 2 & LUB & Binary output file unit from DATAINH and UNSATH \\
\hline 3 & LUX & Scratch file (for internal code use) \\
\hline 5 & LUR & Read (interactive input) \\
\hline 6 & LUS & Screen (interactive output) \\
\hline 7 & LUW & ASCII output file from all three codes \\
\hline 8 & LUH & ASCII output file from UNSATH; contains hysteresis restart information \\
\hline
\end{tabular}

The first step in running the UNSAT-H code is to create the executable files for DATAINH, UNSATH, and DATAOUT. These files can be created by compiling the main programs and their subroutines (listed in Table 6.1) into object files and then linking the appropriate object files. The result should be three executable files, datainh.exe, unsath.exe, and dataout.exe. When compiling DATAINH and UNSATH, the user must ensure that the files unsath.inc and init.inc are present in the default directory. These two files contain the variable and array declaration statements and are included in the codes automatically via the FORTRAN "INCLUDE" statement. To re-dimension UNSATH, the user must modify the statements in the appropriate file and recompile both programs. Figure 6.6 shows the four array dimensions that users can adjust, if desired, for particular problems. The parameter values shown in Figure 6.6 are sufficient for the vast majority of problems typically encountered, so most users should not need to re-dimension the code.

The second step in running the UNSAT-H code is to process the input data (located in a *.inp file) by typing the command DATAINH (assuming datainh.exe is in the default directory). The user will then be queried for the input file name and the desired level of DATAINH output. Output from DATAINH allows the user to verify that input data were read correctly.

The third step in running the UNSAT-H code is to run the main program by typing the command UNSATH (assuming unsath.exe is in the default directory). Unless instructed otherwise, the system assumes that the input file $\left({ }^{*}\right.$. bin $)$ is located in the default directory; the results file $\left({ }^{*} . r e s\right)$ will be located in the default directory. Output from unsath.exe goes into a ${ }^{*}$.res file. 


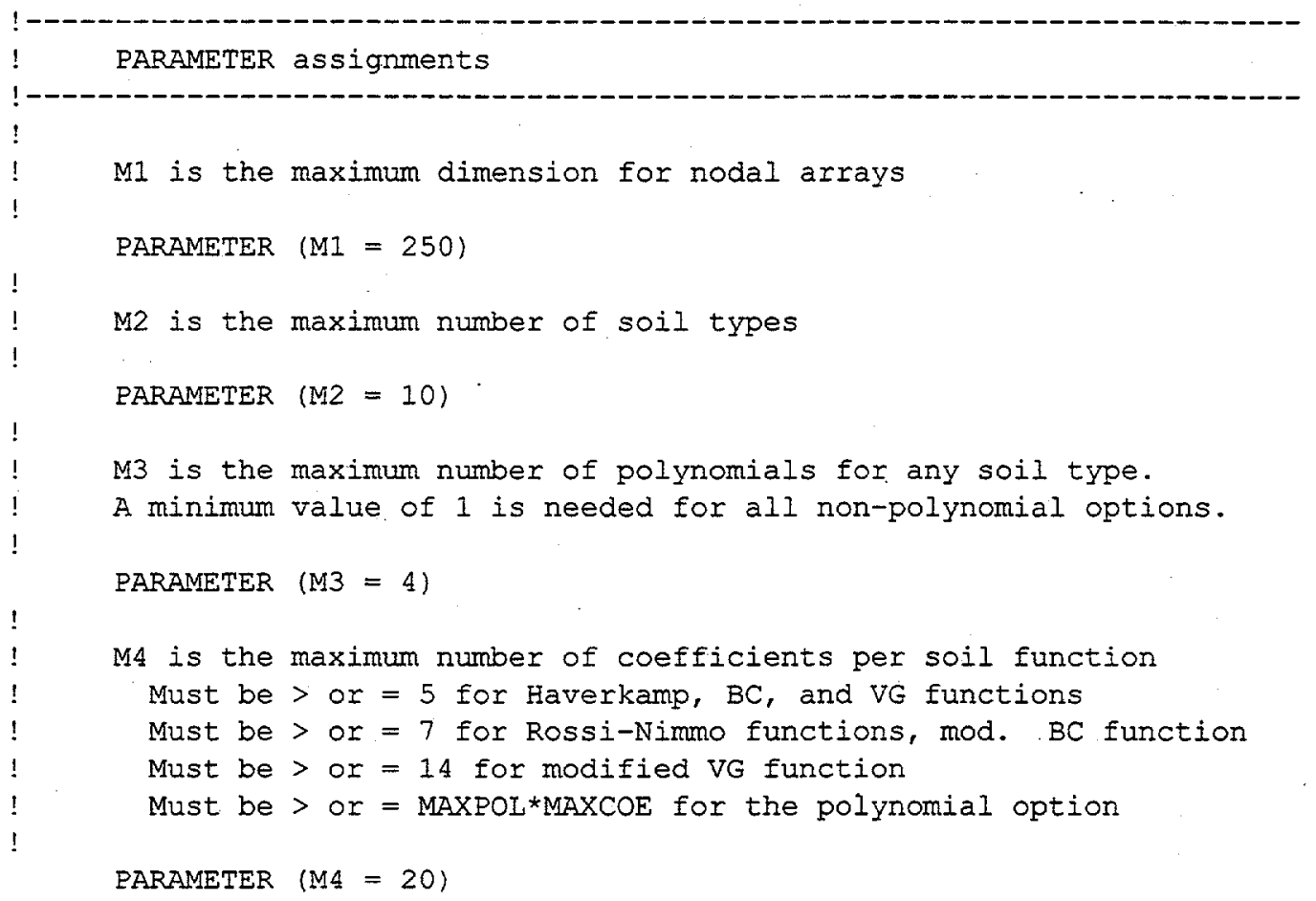

Figure 6.6. Parameter Dimensions Associated with UNSAT-H Version 3.0

The final step in running the UNSAT-H code is to run the post-processor program by typing DATAOUT (assuming dataout.exe is in the default directory). Unless instructed otherwise, the program assumes the *.res file is in the default directory. All output files generated by dataout.exe will go into the default directory unless specified otherwise. 


\subsection{Example Simulations}

Eight examples are provided in this section to illustrate how various UNSAT-H options work. The first four examples are verification tests of infiltration, drainage, heat flow, and hysteresis portions of the UNSAT-H code. The remaining four examples are simulations of water flow in a layered soil system, water and heat flow in a layered system, plant transpiration, and a multiyear simulation. Included in the infiltration verification test is a demonstration of the new solution option (the modified Picard method). Included in the heat flow verification test is a demonstration of the new solution control option involving the heat balance error.

\subsection{Verification of Infiltration}

Haverkamp et al. (1977) performed several infiltration simulations using different models based on the nonlinear flow equation. One of those models, the head-based implicit model (No. 4 in the Haverkamp paper) is the same as that used in UNSAT-H. To simultaneously verify the infiltration component of UNSAT-H and provide an example of how UNSAT-H works, the Haverkamp et al. (1977) infiltration problem was simulated with UNSAT-H. The UNSAT-H results are compared with those of Haverkamp et al. (1977) and with an approximate analytic solution derived by Philip (1969). This verification test was also conducted by Fayer and Jones (1990). Additional simulations were conducted to demonstrate the use of a new solution feature called the modified Picard method.

\subsubsection{Problem Description}

Haverkamp et al. (1977) used two soil types: a clay (Yolo light clay) and a sand. Table 7.1 shows the soil hydraulic property coefficients used. The soil profile depths were 250 and $90 \mathrm{~cm}$ for the clay and

Table 7.1. Parameters Used in the Infiltration Simulations

\begin{tabular}{|l|c|l|}
\hline \multicolumn{1}{|c|}{ Parameter } & Clay & \multicolumn{1}{c|}{ Sand } \\
\hline$\theta_{s}\left(\mathrm{~cm}^{3} \mathrm{~cm}^{-3}\right)$ & 0.495 & 0.287 \\
\hline$\theta_{r}\left(\mathrm{~cm}^{3} \mathrm{~cm}^{-3}\right)$ & 0.124 & 0.075 \\
\hline$\alpha\left(\mathrm{cm}^{-1}\right)$ & 739.0 & $1.611 \times 10^{6}$ \\
\hline$\beta(\mathrm{unitless})$ & 4.0 & 3.96 \\
\hline$h_{e}(\mathrm{~cm})$ & 1.0 & 1.0 \\
\hline$K_{s}\left(\mathrm{~cm} \mathrm{hr}^{-1}\right)$ & $4.428 \times 10^{-2}$ & 34.0 \\
\hline$A\left(\mathrm{~cm}^{-1}\right)$ & 124.6 & $1.175 \times 10^{6}$ \\
\hline$B(\mathrm{unitless})$ & 1.77 & 4.74 \\
\hline$h_{e}(\mathrm{~cm})$, for the conductivity function & 0.0 & 1.0 \\
\hline
\end{tabular}


sand, respectively. Depth increments were $1.0 \mathrm{~cm}$. For the lower boundary, the head at the bottom node was held constant at the initial value of $600 \mathrm{~cm}$ for the clay and $61.4 \mathrm{~cm}$ for the sand. For the upper boundary, the head at the surface node was held constant at $0.0 \mathrm{~cm}$ for the clay and at $20.73 \mathrm{~cm}$ for the sand. The minimum and maximum time steps were 0.0125 and $0.15 \mathrm{hr}$, respectively, for the clay, and $10^{-5}$ and $0.0025 \mathrm{hr}$, respectively, for the sand. Haverkamp et al. (1977) allowed the time step to vary between 40 and $500 \mathrm{~s}(0.0111$ to $0.139 \mathrm{hr})$ for the clay and used a constant time step of $5 \mathrm{~s}\left(1.39 \times 10^{-3} \mathrm{hr}\right)$ for the sand. Figures B.1 (clay) and B.2 (sand) of Appendix B show the input files.

\subsubsection{Results}

Figure 7.1 illustrates the results from Haverkamp et al. (1977, Figure 6), the quasi-analytic series solution (Philip 1969), and UNSAT-H. According to Haverkamp et al. (1977), the series solution is valid (i.e., the solution converges) only for times less than $600 \mathrm{hr}$ for the clay and $0.29 \mathrm{hr}$ for the sand. For both soils, the agreement among the results of Haverkamp et al. (1977), Philip (1969), and UNSAT-H is excellent. This agreement indicates that the infiltration component of UNSAT-H performs satisfactorily for this type of problem. Figures B.3 and B.4 of Appendix B show the clay and sand output files.

The clay and sand tests were repeated using the new modified Picard solution technique (Celia et al. 1990). The test names were clay_st, and sand_st. The maximum number of iterations was increased to five to enable the modified Picard method to function. For comparison purposes, clay and sand were rerun using the same maximum number of iterations. Table 7.2 shows that the new solution technique dramatically lowered the mass balance error.

\subsection{Verification of Drainage}

Kool et al. (1985) used the parameter estimation program ONESTEP to fit drainage data from an outflow experiment. The program estimated values for three parameters of the van Genuchten water retention function. The Kool et al. (1985) experiment was simulated with UNSAT-H, using their fitted parameters, to verify the drainage component of UNSAT-H and the implementation of the van Genuchten water retention and Mualem hydraulic conductivity models. This verification test was also conducted by Fayer and Jones (1990).

\subsubsection{Problem Description}

Kool et al. (1985) sampled an undisturbed core of silty loam soil from a field in Virginia. They equilibrated the core at zero suction head in a Tempe pressure cell with a ceramic plate located at the bottom. The soil core was $3.95 \mathrm{~cm}$ long and $5.4 \mathrm{~cm}$ in diameter. The porous ceramic plate was $0.57 \mathrm{~cm}$

thick. After a complete cycle of drying and wetting, the core was subjected to an air pressure of $1000 \mathrm{~cm}$. The drainage that resulted was monitored until it nearly ceased. 

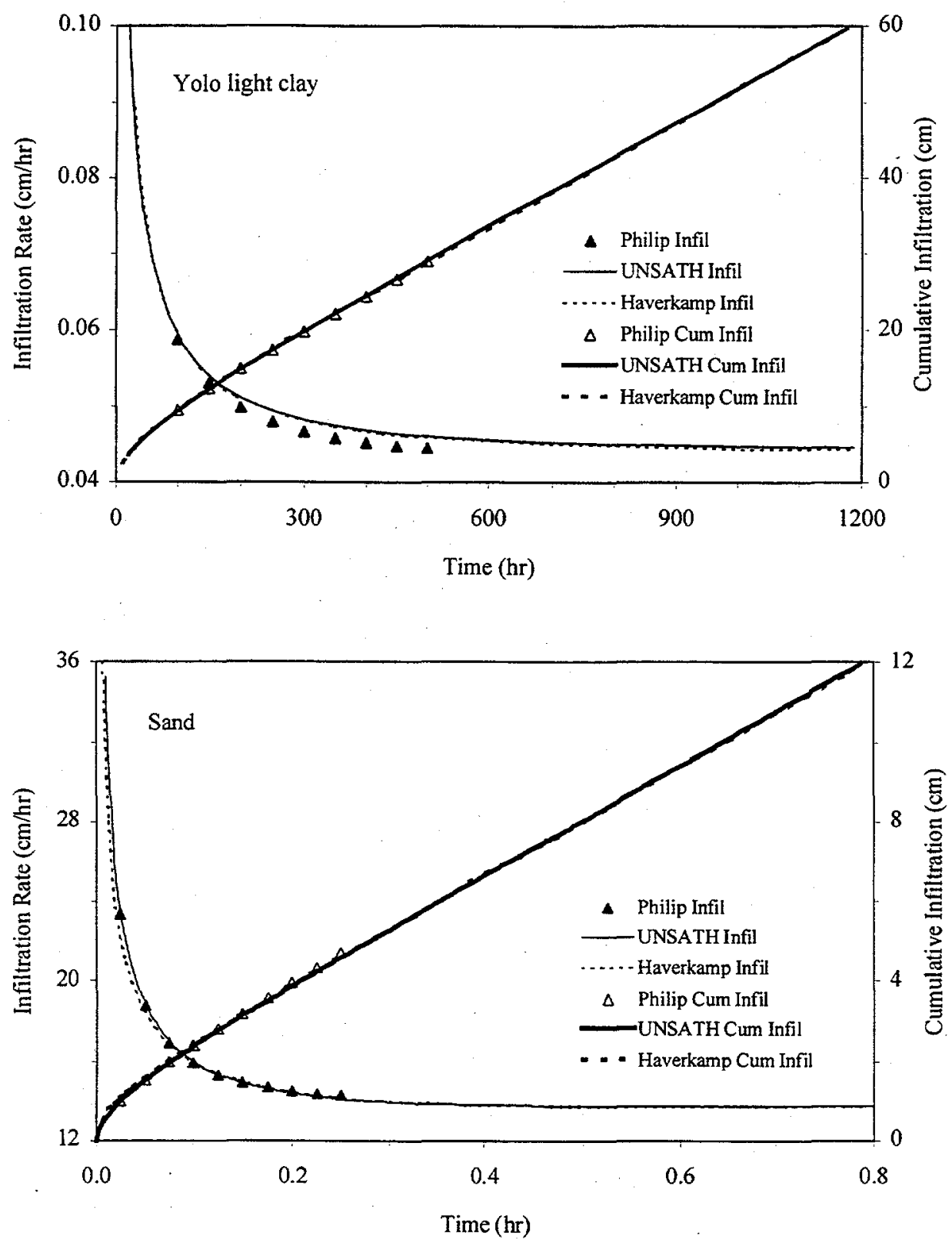

Figure 7.1. Infiltration Rate and Cumulative Infiltration Versus Time as Determined Using the Philip (1969) Solution, the Numerical Code of Haverkamp et al. (1977), and UNSAT-H 
Table 7.2. Impact of Using the Modified Picard Solution Technique (five iterations per time step)

\begin{tabular}{|l|l|l|l|l|}
\hline \multirow{2}{*}{\multicolumn{1}{|c|}{ Variable }} & \multicolumn{4}{c|}{ Test } \\
\cline { 2 - 5 } & clay & \multicolumn{1}{c|}{ clay_st } & sand & sand_st \\
\hline Infiltration $(\mathrm{cm})$ & 60.666 & 60.663 & 12.134 & 12.134 \\
\hline Evaporation $(\mathrm{cm})$ & na & na & na & na \\
\hline Drainage $(\mathrm{cm})$ & 0.4474 & 0.4475 & 0.10642 & 0.10642 \\
\hline Final storage $(\mathrm{cm})$ & 119.38 & 119.38 & 20.928 & 20.927 \\
\hline Mass balance error $(\mathrm{cm})$ & $3.5 \mathrm{E}-3$ & $-3.4 \mathrm{E}-7$ & $-1.2 \mathrm{E}-3$ & $-3.1 \mathrm{E}-8$ \\
\hline
\end{tabular}

Kool et al. (1985) measured the parameters $\theta_{s}$ and $K_{s}$ in the laboratory. Three parameters $(\alpha, n$, and $\theta_{r}$ ) were adjusted to optimize the fit to the laboratory drainage data. Kool et al. (1985) simulated the ceramic plate using a constant $K_{s}$ and a specific capacity of zero. For the UNSAT-H simulation, all materials must be described using the same hydraulic property model. Therefore, a set of van Genuchten parameters were derived that would allow the simulated plate to remain nearly saturated at suction heads up to $1000 \mathrm{~cm}$. The parameters for both materials are summarized in Table 7.3. At the start of the simulation, the matric suction at the base of the ceramic plate was increased to $1000 \mathrm{~cm}$.

To obtain frequent simulation output during the first $16 \mathrm{hr}$ and less frequent output during the remainder of the simulation, three separate simulations were conducted. The first simulation, using the input file vgtesta.inp, generated output every $0.002 \mathrm{hr}$ for a $0.5 \mathrm{hr}$ period. The second simulation generated output every $0.1 \mathrm{hr}$ for a $15.5 \mathrm{hr}$ period. The third simulation generated output every $24 \mathrm{hr}$ for a 984-hr period. The drainage results from all three simulations were then combined.

An aspect of the work of Kool et al. (1985) that cannot be duplicated by UNSAT-H is the approximation used for describing flow in portions of the core that remained saturated during the very early times of drainage. This difference between the two models should not significantly affect the comparison of results because saturated conditions in the simulated core disappeared after less than 0.01 hr. Figure B.5 of Appendix B shows the input file.

Table 7.3. Hydraulic Property Parameters for Silt Loam Soil and Ceramic Plate

\begin{tabular}{|l|l|l|}
\hline \multicolumn{1}{|c|}{ Parameter } & Silt Loam & Ceramic Plate \\
\hline$\theta_{s}\left(\mathrm{~cm}^{3} \mathrm{~cm}^{-3}\right)$ & 0.388 & 0.388 \\
\hline$\theta_{r}\left(\mathrm{~cm}^{3} \mathrm{~cm}^{-3}\right)$ & 0.17321 & 0.387 \\
\hline$\alpha\left(\mathrm{cm}^{-1}\right)$ & 0.04705 & $4.705 \times 10^{-6}$ \\
\hline$n$ & 1.46097 & 3.0 \\
\hline$K_{s}\left(\mathrm{~cm} \mathrm{hr}^{-1}\right)$ & 5.4 & 0.003 \\
\hline
\end{tabular}




\subsubsection{Results}

Figure 7.2 shows the cumulative drainage results from the UNSAT-H simulations, along with the simulation results and laboratory measurements from Kool et al. (1985). The close agreement among the two code solutions and the measurements indicates that UNSAT-H simulates drainage correctly. The agreement also indicates that the van Genuchten retention function and the Mualem conductivity model have been implemented correctly in UNSAT-H. Figure B.6 of Appendix B shows the output file.

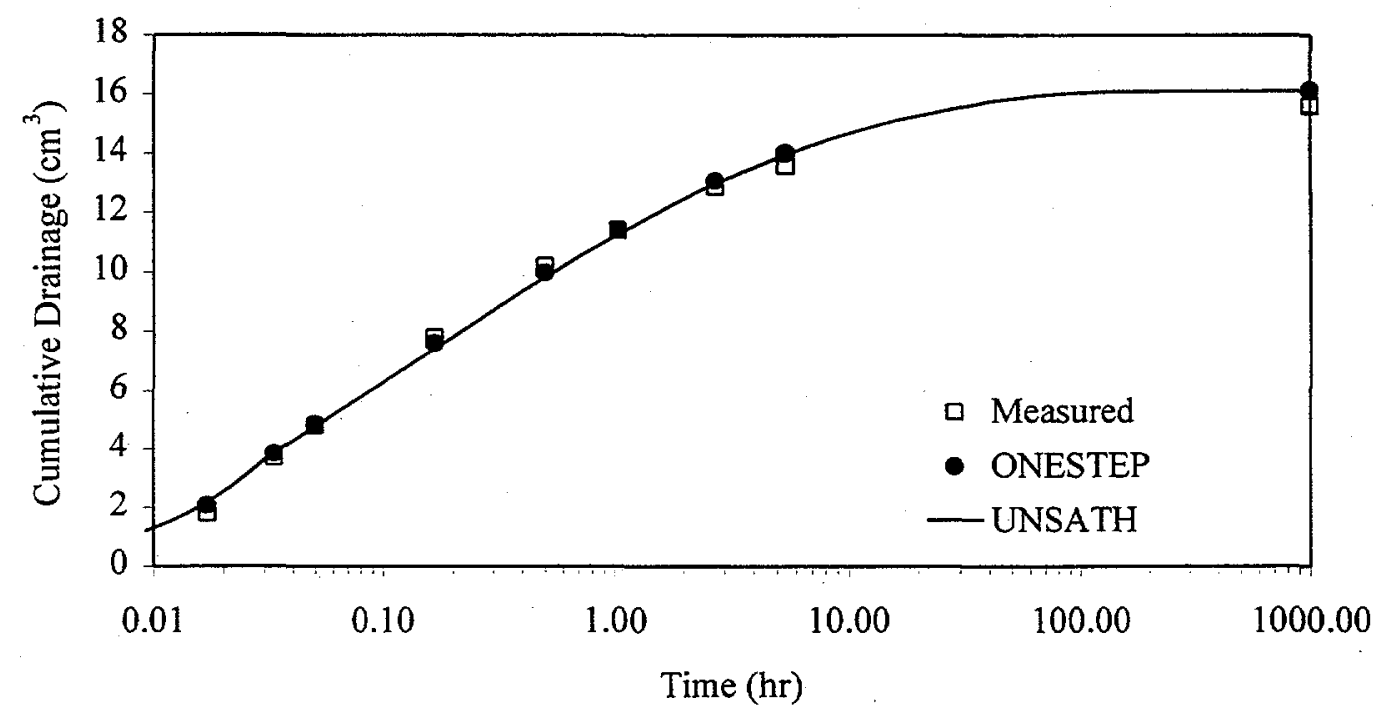

Figure 7.2. Cumulative Drainage Versus Time as Determined by Kool et al. (1985) and UNSAT-H

\subsection{Verification of Heat Flow}

In this test, the UNSAT-H model is used to simulate the diurnal variation in soil temperatures caused by an imposed cyclic variation in soil surface temperature. This verification test was also conducted by Fayer and Jones (1990).

Campbell (1977) reported an analytic solution to a heat conduction problem in which the temperature $(T)$ at the soil surface varies by

$$
T(0, t)=\bar{T}+A(0) \sin (\omega t)
$$

where $\quad \bar{T}=$ mean soil surface temperature, $\mathrm{K}$

$A(0)=$ amplitude of soil surface temperature, $\mathrm{K}$

$\omega=$ angular frequency of the soil surface temperature oscillation, $\mathrm{hr}^{-1}$

$t=$ time, hr. 
Assuming the soil is uniform and infinitely deep, the solution for a temperature wave is (Campbell 1977):

$$
T(z, t)=\bar{T}+A(0) e^{-z / z_{d}} \sin \left[\omega(t-6)-z / z_{d}\right]
$$

where

$$
\omega=2 \pi / 24
$$

and

$$
z_{d}=\sqrt{\frac{2 k_{h}}{\omega C_{h}}}
$$

where $z_{d}$ is the damping depth, which is the depth at which the temperature fluctuation has been reduced to $37 \%$ (i.e., 1/e) of its surface value. For this case, the angular frequency yields a complete surface temperature cycle in $24 \mathrm{hr}$. To specify that the peak temperature occurs at noon, as is done for this example, the $t$ value in Equation (7.2) is modified by subtracting $6 \mathrm{hr}$.

\subsubsection{Problem Description}

A $1-\mathrm{m}$-deep soil profile is subjected to a temperature variation of $10 \mathrm{~K}$ from a mean surface temperature of $288 \mathrm{~K}$ occurring at noon. A total of 101 nodes, evenly spaced $1 \mathrm{~cm}$ apart, are used to discretize the soil profile. The soil type is a loamy sand known as lysimeter sand or L-soil (Rockhold et al. 1988). The hydraulic properties are described using the Brooks-Corey functions, with $\theta_{s}=0.4326, \theta_{r}=0.0381$, $h_{e}=9.4 \mathrm{~cm}, b=1.2846$, and $K_{s}=35.3 \mathrm{~cm} / \mathrm{hr}$. The thermal properties are taken from Cass et al. (1981) for lysimeter sand at $22.5^{\circ} \mathrm{C}$. The initial temperature at all nodes is $288 \mathrm{~K}$; the initial suction at all nodes is $100 \mathrm{~cm}\left(\theta_{i}=0.1007\right)$.

A horizontal profile is simulated to minimize water movement. Vapor flow is not included so that water contents and thermal conductivities remain constant during the simulation. Figure B.7 of Appendix B shows the input file. For the analytic solution, $k_{h}=27.448 \mathrm{~J} \mathrm{~cm}^{-1} \mathrm{~mole}^{-1} \mathrm{~K}^{-1}$, $C_{h}=1.1927 \mathrm{~J} \mathrm{~cm}^{-3} \mathrm{~K}^{-1}$, and $z_{d}=13.26 \mathrm{~cm}$.

\subsubsection{Results}

Figure 7.3 shows the soil temperature results for the analytic solution and UNSAT-H. The closeness of the match between the analytic solution and the simulated temperatures at all depths and times indicates that UNSAT-H correctly solves the heat conduction equation. Figure B.8 of Appendix B shows the output file. 

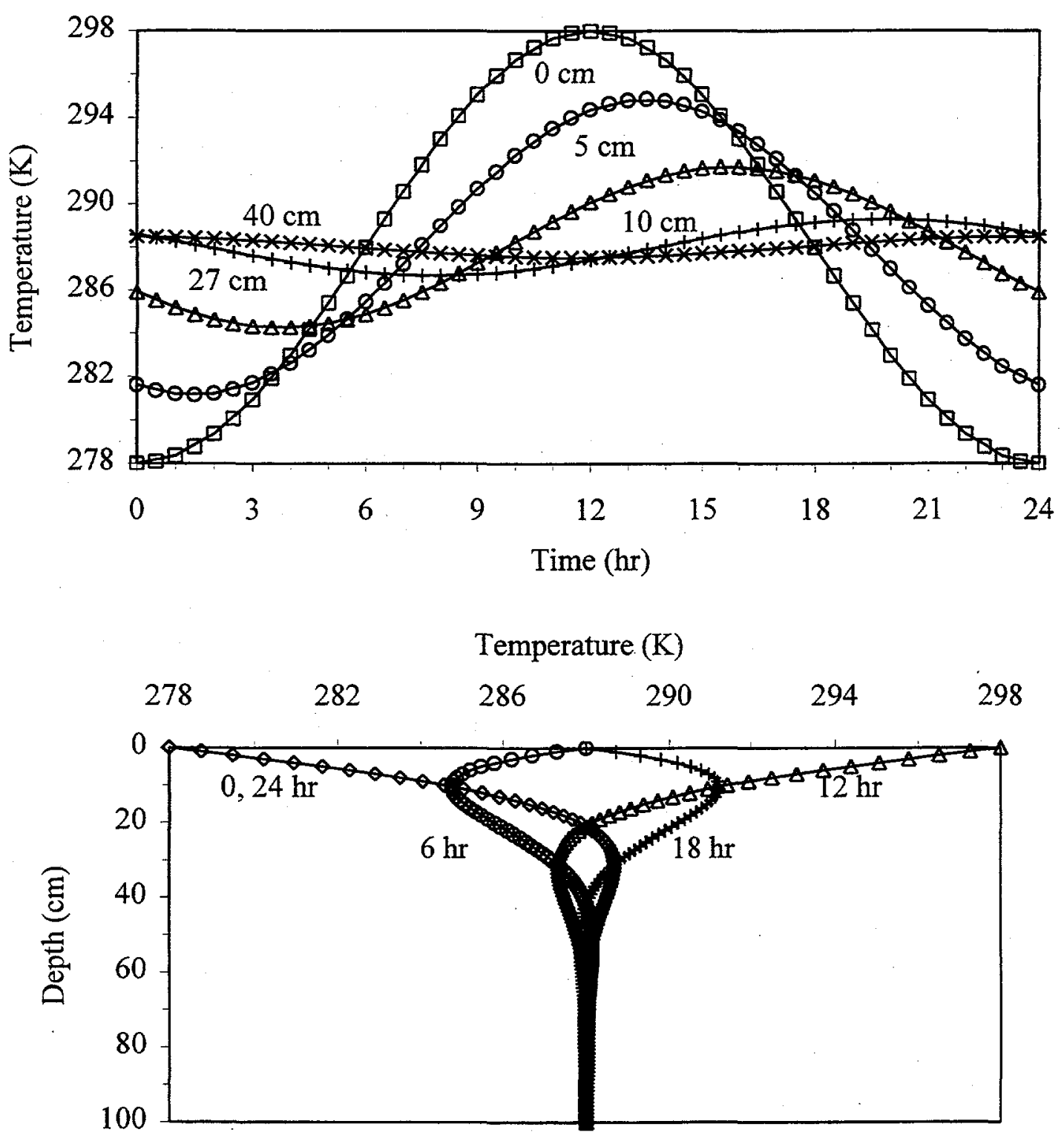

Figure 7.3. Soil Temperature as a Function of Time (a) and Depth (b) as Determined Using an Analytic Solution (symbols) and UNSAT-H (lines)

\subsection{Hysteresis}

A new feature of UNSAT-H is the ability to consider hysteresis in the water retention function. Fayer et al. (1992) observed that hysteresis was an important phenomenon in the movement of water within lysimeter D9 at the Field Lysimeter Test Facility. Therefore, the hysteresis model described by Lenhard et al. (1991) was added to the UNSAT-H model. A set of simulations was conducted to verify that the hysteresis capability in UNSAT-H is operational. 


\subsubsection{Problem Description}

Lenhard et al. (1991) conducted an experiment in which a sand-filled column was subjected to a fluctuating water table while water contents and matric potentials were monitored throughout the column. The water table position was changed four times: lowered, then raised, then lowered, then raised back to the original elevation. A single-beam gamma system was used to measure water saturation at multiple levels within the column during these changes. The values at the $70-\mathrm{cm}$ elevation above the base of the column were used for the UNSAT-H verification test. Lenhard et al. (1991) also simulated the experiment with a computer code that incorporated their hysteresis model. Their measured and simulated values of water saturation are reported in Fayer (1993).

The hydraulic properties are described using the van Genuchten water retention function, with $\theta_{s}=0.355, \theta_{r}=0.06035, \alpha=0.042 \mathrm{~cm}^{-1}, n=5.25$, and $K_{s}=119 \mathrm{~cm} / \mathrm{hr}$. The Mualem conductivity model was used with a pore interaction exponent value of 0.5 . Only two additional parameters were needed: the maximum amount of entrapped air $\left({ }^{i} S_{n r}\right)$ and the imbibition $\alpha_{i}$ parameter for the van Genuchten retention function. As done by Lenhard et al. (1991), the parameter ${ }^{i} S_{n r}$ was set to 0.25 and the parameter $\alpha_{i}$ was set equal to $2 \alpha_{d}$, the comparable parameter for drainage. The final specification was that up to seven hysteretic paths could be used by the hysteresis model. Figure B.9 of Appendix B shows a portion of the input file used for this simulation.

Three separate simulations were conducted: 1) no hysteresis or air entrapment, 2) no hysteresis but air entrapment, and 3) hysteresis and air entrapment.

\subsubsection{Results}

Figure 7.4 shows that the UNSAT-H results are nearly identical to the Lenhard simulation results for all three cases. Figure 7.4 also shows that the best match to the measured saturation values was achieved using the full model of hysteresis with air entrapment. The hysteresis option was judged to be operational. Figure B.10 of Appendix B shows the output file.

\subsection{Layered Soil Simulation}

The UNSAT-H model is used to simulate the water balance of various protective barrier designs. In this example, the functioning of a specific barrier design was simulated for weather conditions in 1962. This verification test was also conducted by Fayer and Jones (1990).

\subsubsection{Problem Description}

The protective barrier concept limits deep percolation by relying on the capillary break created when fine-textured soils are placed over coarse-textured soils. In one of the barrier designs, the top $30 \mathrm{~cm}$ of material is composed of the Composite soil described by Fayer et al. (1985) and gravel 0.5 to $1.0 \mathrm{~cm}$ in diameter ( $15 \%$ by weight). The material between the $30-$ and $150-\mathrm{cm}$ depths is Composite soil. Gravel 


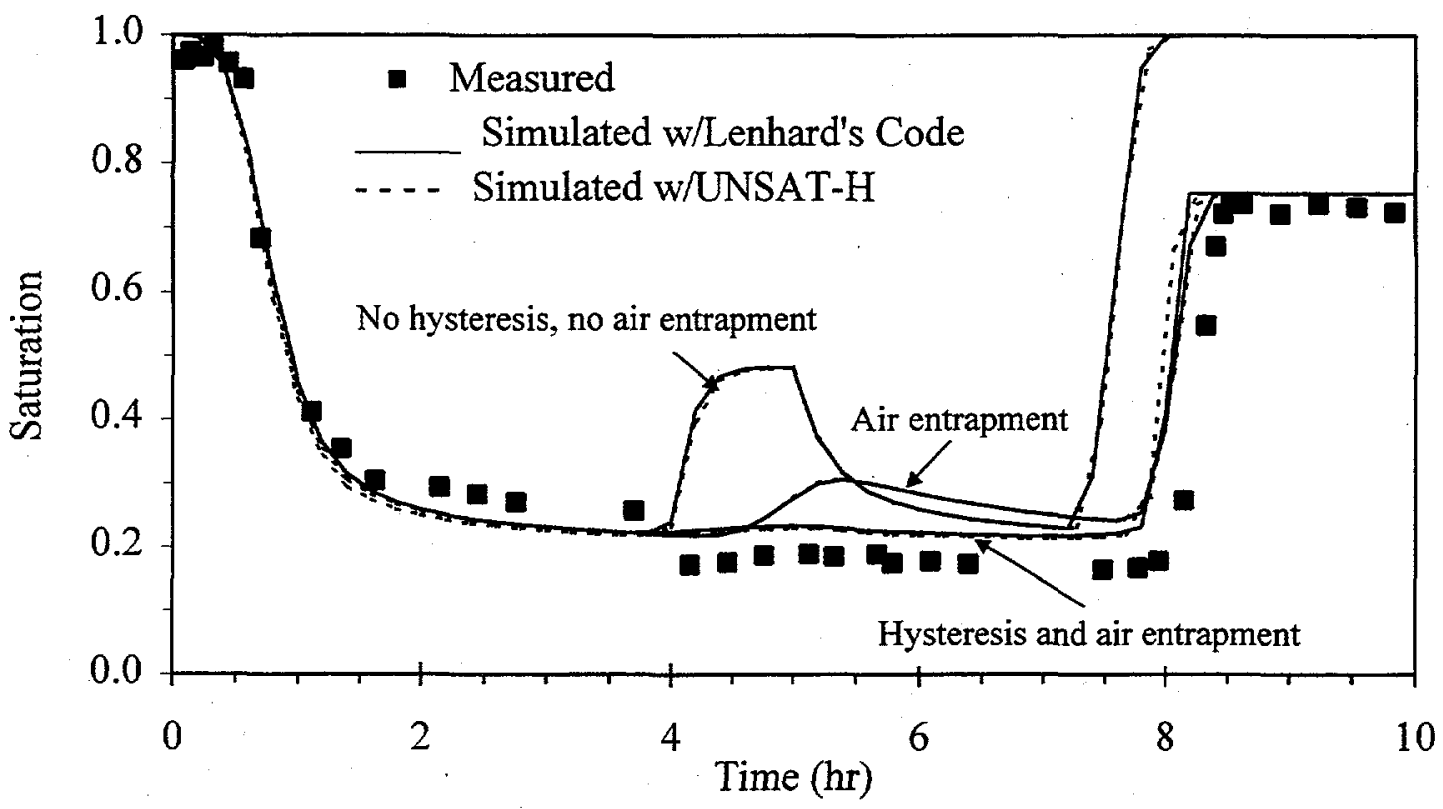

Figure 7.4. Degree of Saturation Measured, Predicted by Lenhard et al. (1991), and Predicted by UNSAT-H

0.6 to $1.3 \mathrm{~cm}$ in diameter is below the $150-\mathrm{cm}$ depth. The hydraulic properties of all three materials were represented with polynomials given in Fayer et al. (1985). Vapor flow was also included. Initial head values for each node were obtained from the output of a previous simulation for the year 1961 .

A unit hydraulic gradient was chosen as the lower boundary condition. This choice was reasonable because the lower boundary was located more than $5 \mathrm{~m}$ from the surface and well below the zone of possible upward water movement. For the upper boundary condition, hourly values of precipitation and daily values of PET were used. The precipitation data were obtained from the Hanford Meteorological Station (HMS). The PET values were calculated using the Penman equation given by Doorenbos and Pruitt (1977) and meteorological data from the HMS. The upper and lower head limits for the surface boundary node were 100,000 and $1 \mathrm{~cm}$, respectively. Figure B.11 of Appendix B shows the input file for this simulation.

\subsubsection{Results}

Drainage through the barrier amounted to $1.5 \mathrm{~cm}$ for the given barrier design and 1962 weather conditions. Annual evaporation was $12.8 \mathrm{~cm}$, which is only $8 \%$ of the annual potential evaporation of $161.1 \mathrm{~cm}$. Clearly, potential evaporation rates should not be used as indicators of actual evaporation. Figure 7.5 shows that the capillary break causes water to be retained within the fine-textured soil. This impact, whereby water storage is increased, is why capillary breaks are being considered for surface cover designs. Figure B.12 of Appendix B shows the output file for this simulation. 


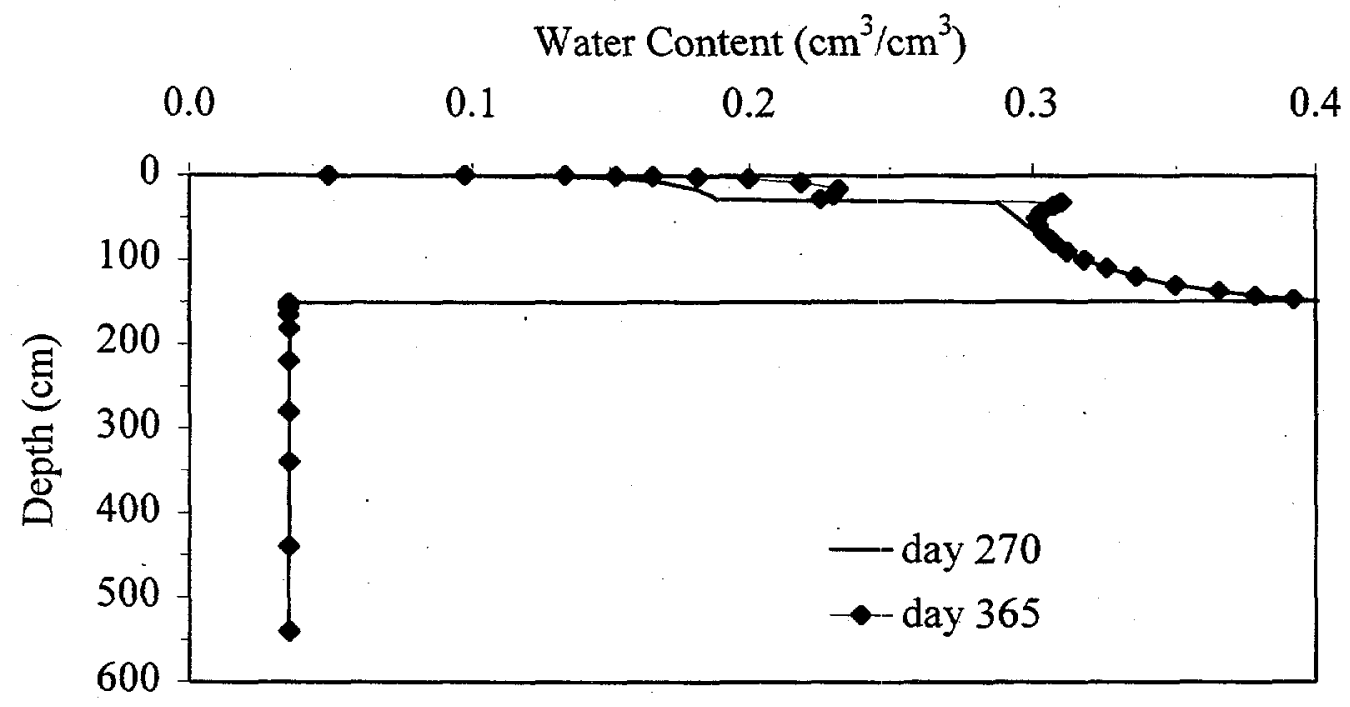

Figure 7.5. Water Content Profiles Within a Layered Soil

\subsection{Layered Soil Simulation with Heat Flow}

The layered soil simulation in Section 7.5 was repeated with the heat flow option to demonstrate the concurrent flow of water and heat. This verification test was also conducted by Fayer and Jones (1990).

\subsubsection{Problem Description}

The input file used in Section 7.5 was modified for this example to include the addition of soil thermal properties, aerodynamic coefficients, time-stepping controls, initial suction heads and temperatures for the end of day 143, and weather data.

Because hourly output was desired, the simulation was conducted for only three days: 144,145 , and 146. Precipitation on day 144 amounted to $1.30 \mathrm{~cm}$; no precipitation occurred on days 145 and 146 .

Thermal conductivity parameters for the barrier materials were taken from Cass et al. (1984). For the Composite soil and the Composite-gravel mix, the parameters for the Portneuf silt loam at $32.5^{\circ} \mathrm{C}$ were used. For the gravel layer, the parameters for the Lysimeter sand at $22.5^{\circ} \mathrm{C}$ were used. Although provided by Cass et al. (1984), parameters for the enhancement factor $(\eta)$ were chosen to provide $\eta$ values of 1 (i.e., no enhancement).

The measurement heights for temperature and wind speed were 0.914 and $15.24 \mathrm{~m}$, respectively. Data from Ligotke (1988) indicate a roughness length for momentum of $4.9 \times 10^{-4} \mathrm{~m}$ for a soil mix containing $70 \%$ silt loam and $30 \% 0.7-\mathrm{cm}$-diameter gravel. The roughness length for heat was assumed to equal that for momentum. 
The minimum and maximum time-step sizes were reduced from $10^{-7}$ and 1.0 to $10^{-8}$ and $0.025 \mathrm{hr}$, respectively. The mass balance criterion was decreased from $10^{-4}$ to $10^{-5} \mathrm{~cm}$. In addition, changes in head per time step were limited to $2 \times 10^{4} \mathrm{~cm}$; otherwise, the time-step size was reduced by half. The iteration number for water flow was increased from 2 to 3 . The iteration number for heat flow was 2 . Hourly rather than daily output was specified.

Initial suction head values for the end of day 143 were obtained from the results of the simulation in Section 7.4. The lower suction head limit for the surface boundary node was $1 \mathrm{~cm}$; no upper limit was specified. Initial soil temperature values for the end of day 143 were specified using the historical average for May for the $91.4-\mathrm{cm}$ depth (Hoitink et al. 1999). That average, $15.9^{\circ} \mathrm{C}$, was applied to all nodes. Figure B.13 of Appendix B shows the input file for this simulation.

\subsubsection{Results}

Figure 7.6 shows the surface energy fluxes, suction heads of the top two nodes, air and surface temperatures, and precipitation for the 3-day period. In Figure 7.6a, the latent heat flux is small on day 144 because of the precipitation. The abrupt changes in soil heat flux on this day are caused by the intermittent nature of the precipitation (see Figure 7.6d). On day 145, the latent heat flux rises steadily during the day until $1400 \mathrm{hr}$. By that time, the surface node has dried to a suction head of $6.2 \times 10^{5} \mathrm{~cm}$ (Figure 7.6b). This surface dryness reduces the latent heat flux (i.e., the evaporation rate). On day 146, the surface node again dries to a high suction head $\left(1.2 \times 10^{6}\right)$ by midday. As on day 145 , the dryness of the surface limits the latent heat flux during midday.

The results in Figure 7.6c show that the surface temperature remains higher than air temperature throughout the 3-day period. For the rainy day 144 and the nighttime of days 145 and 146, the surface temperature is within $5 \mathrm{~K}$ of air temperature. During the daytime of days 145 and 146, however, the surface temperature exceeds the air temperature by as much as $18 \mathrm{~K}$. Peak surface temperature occurs between the noon peak of net radiation and the $1500 \mathrm{hr}$ peak of air temperature.

Total evaporation for this 3-day period was $0.557 \mathrm{~cm}$, compared to $0.386 \mathrm{~cm}$ for the same period for the simulation in Section 7.5. Because of the time-step differences between the two simulations, the isothermal problem in Section 7.5 was repeated with time-step information identical to the problem described in this section. The results from this third simulation show total evaporation to be $0.375 \mathrm{~cm}$.

This simulation of a layered soil with concurrent water and heat flow was repeated using the option of controlling the time step according to the heat balance error. The control was $0.001 \mathrm{~J} / \mathrm{m}^{2}$. Using the energy balance control of the time step caused a doubling of the number of time steps (to 4838 ). The impact from using this criterion was very minor for the water balance variables. Both evaporation and drainage changed by less than $0.01 \%$. The impact was a bit more substantial for the mass balance error, which dropped 10 -fold to $-2 \times 10^{-5} \mathrm{~cm}$. As expected, the impact on the heat balance error was substantial. The heat balance error dropped 4-fold to $0.4 \mathrm{~J} / \mathrm{m}^{2}$, allowing the energy balance check to be judged operational. Figure B.14 of Appendix B shows the output file for this simulation. 

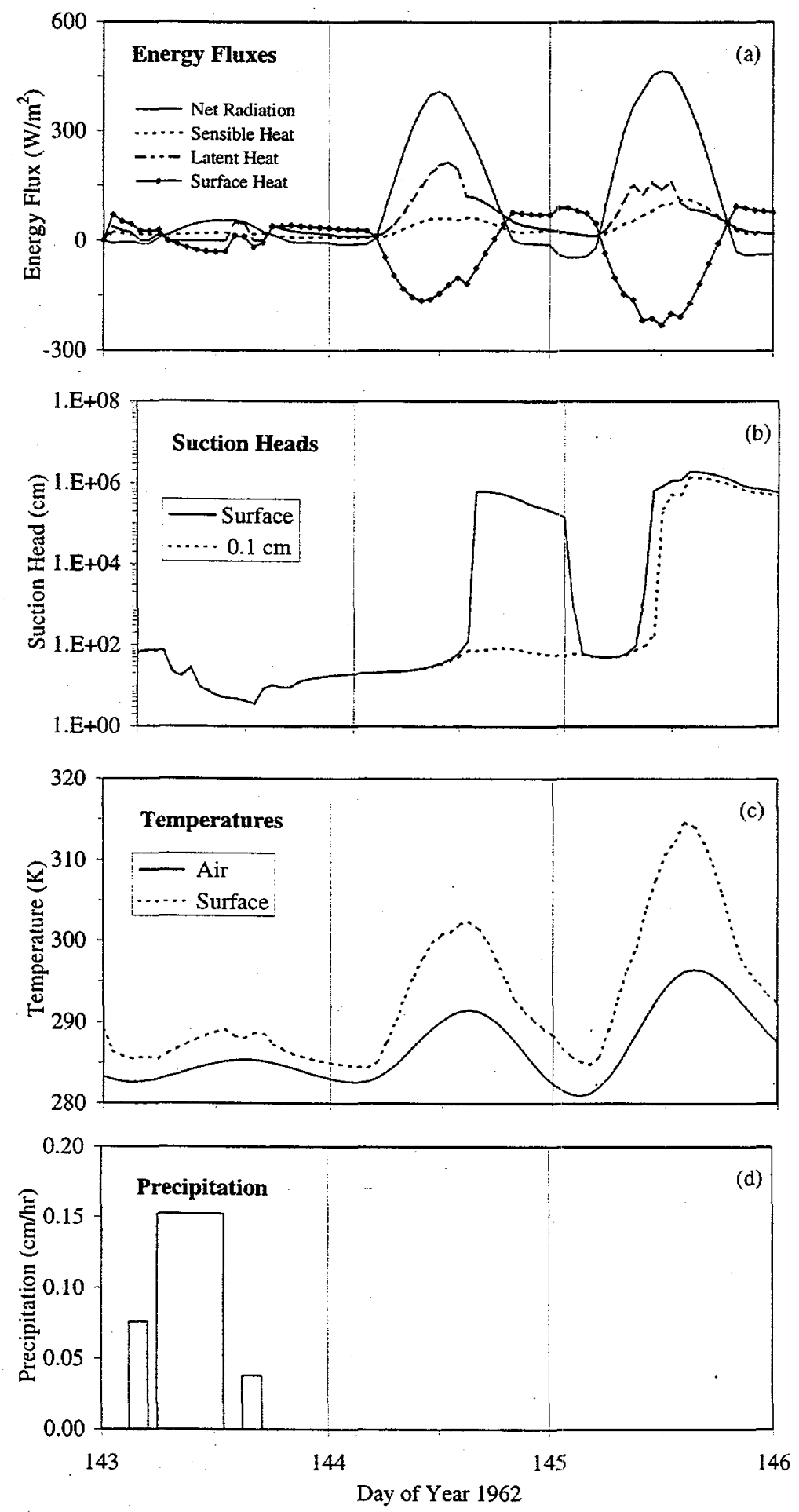

Figure 7.6. Simulation Results for Water and Heat Flow in a Layered Soil: a) energy fluxes at the soil surface, b) suction heads at and $0.1 \mathrm{~cm}$ below the soil surface, c) air and soil surface temperature, and d) precipitation 


\subsection{Transpiration Simulation}

This simulation was conducted to demonstrate how UNSAT-H might be used to model transpiration. This simulation was also conducted by Fayer and Jones (1990).

\subsubsection{Problem Description}

Two 15.2-m-deep lysimeters were constructed in the 200 Area at the Hanford Site to study downward water movement (Hsieh et al. 1973; Brownell et al. 1975). One of the two lysimeters had a closed bottom. Year after year, soil water contents measured in the closed-bottom lysimeter appeared to indicate no downward water movement (e.g., Jones 1978). This observation was always attributed to evaporation; the plant component was always neglected. Through photographs, Gee and Heller (1985) documented that Russian thistle plants were growing on the lysimeter during 1974. Unfortunately, the plant community was never quantitatively characterized. Therefore, a simulation was conducted to predict the water dynamics in the lysimeter in 1974.

The lysimeter, which is $1829 \mathrm{~cm}(60 \mathrm{ft})$ deep, was represented with 43 nodes. Figure 7.7 shows the parameters used for the Brooks-Corey hydraulic functions. These parameters were taken from Fayer and Jones (1990). Initial conditions (i.e., initial head values) were obtained from the *.res file of a simulation for the year 1973 .

The plant data needed for the simulation include the $I_{L A}$, fraction of the soil surface that is bare, rooting density and depth, and plant response to water content (the sink functions). In lieu of site measurements, the plant parameters had to be estimated. The assumed $I_{L A}$ and maximum rooting depth are shown in Figure 7.8. Note that growth started on day 121 and stopped on day 274 of the simulation. In addition, roots were allowed to penetrate to the 3-m depth by day 244 . The bare fraction of soil surface was 0.94. Rooting density was calculated using Equation (4.49) such that $a=4.0, b=0.034$, and $c=1.0$. Finally, the sink function (Figure 4.5) was approximated with $\theta_{w}=0.031, \theta_{d}=0.0374$, and $\theta_{n}=0.4125$. Figure B.15 of Appendix B shows the input file for this simulation.

\subsubsection{Results}

Although they covered only $6 \%$ of the lysimeter surface, the simulated plants were able to remove $2.4 \mathrm{~cm}$ of water from the lysimeter. This transpired water represents $18 \%$ of the $13.5 \mathrm{~cm}$ of precipitation. Evaporation removed an additional $16 \mathrm{~cm}$ of water, resulting in a combined evapotranspiration loss of $18.4 \mathrm{~cm}$ (versus $16.9 \mathrm{~cm}$ when plants are not present). Storage in the lysimeter decreased by $5.0 \mathrm{~cm}$ during the year, a condition that is not conducive to long-term deep drainage or recharge. Figure B.16 of Appendix B shows the output file for this simulation. 

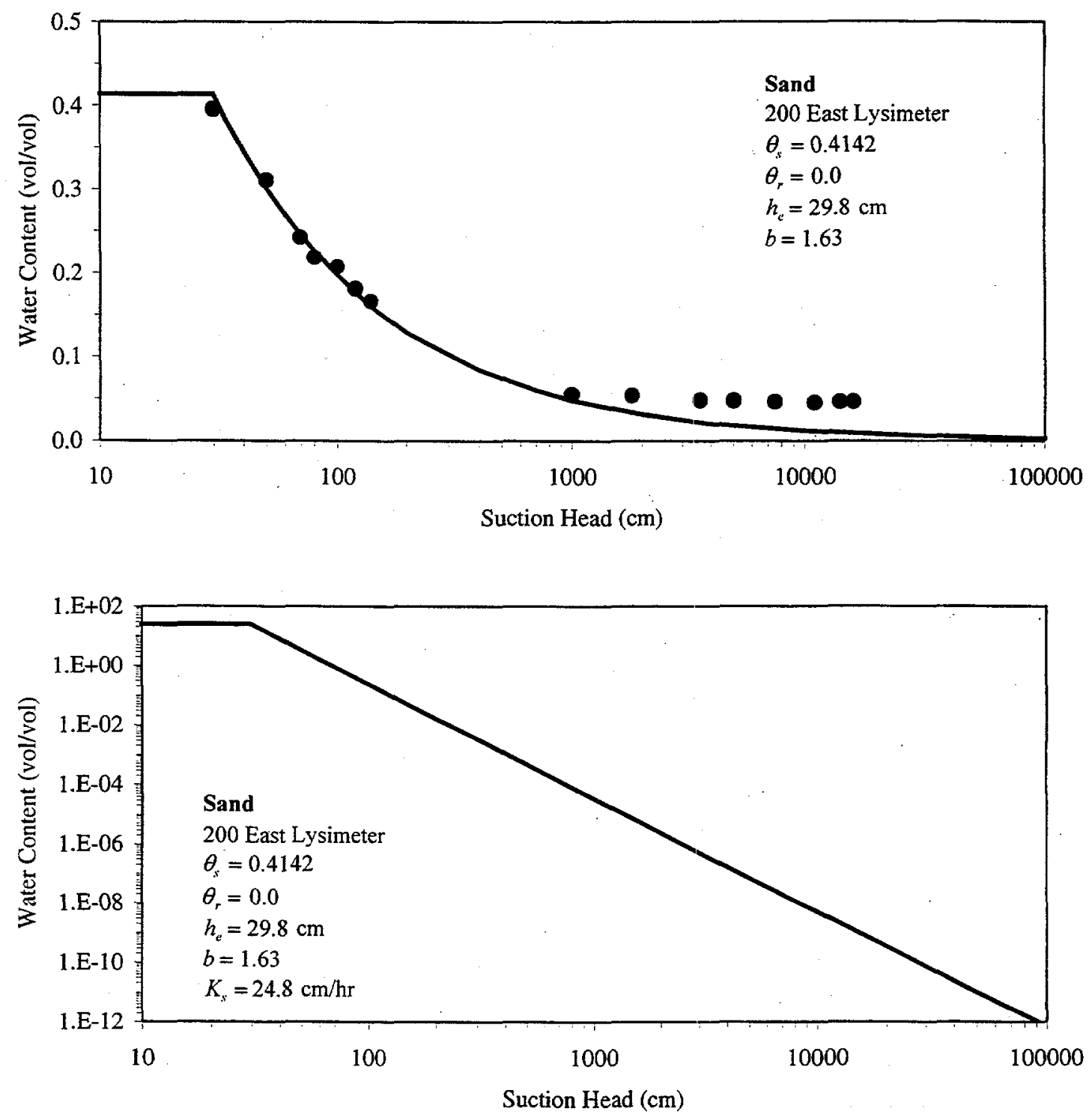

Figure 7.7. Soil Hydraulic Properties for the 200 Area Lysimeter

\subsection{Multiyear Simulation}

A new feature of UNSAT-H is the ability to conduct multiyear simulations. Fayer and Walters (1995) simulated 35 years of recharge in the soil type known locally as Ephrata sandy loam using an external batch program. This simulation was conducted without plants to understand possible recharge rates if this soil type was disturbed. To demonstrate the multiyear simulation capability, the Fayer and Walters (1995) simulation was repeated. 

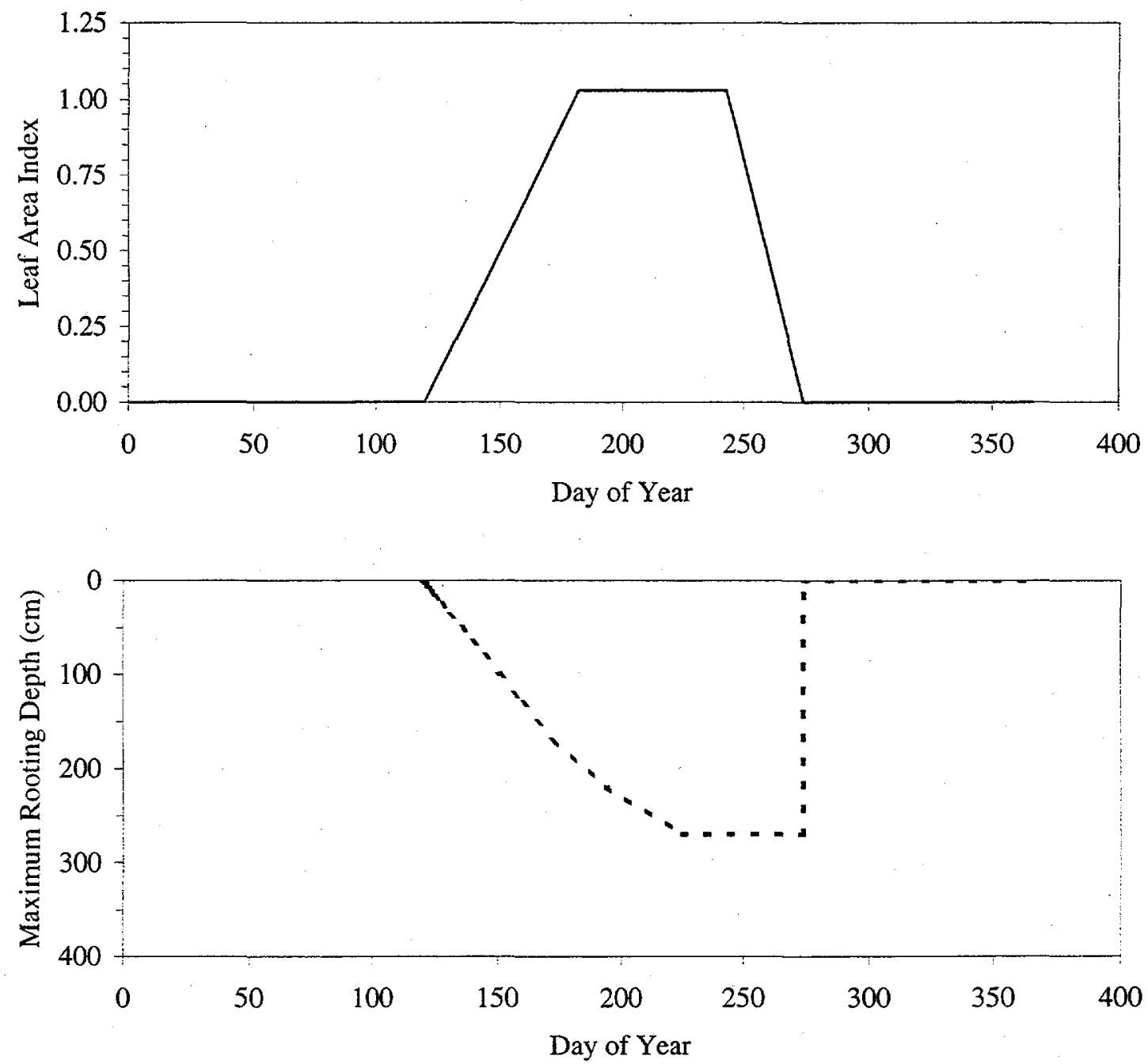

Figure 7.8. Plant Parameters: a) assumed leaf area index, b) assumed maximum rooting depth

\subsubsection{Problem Description}

The model domain was $400 \mathrm{~cm}$ deep. Node spacing ranged from $0.2 \mathrm{~cm}$ at the soil surface, to $2.0 \mathrm{~cm}$ at the interface of different sediments, to $70 \mathrm{~cm}$ at the bottom of the profile. Table 7.4 shows the soil hydraulic parameters that were obtained from Fayer and Walters (1995). The soil matric suction of all nodes was initialized at $1000 \mathrm{~cm}$.

The surface boundary condition was controlled using weather data from the years 1957 to 1992 from the HMS (Hoitink et al. 1999). The data included hourly precipitation and daily values of maximum and minimum air temperature, total solar radiation, and average daily wind speed, dew point temperature, and cloud cover. The daily data were used to calculate the daily PET rate using the Penman equation. The 
Table 7.4. Parameters Used in the Multiyear Simulation

\begin{tabular}{|l|c|c|c|}
\hline \multicolumn{1}{|c|}{ Parameter } & $\begin{array}{c}\text { Layer 1 } \\
\text { Sandy Loam } \\
\mathbf{0} \text { to } 33 \mathbf{~ c m}\end{array}$ & $\begin{array}{c}\text { Layer 2 } \\
\text { Sandy Gravel } \\
\mathbf{3 3} \text { to } \mathbf{7 1} \mathbf{~ c m}\end{array}$ & $\begin{array}{c}\text { Layer 3 } \\
\text { Sandy Gravel } \\
\mathbf{7 1} \text { to } \mathbf{4 0 0} \mathbf{~ c m}\end{array}$ \\
\hline$\theta_{s}\left(\mathrm{~cm}^{3} \mathrm{~cm}^{-3}\right)$ & 0.47 & 0.141 & 0.0833 \\
\hline$\theta_{r}\left(\mathrm{~cm}^{3} \mathrm{~cm}^{-3}\right)$ & 0.0426 & 0.0128 & 0.0084 \\
\hline$\alpha\left(\mathrm{cm}^{-1}\right)$ & 0.117 & 0.117 & 0.0061 \\
\hline$\left.n(\mathrm{unitless})^{-1}\right)$ & 1.48 & 1.48 & 1.52 \\
\hline$K_{s}(\mathrm{~cm} \mathrm{hr})$ & 3.2 & 0.592 & 0.572 \\
\hline
\end{tabular}

bottom boundary was considered deep enough to be unaffected by surface evaporation. Therefore, a unit gradient condition was specified for this boundary. Figure B.17 of Appendix B shows the input file for this simulation.

\subsubsection{Results}

Figure 7.9 shows the predicted annual recharge rates from Fayer and Walters (1995) using the external batch program and the results of UNSAT-H Version 3.0 using the internal multiyear capability. There is no discernible difference between the two solutions, thus showing that the internal multiyear capability is operational. The average drainage rate for the 35 -year simulation was $17.3 \mathrm{~mm}$, which is much higher than the $2.6 \mathrm{~mm} / \mathrm{yr}$ reported by Fayer and Walters (1995) for this soil type with shrub-steppe vegetation. This simulation shows that recharge rates can be high if the site is disturbed by vegetation removal or suppression. Figure B.18 of Appendix B shows the output file for this simulation.

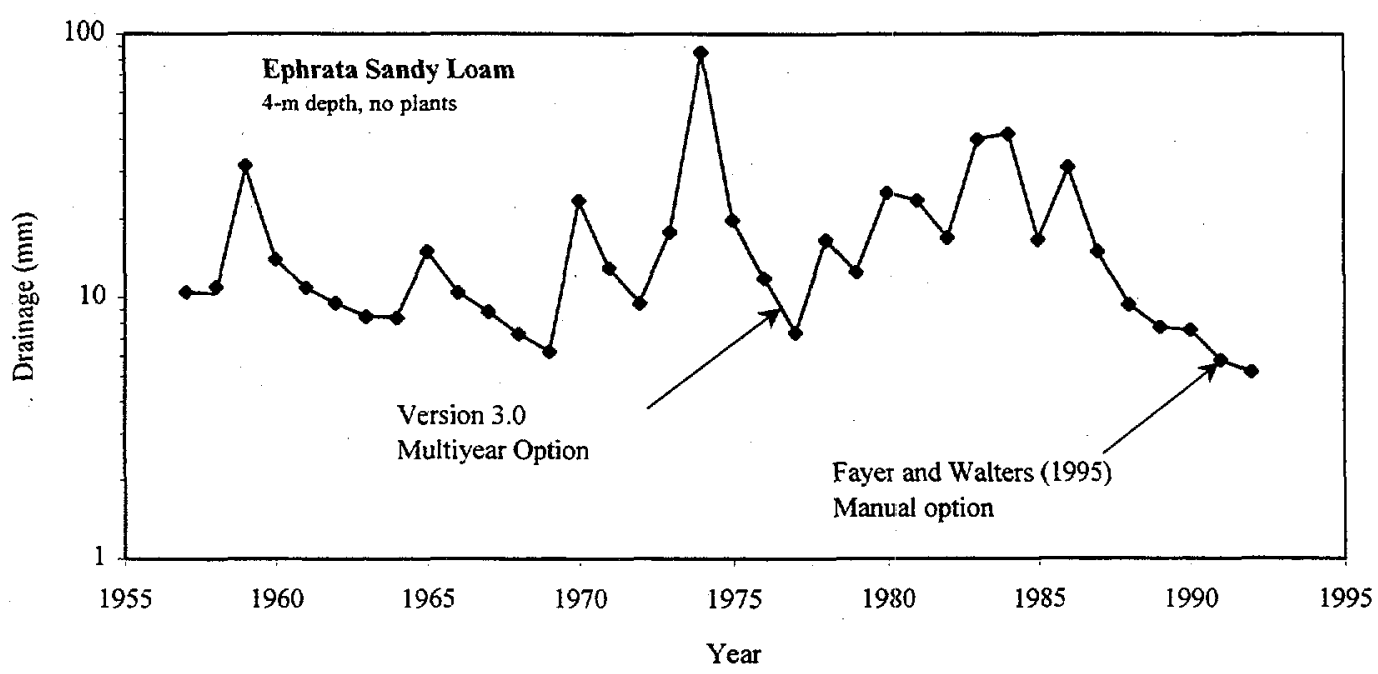

Figure 7.9. Variation in Annual Deep Drainage for the Multiyear Simulation Example 


\subsection{References}

Baca RG and SO Magnuson, 1990. Independent verification and benchmark testing of the UNSAT-H computer code, Version 2.0, EGG-BEG-8811, EG\&G Idaho, Idaho Falls, Idaho.

Bond FW, CR Cole, and PJ Gutknecht. 1984. Unsaturated groundwater flow model (UNSAT1D) computer code manual. CS-2434-CCM, Electric Power Research Institute, Palo Alto, California.

Brownell LE, JG Backer, RE Isaacson, and DJ Brown. 1975. Soil moisture transport in arid site vadoze zone. ARH-ST-123, Atlantic Richfield Hanford Company, Richland, Washington.

Brutsaert W. 1975. "On a derivable formula for long-wave radiation from clear skies." Water Resour. Res. 11:742-744.

Burdine NT. 1953. "Relative permeability calculation from size distribution data." Petr. Trans., Am. Inst. Mining Metall. Eng. 198:71-77.

Bussinger JA. 1975. "Aerodynamics of vegetated surfaces." In Heat and Mass Transfer in the Biosphere, eds. DA de Vries and NH Afgan, pp. 11. Wiley and Sons, New York.

Campbell GS. 1985. Soil physics with BASIC. Elsevier, New York.

Campbell GS. 1977. An introduction to environmental biophysics. Springer-Verlag, New York.

Campbell GS and S Shiozawa. 1992. "Prediction of hydraulic properties of soils using particle-size distribution and bulk density data." In International Workshop on Indirect Methods for Estimating the Hydraulic Properties of Unsaturated Soil, eds. MTh van Genuchten, RJ Leif, and LH Lund. University of California, Riverside.

Cass A, GS Campbell, and TL Jones. 1981. Hydraulic and thermal properties of soil samples from the Buried Waste Test Facility. PNL-4015, Pacific Northwest Laboratory, Richland, Washington.

Cassel DK, DR Nielsen, and JW Biggar. 1969. "Soil-water movement in response to improved temperature gradients." Soil Sci. Soc. Am. Proc. 33:493-500.

Celia MA, ET Bouloutas, and RL Zarba. 1990. "A general mass-conservative numerical solution for the unsaturated flow equation." Water Resour. Res. 26:1483-1496.

Cline JF, DW Uresk, and WH Rickard. 1977. "Comparison of soil water used by a sagebrushbunchgrass and a cheatgrass community." J. Range Manage. 30:199-201.

Corey AT. 1977. Mechanics of heterogeneous fluids in porous media. Water Resources Publications, Fort Collins, Colorado. 
Currie JA. 1965. "Diffusion within soil microstructure: A structural parameter for soil." J. Soil Sci. $16: 279-289$.

DOE. 1987. Final environmental impact statement: Disposal of Hanford defense high-level transuranic and tank wastes. DOE/EIS-0113, U.S. Department of Energy, Washington, D.C.

Doorenbos J and WO Pruitt. 1977. "Guidelines for predicting crop water requirements." FAO Irrigation Paper No. 24, 2nd ed., Food and Agriculture Organization of the United Nations, Rome, Italy, pp. 1-107.

Fayer MJ, EM Murphy, JL Downs, FO Khan, CW Lindenmeier, and BN Bjornstad. 1999. Recharge data package for the immobilized low-activity waste 2001 performance assessment. PNNL-13033, Pacific Northwest National Laboratory, Richland, Washington.

Fayer MJ and GW Gee. 1997. "Hydrologic model tests for landfill covers using field data." In Landfill capping in the semi-arid west: problems, perspectives, and solutions," TD Reynolds and RC Morris, May 21-22, 1997, Jackson, Wyoming, ESRF-019, Env. Sci. Res. Foundation, Idaho Falls, Idaho.

Fayer MJ and CS Simmons. 1995. "Modified soil water retention functions for all matric suctions." Water Resour. Res. 31:1233-1238.

Fayer MJ and TB Walters. 1995. Estimated recharge rates at the Hanford Site. PNL-10285, Pacific Northwest Laboratory, Richland, Washington.

Fayer MJ. 1993. Model assessment of protective barrier designs: Part IV, status of FY 1992 work. PNL-8498, Pacific Northwest Laboratory, Richland, Washington.

Fayer MJ and GW Gee. 1992. "Predicted drainage at a semiarid site: Sensitivity to hydraulic property description and vapor flow." p. 609-619. In Proceedings of the international workshop on indirect methods for estimating the hydraulic properties of unsaturated soils. MTh van Genuchten, FJ Leij, and LJ Lund (eds.), University of California, Riverside, California.

Fayer MJ, ML Rockhold, and MD Campbell. 1992. "Hydrologic modeling of protective barriers: Comparison of field data and simulation results." Soil Sci. Soc. of Am. J., 56:690-700.

Fayer MJ and TL Jones. 1990. UNSAT-H Version 2.0: Unsaturated soil water and heat flow model. PNL-6779, Pacific Northwest Laboratory, Richland, Washington.

Fayer MJ, GW Gee, and TL Jones. 1986. UNSAT-H Version 1.0: Unsaturated flow code documentation and application for the Hanford Site. PNL-5899, Pacific Northwest Laboratory, Richland, Washington.

Fayer MJ, W Conbere, RR Heller, and GW Gee. 1985. Model assessment of protective barrier designs. PNL-5604, Pacific Northwest Laboratory, Richland, Washington. 
Feddes RA, PJ Kowalik, and H. Zaradny. 1978. Simulation of field water use and crop yield. John Wiley and Sons, Inc., New York.

Gee GW. 1987. Recharge at the Hanford Site: Status report. PNL-6403, Pacific Northwest Laboratory, Richland, Washington.

Gee GW and PR Heller. 1985. Unsaturated water flow at the Hanford Site: A review of literature and annotated bibliography. PNL-5428, Pacific Northwest Laboratory, Richland, Washington.

Gee GW and CS Simmons. 1979. Characterization of the Hanford 300 Area burial grounds. Task III fluid transport and modeling. PNL-2921, Pacific Northwest Laboratory, Richland, Washington.

Gillham RW, A Klute, and DF Heermann. 1979. "Measurement and numerical simulation of hysteresis flow in a heterogeneous porous medium." Soil Sci. Soc. Am. J. 43:1061-1067.

Gupta SK, KK Tanji, DR Nielsen, JW Biggar, CS Simmons, and JL MacIntyre. 1978. Field simulation of soil-water movement with crop water extraction. Water Science and Engineering Paper No. 4013, Department of Land, Air, and Water Resources, University of California, Davis.

Gurr CG, TJ Marshall, and JT Hutton. 1952. "Movement of water in soil due to a temperature gradient.". Soil Sci. 74:335-345.

Hammel JE, RI Papendick, and GS Campbell. 1981. "Fallow tillage effects on evaporation and seedzone water content in a dry summer climate." Soil Sci. Soc. Am. J. 45:1016-1022.

Haverkamp R, M Vaclin, J Touma, PJ Wierenga, and G Vachaud. 1977. "A comparison of numerical simulation models for one-dimensional infiltration." Soil Sci. Soc. Am. J. 41:285-294.

Hillel D. 1980. Applications of soil physics. Academic Press, Inc., New York.

Hillel D. 1977. Computer simulations of soil-water dynamics. International Development Research Centre, Ottawa, Canada.

Hinds WT. 1975. "Energy and carbon balances in cheatgrass: An essay in autecology." Ecological Monogr. 45:367-388.

Hoitink DJ, KW Burk, and JV Ramsdell. 1999. Hanford Site climatological data summary 1998 with historical data. PNNL-12087, Pacific Northwest National Laboratory, Richland, Washington.

Hsieh JJC, LE Brownell, and AE Reisenauer. 1973. Lysimeter experiments, description and progress report on neutron measurements. BNWL-1711, Pacific Northwest Laboratory, Richland, Washington.

Jones TL. 1978. Sediment moisture relations: Lysimeter project 1976-1977 water year. RHO-ST-15, Rockwell Hanford Operations, Richland, Washington. 
Jury WA. 1973. Simultaneous transport of heat and moisture through a medium sand. Ph.D. Dissertation, University of Wisconsin, Madison.

Khire MV, CH Benson, and PJ Bosscher. 1997. "Water balance modeling of earthen final covers." J. of Geotech. Geoenviron. Eng. 123:744-754.

Klemmedson JO and JG Smith. 1964. "Cheatgrass (Bromus TectorumL.)." Bot. Rev. 30:226-262.

Kool JB and JC Parker. 1987. "Development and evaluation of closed-form expressions for hysteretic soil hydraulic properties." Water Resour. Res. 23:105-114.

Kool JB, JC Parker, and M Th van Genuchten. 1985. "ONESTEP: A nonlinear parameter estimation program for evaluating soil hydraulic properties from one-step outflow experiments." Bulletin 85-3, Virginia Polytechnic Institute and State University, Blacksburg, Virginia.

Lenhard RJ, JC Parker, and JJ Kaluarachchi. 1991. "Comparing simulated and experimental hysteretic two-phase transient fluid flow phenomena." Water Resour. Res. 27:2113-2124.

Ligotke MW. 1988. Soil erosion rates from mixed soil and gravel surfaces in a wind tunnel: A preliminary report. PNL-6677, Pacific Northwest Laboratory, Richland, Washington.

LMHC. 1999. Statements of work for FY 2000 to 2005 for the Hanford low-activity tank waste performance assessment program. HNF-SD-WM-PAP-062, Rev. 4, Lockheed Martin Hanford Company, Richland, Washington.

Magnuson SO. 1993. A simulation study of moisture movement in proposed barriers for the Subsurface Disposal Area, INEL. EGG-WM-10974, EG\&G Idaho, Idaho Falls, Idaho.

Marshall TJ. 1959. "The diffusion of gases through porous media." J. Soil Sci. 10:79-82.

Monteith JL. 1975. Principles of environmental physics. Edward Arnold, London.

Monteith JL. 1980. "The development and extension of Penman's evaporation formula." In Applications of Soil Physics, D. Hillel, Academic Press, New York.

Mualem Y. 1976. "A new model for predicting the hydraulic conductivity of unsaturated porous media." Water Resour. Res. 12(3):513-522.

Neitzel DA (ed.). 1999. Hanford Site National Environmental Policy Act (NEPA) Characterization. PNNL-6415, Rev. 10, Pacific Northwest National Laboratory, Richland, Washington.

Nimmo JR and EE Miller. 1986. "The temperature dependence of isothermal moisture vs. potential characteristics of soils." Soil Sci. Soc. Amer. J. 50:1105-1113. 
Penman HL. 1940. "Gas and vapour movements in soil: I. The diffusion of vapours through porous solids.” J. Agric. Sci. (England) 30:347-462.

Philip JR. 1969. "Theory of infiltration." Adv. Hydrosci. 5:215-296.

Philip JR and DA de Vries. 1957. "Moisture movement in porous materials under temperature gradients." Trans. Am. Geophys. Union 38:222-232.

Reisenauer AE, DB Cearlock, CA Bryan, and GS Campbell. 1975. Partially Saturated Transient Groundwater Flow Model Theory and Numerical Implementation. BNWL-1713, Pacific Northwest Laboratory, Richland, Washington.

Richards LA. 1931. "Capillary conduction of liquids through porous mediums." Physics 1:318-333.

Ritchie JT. 1972. "Model for predicting evaporation from a row crop with incomplete cover." Water Resour. Res. 8(5):1204-1212.

Ritchie JT and E Burnett. 1971. "Dryland evaporative flux in a subhumid climate, 2, plant influences." Agron. J. 63:56-62.

Rockhold ML, MJ Fayer, GW Gee, and CT Kincaid. 1995. Estimation of natural groundwater recharge for the performance assessment of a low-level waste disposal facility at the Hanford Site. PNL-10508, Pacific Northwest Laboratory, Richland, Washington.

Rockhold ML, MJ Fayer, and GW Gee. 1988. Characterization of unsaturated hydraulic conductivity at the Hanford Site. PNL-6488, Pacific Northwest Laboratory, Richland, Washington.

Rosenberg NJ, BL Blad, and SB Verma. 1983. Microclimate: The biological environment. John Wiley and Sons, Inc., New York.

Rossi C and JR Nimmo. 1994. "Modeling of soil water retention from saturation to oven dryness." Water Resour. Res. 30, 701-708, 1994.

Scotter DR. 1976. “Liquid and vapour phase transport in soil.” Aust. J. Soil Res. 14:33-41.

Simmons CS and GW Gee. 1981. Simulation of water flow and retention in earthen cover materials overlying uranium mill tailings. PNL-3877, Pacific Northwest Laboratory, Richland, Washington.

Taylor SA and L Cavazza. 1954. "The movement of soil moisture in response to temperature gradients." Soil Sci. Soc. Am. Proc. 18:351-358.

Troeh FR, JD Jabro, and D Kirkham. 1982. "Gaseous diffusion equations for porous materials." Geoderma. 27:239-253. 
van Bavel CHM. 1952. "Gaseous diffusion and porosity in porous media." Soil Sci. 73:91-104.

van Bavel CHM and D. Hillel. 1976. "Calculating potential and actual evaporation from a bare soil surface by simulation of concurrent flow of water and heat." Agric. Meteor. 17:453-476.

van Genuchten R. 1978. Calculating the unsaturated hydraulic conductivity with a new closed-form analytical model. Water Resource Program, Department of Civil Engineering, Princeton University, Princeton, New Jersey. 


\section{Appendix A}

UNSAT-H Version 3.0 Input Manual 


\section{Appendix A}

\section{UNSAT-H Version 3.0 Input Manual}

This UNSAT-H Version 3.0 input manual is organized into five sections:
A.1 Options, Constants, and Limits
A.2 Soil Property Information
A.3 Initial Conditions
A.4 Plant Information (optional)
A.5 Boundary Conditions

Within each section are records (or lines) that must be filled with the appropriate parameter values. Three format types are possible: A for CHARACTER type, I for INTEGER type, and R for REAL type parameters. A comma must separate all parameter values. Every line must end with a comma (with one or two exceptions as noted).

The input manual structure differs from previous versions of UNSAT-H in two regards. First, we rearranged the location of parameters to group similar parameters (e.g., placing heat flow options together). Second, we reduced the reliance on strict formatting of input values. With Version 3.0, users are free to enter values as they desire as long as the values adhere to the specified data type (A, I, or R) and the values are separated by a comma. The change in formatting will make it difficult to convert input files from Version 2.05 to Version 3.0, but $I$ believe that the elimination of the fixed-format inputs used in Version 2.05 will be beneficial.

The modifications that were implemented after Version 2.05 are as follows.

Hysteresis. This hysteresis model described by Lenhard et al. (1991) was implemented in UNSAT-H Version 3.0. The basis for this hysteresis model is that the internal scanning curves can be scaled from either the primary drainage curve or the primary imbibition curve. The scanning curves and the primary imbibition curve are further scaled according to the amount of entrapped air. The Lenhard et al. (1991) hysteresis model was chosen for its simplicity: only two parameters are required. The first parameter is ${ }^{i} S_{n r}$ (superscript $i$ refers to imbibition) the maximum amount of air that becomes entrapped when the soil is wetted from an air dry condition to satiation, a condition whereby the sediment has a matric potential of zero but is not necessarily completely saturated. The other parameter is $\alpha_{i}$ (subscript $i$ refers to imbibition), one of the parameters used to describe the primary imbibition curve. The only restriction on the parameter $\alpha_{i}$ is that it must be greater than or equal to the value of $\alpha_{d}$, a similar parameter but associated with the primary drainage curve. 
Iterative Solution of Head and Temperature. UNSAT-H Version 2.0 solves the equations for head and temperature separately. During a time step, the code solves the head equation while holding temperatures constant, then it solves the temperature equation while holding heads constant. This technique worked best when time steps were small. As the step size increased, the solution became less stable and users reported seeing oscillatory behavior in the solutions from one step to the next. Also, this increasing instability caused the time step algorithm to reduce the time step, which increased the computational time dramatically. A solution to these problems was to solve the head and temperature equations iteratively within the time step, thus ensuring that the head and temperature solution at the end of the time step was in equilibrium. This scheme was implemented in UNSAT-H 3.0.

Energy Balance Check. UNSAT-H Version 2.0 can use either the water balance error or the maximum fractional change in water content to control the size of the time step. There is no mechanism for the code to alter the time step if the heat balance error is unacceptable. The means to control the time step using the heat balance error (in addition to the water-based control) was implemented in UNSAT-H 3.0 .

Solution Technique. UNSAT-H Version 2.0 solves for water and heat flow using the standard Picard iteration approach in which the system of head-based (or temperature-based) equations is solved iteratively until some criterion is satisfied. Celia et al. (1990) found that this technique can be improved from the standpoint of mass balance and numerical effort by recasting the equations in a mixed form, called the "modified Picard" technique. This technique was implemented for the head solution in UNSAT-H 3.0.

Hydraulic Functions. Since completion of the UNSAT-H Version 2.0 code, numerous functions have been proposed for describing soil hydraulic properties. In general, these newer functions are more complex because they must account for unusual features that are difficult to describe using standard functions (such as those of Brooks and Corey and van Genuchten). Four functions were specifically designed to provide detail in the dry range. Two of these functions, called the "sum" and "junction" models, were proposed by Rossi and Nimmo (1994). The other two functions, which are modifications of the Brooks-Corey and van Genuchten functions, were proposed by Fayer and Simmons (1995). These four functions were implemented in UNSAT-H 3.0.

Multiple Year Simulations. UNSAT-H is commonly used to simulate recharge rates for multiple years. For periods of a few years, this can be accomplished by simulating a year, manually building the input file for the next year, then continuing the simulation. For longer periods, this can be accomplished external to the UNSAT-H code using script or batch files. This method works (and was necessary for Version 2.0) but is not convenient. The capability for multi-year simulations was implemented in UNSAT-H 3.0.

General Enhancements. In addition to the above changes, some simple changes were implemented. These are related to 1) precision, 2) compilation, 3) time stepping, 4) the Ritchie Equation, and 5) output.

1. The code was revised to make its standard mode "double precision." This change allows mass balance errors to be reduced, but it increases the size of output files. 
2. The code was slightly adjusted to make compilation easier. The changes were primarily in the initialization blocks.

3. The ability of the code to continue a problem with the time step size at the minimum value, even though the solution was unacceptable, was eliminated. Instead, the code is stopped if it tries to reduce the time step below the minimum acceptable value. Another change was to eliminate faulty logic in the time stepping algorithm that allowed the code to settle into an infinite loop.

4. An option was added to use a revised version of the Ritchie method for partitioning potential evapotranspiration (PET). The method was revised to address an error in the original Ritchie equation. An option to use the original method was retained for comparison purposes.

5. An option was added for screen output during code operation to allow the user to monitor the progress of a simulation.

UNSAT-H Version 2.05 is still available and supported, and a copy of Version 2.05 will be maintained on the $\mathrm{ftp}$ site. My experience indicates that the answers provided by UNSAT-H Version 3.0 are very similar to those provided by Version 2.05 . Unless there is a need to use one of the new features, most users can continue to use Version 2.05 .

Forward all comments to mike.fayer@pnl.gov. Suggestions for additional capability will be considered for the next version.

Mike Fayer

Pacific Northwest National Laboratory

Box 999, K9-33

Richland, Washington 99352

(509) 372-6045 


\section{A.1 Options, Constants, and Limits}

\begin{tabular}{|c|c|c|c|}
\hline $\begin{array}{c}\text { Record } \\
\text { No. }\end{array}$ & Format & & Variables and Descriptions \\
\hline 1 & $\mathrm{~A}$ & $\begin{array}{l}\text { TITLE, } \\
\text { TITLE }\end{array}$ & Input file description \\
\hline 2 & $2 \mathrm{I}$ & $\begin{array}{l}\text { IPLANT, } \\
\text { IPLANT } \\
\text { NGRAV }\end{array}$ & $\begin{array}{l}\text { GRAV, } \\
\text { Option for plants } \\
\text { 0) no plants } \\
\text { 1) plants (this option is not available with heat flow) } \\
\text { Domain orientation } \\
\text { 0) horizontal (no gravity) } \\
\text { 1) vertical (gravity) }\end{array}$ \\
\hline 3 & $3 I$ & $\begin{array}{l}\text { IFDEND, I } \\
\text { IFDEND } \\
\text { IDTBEG } \\
\text { IDTEND }\end{array}$ & $\begin{array}{l}\text { TBEG,IDTEND, } \\
\text { Last day of the last year of the simulation } \\
\text { First day for which data have been provided (first year of simulation) } \\
\text { Last day for which data have been provided (last year of simulation) }\end{array}$ \\
\hline 4 & SI & $\begin{array}{l}\text { IYS,NYEA } \\
\text { IYS } \\
\text { NYEARS } \\
\text { ISTEAD } \\
\text { IFLIST }\end{array}$ & $\begin{array}{l}\text { RS,ISTEAD,IFLIST,NFLIST, } \\
\text { Year of the simulation. For multiyear simulations, this year serves as the } \\
\text { base year on which all subsequent years are incremented. Minimum } \\
\text { value is } 1 \text {. } \\
\text { Number of years to simulate. A. value of } 1 \text { will result in a single-year } \\
\text { simulation. A value greater than } 1 \text { will result in a multiyear simulation. } \\
\text { Steady state option. } \\
\text { 0) transient solution (typical) } \\
\text { 1) steady state solution. This option causes the simulation to be } \\
\text { repeated NYEARS times. The output file for each intermediate } \\
\text { year is saved, so ensure the availability of sufficient disk space. } \\
\text { If IFLIST is greater than 0, the code uses the meteorological } \\
\text { data from the first year files only. } \\
\text { Option for entering meteorological information } \\
\text { 0) meteorological data included in input file; single year simulation } \\
\text { 1) meteorological data in separate files; filenames defined by } \\
\text { filename prefix, starting year, and filename suffix provided by } \\
\text { the code user } \\
\text { 2) meteorological data in separate files; filenames are listed in the } \\
\text { input file } \\
\text { 3) meteorological data in separate files; filenames are listed in an } \\
\text { external file whose name is provided in the input file (option not } \\
\text { available when ISTEAD equals 1) }\end{array}$ \\
\hline
\end{tabular}




\begin{tabular}{|c|c|c|c|}
\hline $\begin{array}{l}\text { Record } \\
\text { No. }\end{array}$ & Format & & Variables and Descriptions \\
\hline 5 & $2 I$ & $\begin{array}{l}\text { NPRINT,S } \\
\text { NPRINT } \\
\text { STOPHR }\end{array}$ & $\begin{array}{l}\text { TOPHR, } \\
\text { Option for level of output } \\
\text { 0) Daily summaries and end-of-simulation summary } \\
\text { 1) DELSUB and daily summaries and end-of-simulation summary. } \\
\text { Use of this option may result in large *.RES output files if } \\
\text { IDTEND-NDAY is large: } \\
\text { Stopping time when IDAY equals IDTEND and NPRINT equals } 1 \text {. This } \\
\text { feature is useful for stopping a simulation at a time other than the end of } \\
\text { a day. A particular instance for using STOPHR would be for simulating } \\
\text { a time period less than a day. A normal value of STOPHR is } 24 \text {. (units: } \\
\text { hr) }\end{array}$ \\
\hline 6 & $3 \mathrm{I}, \mathrm{R}$ & $\begin{array}{l}\text { ISMETH,II } \\
\text { ISMETH } \\
\text { INMAX } \\
\text { ISWDIF }\end{array}$ & $\begin{array}{l}\text { NMAX,ISWDIF,DMAXBA, } \\
\text { Option for method of solution } \\
\text { 0) Crank-Nicholson (standard method of previous versions of } \\
\text { UNSAT-H) } \\
\text { 1) Modified Picard iteration } \\
\text { Number of iterations allowed for solving the water flow equation. A } \\
\text { value of } 2 \text { is the minimum allowed. INMAX steps will be taken if } \\
\text { DHTOL=0. } \\
\text { Option for time step control } \\
\text { 0) Check all nodes to see if the relative change in THETA of every } \\
\text { node is less than DMAXBA } \\
\text { 1) Reduce the time step if the mass balance for the whole profile } \\
\text { exceeds DMAXBA } \\
\text { Time step control parameter. If ISWDIF = 0, DMAXBA is the } \\
\text { maximum allowable relative change in the water content of any node } \\
\text { [suggested value is } 0.01 \text { (no units)]. If ISWDIF equals } 1, \text { DMAXBA is } \\
\text { the maximum allowable mass balance error (units: cm) }\end{array}$ \\
\hline 7 & $\overline{3 R}$ & $\begin{array}{l}\text { DELMAX,I } \\
\text { DELMAX } \\
\text { DELMIN } \\
\text { OUTTIM }\end{array}$ & $\begin{array}{l}\text { DELMIN,OUTTIM, } \\
\text { Maximum allowable time step, normally } 1 \mathrm{hr} \text {. The value of DELMAX } \\
\text { must be less than or equal to OUTTIM, otherwise DELMAX is set equal } \\
\text { to OUTTIM (units: hr) } \\
\text { Minimum allowable time step. The value must be less than or equal to } \\
\text { DELMAX. (units: hr) } \\
\text { Determines the size of the DELSUB period, which is used to divide each } \\
\text { day into equal increments for calculations; if NPRINT equals } 1 \text {, } \\
\text { OUTTIM is also the time interval for generating output. If equal to zero, } \\
\text { OUTTIM is reset to the DELMAX value (in which case, the following } \\
\text { OUTTIM restrictions apply to the DELMAX value). For values of } \\
\text { OUTTIM greater than } 1.0,24 / O U T T I M \text { must produce an integer value. } \\
\text { Values cannot be greater than } 24 \text {. For values of OUTTIM less than } 1.0 \text {, } \\
\text { 1.0/OUTTIM must produce an integer value if using hourly precipitation } \\
\text { and evaporation data. (units: hr) }\end{array}$ \\
\hline
\end{tabular}




\begin{tabular}{|c|c|c|c|}
\hline $\begin{array}{l}\text { Record } \\
\text { No. }\end{array}$ & Format & & Variables and Descriptions \\
\hline 8 & $5 \mathrm{R}$ & $\begin{array}{l}\text { RFACT, } \\
\text { RFACT } \\
\text { RAINIF } \\
\text { DHTOL }\end{array}$ & $\begin{array}{l}\text { INIF,DHTOL,DHMAX,DHFACT, } \\
\text { Maximum time-step factor. The time step can potentially be increased } \\
\text { by this factor following the completion of a successful time step. } \\
\text { Rainfall time-step reduction factor. At the start of water application } \\
\text { event, the time step will be reduced by the RAINIF factor. } \\
\text { Iteration control parameter. If the relative change in head during an } \\
\text { iteration } \\
\qquad\left|\frac{h^{j}-h^{j-1}}{h^{j-1}}\right| \\
\text { exceeds DHTOL, the time step is reduced by half. If the value of } \\
\text { DHTOL is } 0 \text {, then this control parameter is not used. (units: cm) } \\
\text { Iteration control parameter. If DHMAX is positive, each potential head } \\
\text { solution is checked to see if the change in head } \\
\qquad\left|h^{j}-h^{j-1}\right| \\
\text { exceeds DHMAX. If so, the time step size is reduced by the factor } \\
\text { DHFACT and re-solved. (units: cm) } \\
\text { Time sten reduction factor if DHMAX }>0\end{array}$ \\
\hline 9 & $2 \mathrm{I}, \mathrm{R}$ & \multicolumn{2}{|c|}{ KOPT,KEST,WTF, } \\
\hline & & KEST & $\begin{array}{l}\text { Options for describing the soil hydraulic properties } \\
\text { 1) Polynomial } \\
\text { 2) Haverkamp (Haverkamp et al. 1977) } \\
\text { 3) Brooks-Corey (Corey 1977) } \\
\text { 4) van Genuchten (van Genuchten 1978) } \\
\text { 5) Modified Brooks-Corey (Fayer and Simmons 1995) } \\
\text { 6) Modified van Genuchten (Fayer and Simmons 1995) } \\
\text { 7) Rossi and Nimmo "sum" model (Rossi and Nimmo 1994) } \\
\text { 8) Rossi and Nimmo "junction" model (Rossi and Nimmo 1994) } \\
\text { Option for estimating the liquid conductivity at the midpoint between } \\
\text { nodes } \\
\text { 1) Arithmetic mean with an option for upstream weighting (see } \\
\text { 2) HTF) } \\
\text { 3) Geometric mean } \\
\text { Weighting factor (from 0.0 to 1.0) used to weight the conductivity of the } \\
\text { upstream node in the calculation of conductivities between nodes. A } \\
\text { value of } 0.5 \text { weights the nodes equally. WTF applies only when KEST is } \\
\text { 1. }\end{array}$ \\
\hline
\end{tabular}




\begin{tabular}{|c|c|c|c|}
\hline $\begin{array}{c}\text { Record } \\
\text { No. }\end{array}$ & Format & & Variables and Descriptions \\
\hline 10 & $4 \mathrm{I}$ & $\begin{array}{l}\text { ITOPBC,I } \\
\text { ITOPBC } \\
\text { IEVOPT } \\
\text { NFHOUR } \\
\text { LOWER }\end{array}$ & $\begin{array}{l}\text { VOPT,NFHOUR,LOWER, } \\
\text { Option for the surface-boundary condition } \\
\text { 0) Flux } \\
\text { 1) Constant head equal to HTOP } \\
\text { Option to allow evaporation } \\
\text { 0) No evaporation } \\
\text { 1) Evaporation } \\
\text { Option to distribute the daily potential evapotranspiration (PET) value } \\
\text { over the } 24 \text { hours of the day } \\
\text { 1) User supplies } 24 \text { hourly factors } \\
\text { 2) Hourly factors are generated with a sine wave function for the } \\
\text { hours between } 0600 \text { and } 1800 \text {, while the remaining hourly } \\
\text { factors are set equal to } 0.01 \\
\text { Lower boundary condition option } \\
\text { 1) Unit gradient } \\
\text { 2) Constant head (the initial value is maintained). A value of zero } \\
\text { would correspond to a static water table } \\
\text { 3) Specified flux } \\
\text { 4) Impermeable boundary } \\
\text { 5) Specified head }\end{array}$ \\
\hline 11 & $4 \mathrm{R}$ & $\begin{array}{l}\text { HIRRI,HD } \\
\text { HIRRI } \\
\text { HDRY } \\
\text { HTOP } \\
\text { RHA }\end{array}$ & $\begin{array}{l}\text { RY,HTOP,RHA, } \\
\text { Minimum head to which the soil can wet up (units: cm) } \\
\text { Maximum head to which the soil can dry out when IHEAT equals } 0 \text { and } \\
\text { ISHOPT equals } 0 \text { (units: } \mathrm{cm} \text { ) } \\
\text { Constant head value of the surface node when ITOPBC equals } 1 \text { (units: } \\
\mathrm{cm} \text { ) } \\
\text { Relative humidity of the air (units: fractional). This parameter is used to } \\
\text { calculate HDRY if the input value of HDRY is zero, ISHOPT is zero, } \\
\text { and IHEAT is zero. }\end{array}$ \\
\hline 12 & $3 \mathrm{I}$ & $\begin{array}{l}\text { IETOPT,I } \\
\text { IETOPT } \\
\text { ICLOUD }\end{array}$ & $\begin{array}{l}\text { LOUD,ISHOPT, } \\
\text { Option to input daily meteorological data } \\
\text { 0) No meteorological data (use potential evapotranspiration data) } \\
\text { 1) Daily meteorological data are entered (IEVOPT must equal 1) } \\
\text { Option to use cloud cover data from the meteorological record } \\
\text { (applicable when IHEAT equals } 1 \text { and UPPERH equals } 0 \text { ) } \\
\text { 0) No. Cloud cover calculated from measured and potential solar } \\
\text { radiation } \\
\text { 1) Yes, use the cloud cover data provided } \\
\text { Option for the upper surface head limit when IHEAT equals } 0 \\
\text { 0) Constant surface head equal to HDRY } \\
\text { 1) Calculate a daily HDRY value based on atmospheric humidity } \\
\text { (requires IETOPT equal l) }\end{array}$ \\
\hline
\end{tabular}




\begin{tabular}{|c|c|c|c|}
\hline $\begin{array}{l}\text { Record } \\
\text { No. }\end{array}$ & Format & & Variables and Descriptions \\
\hline 13 & $\bar{I}, \bar{R}$ & $\begin{array}{l}\text { IRAIN,HPI } \\
\text { IRAIN } \\
\text { HPR }\end{array}$ & $\begin{array}{l}\text { Option for water application information } \\
\text { 0) Enter hourly precipitation data (see Boundary Condition } \\
\text { section) } \\
\text { 1) Use the daily precipitation values that are included with the } \\
\text { meteorological data and apply at the HPR rate. } \\
\text { Hourly precipitation rate when IETOPT equals } 1 \text {. Starting at } 0000 \mathrm{hr} \text {, } \\
\text { precipitation is applied at the HPR rate until the amount to be applied is } \\
\text { less than the amount that would fall in one hour at the HPR rate, after } \\
\text { which the remainder is applied over the next hour. The default value is } \\
1.0 \mathrm{~cm} / \mathrm{hr} \text { (units: } \mathrm{cm} / \mathrm{hr} \text { ) }\end{array}$ \\
\hline 14 & $\mathrm{I}, \overline{\mathrm{R}}, \mathrm{A}$ & $\begin{array}{l}\text { IHYS,AIR] } \\
\text { IHYS } \\
\text { AIRTOL } \\
\text { HYSTOL } \\
\text { HYSMXH } \\
\text { HYFILE }\end{array}$ & $\begin{array}{l}\text { OL,HYSTOL,HYSMXH,HYFILE, } \\
\text { Option for hysteresis (only uses the van Genuchten soil water retention } \\
\text { function, KOPT=4) } \\
\text { 0) no hysteresis } \\
\text { 1) hysteresis, starting on the primary drainage path } \\
\text { 2) hysteresis, starting on the primary sorption path } \\
\text { 3) hysteresis, starting on the main drainage path. } \\
\text { 4) hysteresis restart, using hysteresis information from file with } \\
\text { extension "HRI" that was created during previous hysteresis } \\
\text { simulation } \\
\text { Tolerance limit on entrapped air content below which volumetric air } \\
\text { content is considered zero in hysteresis simulations (units: } \mathrm{cm}^{3} / \mathrm{cm}^{3} \text { ) } \\
\text { Tolerance limit on head changes below which a change in head does not } \\
\text { trigger a path reversal during hysteresis simulations (units: } \mathrm{cm}^{\text {) }} \\
\text { Maximum head value for all materials above which hysteresis does not } \\
\text { occur. Used to avoid large changes in the head value of the surface node } \\
\text { (units: cm) } \\
\text { Name of restart file when IHYS equals } 1 \text {; place no extra characters or } \\
\text { comments after the filename. }\end{array}$ \\
\hline 15 & $2 \overline{\mathrm{I}, \mathrm{R}}$ & $\begin{array}{l}\text { IHEAT,IC } \\
\text { IHEAT } \\
\text { ICONVH } \\
\text { DMAXHE }\end{array}$ & $\begin{array}{l}\text { ONVH,DMAXHE, } \\
\text { Option for simulating heat flow } \\
\text { 0) No heat flow } \\
\text { 1) Heat flow (this option is not available with the plant option) } \\
\text { Option to allow convective heat flow via water flow } \\
\text { 0) No convective heat flow allowed } \\
\text { 1) Convective heat flow allowed. Use caution when solving } \\
\text { convection-dominated problems because there is no upstream } \\
\text { weighting. Precipitation temperature depends on the value of } \\
\text { UPPERH: if } 0 \text {, TA; if } 1 \text { or } 2 \text {, TS; if } 3 \text {, TSMEAN (units: } \mathrm{J} / \mathrm{m}^{2} \text { ) } \\
\text { Time step control parameter when greater than zero and IHEAT }=1 \text {. } \\
\text { Represents the maximum allowable heat balance error (units: } \mathrm{J} / \mathrm{m}^{2} \text { ) }\end{array}$ \\
\hline
\end{tabular}




\begin{tabular}{|c|c|c|c|}
\hline $\begin{array}{c}\text { Record } \\
\text { No. }\end{array}$ & Format & & Variables and Descriptions \\
\hline 16 & $\overline{I, 3 R}$ & $\begin{array}{l}\text { UPPERH,T } \\
\text { UPPERH } \\
\text { TSMEAN } \\
\text { TSAMP } \\
\text { QHCTOP }\end{array}$ & $\begin{array}{l}\text { SMEAN,TSAMP,QHCTOP, } \\
\text { Option for the upper boundary condition for heat flow } \\
\text { 0) Flux that is calculated based on weather and soil parameters } \\
\text { 1) Constant temperature (specified in initial conditions) } \\
\text { 2) Variable temperature (must specify TSMEAN and TAMP) } \\
\text { 3) Specified heat flux (must specify QHCTOP). Any convective } \\
\text { flow (e.g., heat associated with precipitation) will be added to } \\
\text { QHCTOP. The water temperature will be set to TSMEAN. } \\
\text { Daily mean surface temperature when UPPERH equals } 2 \text {; temperature of } \\
\text { infiltrating water when UPPERH equals } 3 \text { (units: K) } \\
\text { Daily surface temperature amplitude about TSMEAN when UPPERH } \\
\text { equals } 2 \text { (units: K) } \\
\text { User-specified surface heat flux when UPPERH equals } 3 \\
\text { (units: } \mathrm{J} \mathrm{s}^{-1} \mathrm{~m}^{-2} \text { ) }\end{array}$ \\
\hline 17 & $1,2 \mathrm{R}$ & $\begin{array}{l}\text { LOWERH, } \\
\text { LOWERH } \\
\text { QHLEAK } \\
\text { TGRAD }\end{array}$ & $\begin{array}{l}\text { QHLEAK,TGRAD, } \\
\text { Option for the lower boundary condition for heat flow } \\
\text { 1) Temperature gradient (must specify TGRAD). } \\
\text { 2) Constant temperature (specified in initial conditions). Can } \\
\text { specify TGRAD. } \\
\text { 3) Constant heat flux (must specify QHLEAK). TGRAD is not } \\
\text { used. } \\
\text { Heat flux at the bottom boundary when LOWERH equals } 3 \\
\text { (units: } \mathrm{J} \mathrm{hr}^{-1} \mathrm{~cm}^{-2} \text { ) } \\
\text { Temperature gradient at the bottom boundary when IHEAT equals } 1 \text { and } \\
\text { LOWERH equals } 1 \text {. A positive value indicates an upward gradient } \\
\text { because depth is positive downward (units: } \mathrm{K} / \mathrm{cm} \text { ) }\end{array}$ \\
\hline 18 & $\overline{\mathrm{I}, 3 \mathrm{R}}$ & $\begin{array}{l}\text { TVAPOR,T } \\
\text { IVAPOR } \\
\text { TORT } \\
\text { TSOIL } \\
\text { VAPDIF }\end{array}$ & $\begin{array}{l}\text { ORT,TSOIL,VAPDIF, } \\
\text { Option to allow vapor flow. If chosen, values must be supplied for } \\
\text { TORT, TSOIL, and VAPDIF. If IHEAT=1, vapor can diffuse across the } \\
\text { bottom boundary in response to a temperature gradient (TGRAD) if } \\
\text { LOWERH equals } 1 \text { (temperature gradient boundary) or } 2 \text { (constant } \\
\text { temperature boundary). } \\
\text { 0) No, vapor flow not allowed } \\
\text { 1) Yes, vapor flow allowed } \\
\text { Tortuosity } \\
\text { Average temperature of the soil for use in calculations of isothermal } \\
\text { vapor flow (units: K) } \\
\text { Diffusion coefficient of vapor in air (units: } \mathrm{cm}^{2} / \mathrm{s} \text { ) }\end{array}$ \\
\hline 19 & $2 \mathrm{I}$ & $\begin{array}{l}\text { MATN,NP' } \\
\text { MATN } \\
\text { NPT }\end{array}$ & $\begin{array}{l}\text { Number of different soil materials } \\
\text { Number of nodes }\end{array}$ \\
\hline
\end{tabular}




\begin{tabular}{|c|c|c|}
\hline $\begin{array}{c}\text { Record } \\
\text { No. }\end{array}$ & Format & Variables and Descriptions \\
\hline 20 & $\begin{array}{c}4(\mathrm{I}, \mathrm{R}) \\
\text { per line }\end{array}$ & $\begin{array}{l}\text { MAT,Z, } \\
\text { MAT } \quad \text { Soil material identification number for the given node } \\
Z \quad \text { Depth of node below the surface (units: } \mathrm{cm} \text { ) } \\
\text { Repeat Record } 20 \text { until MATN nodes defined }\end{array}$ \\
\hline
\end{tabular}




\section{A.2 Soil Property Information}

IF KOPT $=1$ (polynomial description) THEN

\begin{tabular}{|c|c|c|c|}
\hline $\begin{array}{l}\text { Record } \\
\text { No. }\end{array}$ & Format & & Variables and Descriptions \\
\hline 1 & $2 I$ & $\begin{array}{l}\text { MAXPOL } \\
\text { MAXPOL } \\
\text { MAXCOE }\end{array}$ & $\begin{array}{l}\text { MAXCOE, } \\
\text { Maximum number of polynomials for any given soil hydraulic } \\
\text { property function (limited to M2 in unsath.inc) } \\
\text { Maximum number of polynomial coefficients per soil hydraulic } \\
\text { property function (MAXPOL*MAXCOE is limited to M4 in } \\
\text { unsath.inc) }\end{array}$ \\
\hline 2 & $\bar{A}$ & $\begin{array}{l}\text { DUMMY, } \\
\text { DUMMY }\end{array}$ & $\begin{array}{l}\text { Dummy title that can be used to describe the soil type and } \\
\text { indicate that what follows are water retention parameters }\end{array}$ \\
\hline 3 & $\overline{\mathrm{I}, 2 \mathrm{R}}$ & $\begin{array}{l}\text { NSUBTH, } \\
\text { NSUBTH } \\
\text { AIRINT } \\
\text { THET }\end{array}$ & $\begin{array}{l}\text { IRINT,THET, } \\
\text { Number of subdivisions of the water retention curve for that } \\
\text { particular material } \\
\text { Air entry head (units: } \mathrm{cm} \text { ) } \\
\text { Saturated water content (units: } \mathrm{cm}^{3} / \mathrm{cm}^{3} \text { ) }\end{array}$ \\
\hline 4 & $2 \mathrm{I}, 2 \mathrm{R}$ & $\begin{array}{l}\text { II,NDEGT } \\
\text { II } \\
\text { NDEGTH } \\
\text { XX } \\
\text { XDIVTH }\end{array}$ & $\begin{array}{l}\text { I,XX,XDIVTH, } \\
\text { Index of the water retention polynomial } \\
\text { Number of polynomial coefficients, or polynomial degree }+1 \\
\text { Minimum head for which the given polynomial applies } \\
\text { (units: } \mathrm{cm} \text { ) } \\
\text { Maximum head for which the given polynomial applies } \\
\text { (units: } \mathrm{cm} \text { ). }\end{array}$ \\
\hline 5 & $5 \bar{R}$ & $\begin{array}{l}\text { CREGTH, } \\
\text { CREGTH } \\
\text { Repeat Rec }\end{array}$ & $\begin{array}{l}\text { Polynomial coefficients for describing water retention; enter } \\
\text { NDEGTH values of CREGTH } \\
\text { rds 4-5 NSUBTH times }\end{array}$ \\
\hline 6 & $\bar{A}$ & $\begin{array}{l}\text { DUMMY, } \\
\text { DUMMY }\end{array}$ & $\begin{array}{l}\text { Dummy title that can be used to describe the soil type and } \\
\text { indicate that what follows are conductivity parameters }\end{array}$ \\
\hline 7 & $\overline{\mathrm{I}, 2 \mathrm{R}}$ & $\begin{array}{l}\text { NSUBKH, } \\
\text { NSUBKH } \\
\text { AIRINK } \\
\text { SK }\end{array}$ & $\begin{array}{l}\text { NRINK,SK, } \\
\text { Number of subdivisions of conductivity curve for that particular } \\
\text { material } \\
\text { Air entry head (units: } \mathrm{cm} \text { ) } \\
\text { Saturated hydraulic conductivity (units: } \mathrm{cm} / \mathrm{hr} \text { ) }\end{array}$ \\
\hline
\end{tabular}




\begin{tabular}{|c|c|c|c|}
\hline $\begin{array}{c}\text { Record } \\
\text { No. }\end{array}$ & Format & & Variables and Descriptions \\
\hline 8 & $2 \mathrm{I}, 2 \mathrm{R}$ & $\begin{array}{l}\text { II,NDEGK } \\
\text { II } \\
\text { NDEGKH } \\
\mathrm{XX} \\
\text { XDIVKH }\end{array}$ & $\begin{array}{l}\text { Y,XX,XDIVKH, } \\
\text { Index of the conductivity polynomial } \\
\text { Number of polynomial coefficients, or polynomial degree }+1 \\
\text { Minimum head for which the given polynomial applies } \\
\text { (units: } \mathrm{cm} \text { ) } \\
\text { Maximum head for which the given polynomial applies } \\
\text { (units: } \mathrm{cm} \text { ) }\end{array}$ \\
\hline 9 & $5 \mathrm{R}$ & $\begin{array}{l}\text { CREGKH } \\
\text { CREGKH } \\
\text { Repeat Rec } \\
\text { Repeat Rec }\end{array}$ & $\begin{array}{l}\text { Polynomial coefficients for describing conductivity; enter } \\
\text { NDEGKH values of CREGKH } \\
\text { rds 8-9 NSUBKH times } \\
\text { rds 2-9 MATN times }\end{array}$ \\
\hline
\end{tabular}

IF KOPT $=2$ (Haverkamp functions) THEN

\begin{tabular}{|c|c|c|c|}
\hline $\begin{array}{c}\text { Record } \\
\text { No. }\end{array}$ & Format & & Variables and Descriptions \\
\hline 1 & $\bar{A}$ & $\begin{array}{l}\text { DUMMY, } \\
\text { DUMMY }\end{array}$ & $\begin{array}{l}\text { Dummy title that can be used to describe the soil type and } \\
\text { indicate that what follows are water retention parameters }\end{array}$ \\
\hline 2 & $6 \mathrm{R}$ & $\begin{array}{l}\text { THET,TH' } \\
\text { THET } \\
\text { THTR } \\
\text { AIRINT } \\
\text { ALPHA } \\
\text { BETA } \\
\text { RETOPT }\end{array}$ & $\begin{array}{l}\text { R,AIRINT,ALPHA,BETA,RETOPT, } \\
\text { Saturated water content (units: } \mathrm{cm}^{3} / \mathrm{cm}^{3} \text { ) } \\
\text { Residual water content (units: } \mathrm{cm}^{3} / \mathrm{cm}^{3} \text { ) } \\
\text { Air entry head (units: } \mathrm{cm} \text { ) } \\
\text { Coefficient of Haverkamp function (Haverkamp et al. 1977) } \\
\text { Coefficient of Haverkamp function } \\
\text { Retention option } \\
\text { 1) function operates on head value } \\
\text { 2) function operates on } \ln (\text { head) value }\end{array}$ \\
\hline 3 & $\overline{\mathrm{A}}$ & $\begin{array}{l}\text { DUMMY, } \\
\text { DUMMY }\end{array}$ & $\begin{array}{l}\text { Dummy title that can be used to describe the soil type and } \\
\text { indicate that what follows are conductivity parameters }\end{array}$ \\
\hline
\end{tabular}




\begin{tabular}{|c|c|c|}
\hline $\begin{array}{c}\text { Record } \\
\text { No. }\end{array}$ & Format & Variables and Descriptions \\
\hline 4 & $4 \mathrm{R}$ & $\begin{array}{ll}\text { AIRINK,SK,A,B, } \\
\\
\text { AIRINK } \quad \text { Air entry head (units: } \mathrm{cm} \text { ) } \\
\text { SK } & \text { Saturated hydraulic conductivity (units: } \mathrm{cm} / \mathrm{hr} \text { ) } \\
\text { A } & \text { Coefficient of Haverkamp function } \\
\text { B } & \text { Coefficient of Haverkamp function } \\
& \\
\text { Repeat Records I-4 MATN times }\end{array}$ \\
\hline
\end{tabular}

IF KOPT $=3$ (Brooks-Corey functions) THEN

\begin{tabular}{|c|c|c|c|}
\hline $\begin{array}{l}\text { Record } \\
\text { No. }\end{array}$ & Format & \multicolumn{2}{|r|}{ Variables and Descriptions } \\
\hline 1 & $\bar{A}$ & $\begin{array}{l}\text { DUMMY, } \\
\text { DUMMY }\end{array}$ & $\begin{array}{l}\text { Dummy title that can be used to describe the soil type and } \\
\text { indicate that what follows are water retention parameters }\end{array}$ \\
\hline 2 & $4 \mathrm{R}$ & $\begin{array}{l}\text { THET,TH } \\
\text { THET } \\
\text { THTR } \\
\text { AIRINT } \\
\text { B }\end{array}$ & $\begin{array}{l}\text { R,AIRINT,B, } \\
\text { Saturated water content (units: } \mathrm{cm}^{3} / \mathrm{cm}^{3} \text { ) } \\
\text { Residual water content (units: } \mathrm{cm}^{3} / \mathrm{cm}^{3} \text { ) } \\
\text { Air entry head (units: } \mathrm{cm} \text { ) } \\
\text { Coefficient of Brooks-Corey function }\end{array}$ \\
\hline 3 & $\mathrm{~A}$ & $\begin{array}{l}\text { DÜMMY, } \\
\text { DUMMY }\end{array}$ & $\begin{array}{l}\text { Dummy title that can be used to describe the soil type and } \\
\text { indicate that what follows are conductivity parameters }\end{array}$ \\
\hline 4 & $5 \mathrm{R}$ & $\begin{array}{l}\text { RKMOD,S } \\
\text { RKMOD } \\
\text { SK } \\
\text { AIRENK } \\
\text { B } \\
\text { EPIT } \\
\text { Repeat Rec }\end{array}$ & $\begin{array}{l}\text { K,AIRENK,B,EPIT, } \\
\text { Conductivity model option: } \\
\text { 1) Burdine (Burdine 1953) } \\
\text { 2) Mualem (Mualem 1976) } \\
\text { Saturated hydraulic conductivity (units: } \mathrm{cm} / \mathrm{hr} \text { ) } \\
\text { Air entry. head (units: cm) } \\
\text { Coefficient of Brooks-Corey function } \\
\text { Exponent of the pore interaction term. Values of } 2 \text { and } 0.5 \text { are } \\
\text { standard for the Burdine and Mualem models, respectively. } \\
\text { ords 1-4 MATN times }\end{array}$ \\
\hline
\end{tabular}


IF KOPT $=4$ (van Genuchten functions) THEN

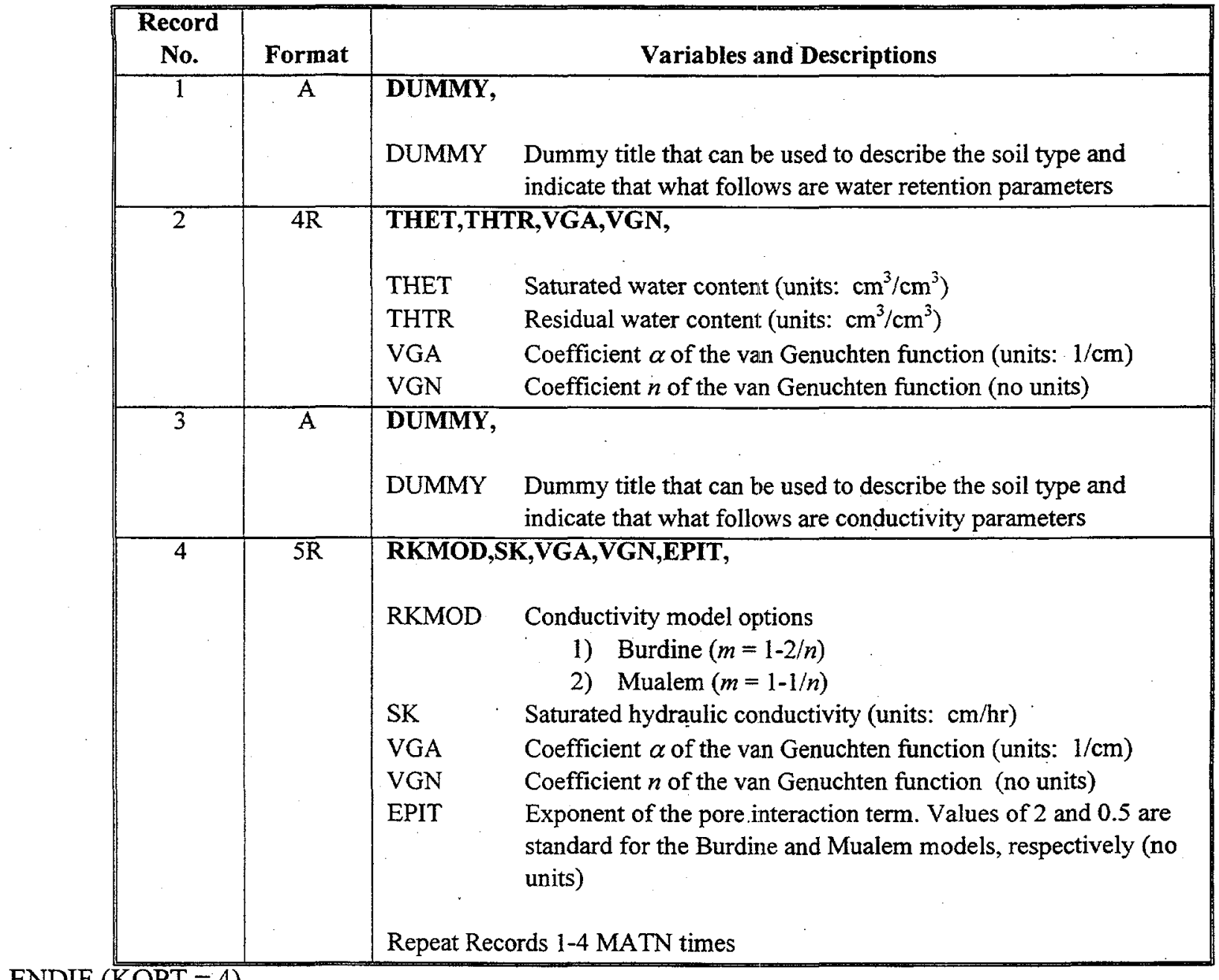

ENDIF $(\overline{\mathrm{KOPT}}=4)$

IF KOPT $=5$ (modified Brooks-Corey functions) THEN

\begin{tabular}{|c|c|c|c|}
\hline $\begin{array}{c}\text { Record } \\
\text { No. }\end{array}$ & Format & & Variables and Descriptions \\
\hline$\overline{1}$ & $\bar{A}$ & $\begin{array}{l}\text { DUMMY, } \\
\text { DUMMY }\end{array}$ & $\begin{array}{l}\text { Dummy title that can be used to describe the soil type and } \\
\text { indicate that what follows are water retention parameters }\end{array}$ \\
\hline 2 & $5 \mathrm{R}$ & $\begin{array}{l}\text { THET,TH } \\
\text { THET } \\
\text { THTA } \\
\text { AIRINT } \\
\text { B } \\
\text { HM }\end{array}$ & $\begin{array}{l}\text { A,AIRINT,B,HM, } \\
\text { Saturated water content (units: } \mathrm{cm}^{3} / \mathrm{cm}^{3} \text { ) } \\
\text { Transition water content (units: } \mathrm{cm}^{3} / \mathrm{cm}^{3} \text { ) } \\
\text { Air entry head (units: } \mathrm{cm} \text { ) } \\
\text { Coefficient equal to inverse of Brooks-Corey } \lambda \text { parameter } \\
\text { Suction head corresponding to zero water content (units: } \mathrm{cm} \text { ) }\end{array}$ \\
\hline
\end{tabular}




\begin{tabular}{|c|c|c|c|}
\hline $\begin{array}{l}\text { Record } \\
\text { No. }\end{array}$ & Format & & Variables and Descriptions \\
\hline 3 & $A$ & $\begin{array}{l}\text { DUMMY, } \\
\text { DUMMY }\end{array}$ & $\begin{array}{l}\text { Dummy title that can be used to describe the soil type and } \\
\text { indicate that what follows are conductivity parameters }\end{array}$ \\
\hline 4 & $5 \mathrm{R}$ & $\begin{array}{l}\text { SK,EPIT, } \\
\text { SK } \\
\text { EPIT } \\
\text { Repeat Recc }\end{array}$ & $\begin{array}{l}\text { Saturated hydraulic conductivity (units: } \mathrm{cm} / \mathrm{hr} \text { ) } \\
\text { Exponent of the pore interaction term. A value of } 0.5 \text { is } \\
\text { standard for the Mualem model. } \\
\text { rds 1-4 MATN times }\end{array}$ \\
\hline
\end{tabular}

ENDIF $(\overline{\mathrm{KOPT}}=5)$

IF KOPT $=6$ (modified van Genuchten functions) THEN

\begin{tabular}{|c|c|c|c|}
\hline $\begin{array}{l}\text { Record } \\
\text { No. }\end{array}$ & Format & & Variables and Descriptions \\
\hline 1 & $\bar{A}$ & $\begin{array}{l}\text { DUMMY, } \\
\text { DUMMY }\end{array}$ & $\begin{array}{l}\text { Dummy title that can be used to describe the soil type and } \\
\text { indicate that what follows are water retention parameters }\end{array}$ \\
\hline 2 & $\overline{5 R}$ & \multicolumn{2}{|c|}{$\begin{array}{ll}\text { THET, THTA,VGA,VGN,HM, } \\
\\
\text { THET } & \text { Saturated water content (units: } \mathrm{cm}^{3} / \mathrm{cm}^{3} \text { ) } \\
\text { THTA } & \text { Transition water content (units: } \mathrm{cm}^{3} / \mathrm{cm}^{3} \text { ) } \\
\text { VGA } & \text { Coefficient similar to van Genuchten } \alpha \text { (units: } 1 / \mathrm{cm} \text { ) } \\
\text { VGN } & \text { Coefficient similar to van Genuchten } n \text { (no units) } \\
\text { HM } & \text { Suction head corresponding to zero water content (units: } \mathrm{cm} \text { ) }\end{array}$} \\
\hline 3 & $\overline{\mathrm{A}}$ & $\begin{array}{l}\text { DUMMY, } \\
\text { DUMMY }\end{array}$ & $\begin{array}{l}\text { Dummy title that can be used to describe the soil type and } \\
\text { indicate that what follows are conductivity parameters }\end{array}$ \\
\hline 4 & $2 \mathrm{R}$ & $\begin{array}{l}\text { SK,EPIT, } \\
\text { SK } \\
\text { EPIT } \\
\text { Repeat Rec }\end{array}$ & $\begin{array}{l}\text { Saturated hydraulic conductivity (units: } \mathrm{cm} / \mathrm{hr} \text { ) } \\
\text { Exponent of the pore interaction term (no units). A value of } \\
0.5 \text { is standard for the Mualem model. } \\
\text { rds 1-4 MATN times }\end{array}$ \\
\hline
\end{tabular}


IF KOPT $=7$ (Rossi-Nimmo sum model) THEN

\begin{tabular}{|c|c|c|c|}
\hline $\begin{array}{l}\text { Record } \\
\text { No. }\end{array}$ & Format & & Variables and Descriptions \\
\hline 1 & $\bar{A}$ & $\begin{array}{l}\text { DUMMY, } \\
\text { DUMMY }\end{array}$ & $\begin{array}{l}\text { Dummy title that can be used to describe the soil type and } \\
\text { indicate that what follows are water retention parameters }\end{array}$ \\
\hline$\overline{2}$ & $\overline{5 R}$ & $\begin{array}{l}\text { THET,PSI } \\
\text { THET } \\
\text { PSID } \\
\text { PSIO } \\
\text { RLAM } \\
\text { PSII }\end{array}$ & $\begin{array}{l}\text {,PSIO,RLAM,PSII, } \\
\text { Saturated water content (units: } \mathrm{cm}^{3} / \mathrm{cm}^{3} \text { ) } \\
\text { Suction head corresponding to zero water content (units: } \mathrm{cm} \text { ) } \\
\text { Curve-fitting parameter (units: } \mathrm{cm} \text { ) } \\
\text { Curve-fitting parameter (no units) } \\
\text { Curve-fitting parameter (units: } \mathrm{cm} \text { ) }\end{array}$ \\
\hline 3 & $\bar{A}$ & $\begin{array}{l}\text { DUMMY, } \\
\text { DUMMY }\end{array}$ & $\begin{array}{l}\text { Dummy title that can be used to describe the soil type and } \\
\text { indicate that what follows are conductivity parameters }\end{array}$ \\
\hline 4 & $2 \mathrm{R}$ & $\begin{array}{l}\text { SK,EPIT, } \\
\text { SK } \\
\text { EPIT } \\
\text { Repeat Recc }\end{array}$ & $\begin{array}{l}\text { Saturated hydraulic conductivity (units: } \mathrm{cm} / \mathrm{hr} \text { ) } \\
\text { Exponent of the pore interaction term (no units). A value of } 0.5 \\
\text { is standard for the Mualem model. } \\
\text { rds 1-4 MATN times }\end{array}$ \\
\hline
\end{tabular}

ENDIF $(\overline{\mathrm{KOPT}}=7)$

IF KOPT $=8$ (Rossi-Nimmo junction model) THEN

\begin{tabular}{|c|c|c|c|}
\hline $\begin{array}{c}\text { Record } \\
\text { No. }\end{array}$ & Format & & Variables and Descriptions \\
\hline 1 & $\bar{A}$ & $\begin{array}{l}\text { DUMMY, } \\
\text { DUMMY }\end{array}$ & $\begin{array}{l}\text { Dummy title that can be used to describe the soil type and } \\
\text { indicate that what follows are water retention parameters }\end{array}$ \\
\hline 2 & $4 R$ & $\begin{array}{l}\text { THET,PSI } \\
\text { THET } \\
\text { PSID } \\
\text { PSIO } \\
\text { RLAM }\end{array}$ & $\begin{array}{l}\text { PSIO,RLAM, } \\
\text { Saturated water content (units: } \mathrm{cm}^{3} / \mathrm{cm}^{3} \text { ) } \\
\text { Suction head corresponding to zero water content (units: } \mathrm{cm} \text { ) } \\
\text { Curve-fitting parameter (units: } \mathrm{cm} \text { ) } \\
\text { Curve-fitting parameter (no units) }\end{array}$ \\
\hline 3 & $\bar{A}$ & $\begin{array}{l}\text { DUMMY, } \\
\text { DUMMY }\end{array}$ & $\begin{array}{l}\text { Dummy title that can be used to describe the soil type and } \\
\text { indicate that what follows are conductivity parameters }\end{array}$ \\
\hline
\end{tabular}




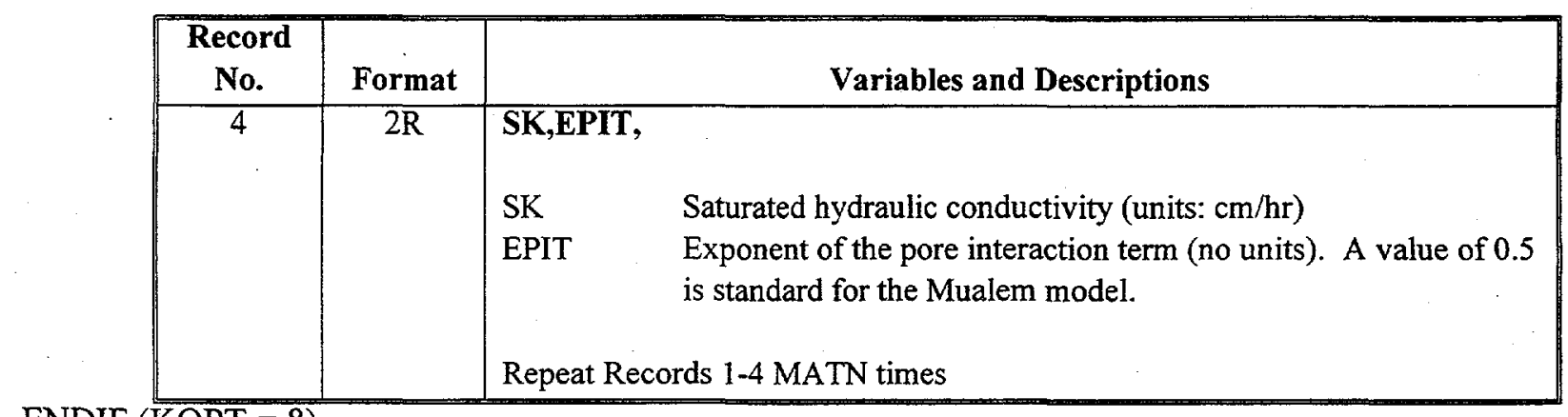

ENDIF $(\overline{\mathrm{KOPT}}=8)$

IF IHYS $=1$ (Hysteresis properties) THEN

\begin{tabular}{|c|c|c|c|}
\hline $\begin{array}{c}\text { Record } \\
\text { No. }\end{array}$ & Format & & Variables and Descriptions \\
\hline 1 & $\bar{A}$ & $\begin{array}{l}\text { DUMMY, } \\
\text { DUMMY }\end{array}$ & $\begin{array}{l}\text { Dummy title that can be used to describe the soil type and } \\
\text { indicate that what follows are soil-specific hysteresis parameters }\end{array}$ \\
\hline 2 & $\overline{\mathrm{I}, 3 \mathrm{R}}$ & $\begin{array}{l}\text { IPATHA,S } \\
\text { IPATHA } \\
\text { SARWA } \\
\text { ALFACT } \\
\text { HYSHPH } \\
\text { Repeat Rec }\end{array}$ & $\begin{array}{l}\text { RWA,ALFACT,HYSHPH, } \\
\text { Maximum number of hysteretic paths (suggested value =7) } \\
\text { Maximum entrapped air content (units: } \mathrm{cm}^{3} / \mathrm{cm}^{3} \text { ) } \\
\text { Factor that relates the imbibition } \alpha_{i} \text { to the desorption } \alpha_{d} \text {. } \\
\text { Typical value is } 2.0 \text {. The value must be greater than or equal to } \\
\alpha_{d} \text {. } \\
\text { Soil-specific maximum suction head above which hysteresis is } \\
\text { not operable (units: } \mathrm{cm} \text { ). If HYSHPH less than or equal to zero, } \\
\text { or greater than HYSMXH (the global limit), the HYSHPH value } \\
\text { for that material is reset to HYSMXH. } \\
\text { rds } 1-2 \text { MATN times }\end{array}$ \\
\hline
\end{tabular}

IF IHEAT $=1$ (Thermal properties) THEN

\begin{tabular}{|c|c|cc|}
\hline $\begin{array}{c}\text { Record } \\
\text { No. }\end{array}$ & Format & & \multicolumn{1}{c|}{ Variables and Descriptions } \\
\hline 1 & A & DUMMY, & \\
& DUMMY & $\begin{array}{l}\text { Dummy title that can be used to describe the soil type and } \\
\text { indicate that what follows are soil-specific thermal conductivity } \\
\text { and heat capacity parameters. Coefficients for the thermal } \\
\text { conductivity equation can be found in Cass et al. (1984). }\end{array}$ \\
\hline
\end{tabular}




\begin{tabular}{|c|c|c|c|}
\hline \multirow{2}{*}{$\begin{array}{c}\begin{array}{c}\text { Record } \\
\text { No. }\end{array} \\
2\end{array}$} & \multirow{2}{*}{$\frac{\text { Format }}{6 \mathrm{R}}$} & \multicolumn{2}{|r|}{ Variables and Descriptions } \\
\hline & & $\begin{array}{l}\text { TCON(1:5 } \\
\text { TCON(1) } \\
\text { TCON(2) } \\
\text { TCON(3) } \\
\text { TCON(4) } \\
\text { TCON(5) } \\
\text { CHS }\end{array}$ & $\begin{array}{l}\text { CHS, } \\
\text { Thermal conductivity }\left(k_{h}\right) \text { coefficient } a \text {, where } \\
\qquad k_{h}=a+b\left(\theta / \theta_{s}\right)+(a-d) \exp \left[-c\left(\theta / \theta_{s}\right)^{e}\right] \\
\text { Thermal conductivity coefficient } b \\
\text { Thermal conductivity coefficient } c \\
\text { Thermal conductivity coefficient } d \\
\text { Thermal conductivity coefficient } e \\
\text { Volumetric heat capacity of the soil particles (units: } \mathrm{J} \mathrm{cm}^{-3} \mathrm{~K}^{-1} \text { ) }\end{array}$ \\
\hline 3 & $\overline{\mathrm{A}}$ & $\begin{array}{l}\text { DUMMY, } \\
\text { DUMMY }\end{array}$ & $\begin{array}{l}\text { Dummy title that can be used to describe the soil type and } \\
\text { indicate that what follows are soil-specific parameters that } \\
\text { define the vapor flow enhancement factor. Coefficients for the } \\
\text { enhancement factor equation can be found in Cass et al. (1984) }\end{array}$ \\
\hline 4 & $5 \mathrm{R}$ & $\begin{array}{l}\text { EF(1:5), } \\
\text { EF(1) } \\
\text { EF(2) } \\
\text { EF(3) } \\
\text { EF(4) } \\
\text { EF(5) } \\
\text { Note: To a } \\
\text { coefficient } \\
\text { Repeat Rec }\end{array}$ & $\begin{array}{l}\text { Enhancement factor }(\eta) \text { coefficient } a \text {, where } \\
\qquad \eta=a+b\left(\theta / \theta_{s}\right)+(a-d) \exp \left[-c\left(\theta / \theta_{s}\right)^{e}\right] \\
\text { Enhancement factor coefficient } b \\
\text { Enhancement factor coefficient } c \\
\text { Enhancement factor coefficient } d \\
\text { Enhancement factor coefficient } e \\
\text { hieve an enhancement factor of } 1.0 \text { (i.e., no enhancement), set } \\
\text { to } 1.0 \text { and } b \text { through } e \text { to zero. } \\
\text { Ids } 1-4 \text { MATN times }\end{array}$ \\
\hline
\end{tabular}




\section{A.3 Initial Conditions}

\begin{tabular}{|c|c|c|c|}
\hline $\begin{array}{c}\text { Record } \\
\text { No. }\end{array}$ & Format & & Variables and Descriptions \\
\hline 1 & $\mathrm{I}$ & $\begin{array}{l}\text { NDAY, } \\
\text { NDAY }\end{array}$ & $\begin{array}{l}\text { Day for which end-of-day suction head values are specified as initial } \\
\text { conditions. For example, when NDAY }=0, \text { the initial head values are for } \\
\text { the end of the day before simulation day } 1 \text {. NDAY }=90 \text { would indicate } \\
\text { that the initial head values are from the end of day } 90 \text { and will serve as } \\
\text { initial head values for day } 91 .\end{array}$ \\
\hline 2 & $\begin{array}{c}4 \mathrm{R} \\
\text { per line }\end{array}$ & $\begin{array}{l}\mathbf{H}(\mathbf{1} \ldots \mathbf{N P T}) \\
\mathrm{H}\end{array}$ & $\begin{array}{l}\text { Initial suction head. Values must be less than or equal to HDRY when } \\
\text { IHEAT equals } 0 \text { (units: } \mathrm{cm} \text { ) }\end{array}$ \\
\hline
\end{tabular}

IF IHEAT $=1$

\begin{tabular}{|c|c|cc|}
\hline $\begin{array}{c}\text { Record } \\
\text { No. }\end{array}$ & Format & \multicolumn{1}{c|}{ Variables and Descriptions } \\
\hline 1 & $\begin{array}{c}4 \mathrm{R} \\
\text { per line }\end{array}$ & $\begin{array}{ll}\mathrm{T}(1 \ldots \mathrm{NPT}), \\
\mathrm{T}\end{array}$ & Initial soil temperature (units: $\mathrm{K})$ \\
\hline
\end{tabular}

ENDIF (IHEAT = 1) 


\section{A.4 Plant Information}

IF IPLANT $=1$ (plant parameters) THEN

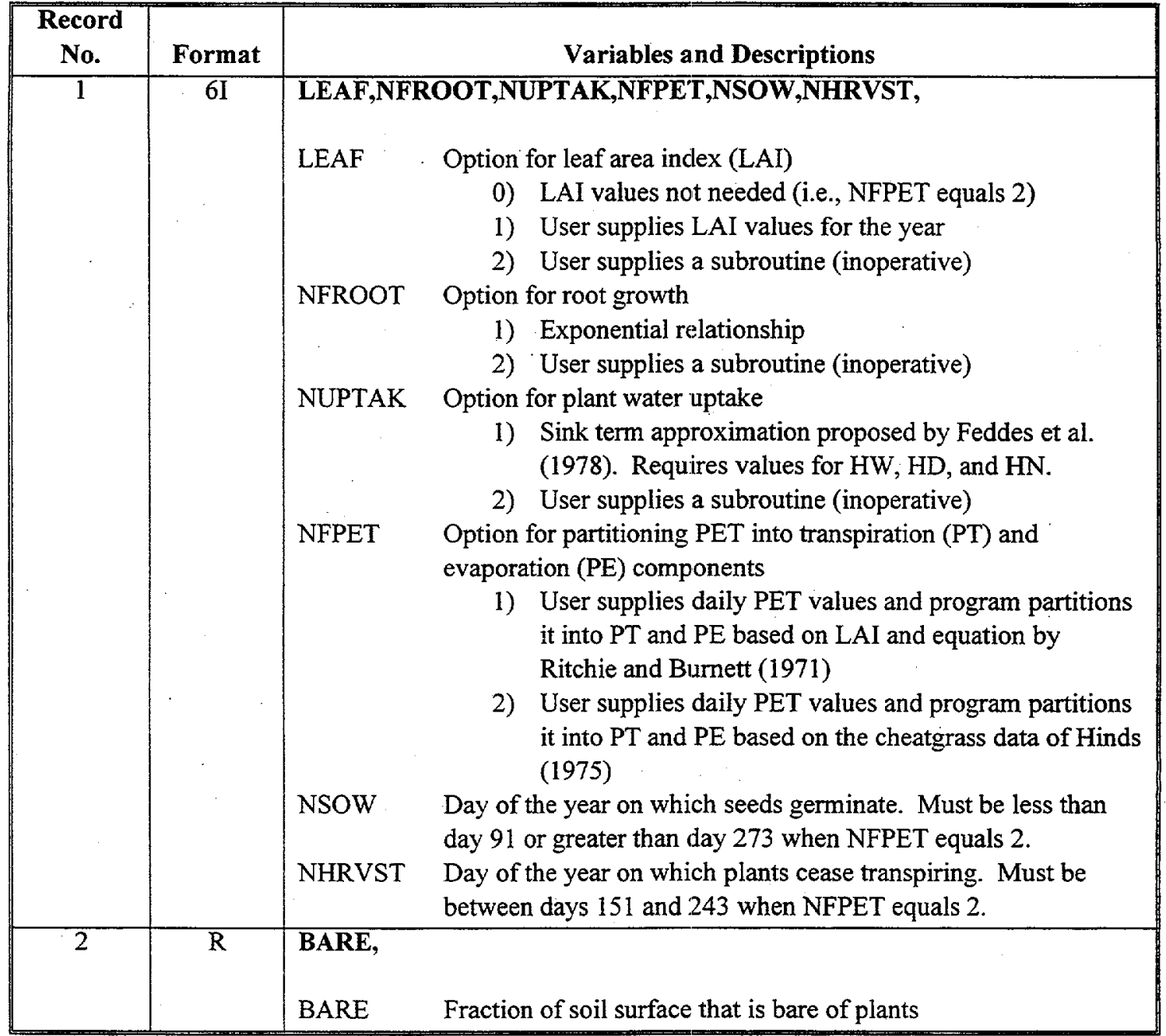

IF LEAF $=1$ (leaf area index)

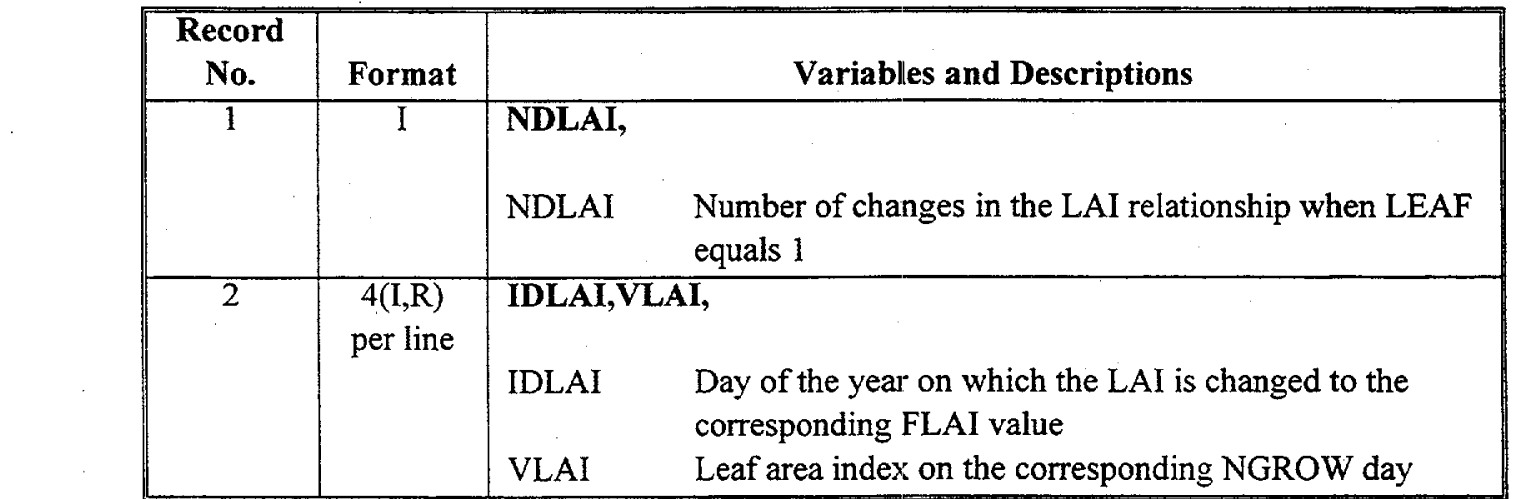

END (LEAF $=1)$ 
IF NFROOT $=1$ (root density and depth parameters)

\begin{tabular}{|c|c|lc|}
\hline $\begin{array}{c}\text { Record } \\
\text { No. }\end{array}$ & Format & \multicolumn{2}{c|}{ Variables and Descriptions } \\
\hline 1 & $3 \mathrm{R}$ & AA,B1,B2, \\
& & AA & $\begin{array}{c}\text { Coefficient } a \text { in the root growth equation } \\
\text { RLD }=a \text { exp(-bz)+c } \\
\text { Coefficient } b \text { in the root growth equation } \\
\text { Coefficient } c \text { in the root growth equation }\end{array}$ \\
\hline 2 & $\begin{array}{c}\text { B1 } \\
\text { per line }\end{array}$ & $\begin{array}{l}\text { NTROOT(1..NPT), } \\
\text { NTROOT } \\
\text { Growth day on which roots reach the corresponding } \\
\text { node }\end{array}$ \\
\hline
\end{tabular}

ENDIF (NFROOT $=1$ )

IF NUPTAK = 1 (plant water uptake parameters)

\begin{tabular}{|c|c|cc|}
\hline $\begin{array}{c}\text { Record } \\
\text { No. }\end{array}$ & Format & \multicolumn{1}{c|}{ Variables and Descriptions } \\
\hline 1 & $3 \mathrm{R}$ & HW,HD,HN, \\
& HW & $\begin{array}{l}\text { Head corresponding to water content below which } \\
\text { plants wilt and stop transpiring. HW must be less than } \\
\text { HDRY. (units: cm) }\end{array}$ \\
Head corresponding to water content below which plant \\
transpiration starts to decrease (units: cm) \\
Head corresponding to water content above which plants \\
do not transpire because of anaerobic conditions (units: \\
cm)
\end{tabular}

ENDIF (NUPTAK $=1$ )

IF NFPET $=1$ (partition PET using leaf area index)

\begin{tabular}{|c|c|cc|}
\hline $\begin{array}{c}\text { Record } \\
\text { No. }\end{array}$ & Format & \multicolumn{1}{c|}{ Variables and Descriptions } \\
\hline 1 & 5R & PETPC(1:5), & \\
& & PETPC(1) & $\begin{array}{l}\text { Coefficient } a \text { of Ritchie equation }(=a+b \text { LAI }) \text { (the } \\
\text { original values for } a, b \text {, and } c \text { were }-0.21,0.7, \text { and } 0.5 ; \\
\text { the new values, derived by Mark Ankeny from a re- } \\
\text { analysis of the original data, are } 0.0,0.52, \text { and 0.5) }\end{array}$ \\
& & PETPC(2) & $\begin{array}{l}\text { Coefficient } b \text { of Ritchie equation } \\
\end{array}$ \\
& & PETPC(3) & Coefficient $c$ of Ritchie equation \\
& PETPC(4) & Lower limit of Ritchie equation (original value was 0.1) \\
& PETPC(5) & Upper limit of Ritchie equation (original value was 2.7) \\
\hline
\end{tabular}


ELSE IF NFPET $=2$ (partition PET using cheatgrass algorithm)

\begin{tabular}{|c|c|cc|}
\hline $\begin{array}{c}\text { Record } \\
\text { No. }\end{array}$ & Format & \multicolumn{1}{c|}{ Variables and Descriptions } \\
\hline 1 & $\mathrm{R}$ & BIOMAS, & \\
& & BIOMAS & $\begin{array}{l}\text { Plant shoot biomass scaling factor used in adjusting the } \\
\text { transpiration component of PET. The base value is } \\
\end{array}$ \\
& & $\begin{array}{l}220 \mathrm{~g} / \mathrm{m}^{2} . \text { A lower value will result in lower } \\
\text { transpiration and higher evaporation, while a higher } \\
\text { value will result in higher transpiration and lower } \\
\text { evaporation }\left(\text { units: } \mathrm{g} / \mathrm{m}^{2}\right) .\end{array}$ \\
\hline
\end{tabular}

ENDIF (NFPET)

ENDIF (IPLANT $=1$ ) 


\section{A.5 Boundary Conditions}

IF $(($ IEVOPT $=1$ OR IPLANT $=1)$ and IHEAT $=0)$ THEN

IF $($ NFHOUR $=1)$ THEN

\begin{tabular}{|c|c|cc|}
\hline $\begin{array}{c}\text { Record } \\
\text { No. }\end{array}$ & Format & \multicolumn{1}{c|}{ Variables and Descriptions } \\
\hline 1 & $\begin{array}{c}8 \mathrm{R} \\
\text { per line }\end{array}$ & FPET(1:24), \\
& FPET & $\begin{array}{l}\text { Hourly PET distribution factors. The 24 FPET factors } \\
\text { must sum to } 1.0\end{array}$ \\
& Note: Repeat Record 1 three times \\
\hline
\end{tabular}

ENDIF

\section{ENDIF}

IF IETOPT $=1$ (Meteorological parameters)

IF IHEAT $=0$ (isothermal) THEN

\begin{tabular}{|c|c|ll|}
\hline $\begin{array}{c}\text { Record } \\
\text { No. }\end{array}$ & Format & \multicolumn{1}{c|}{ Variables and Descriptions } \\
\hline 1 & $4 \mathrm{R}$ & ALBEDO,ALT,ZU,PMB, \\
& & ALBEDO & Potential evapotranspiration (units: cm/day) \\
& & ALT & Altitude of the site being simulated (units: m) \\
& & ZU & Height of the wind speed measurement (units: $\mathrm{m}$ ) \\
& & PMB & Average annual atmospheric pressure (units: $\mathrm{mb}$ ) \\
\hline
\end{tabular}

ELSE IF IHEAT =1 (thermal) THEN

\begin{tabular}{|c|c|ll|}
\hline $\begin{array}{c}\text { Record } \\
\text { No. }\end{array}$ & Format & \multicolumn{1}{c|}{ Variables and Descriptions } \\
\hline 1 & $4 \mathrm{R}$ & ZH,ZM,ZT,ZU,D,LAT, \\
& & & \\
& & ZH & Roughness length for heat transfer (units: m) \\
& & ZM & Roughness length for momentum transfer (units: m) \\
& ZT & Height of air temperature measurement (units: m) \\
& ZU & Height of the wind speed measurement (units: m) \\
& D & Zero plane displacement height (units: m) \\
& & LAT & Latitude of the site being simulated (units: degrees) \\
\hline
\end{tabular}

ENDIF

ENDIF (IETOPT $=1$ ) 
IF LOWER $=3$ (Lower boundary condition specified fluxes) THEN

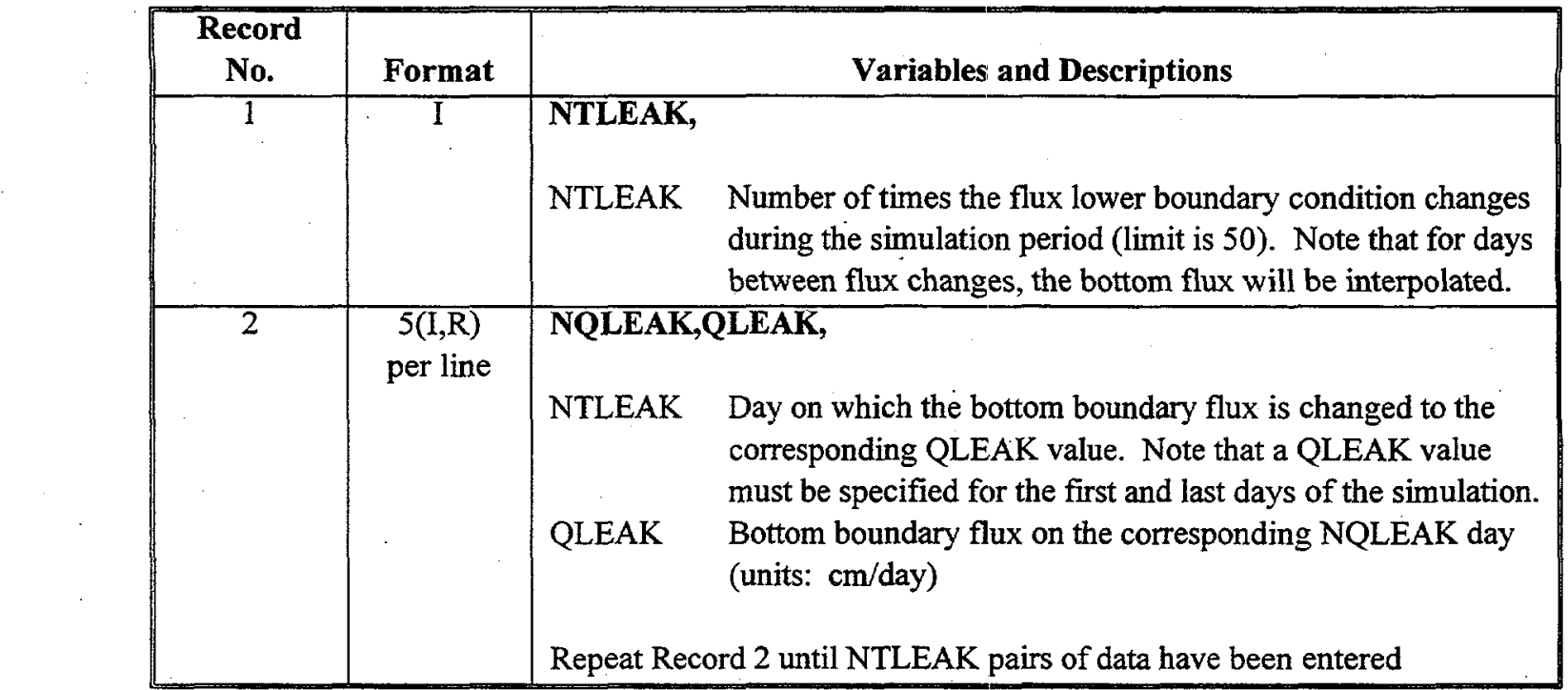

ENDIF (LOWER = 3)

IF LOWER $=5$ (Lower boundary condition specified head) THEN

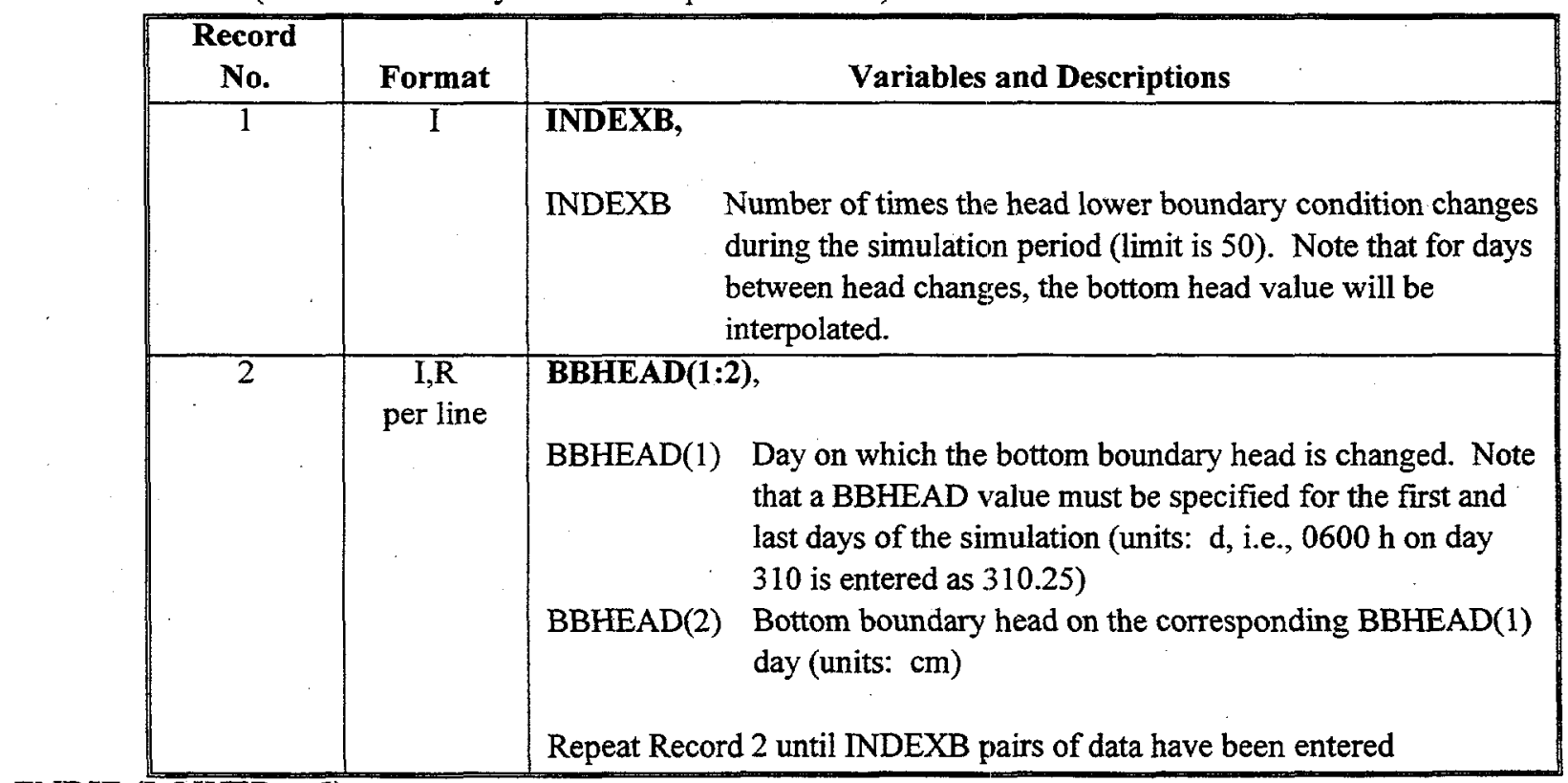

ENDIF (LOWER $=5$ ) 
IF IFLIST $=0$ (meteorological data included with input file) THEN

IF IETOPT $=0$ (PET values) $\mathrm{THEN}$

\begin{tabular}{|c|c|lc|}
\hline $\begin{array}{c}\text { Record } \\
\text { No. }\end{array}$ & Format & \multicolumn{2}{|c|}{ Variables and Descriptions } \\
\hline 1 & $\begin{array}{c}\text { 8R } \\
\text { per line }\end{array}$ & $\begin{array}{l}\text { PET(1:IDEND), } \\
\text { PET }\end{array}$ & Potential evapotranspiration (units: $\mathrm{cm} / \mathrm{day})$ \\
\hline
\end{tabular}

ELSE IF IETOPT $=1$ (daily meteorological data) THEN

\begin{tabular}{|c|c|c|c|}
\hline $\begin{array}{c}\text { Record } \\
\text { No. }\end{array}$ & Format & & Variables and Descriptions \\
\hline 1 & $8 \mathrm{R}$ & $\begin{array}{l}\text { MEDAT(1:8), } \\
\operatorname{RMDATA}(1, \mathrm{~J}) \\
\operatorname{RMDATA}(2, \mathrm{~J}) \\
\operatorname{RMDATA}(3, \mathrm{~J}) \\
\operatorname{RMDATA}(4, \mathrm{~J}) \\
\operatorname{RMDATA}(5, \mathrm{~J}) \\
\operatorname{RMDATA}(6, \mathrm{~J}) \\
\operatorname{RMDATA}(7, \mathrm{~J}) \\
\operatorname{RMDATA}(8, \mathrm{~J}) \\
\\
\operatorname{Reneat} \operatorname{Record}\end{array}$ & $\begin{array}{l}\text { Day of the year for which the following data } \\
\text { apply } \\
\text { Maximum air temperature (units: }{ }^{\circ} \mathrm{F} \text { ) } \\
\text { Minimum air temperature (units: }{ }^{\circ} \mathrm{F} \text { ) } \\
\text { Dew point temperature (units: }{ }^{\circ} \mathrm{F} \text { ) } \\
\text { Solar radiation (units: langleys) } \\
\text { Average wind speed (units: miles/hr) } \\
\text { Average cloud cover (units: tenths) } \\
\text { Precipitation (units: inches) }\end{array}$ \\
\hline
\end{tabular}

ENDIF

IF $($ IRAIN $=0)$ THEN

\begin{tabular}{|c|c|c|c|}
\hline $\begin{array}{c}\text { Record } \\
\text { No. }\end{array}$ & Format & & Variables and Descriptions \\
\hline 1 & $\mathrm{I}$ & $\begin{array}{l}\text { NWATER, } \\
\text { NWATER }\end{array}$ & $\begin{array}{l}\text { Total number of days during which there is water } \\
\text { application }\end{array}$ \\
\hline$\overline{2}$ & $3 \mathrm{I}, \mathrm{R}$ & $\begin{array}{l}\text { IRDAY,IR] } \\
\text { IRDAY } \\
\text { IRTYPE } \\
\text { NP } \\
\text { EFICEN }\end{array}$ & $\begin{array}{l}\text { YPE,NP,EFICEN, } \\
\text { Day on which a water application event occurs } \\
\text { Option for type of water application } \\
\text { 1) rainfall } \\
\text { 2) irrigation } \\
\text { 3) constant ponding depth less than } 1 \text { day } \\
\text { 4) constant ponding depth greater than } 1 \text { day } \\
\text { Number of times during the day that the water } \\
\text { application rate changes } \\
\text { Efficiency of the irrigation scheme (i.e., how much of } \\
\text { the water actually gets onto the soil surface) }\end{array}$ \\
\hline
\end{tabular}




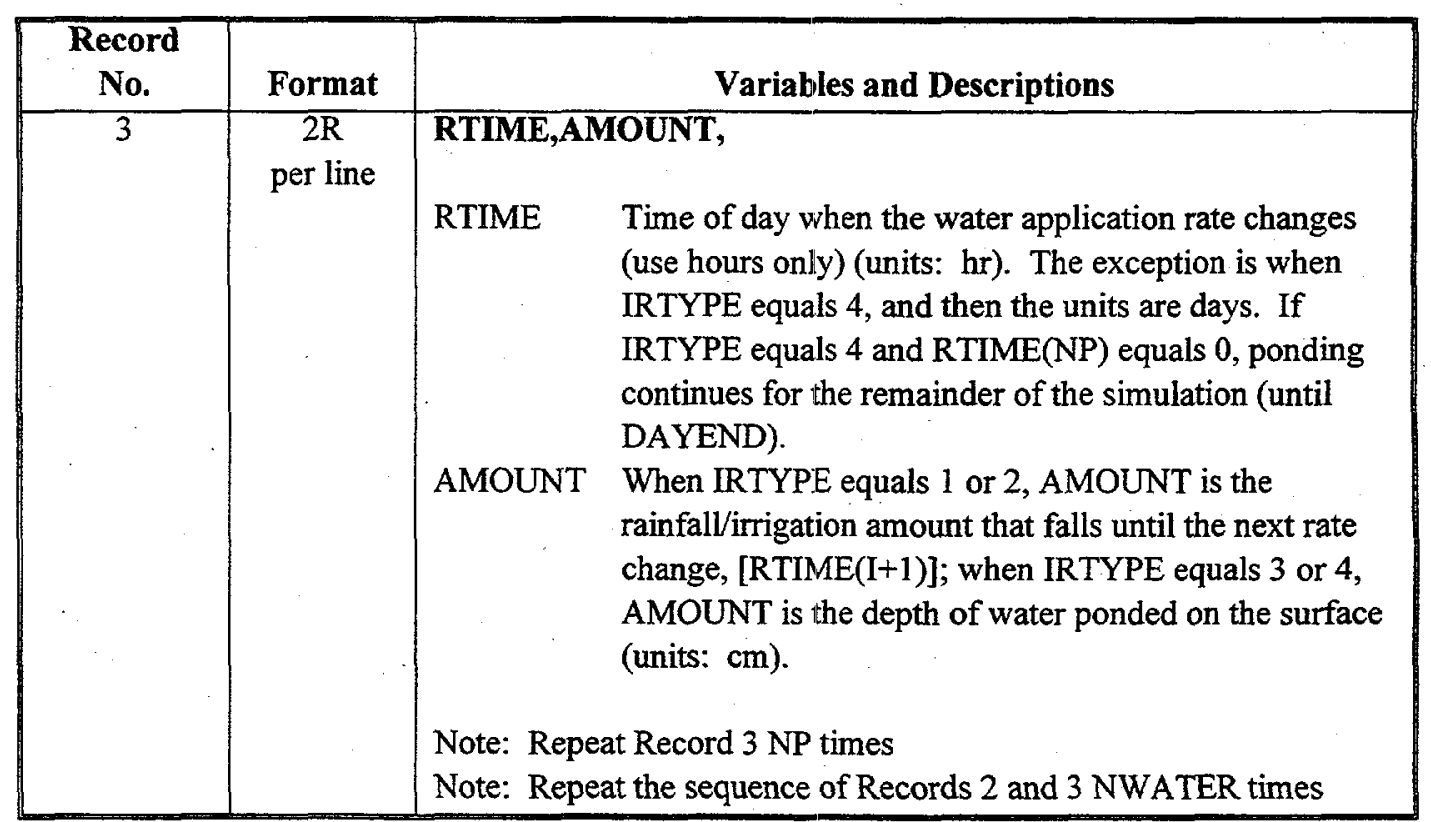

ENDIF (IRAIN $=0$ )

ELSE IF IFLIST = 1 (meteorological data in separate files; filenames provided in input file) THEN

\begin{tabular}{|c|c|c|c|}
\hline $\begin{array}{c}\text { Record } \\
\text { No. }\end{array}$ & Format & & Variables and Descriptions \\
\hline 1 & $\bar{A}$ & $\begin{array}{l}\text { DIRLOC, } \\
\text { DIRLOC }\end{array}$ & $\begin{array}{l}\text { Directory name within which resides the files } \\
\text { containing PET or meteorological data. The file names } \\
\text { similar except for their year designation (e.g., } \\
\text { filpre9999.dat) }\end{array}$ \\
\hline 2 & $\overline{\mathrm{A}}$ & $\begin{array}{l}\text { FחLPRE, } \\
\text { FILPRE }\end{array}$ & Common filename prefix (e.g., filpre9999.dat) \\
\hline 3 & $\mathrm{~A}$ & $\begin{array}{l}\text { FILEXT, } \\
\text { FILEXT }\end{array}$ & Common filename extension (e.g., filpre9999.dat) \\
\hline
\end{tabular}

IF IRAIN $=0$ (precipitation data provided separate from meteorological data)

\begin{tabular}{|c|c|ll|}
\hline $\begin{array}{c}\text { Record } \\
\text { No. }\end{array}$ & Format & \multicolumn{1}{c|}{ Variables and Descriptions } \\
\hline 1 & A & DIRLOC, & \\
& & DIRLOC & $\begin{array}{l}\text { Directory name within which resides the files } \\
\text { containing precipitation data. The file names similar } \\
\text { except for their year designation (e.g., filpre9999.dat) }\end{array}$ \\
\hline 2 & A & FILPRE, & \\
& & FILPRE & Common filename prefix (e.g., filpre9999.dat) \\
\hline
\end{tabular}




\begin{tabular}{|c|c|cc|}
\hline $\begin{array}{c}\text { Record } \\
\text { No. }\end{array}$ & Format & \multicolumn{1}{c|}{ Variables and Descriptions } \\
\hline 3 & A & FILEXT, & \\
& & FILEXT $\quad$ Common filename extension (e.g., filpre9999.dat) \\
\hline
\end{tabular}

ENDIF (IRAIN $=0$ )

ELSE IF IFLIST $=2$ (meteorological data in separate files; filenames provided in input file) THEN

\begin{tabular}{|c|c|cc|}
\hline $\begin{array}{c}\text { Record } \\
\text { No. }\end{array}$ & Format & \multicolumn{1}{c|}{ Variables and Descriptions } \\
\hline 1 & A & PMFN, & \\
& & PMFN & $\begin{array}{l}\text { Filename containing PET or meteorological data for first } \\
\text { year of multiyear simulation }\end{array}$ \\
& Note: Repeat Record 1 NYEARS times \\
\hline
\end{tabular}

IF (IRAIN $=0)$

\begin{tabular}{|c|c|c|}
\hline $\begin{array}{c}\text { Record } \\
\text { No. }\end{array}$ & Format & Variables and Descriptions \\
\hline$\overline{2}$ & A & $\begin{array}{l}\text { (if IRAIN=0) } \\
\text { PRFN, } \\
\text { PRFN } \quad \begin{array}{l}\text { Filename containing precipitation data for first year of } \\
\text { multiyear simulation }\end{array} \\
\text { Note: }\end{array}$ \\
\hline
\end{tabular}

ENDIF (IRANN $=0)$

ELSE IF IFLIST $=3$ (meteorological data in separate files; filenames provided in separate file) THEN

\begin{tabular}{|c|c|cc|}
\hline $\begin{array}{c}\text { Record } \\
\text { No. }\end{array}$ & Format & \multicolumn{1}{c|}{ Variables and Descriptions } \\
\hline 1 & A & FNAMEL, & \\
& FNAMEL & $\begin{array}{l}\text { Filename containing PET or meteorological data filenames } \\
\text { followed by precipitation filenames (if IRAIN=0) using the } \\
\text { same format as when IFLIST=1 }\end{array}$ \\
\hline
\end{tabular}

ENDIF (IFLIST) 


\section{A.6 References}

Burdine NT. 1953. "Relative permeability calculation from size distribution data." Petr. Trans., Am. Inst. Mining Metall. Eng. 198:71-77.

Cass A., GS Campbell, and TL Jones. 1984. "Enhancement of thermal water vapor diffusion in soil." Soil Sci. Soc. Am. J. 48:25-32.

Celia MA, ET Bouloutas, and RL Zarba. 1990. "A general mass-conservative numerical solution for the unsaturated flow equation." Water Resour. Res. 26:1483-1496.

Corey AT. 1977. Mechanics of Heterogeneous Fluids in Porous Media. Water Resources Publications, Fort Collins, Colorado.

Fayer MJ and CS Simmons. 1995. "Modified soil water retention functions for all matric suctions," Water Resour. Res. 31:1233-1238.

Feddes RA, PJ Kowalik, and H Zaradny. 1978. Simulation of Field Water Use and Crop Yield. John Wiley and Sons, Inc., New York.

Haverkamp R, M Vaclin, J Touma, PJ Wierenga, and G Vachaud. 1977. "A comparison of numerical simulation models for one-dimensional infiltration." Soil Sci. Soc. Am. J. 41:285-294.

Hinds WT. 1975. "Energy and carbon balances in cheatgrass: An essay in autecology." Ecological Monogr. 45:367-388.

Lenhard RJ, JC Parker, and JJ Kaluarachchi. 1991. "Comparing simulated and experimental hysteretic two-phase transient fluid flow phenomena." Water Resour. Res. 27:2113-2124.

Mualem Y. 1976. "A new model for predicting the hydraulic conductivity of unsaturated porous media." Water Resour. Res. 12(3):513-522.

Ritchie JT, and E Burnett. 1971. "Dryland evaporative flux in a subhumid climate, 2, plant influences." Agron. J. 63:56-62.

Rossi C and JR Nimmo. 1994. "Modeling of soil water retention from saturation to oven dryness." Water Resour. Res. 30, 701-708.

van Genuchten R. 1978. Calculating the unsaturated hydraulic conductivity with a new closed-form analytical model. Water Resource Program, Department of Civil Engineering, Princeton University, Princeton, New Jersey. 


\section{Appendix B}

\section{Input and Output Files for Example Simulations}




\section{Appendix B}

\section{Input and Output Files for Example Simulations}

Figure B.1. Input File for Clay Infiltration Simulation

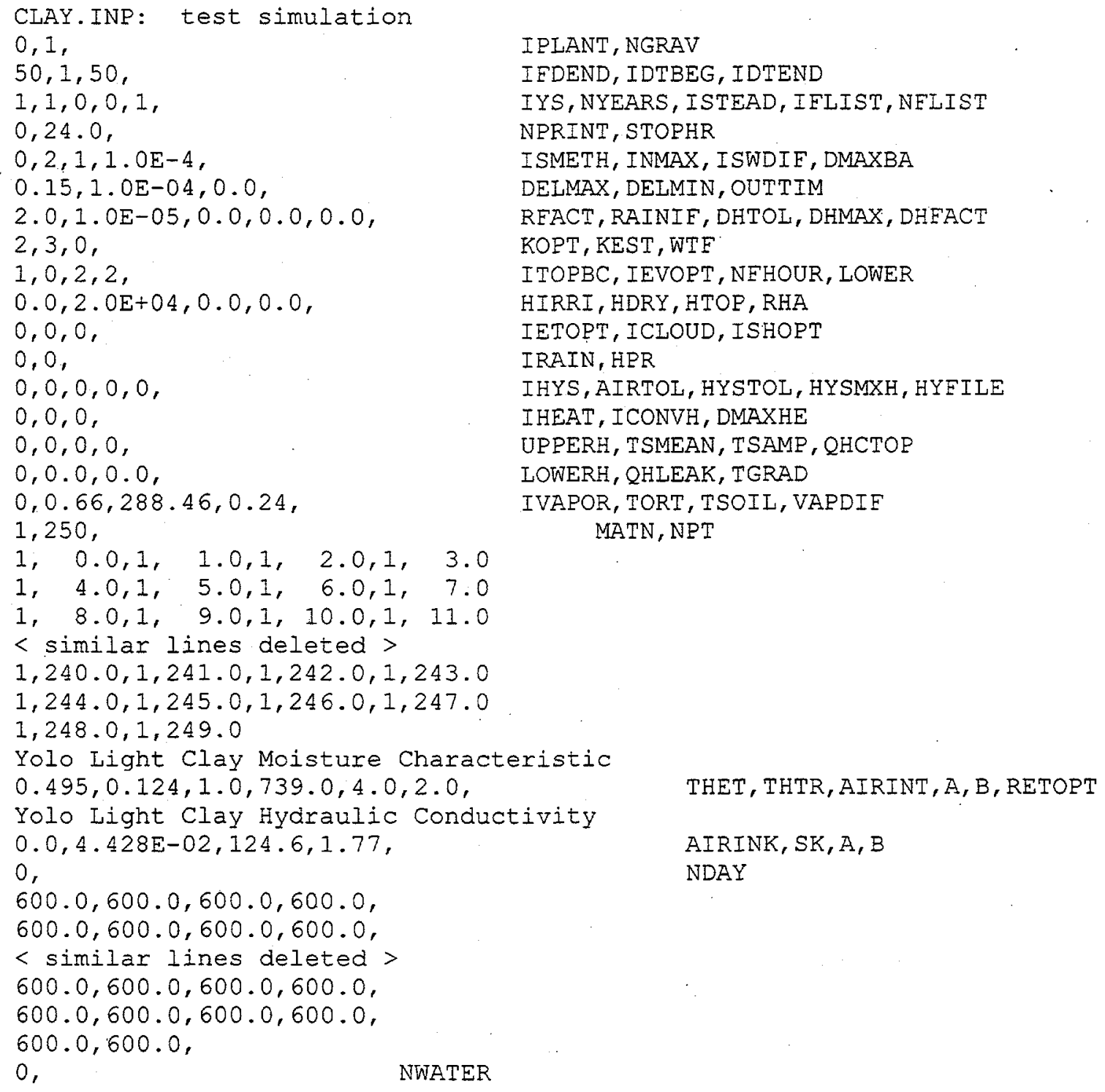


Figure B.2. Input File for Sand Infiltration Simulation

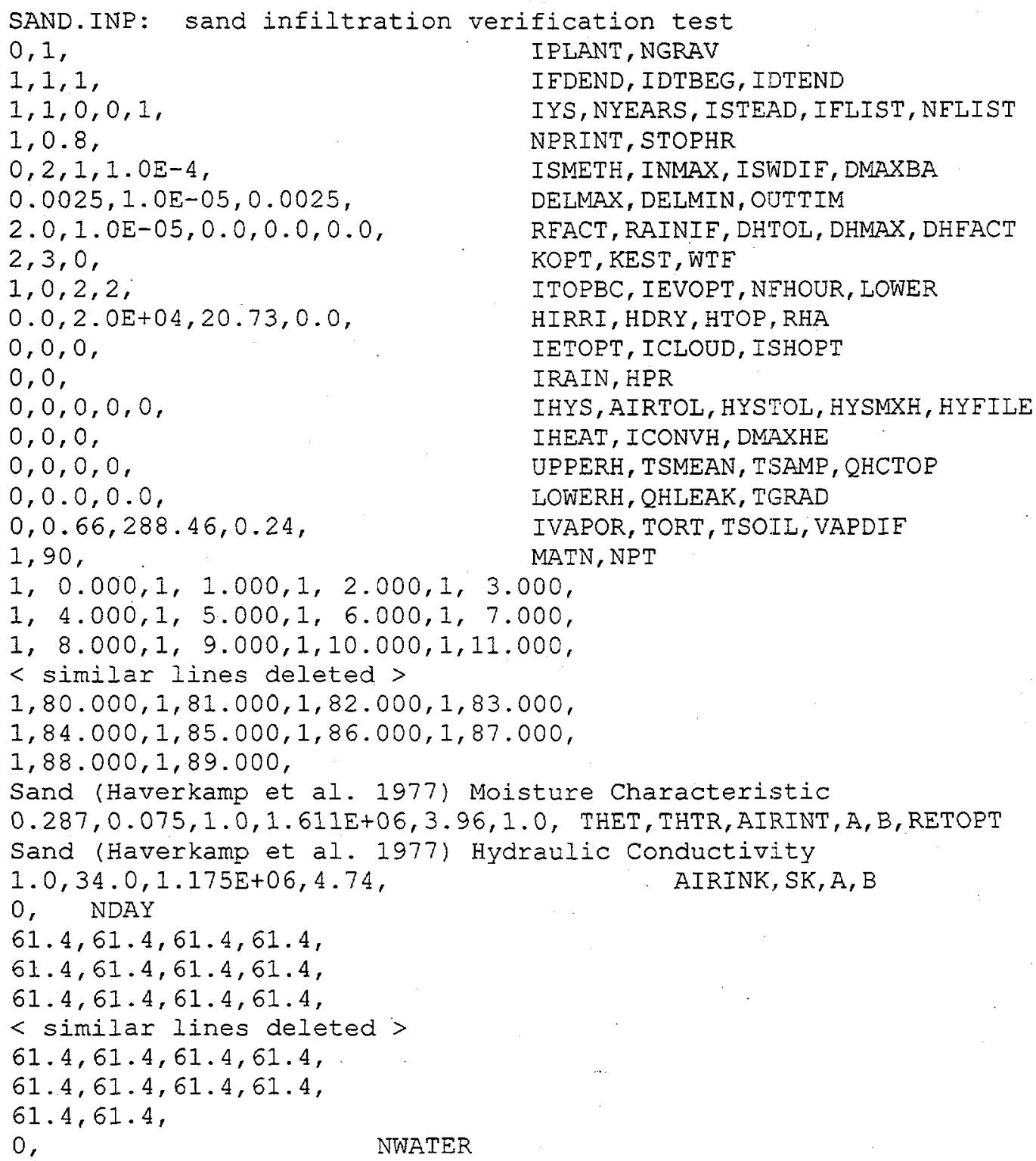


Figure B.3. Output File for Clay Infiltration Simulation

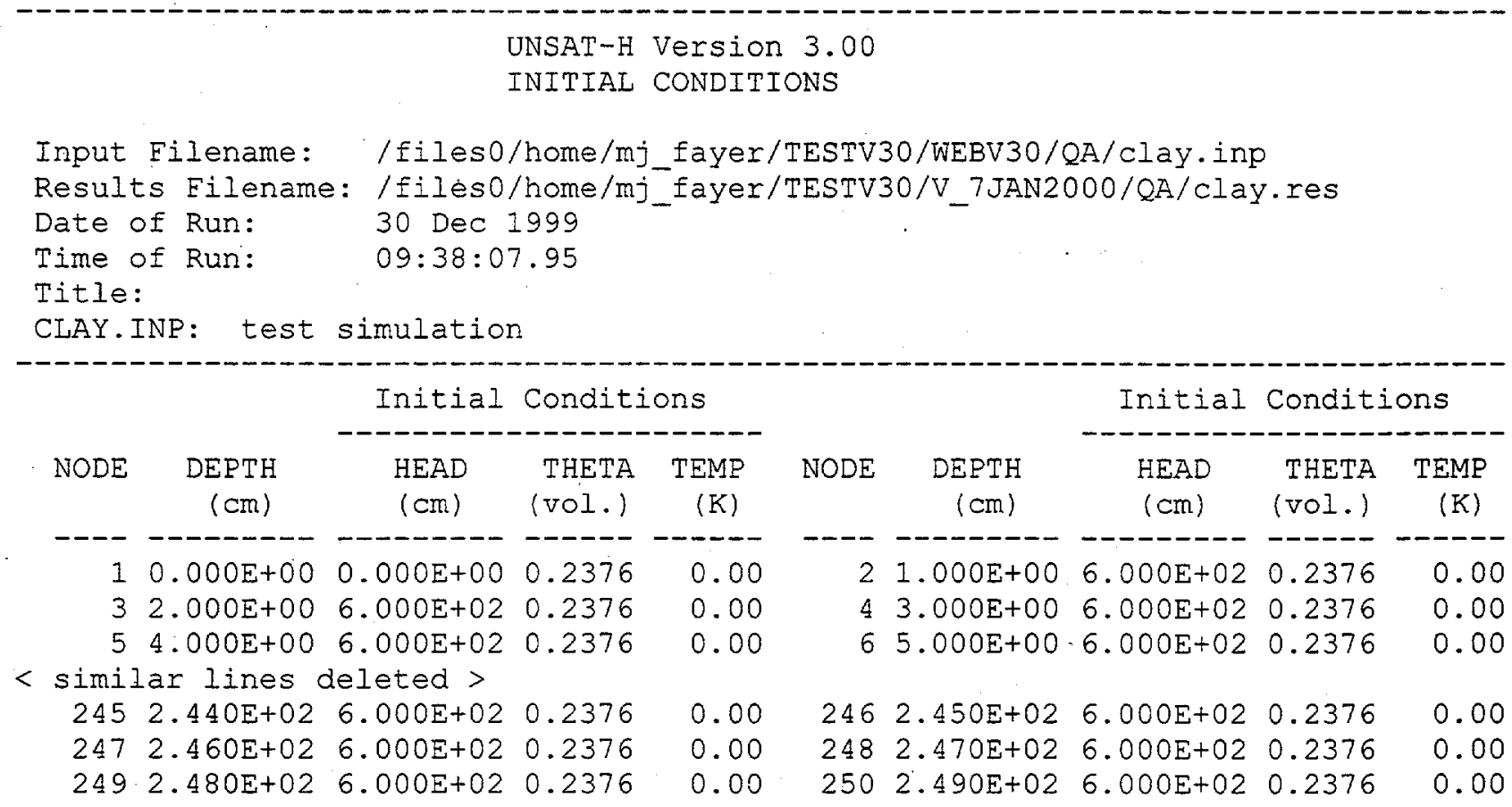

Initial Water Storage $=59.1619 \mathrm{~cm}$

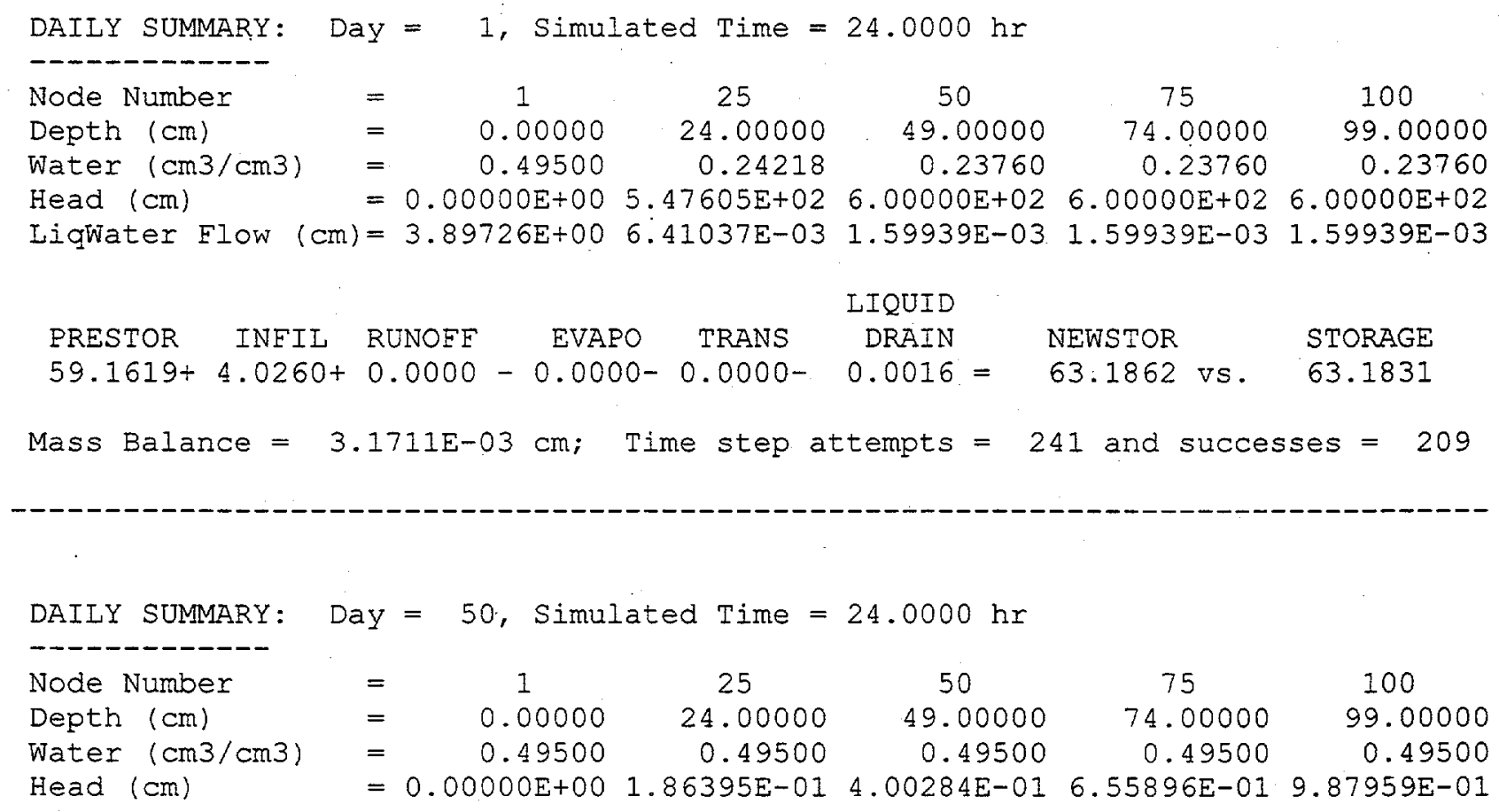


LiqWater Flow $(\mathrm{cm})=1.07098 \mathrm{E}+00 \quad 1.07098 \mathrm{E}+00 \quad 1.07098 \mathrm{E}+00 \quad 1.07098 \mathrm{E}+00 \quad 1.07098 \mathrm{E}+00$

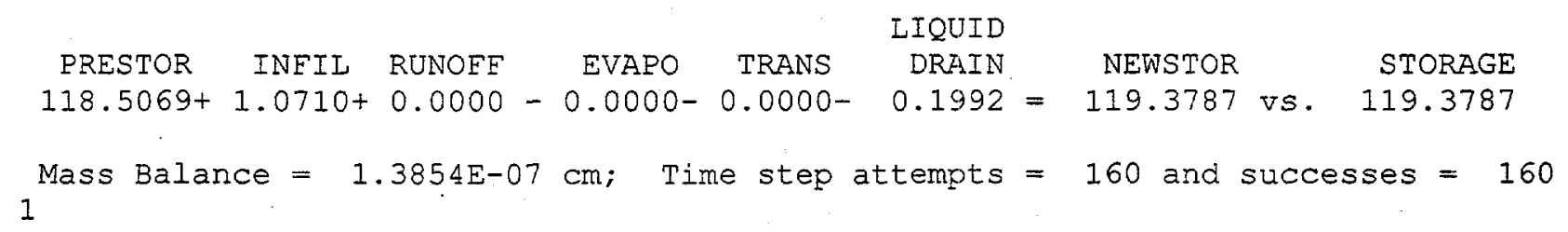

UNSAT-H Version 3.00

SIMULATION SUMMARY

Title:

CLAY.INP: test simulation

$\begin{array}{llll} & & & \\ \text { Transpiration Scheme is: } & 0 & & \\ \text { Potential Evapotranspiration } & =0.0000 E+00 & {[\mathrm{~cm}]} \\ \text { Potential Transpiration } & =0.0000 \mathrm{E}+00 & {[\mathrm{~cm}]} \\ \text { Actual Transpiration } & =0.0000 \mathrm{E}+00 & {[\mathrm{~cm}]} \\ \text { Potential Evaporation } & =0.0000 \mathrm{E}+00 & {[\mathrm{~cm}]} \\ \text { Actual Evaporation } & =0.0000 \mathrm{E}+00 & {[\mathrm{~cm}]} \\ \text { Evaporation during Growth } & =0.0000 \mathrm{E}+00 & {[\mathrm{~cm}]} \\ \text { Total Runoff } & =0.0000 \mathrm{E}+00 & {[\mathrm{~cm}]} \\ \text { Total Infiltration } & =6.0668 \mathrm{E}+01 & {[\mathrm{~cm}]} \\ \text { Total Basal Liquid Flux (drainage) } & =4.4794 \mathrm{E}-01 & {[\mathrm{~cm}]} \\ \text { Total Basal Vapor Elux (temp-grad) } & =0.0000 \mathrm{E}+00 & {[\mathrm{~cm}]} \\ \text { Total Applied Water } & =0.0000 \mathrm{E}+00 & {[\mathrm{~cm}]} \\ \text { Actual Rainfall } & =0.0000 \mathrm{E}+00 & {[\mathrm{~cm}]} \\ \text { Actual Irrigation } & =0.0000 \mathrm{E}+00 & {[\mathrm{~cm}]} \\ \text { Total Final Moisture Storage } & =1.1938 \mathrm{E}+02 & {[\mathrm{~cm}]} \\ \text { Mass Balance Error } & =3.2592 \mathrm{E}-03 & {[\mathrm{~cm}]} \\ \text { Total Successful Time Steps } & = & 8049 & \\ \text { Total Attempted Time Steps. } & = & 8081 & \\ \text { Total Time Step Reductions (DHMAX) } & = & 0 & \\ \text { Total Changes in Surface Boundary } & = & 0 & \\ \text { Total Time Actually Simulated } & =5.0000 \mathrm{E}+01 & {[\mathrm{days}]}\end{array}$

Total liquid water flow $(\mathrm{cm})$ across different depths at the end of $5.0000 \mathrm{E}+01$ days:

\begin{tabular}{rrrrrr} 
DEPTH & FLOW & \multicolumn{1}{c}{ DEPTH } & \multicolumn{1}{c}{ FLOW } & DEPTH & FLOW \\
\hline 0.000 & $6.0668 \mathrm{E}+01$ & 0.500 & $6.0539 \mathrm{E}+01$ & 1.500 & $6.0281 \mathrm{E}+01$ \\
2.500 & $6.0023 \mathrm{E}+01$ & 3.500 & $5.9765 \mathrm{E}+01$ & 4.500 & $5.9507 \mathrm{E}+01$ \\
5.500 & $5.9250 \mathrm{E}+01$ & 6.500 & $5.8992 \mathrm{E}+01$ & 7.500 & $5.8735 \mathrm{E}+01$ \\
imilar Iines deleted > & & & & \\
242.500 & $7.0315 \mathrm{E}-01$ & 243.500 & $6.3209 \mathrm{E}-01$ & 244.500 & $5.7219 \mathrm{E}-01$ \\
245.500 & $5.2359 \mathrm{E}-01$ & 246.500 & $4.8645 \mathrm{E}-01$ & 247.500 & $4.6106 \mathrm{E}-01$ \\
248.500 & $4.4794 \mathrm{E}-01$ & 249.000 & $4.4794 \mathrm{E}-01$ & &
\end{tabular}

B.4 
Figure B.4. Output File for Sand Infiltration Simulation

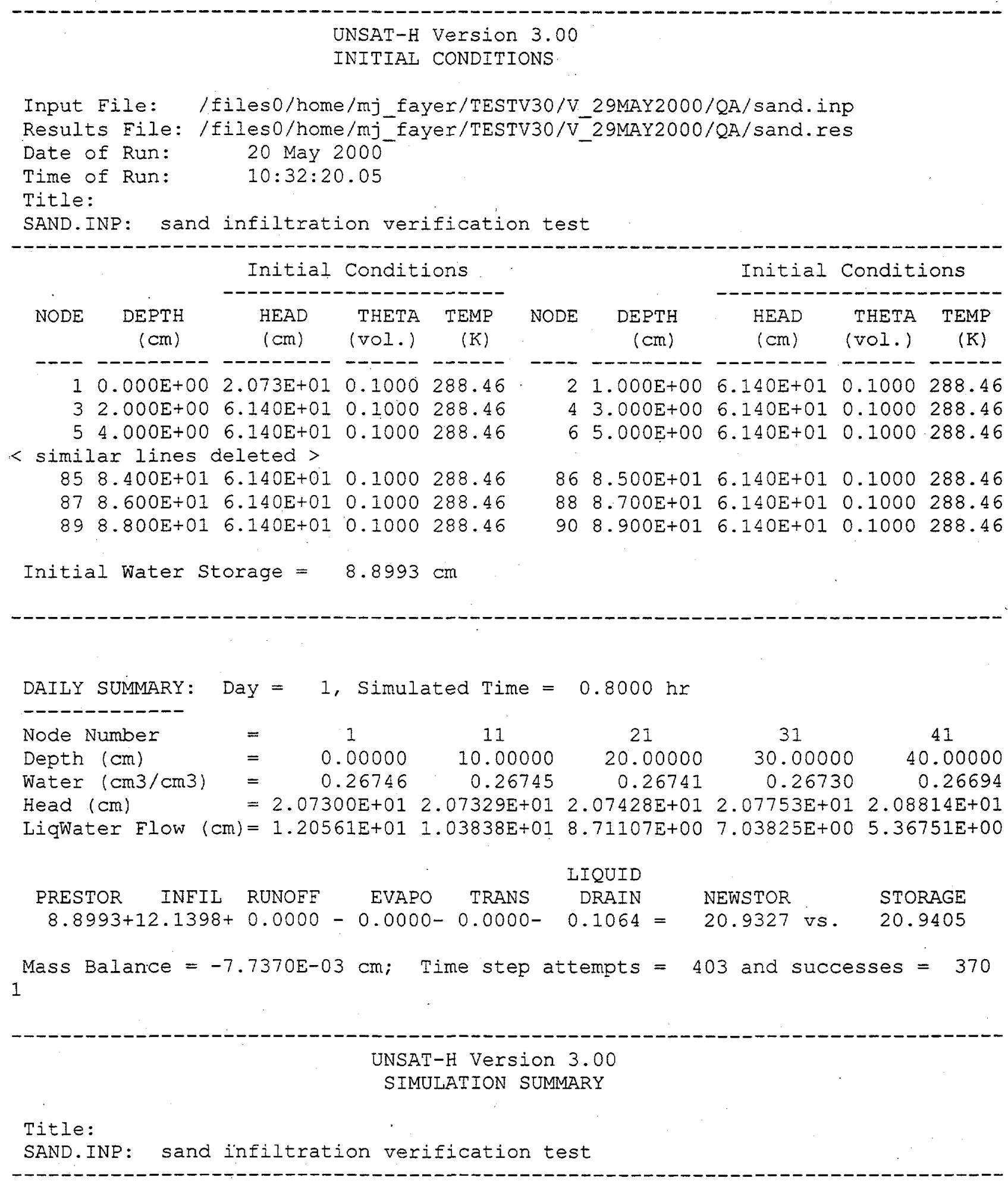




$\begin{array}{llcl}\text { Transpiration Scheme is: } & =0 & \\ \text { Potential Evapotranspiration } & =0.0000 E+00 & {[\mathrm{~cm}]} \\ \text { Potential Transpiration } & =0.0000 \mathrm{E}+00 & {[\mathrm{~cm}]} \\ \text { Actual Transpiration } & =0.0000 \mathrm{E}+00 & {[\mathrm{~cm}]} \\ \text { Potential Evaporation } & =0.0000 \mathrm{E}+00 & {[\mathrm{~cm}]} \\ \text { Actual Evaporation } & =0.0000 \mathrm{E}+00 & {[\mathrm{~cm}]} \\ \text { Evaporation during Growth } & =0.0000 \mathrm{E}+00 & {[\mathrm{~cm}]} \\ \text { Total Runoff } & =0.0000 \mathrm{E}+00 & {[\mathrm{~cm}]} \\ \text { Total Infiltration } & =1.2140 \mathrm{E}+01 & {[\mathrm{~cm}]} \\ \text { Total Basal Iiquid Flux (drainage) } & =1.0642 \mathrm{E}-01 & {[\mathrm{~cm}]} \\ \text { Total Basal Vapor Elux (temp-grad) } & =0.0000 \mathrm{E}+00 & {[\mathrm{~cm}]} \\ \text { Total Applied Water } & =0.0000 \mathrm{E}+00 & {[\mathrm{~cm}]} \\ \text { Actual Rainfall } & =0.0000 \mathrm{E}+00 & {[\mathrm{~cm}]} \\ \text { Actual Irrigation } & =0.0000 \mathrm{E}+00 & {[\mathrm{~cm}]} \\ \text { Total Einal Moisture Storage } & =2.0940 \mathrm{E}+01 & {[\mathrm{~cm}]} \\ \text { Mass Balance Error } & =-7.7370 \mathrm{E}-0.3 & {[\mathrm{~cm}]} \\ \text { Total Successful Time Steps } & = & 370 & \\ \text { Total Attempted Time Steps } & = & 403 & \\ \text { Total Time Step Reductions (DHMAX) } & = & 0 & \\ \text { Total Changes in Surface Boundary } & = & 0 & \\ \text { Total Time Actually Simulated } & =3.3333 \mathrm{E}-02 & {[\mathrm{days}]}\end{array}$

Total liquid water flow $(\mathrm{cm})$ across different depths at the end of $3.3333 \mathrm{E}-02$ days:

\begin{tabular}{rrrrrr} 
DEPTH & FLOW & \multicolumn{1}{c}{ DEPTH } & FLOW & DEPTH & FLOW \\
\hline 0.000 & $1.2140 \mathrm{E}+01$ & 0.500 & $1.2056 \mathrm{E}+01$ & 1.500 & $1.1889 \mathrm{E}+01$ \\
2.500 & $1.1722 \mathrm{E}+01$ & 3.500 & $1.1554 \mathrm{E}+01$ & 4.500 & $1.1387 \mathrm{E}+01$ \\
5.500 & $1.1220 \mathrm{E}+01$ & 6.500 & $1.1053 \mathrm{E}+01$ & 7.500 & $1.0886 \mathrm{E}+01$ \\
imilar lines deleted $>$ & & & & \\
83.500 & $1.0656 \mathrm{E}-01$ & 84.500 & $1.0648 \mathrm{E}-01$ & 85.500 & $1.0644 \mathrm{E}-01$ \\
86.500 & $1.0643 \mathrm{E}-01$ & 87.500 & $1.0642 \mathrm{E}-01$ & 88.500 & $1.0642 \mathrm{E}-01$
\end{tabular}


Figure B.5. Input File for Drainage Simulation

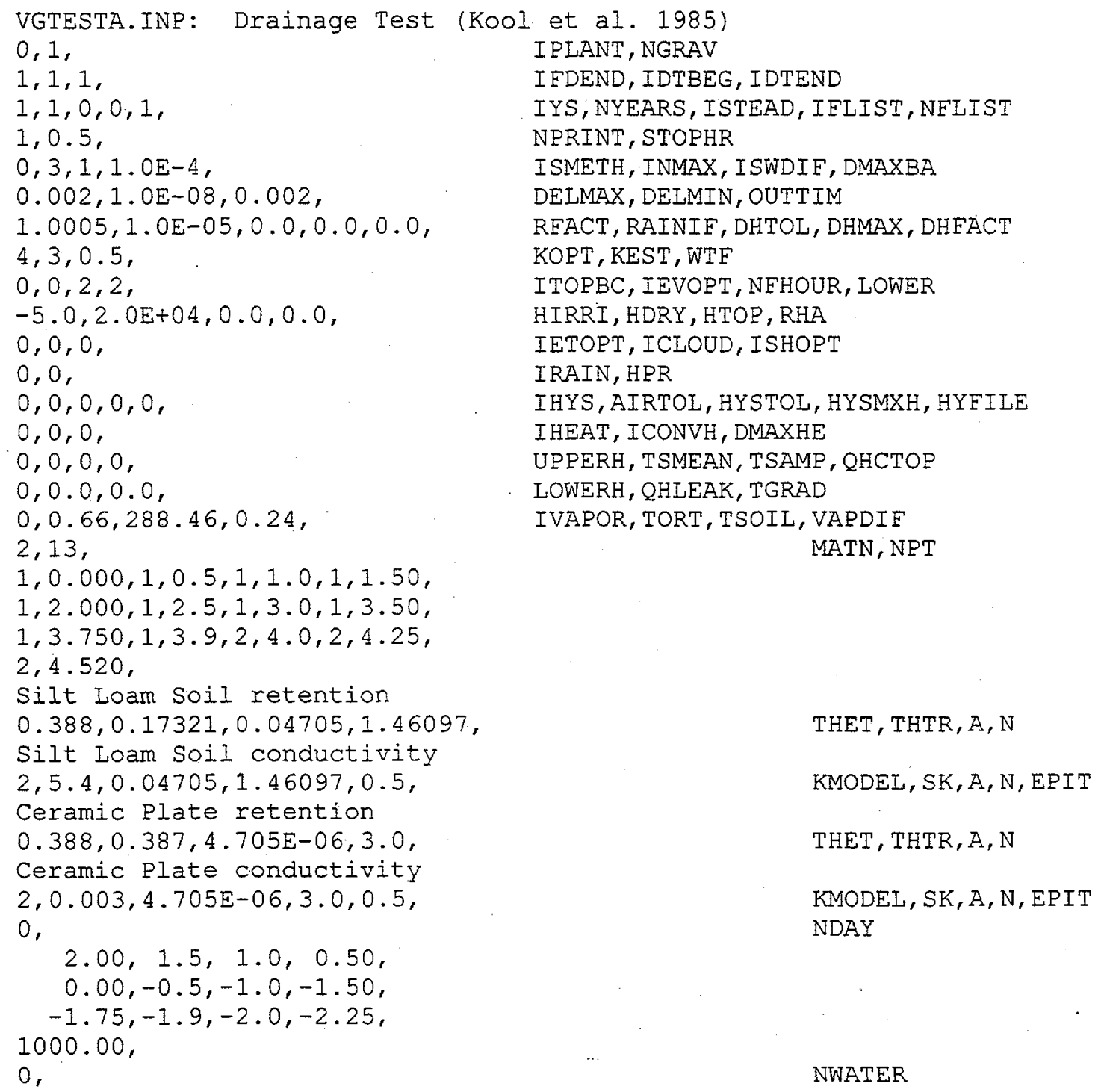




\title{
Figure B.6. Output File for Drainage Simulation
}

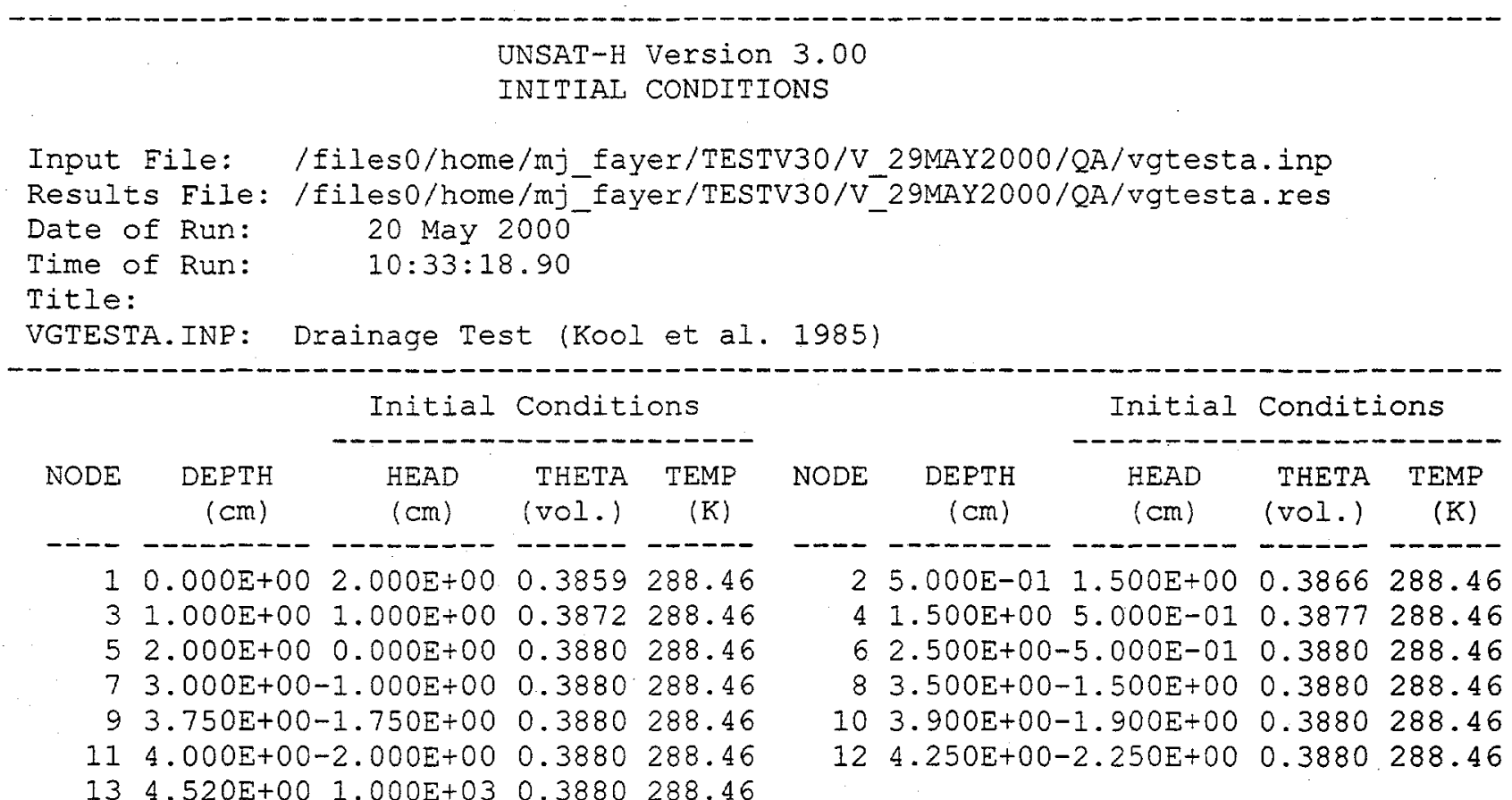

Initial Water Storage $=1.7520 \mathrm{~cm}$

\begin{abstract}
DAILY SUMMARY: Day $=1$, Simulated Time $=0.5000 \mathrm{hr}$

\begin{tabular}{|c|c|c|c|c|c|c|}
\hline Node Number & $=$ & 1 & 2 & 3 & 4 & 5 \\
\hline Depth $(\mathrm{cm})$ & $=$ & 0.00000 & 0.50000 & 1.00000 & 1.50000 & 2.000 \\
\hline Water $(\mathrm{cm} 3 / \mathrm{cm} 3)$ & $=$ & 0.29183 & 0.29176 & 0.29084 & 0.28896 & 0.2 \\
\hline Head $(\mathrm{cm})$ & $=6.88$ & $3111 \mathrm{E}+01$ & $6.89197 \mathrm{E}+01$ & $7.03089 \mathrm{E}+01$ & $7.32438 \mathrm{E}+01$ & $7.83466 \mathrm{E}+$ \\
\hline LiqWater Flow $(\mathrm{cm})$ & $=2.35$ & $161 E-02$ & $7.09404 \mathrm{E}-02$ & $1.19135 \mathrm{E}-01$ & $1.68516 \mathrm{E}-01$ & 2.1957 \\
\hline & & & & LIQUID & & \\
\hline $\begin{array}{cc}\text { PRESTOR } & \text { INEIL } \\
1.7520+ & 0.0000+\end{array}$ & RUNOFF & EVA & PO TRANS & DRAIN & NEWSTOR & STORAGE \\
\hline
\end{tabular}

Mass Balance $=-1.1852 \mathrm{E}-04 \mathrm{~cm}$; Time step attempts $=13626$ and successes $=13626$ 1
\end{abstract}

UNSAT-H Version 3.00

SIMULATION SUMMARY

Title:

VGTESTA.INP: Drainage Test (Kool et al. 1985)

\section{B.8}


Transpiration Scheme is:

Potential Evapotranspiration

$=0$

Potential Transpiration

Actual Transpiration

Potential Evaporation

Actual Evaporation

Evaporation during Growth

Total Runoff

$=0.0000 E+00 \quad[\mathrm{~cm}]$

$=0.0000 \mathrm{E}+00 \quad[\mathrm{~cm}]$

$=0.0000 \mathrm{E}+00 \quad[\mathrm{~cm}]$

$=0.0000 \mathrm{E}+00 \quad[\mathrm{~cm}]$

$=0.0000 \mathrm{E}+00 \quad[\mathrm{~cm}]$

$=0.0000 \mathrm{E}+00 \quad[\mathrm{~cm}]$

$=0.0000 \mathrm{E}+00 \quad[\mathrm{~cm}]$

Total Infiltration $\quad=0.0000 \mathrm{E}+00 \quad[\mathrm{~cm}]$

Total Basal Liquid Flux (drainage) $=4.2800 \mathrm{E}-01 \quad[\mathrm{~cm}]$

Total Basal Vapor Flux (temp-grad) $=0.0000 \mathrm{E}+00 \quad[\mathrm{~cm}]$

Total Applied water $\quad=0.0000 \mathrm{E}+00 \quad[\mathrm{~cm}]$

Actual Rainfall $=0.0000 \mathrm{E}+00 \quad[\mathrm{~cm}]$

Actual Irrigation $\quad=0.0000 \mathrm{E}+00 \quad[\mathrm{~cm}]$

Total Einal Moisture Storage $\quad=1.3241 \mathrm{E}+00 \quad[\mathrm{~cm}]$

Mass Balance Error

Total Successful Time Steps

Total Attempted Time Steps

Total Time Step Reductions (DHMAX)

Total Changes in Surface Boundary

Total Time Actually Simulated

$=-1.1852 \mathrm{E}-04 \quad[\mathrm{~cm}]$

$=13626$

$=\quad 13626$

$=0$

$=0$

$=2.0833 \mathrm{E}-02 \quad$ [days]

Total liquid water flow $(\mathrm{cm})$ across different depths at the end of $2.0833 \mathrm{E}-02$ days:

\begin{tabular}{lcrrrr} 
DEPTH & FLOW & DEPTH & FLOW & DEPTH & FLOW \\
\hline 0.000 & $0.0000 E+00$ & 0.250 & $2.3516 \mathrm{E}-02$ & 0.750 & $7.0940 \mathrm{E}-02$ \\
1.250 & $1.1913 \mathrm{E}-01$ & 1.750 & $1.6852 \mathrm{E}-01$ & 2.250 & $2.1957 \mathrm{E}-01$ \\
2.750 & $2.7297 \mathrm{E}-01$ & 3.250 & $3.3004 \mathrm{E}-01$ & 3.625 & $3.7782 \mathrm{E}-01$ \\
3.825 & $4.0593 \mathrm{E}-01$ & 3.950 & $4.2800 \mathrm{E}-01$ & 4.125 & $4.2800 \mathrm{E}-01$ \\
4.385 & $4.2800 \mathrm{E}-01$ & 4.520 & $4.2800 \mathrm{E}-01$ & &
\end{tabular}


Figure B.7. Input File for Heat Flow Verification Simulation

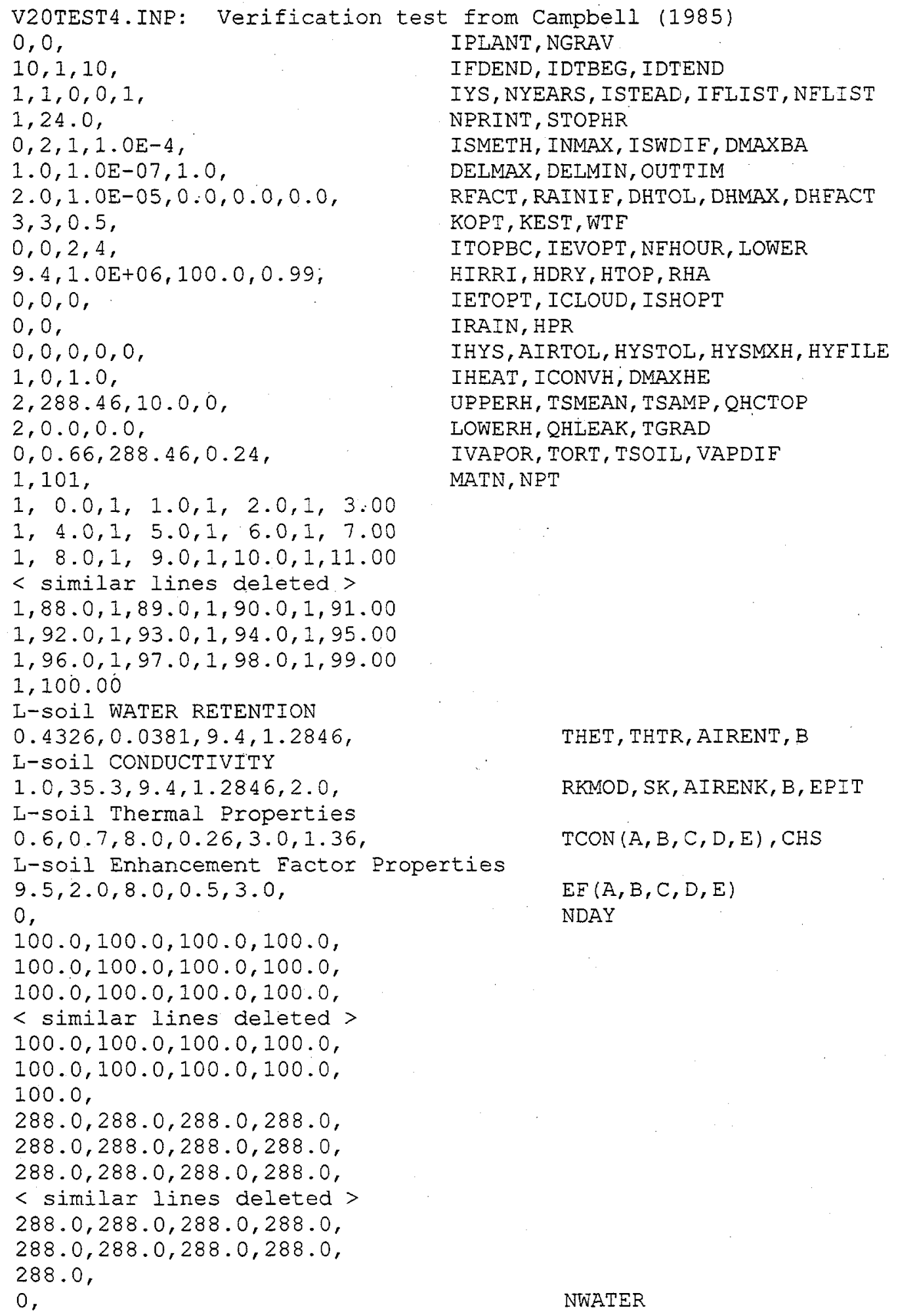

NWATER 
Figure B.8. Output File for Heat Flow Verification Simulation

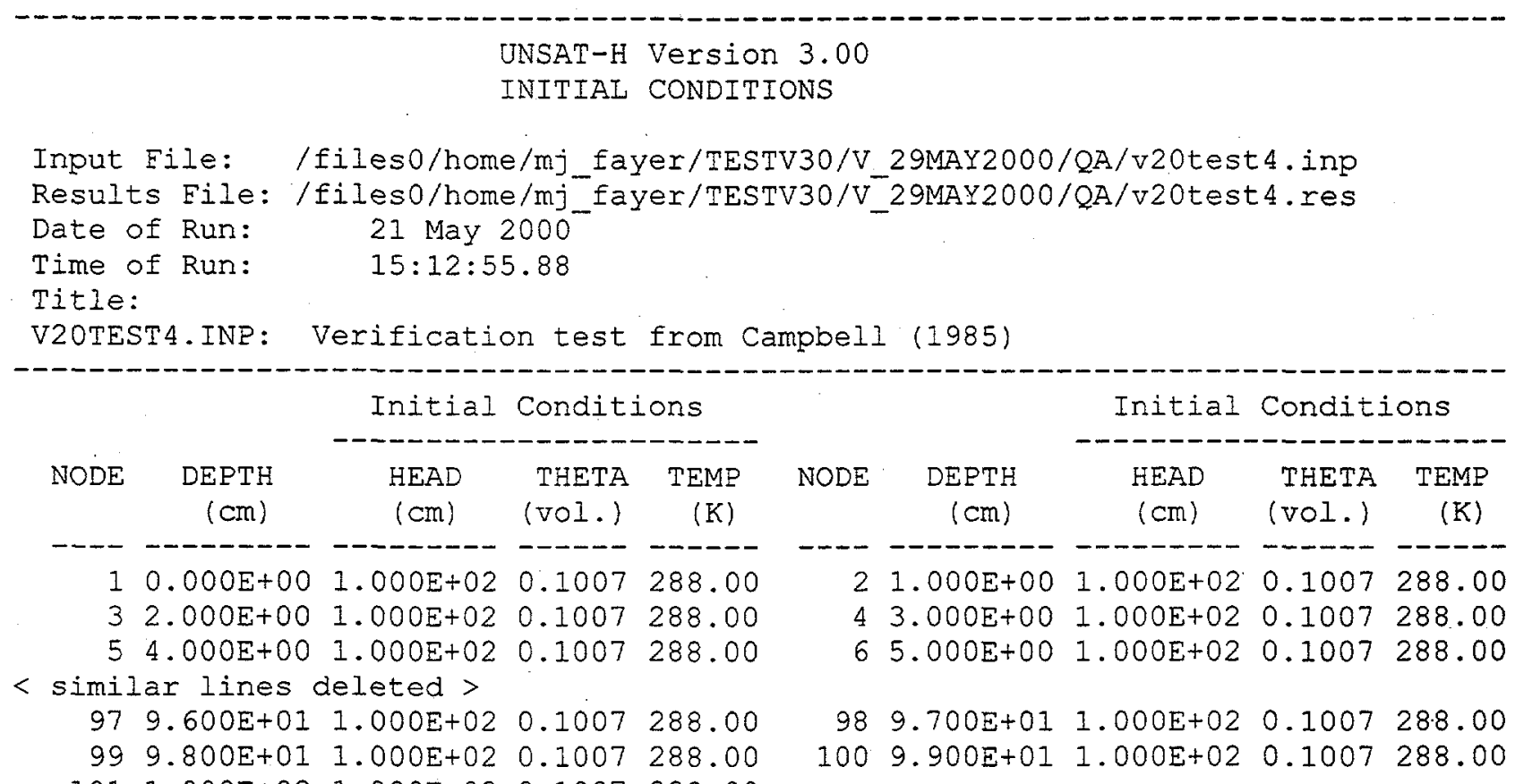

Initial Water Storage $=10.0715 \mathrm{~cm}$

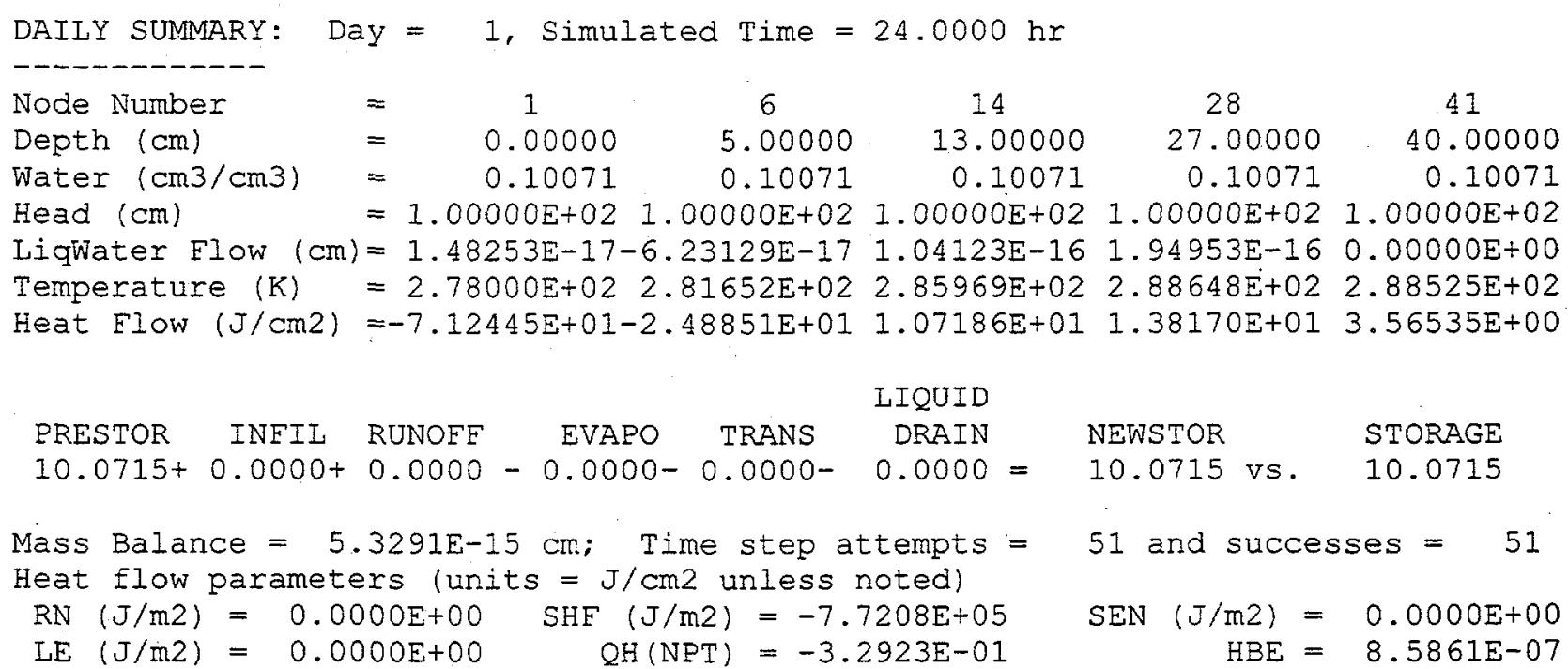

DAILY SUMMARY: Day $=10$, Simulated Time $=24.0000 \mathrm{hr}$

B.11. 


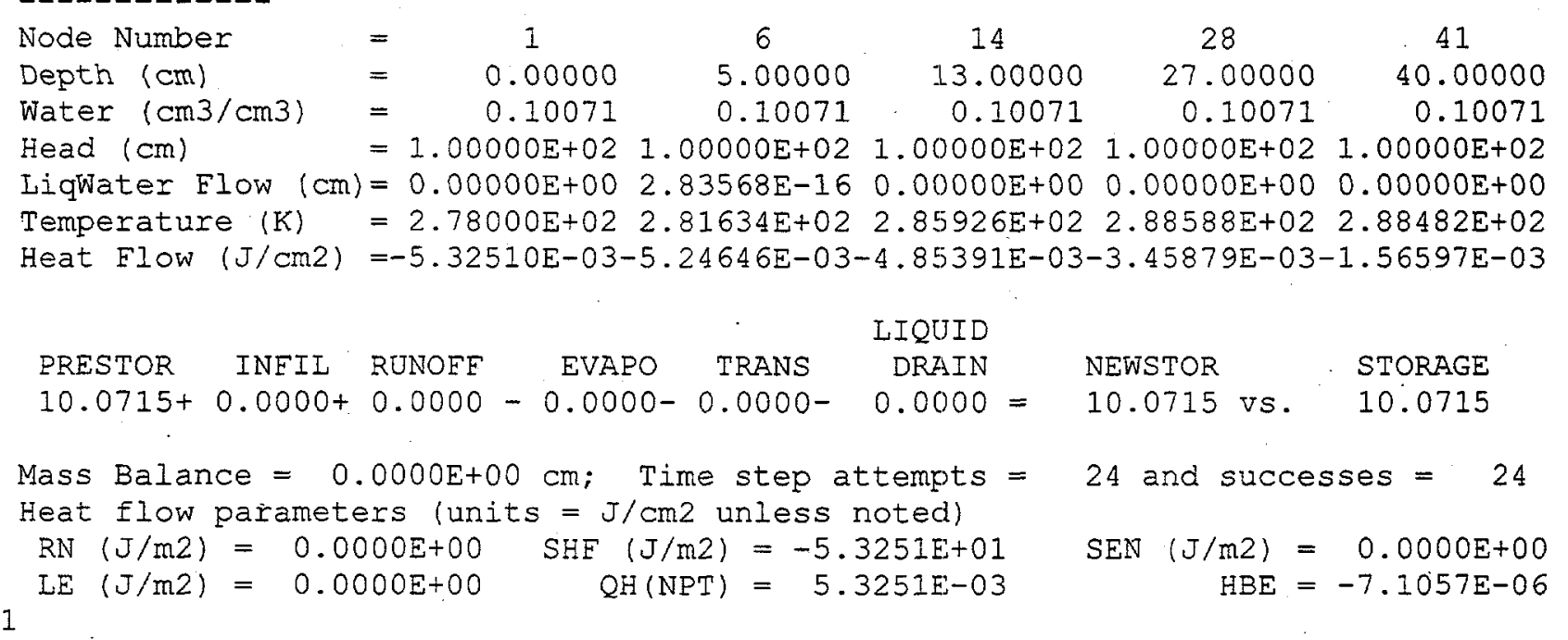

UNSAT-H Version 3.00

SIMULATION SUMMARY

Title:

V2OTEST4.INP: Verification test from Campbell (1985)

\begin{tabular}{|c|c|c|}
\hline Transpiration scheme is: & $=$ & \\
\hline Potential Evapotranspiration & $=0.0000 \mathrm{E}+00$ & {$[\mathrm{~cm}]$} \\
\hline Potential Transpiration & $=0.0000 \mathrm{E}+00$ & {$[\mathrm{~cm}]$} \\
\hline Actual Transpiration & $=0.0000 E+00$ & {$[\mathrm{~cm}]$} \\
\hline Potential Evaporation & $=0.0000 E+00$ & {$[\mathrm{~cm}]$} \\
\hline Actual Evaporation & $=0.0000 \mathrm{E}+00$ & {$[\mathrm{~cm}]$} \\
\hline Evaporation during Growth & $=0.0000 \mathrm{E}+00$ & {$[\mathrm{~cm}]$} \\
\hline Total Runoff & $=0.0000 \mathrm{E}+00$ & {$[\mathrm{~cm}]$} \\
\hline Total Infiltration & $=0.0000 E+00$ & {$[\mathrm{~cm}]$} \\
\hline Total Basal Liquid Flux (drainage) & $=0.0000 E+00$ & {$[\mathrm{~cm}]$} \\
\hline Total Basal Vapor Flux (temp-grad) & $=0.0000 E+00$ & {$[\mathrm{~cm}]$} \\
\hline Total Applied Water & $=0.0000 \mathrm{E}+00$ & {$[\mathrm{~cm}]$} \\
\hline Actual Rainfall & $=0.0000 E+00$ & {$[\mathrm{~cm}]$} \\
\hline Actual Irrigation & $=0.0000 E+00$ & {$[\mathrm{~cm}]$} \\
\hline Total Final Moisture Storage & $=1.0071 \mathrm{E}+01$ & {$[\mathrm{~cm}]$} \\
\hline Mass Balance Error & $8.8818 \mathrm{E}-15$ & {$[\mathrm{~cm}]$} \\
\hline Total Successful Time Steps & 267 & \\
\hline Total Attempted Time Steps & 267 & \\
\hline Total Time Step Reductions (DHMAX) & $=$ & \\
\hline Total Changes in Surface Boundary & $=$ & \\
\hline Total Time Actually Simulated & $=1.0000 \mathrm{E}+01$ & [days] \\
\hline Total Net Radiation & $=0.0000 E+00$ & {$[\mathrm{~J} / \mathrm{m} 2]$} \\
\hline Total Soil-Surface Heat Flow & $=-7.8986 \mathrm{E}+05$ & {$[\mathrm{~J} / \mathrm{m} 2]$} \\
\hline Total Sensible Heat Flow & $=0.0000 E+00$ & {$[\mathrm{~J} / \mathrm{m} 2]$} \\
\hline Total Bottom Heat Flow & $=1.0175 E+02$ & {$[\mathrm{~J} / \mathrm{m} 2]$} \\
\hline Total Latent Heat Flow & $=0.0000 E+00$ & {$[\mathrm{~J} / \mathrm{m} 2]$} \\
\hline Heat Balance Error & $=-4.7473 E-05$ & {$[\mathrm{~J} / \mathrm{m} 2]$} \\
\hline
\end{tabular}

B.12 
Total Convected Heat in Infilt. $=0.0000 \mathrm{E}+00 \quad[\mathrm{~J} / \mathrm{m} 2]$

Total Convected Heat in Drainage $=0.0000 \mathrm{E}+00 \quad[\mathrm{~J} / \mathrm{m} 2]$

Total liquid water flow $(\mathrm{cm})$ across different depths at the end of $1.0000 \mathrm{E}+01$ days:

\begin{tabular}{rrrrrr} 
DEPTH & \multicolumn{1}{c}{ FLOW } & \multicolumn{1}{c}{ DEPTH } & \multicolumn{1}{c}{ FLOW } & \multicolumn{1}{c}{ DEPTH } & \multicolumn{1}{c}{ FLOW } \\
\hline 0.000 & $0.0000 \mathrm{E}+00$ & 0.500 & $-5.6067 \mathrm{E}-17$ & -1.500 & $-1.6643 \mathrm{E}-16$ \\
2.500 & $-3.9055 \mathrm{E}-16$ & 3.500 & $-2.4171 \mathrm{E}-16$ & 4.500 & $1.7694 \mathrm{E}-15$ \\
5.500 & $1.8695 \mathrm{E}-15$ & 6.500 & $1.8118 \mathrm{E}-15$ & 7.500 & $8.5406 \mathrm{E}-16$ \\
$<$ similar lines deleted $>$ & & & & \\
92.500 & $-3.3231 \mathrm{E}-16$ & 93.500 & $-3.1680 \mathrm{E}-16$ & 94.500 & $-2.9760 \mathrm{E}-16$ \\
95.500 & $-3.3452 \mathrm{E}-16$ & 96.500 & $-3.7292 \mathrm{E}-16$ & 97.500 & $-4.8738 \mathrm{E}-16$ \\
98.500 & $-3.4927 \mathrm{E}-16$ & 99.500 & $-1.3470 \mathrm{E}-16$ & 100.000 & $0.0000 \mathrm{E}+00$
\end{tabular}

Total heat flow (J/cm2) across different depths:

\begin{tabular}{rrrrrr} 
DEPTH & \multicolumn{1}{c}{ FLOW } & \multicolumn{1}{c}{ DEPTH } & FLOW & DEPTH & \multicolumn{1}{c}{ FLOW } \\
\hline 0.000 & $-7.8986 \mathrm{E}+01$ & 0.500 & $-7.3022 \mathrm{E}+01$ & 1.500 & $-6.1997 \mathrm{E}+01$ \\
2.500 & $-5.1862 \mathrm{E}+01$ & 3.500 & $-4.2601 \mathrm{E}+01$ & 4.500 & $-3.4189 \mathrm{E}+01$ \\
5.500 & $-2.6596 \mathrm{E}+01$ & 6.500 & $-1.9788 \mathrm{E}+01$ & 7.500 & $-1.3727 \mathrm{E}+01$ \\
similar lines deleted $>$ & & & & \\
92.500 & $-2.3092 \mathrm{E}-02$ & 93.500 & $-1.4613 \mathrm{E}-02$ & 94.500 & $-7.4289 \mathrm{E}-03$ \\
95.500 & $-1.5036 \mathrm{E}-03$ & 96.500 & $3.1956 \mathrm{E}-03$ & 97.500 & $6.6957 \mathrm{E}-03$ \\
98.500 & $9.0173 \mathrm{E}-03$ & 99.500 & $1.0175 \mathrm{E}-02$ & 100.000 & $1.0175 \mathrm{E}-02$
\end{tabular}

\section{B.13}


Figure B.9. Input File for Hysteresis Verification Simulation

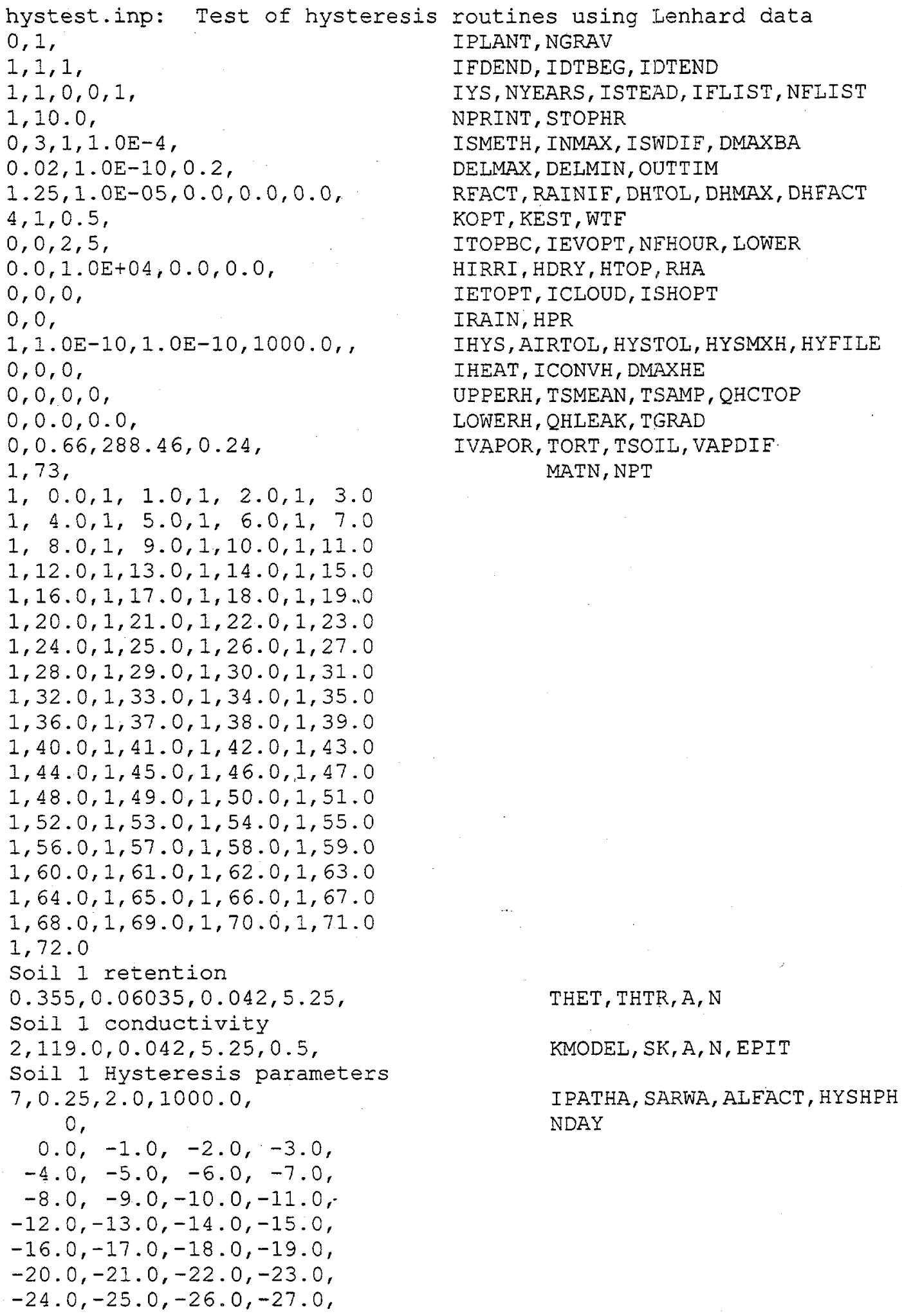


$-28.0,-29.0,-30.0,-31.0$,

$-32.0,-33.0,-34.0,-35.0$,

$-36.0,-37.0,-38.0,-39.0$,

$-40.0,-41.0,-42.0,-43.0$,

$-44.0,-45.0,-46.0,-47.0$,

$-48.0,-49.0,-50.0,-51.0$,

$-52.0,-53.0,-54.0,-55.0$,

$-56.0,-57.0,-58.0,-59.0$,

$-60.0,-61.0,-62.0,-63.0$,

$-64.0,-65.0,-66.0,-67.0$,

$-68.0,-69.0,-70.0,-71.0$,

-72.0 ,

13 ,

INDEXB

$0.00000000,-72.0$,

$0.00000042,-67.0$,

$\operatorname{BBHEAD}(I, 1: 2)$

$0.08333333,-7.0$,

$0.12500000,-7.0$,

$0.12500042,-12.0$,

$0.16666667,-42.0$,

$0.20833333,-42.0$,

$0.20833375,-37.0$,

$0.23611125,-17.0$,

$0.27777792,-17.0$,

$0.27777833,-22.0$,

$0.34722208,-72.0$,

$0.43750000,-72.0$,

0 ,

NWATER

B. 15 
Figure B.10. Output File for Hysteresis Verification Simulation

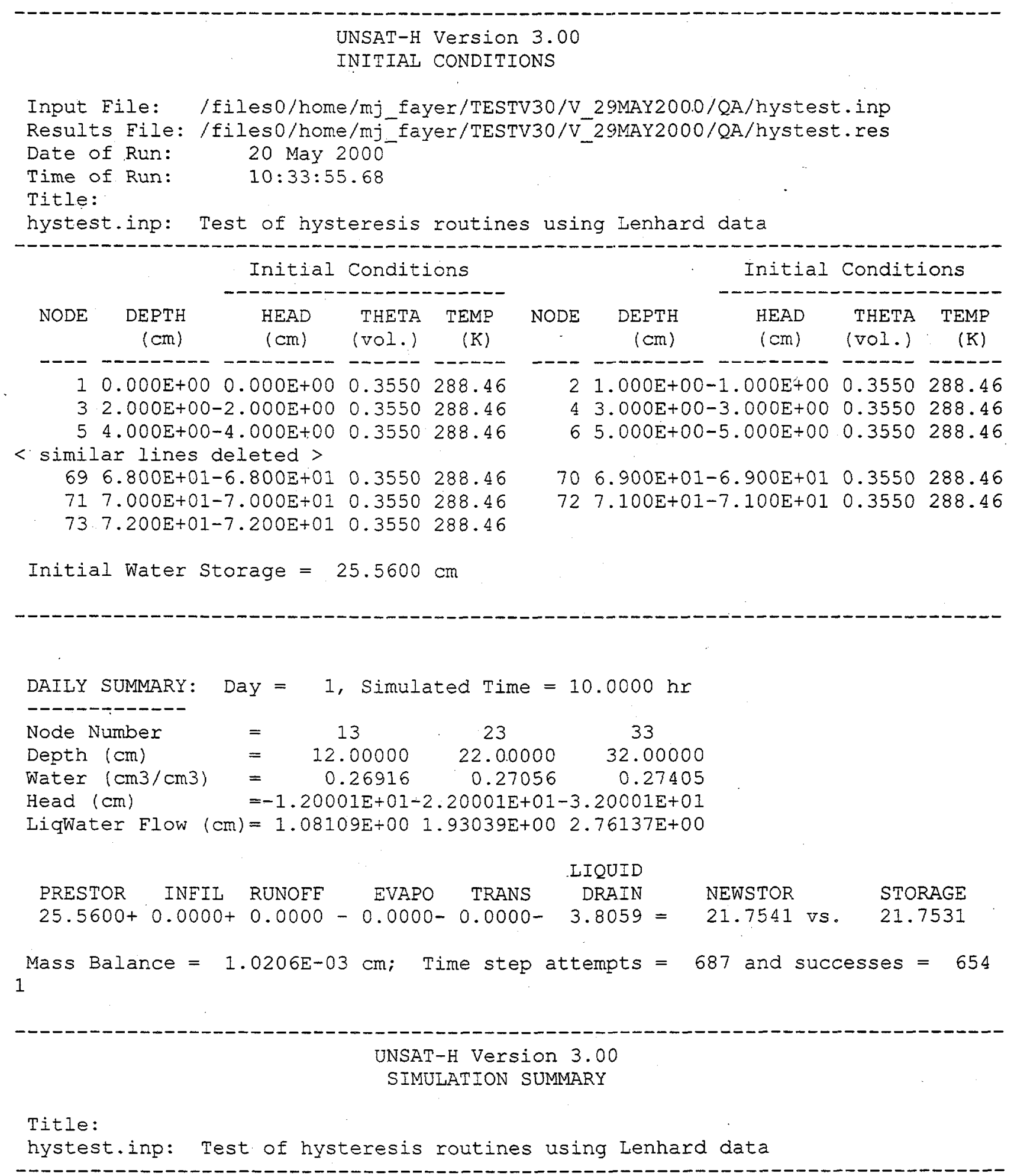

\section{B. 16}




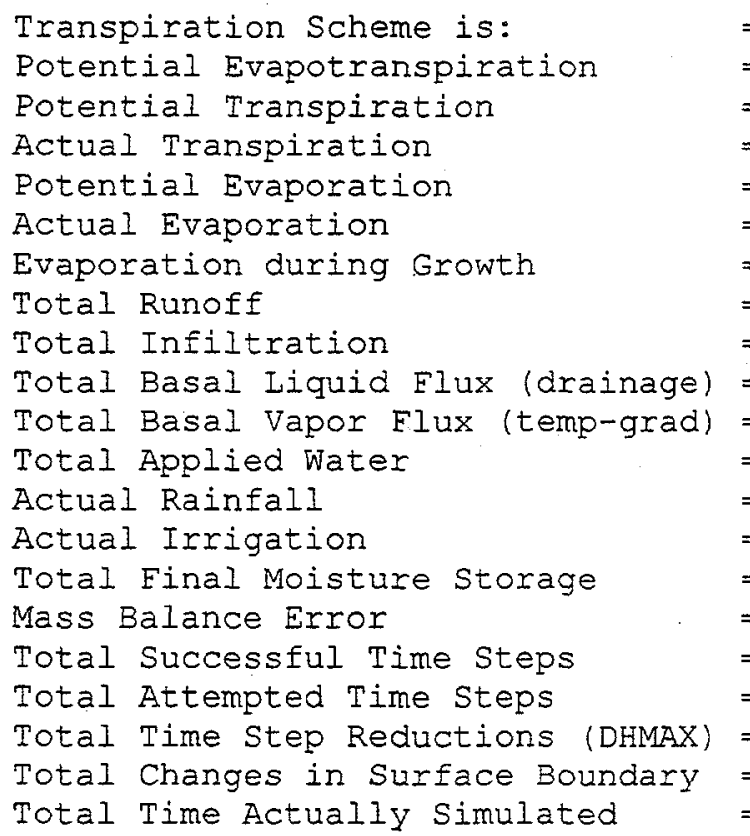

Total liquid water flow (cm) across

different depths
$=0$

$=0.0000 E+00 \quad[\mathrm{~cm}]$

$=0.0000 E+00 \quad[\mathrm{~cm}]$

$=0.0000 E+00 \quad[\mathrm{~cm}]$

$=0.0000 E+00 \quad[\mathrm{~cm}]$

$=0.0000 E+00 \quad[\mathrm{~cm}]$

$=0.0000 E+00 \quad[\mathrm{~cm}]$

$=0.0000 \mathrm{E}+00 \quad[\mathrm{~cm}]$

$=0.0000 E+00 \quad[\mathrm{~cm}]$

$=3.8059 \mathrm{E}+00 \quad[\mathrm{~cm}]$

$=0.0000 E+00 \quad[\mathrm{~cm}]$

$=0.0000 \mathrm{E}+00 \quad[\mathrm{~cm}]$

$=0.0000 \mathrm{E}+00 \quad[\mathrm{~cm}]$

$=0.0000 \mathrm{E}+00 \quad[\mathrm{~cm}]$

$=2.1753 \mathrm{E}+01 \quad[\mathrm{~cm}]$

$=1.0206 \mathrm{E}-03 \quad[\mathrm{~cm}]$

$=654$

$=687$

$=$

$$
\begin{aligned}
& \text { DEPTH } \\
& 0.500 \\
& 3.500 \\
& 6.500
\end{aligned}
$$

$4.7767 \mathrm{E}-01$

- similar lines deleted >

$65.500 \quad 3.8059 E+00$

68.500

$3.8059 E \div 00$

71.500
66.500

69.500

72.000

ELOW
$-4.3602 \mathrm{E}-02$
$3.0453 \mathrm{E}-01$
$5.6415 \mathrm{E}-01$

$3.8059 E+00$

$3.8059 \mathrm{E}+00$

$3.8059 \mathrm{E}+00$
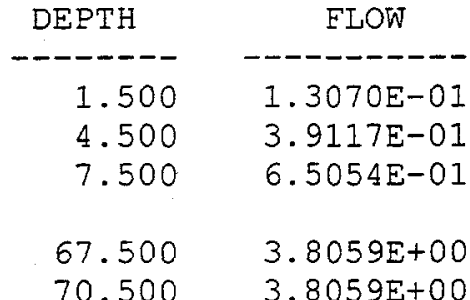

B. 17 
Figure B.11. Input File for Layered Soil Simulation

N62NP: test of evaporation from unvegetated barrier using polys

0,1 ,

$365,1,365$,

$1,1,0,0,1$,

$0,24.0$,

$0,2,1,1.0 \mathrm{E}-4$

1.0,1.0E-07,1.0,

2.0,1.0E-05,0.0,0.0,0.0,

$1,3,0.5$,

$0,1,2,1$

$0.0,1.0 \mathrm{E} \div 05,0,0.99$,

$0,0,0$,

0,0 ,

$0,0,0,0,0$

$0,0,0$,

$0,0,0,0$,

$0,0.0,0.0$

$1,0.66,288.46,0.24$,

3,37 ,

$1,1.000,1,2.000,1,4.000,1,8.000$,

$1,16.000,1,24.000,1,28.000,2,32.000$,

$2,36.000,2,44.000,2,52.000,2,60.000$,

2, 70.000,2, $80.000,2,90.000,2,100.000$,

$2,110.000,2,120.000,2,130.000,2,138.000$,

$2,143.000,2,147.000,2,149.000,3,151.000$,

$3,153.000,3,157.000,3,165.000,3,181.000$,

$3,220.000,3,280.000,3,340.000,3,440.000$,

$3,540.000$,

4,5 ,

MAXPOL, MAXCOE

Mat. 1, COMPGRAV.TH1: Composite soil with $15 \%$ gravel by weight

$4,1.0,0.422$,

$1,4,1.0,12.65$

NPOLY, $X(1), Y(1)$

$I, \operatorname{NDEG}(I)+1, \quad \mathrm{XX} 1, \quad \mathrm{XX} 2$

$4.2199999 E-01,-2.7573731 E-02,-2.3653656 E-03,-3.2151621 E-02,0.0$, $2,5,1.2650003 \mathrm{E}+01,2.4420016 \mathrm{E}+02$,

$-1.38834 \mathrm{E}-01,1.5021513,-1.4785267,5.4422855 \mathrm{E}-01,-7.0263125 \mathrm{E}-02$,

$3,5,2.4420016 \mathrm{E}+02,7.1970044 \mathrm{E}+03$,

$-1.7569752,2.7017555,-1.3545368,2.8460807 \mathrm{E}-01,-2.161908 \mathrm{E}-02$,

$4,5,7.1970044 \mathrm{E}+03,8.6326599 \mathrm{E}+06$,

$-3.4936512 \mathrm{E}-01,3.145951 \mathrm{E}-01,-8.4237993 \mathrm{E}-02,9.1790808 \mathrm{E}-03,-3.5545405$ COMPGRAV.KHI

$2,1.0,3.6 \mathrm{E}-01$,

$1,4,1.0,4.498 \mathrm{E}+01$,

$-4.4369757 \mathrm{E}-01,-5.8029747 \mathrm{E}-01,-2.8344643 \mathrm{E}-01,-2.1685658 \mathrm{E}-01,0.0$,

$2,3,4.498 \mathrm{E}+01,8.6326599 \mathrm{E}+06$,

$2.4089615,-3.4391944,4.3601289 E-02,0.0$,

Mat. 2, COMPOS1.TH1: Composite soil

$4,1.0,4.22 \mathrm{E}-01$,

$1,3,1.0,5.4290004$,

$4.2199999 \mathrm{E}-01,-7.3107332 \mathrm{E}-03,-3.5250444 \mathrm{E}-02,0.0$,

$2,3,5.4290004,5.6900012 \mathrm{E}+02$,

$4.2632636 \mathrm{E}-01,-1.9087702 \mathrm{E}-02,-2.7235843 \mathrm{E}-02,0.0$,

$3,4,5.6900012 \mathrm{E}+02,1.6770025 \mathrm{E}+04$,

$2.4613359,-1.7952768,4.5785773 \mathrm{E}-01,-3.9381173 \mathrm{E}-02$,

$4,4,1.6770025 \mathrm{E}+04,8.6326599 \mathrm{E}+06$,

$3.6377275 \mathrm{E}-01,-1.0580593 \mathrm{E}-01,1.0616908 \mathrm{E}-02,-3.5810552 \mathrm{E}-04$, COMPOS1. KHI
$(\operatorname{COEE}(I, J), \quad J=I, \operatorname{NDEG}(I)+1)$

$I, \operatorname{NDEG}(I)+1, \mathrm{XX1}, \mathrm{XX2}$

$(\operatorname{COEF}(I, J), J=I, \operatorname{NDEG}(I)+1)$

$I, \operatorname{NDEG}(I)+1, \mathrm{XX} 1, \mathrm{XX} 2$

$(\operatorname{COEF}(I, J), J=1, \operatorname{NDEG}(I)+1)$

$I, \operatorname{NDEG}(I)+1, X X 1, X X 2$

NPOIY, $X(1), Y(1)$

I, $\operatorname{NDEG}(I)+1, \quad \mathrm{XX1}, \mathrm{XX} 2$

$(\operatorname{COEF}(I, J), J=1, \operatorname{NDEG}(I)+1)$

$I, \operatorname{NDEG}(I)+1, \mathrm{XXI}, \mathrm{XX} 2$

$(\operatorname{COEF}(I, J), J=1, \operatorname{NDEG}(I)+1)$

NPOLY, $X(1), Y(1)$

$I, \operatorname{NDEG}(I)+1, \quad \mathrm{XXI}, \mathrm{XX} 2$

$(\operatorname{COEF}(I, J), J=1, \operatorname{NDEG}(I)+1)$

$I, \operatorname{NDEG}(I)+1, \quad \mathrm{XX} 1, \quad \mathrm{XX} 2$

$(\operatorname{COEF}(I, J), J=1, \operatorname{NDEG}(I)+1)$

$I, \operatorname{NDEG}(I)+1, \quad \mathrm{XX} 1, \mathrm{XX} 2$

(COEE (I, J), J=1, NDEG (I) +1)

$I, \operatorname{NDEG}(I)+1, \mathrm{XX} 1, \mathrm{XX} 2$

$(\operatorname{COEF}(I, J), J=1, \operatorname{NDEG}(I)+1)$ 
$3,1.0,1.080002 \mathrm{E}-01$,

NPOLY, $X(1), Y(1)$

$1,4,1.0,1.3260002 \mathrm{E}+03$, $I, \operatorname{NDEG}(I)+1, X X 1, X X 2$

$-9.6657562 \mathrm{E}-01,-1.0965506,5.8941185 \mathrm{E}-02,-1.2111266 \mathrm{E}-01,0.0,(\mathrm{COEF}$ (I, J), J=1, NDEG (I) +1)

$2,4,1.3260002 \mathrm{E}+03,7.1970044 \mathrm{E}+03$,

$I, \operatorname{NDEG}(I)+1, X X 1, \quad X X 2$

$-6.3407219 \mathrm{E}+01,6.0421951 \mathrm{E}+01,-2.0131914 \mathrm{E}+01,2.0865219,0.0$,

$3,4,7.1970044 \mathrm{E}+03,8.6326599 \mathrm{E}+06$,

$-9.5900745,1.8411379,-6.0871047 \mathrm{E}-01,2.465306 \mathrm{E}-02,0.0$,

$(\operatorname{COEE}(I, J), J=1, \operatorname{NDEG}(I)+1)$

I, NDEG $(I)+1, X X 1, X X 2$

Mat. 3, GRAVEI1.TH1: Gravel $0.6-1.3 \mathrm{~cm}$ diameter

$4,9.9999998 \mathrm{E}-03,4.19 \mathrm{E}-01$,

$1,3,9.9999998 \mathrm{E}-03,7.743001 \mathrm{E}-02$,

$2.9529411 \mathrm{E}-01,-9.5835656 \mathrm{E}-02,-1.6991356 \mathrm{E}-02,0.0$,

$2,3,7.743001 \mathrm{E}-02,2.7829993 \mathrm{E}-01$,

$-2.0774645 \mathrm{E}-01,-1.0013254,-4.2446923 \mathrm{E}-01,0.0$,

$3,5,2.7829993 \mathrm{E}-01,1.2920002 \mathrm{E}+01$,

$(\operatorname{COEF}(I, J), J=1, \operatorname{NDEG}(I)+1)$

$5.8681458 E-02,-1.1252354 E-01,2.01344 E-01,-1.7054841 E-01,5.2016903 E-02,(\operatorname{COEE}(I, J), J=1, N D E G(I)+1)$

$4,5,1.2920002 \mathrm{E}+01,8.7777891 \mathrm{E}+06$,

NPOLY, $X(1), Y(1)$

$I, \operatorname{NDEG}(I)+1, \quad X X 1, X X 2$

$(\operatorname{COEF}(I, J), J=1, \operatorname{NDEG}(I)+1)$

$I, \operatorname{NDEG}(I)+1, \quad \mathrm{XX1}, \mathrm{XX} 2$

$(\operatorname{COEF}(I, J), J=1, \operatorname{NDEG}(I)+1)$

$I, \mathrm{NDEG}(I)+1, \mathrm{XX} 1, \mathrm{XX} 2$

$4.5875967 \mathrm{E}-02,-2.2514086 \mathrm{E}-02,6.2657609 \mathrm{E}-03,-7.9328578 \mathrm{E}-04,3.5441328 \mathrm{E}-05$, (COEF (I, J), J=1, NDEG (I) + GRAVEL1.KH1

$4,9.9999998 \mathrm{E}-03,1.2600005 \mathrm{E}+03, \quad$ NPOLY, $X(1), Y(1)$

$1,4,9.9999998 \mathrm{E}-03,2.7829993 \mathrm{E}-01, \quad \mathrm{I}, \mathrm{NDEG}(I)+1, \mathrm{XX1}, \mathrm{XX2}$

$-2.7429957,-1.0566543 E+01,-6.7793403,-1.4784553,0.0,(\operatorname{COE} F(I, J), J=1, N D E G(I)+1)$

$2,3,2.7829993 \mathrm{E}-01,4.6420007$,

$-1.3305095,-5.0247631,-5.5922753 \mathrm{E}-01,0.0$,

$I, \operatorname{NDEG}(I)+1, \quad \mathrm{XX} 1, \mathrm{XX} 2$

$3,3,4.6420007,1.6680004 \mathrm{E}+01$

$1.8869209 \mathrm{E}-01,-9.5821028,2.8585794,0.0$,

$4,4,1.6680004 \mathrm{E}+01,8.7777891 \mathrm{E}+06$

$(\operatorname{COEF}(I, J), J=1, \operatorname{NDEG}(I)+1)$

$-3.7477951,-3.1739995,2.7821976 \mathrm{E}-01,-2.2469539 \mathrm{E}-02,0.0$,

$I, \operatorname{NDEG}(I)+1, X X 1, \mathrm{XX} 2$

$(\operatorname{COEF}(I, J), J=1, \operatorname{NDEG}(I)+1)$

0 ,

$I, \mathrm{NDEG}(I)+1, \mathrm{XX} 1, \mathrm{XX} 2$

$22933.596,2400.732,451.194,205.857$,

NDAY

$(\operatorname{COEF}(I, J), J=1, \operatorname{NDEG}(I)+1)$

$142.566,103.126,77.111,60.696$,

$56.325,69.985,81.368,87.254$,

$88.236,85.058,79.992,74.682$,

$68.145,61.625,54.897,47.756$,

$40.062,31.748,22.833,15.331$,

$10.510,6.592,4.617,2.817$,

$2.815,2.812,2.806,2.797$,

$2.761,2.737,2.696,2.638$,

2.595

$0.0087,0.0141,0.1314,0.1198,0.0273,0.0381,0.2410,0.1452$,

$0.1637,0.1134,0.1323,0.0568,0.0266,0.1510,0.0815,0.0906$,

$0.1020,0.0961,0.1251,0.2172,0.0710,0.0840,0.0841,0.1251$,

< similar lines deleted >

$0.0118,0.0117,0.0159,0.0307,0.0045,0.0146,0.0080,0.0134$,

$0.0318,0.0021,0.0575,0.0947,0.0735,0.0841,0.0848,0.0639$,

$0.0695,0.2235,0.1272,0.1530,0.0846$,

62, NWATER (Total for $1962=15.3924 \mathrm{~cm}$ )

$3,1,2,1.000$,

$0.0,0.2032$,

$2.0,0.0000$,

$6,1,2,1.000$,

$14.0,0.0762$,

15.0, 0.0000,

< similar lines deleted >

$352,1,2,1.000$,

$13.0,0.0508$,

$15.0,0.0000$,

$353,1,2,1.000$,

$2.0,0.1270$,

4.0, 0.0000 , 
Figure B.12. Output File for Layered Soil Simulation

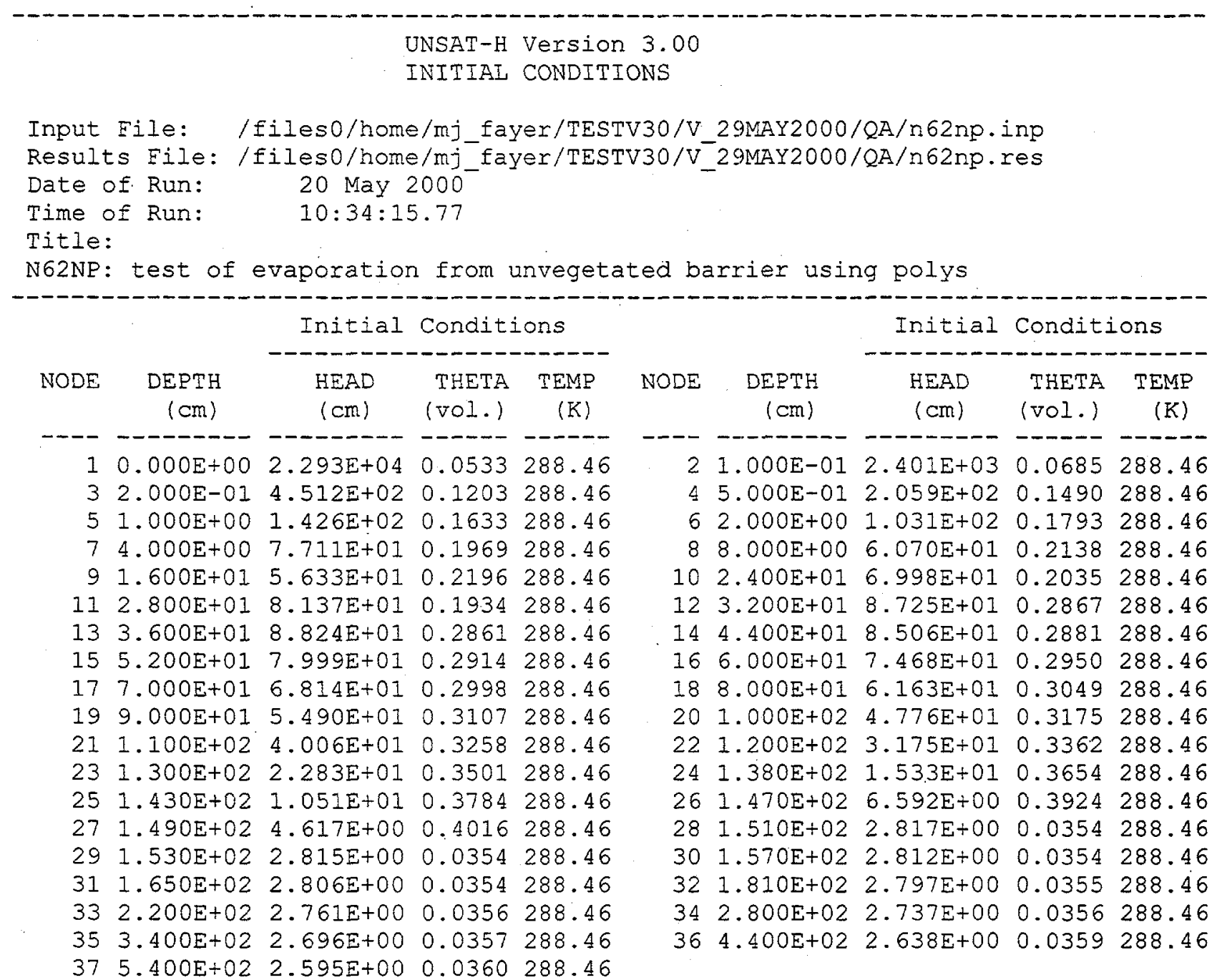

Initial Water Storage $=58.3612 \mathrm{~cm}$

DAILY SUMMARY: Day $=1$, Simulated Time $=24.0000 \mathrm{hr}$

\begin{tabular}{llrrrrr} 
Node Number & $=$ & 1 & 10 & 13 & 20 & \multicolumn{1}{c}{24} \\
Depth $(\mathrm{cm})$ & $=$ & 0.00000 & 24.00000 & 36.00000 & 100.00000 & 138.00000 \\
Water $(\mathrm{cm} 3 / \mathrm{cm} 3)$ & $=$ & 0.13378 & 0.20397 & 0.28653 & 0.31746 & 0.36540 \\
Head $(\mathrm{cm})$ & $=3.18691 \mathrm{E}+02$ & $6.95303 \mathrm{E}+01$ & $8.75161 \mathrm{E}+01$ & $4.77887 \mathrm{E}+01$ & $1.53362 \mathrm{E}+01$ \\
LiqWater Flow $(\mathrm{cm})=-8.42107 \mathrm{E}-03$ & $1.16897 \mathrm{E}-02$ & $2.72425 \mathrm{E}-03$ & $3.96919 \mathrm{E}-03$ & $4.59734 \mathrm{E}-03$ \\
IsoVapor Flow $(\mathrm{cm})$ & $=-4.29972 \mathrm{E}-03$ & $8.09870 \mathrm{E}-08-6.44719 \mathrm{E}-09-1.01590 \mathrm{E}-08-6.30198 \mathrm{E}-09$
\end{tabular}




\begin{tabular}{|c|c|c|c|c|c|c|c|c|}
\hline \multirow{3}{*}{$\begin{array}{l}\text { PRESTOR } \\
58.3612+\end{array}$} & & \multicolumn{7}{|c|}{ LIQUID } \\
\hline & INEIL & RUNOFE & EVAPO & TRANS & DRAIN & & NEWSTOR & STORAGE \\
\hline & $0.0000+$ & 0.0000 & $-0.0087-$ & $0.0000-$ & $0: 0074$ & $=$ & 58.3451 vs. & 58.3450 \\
\hline
\end{tabular}

DAILY SUMMARY: DaY $=365$, Simulated Time $=24.0000 \mathrm{hr}$

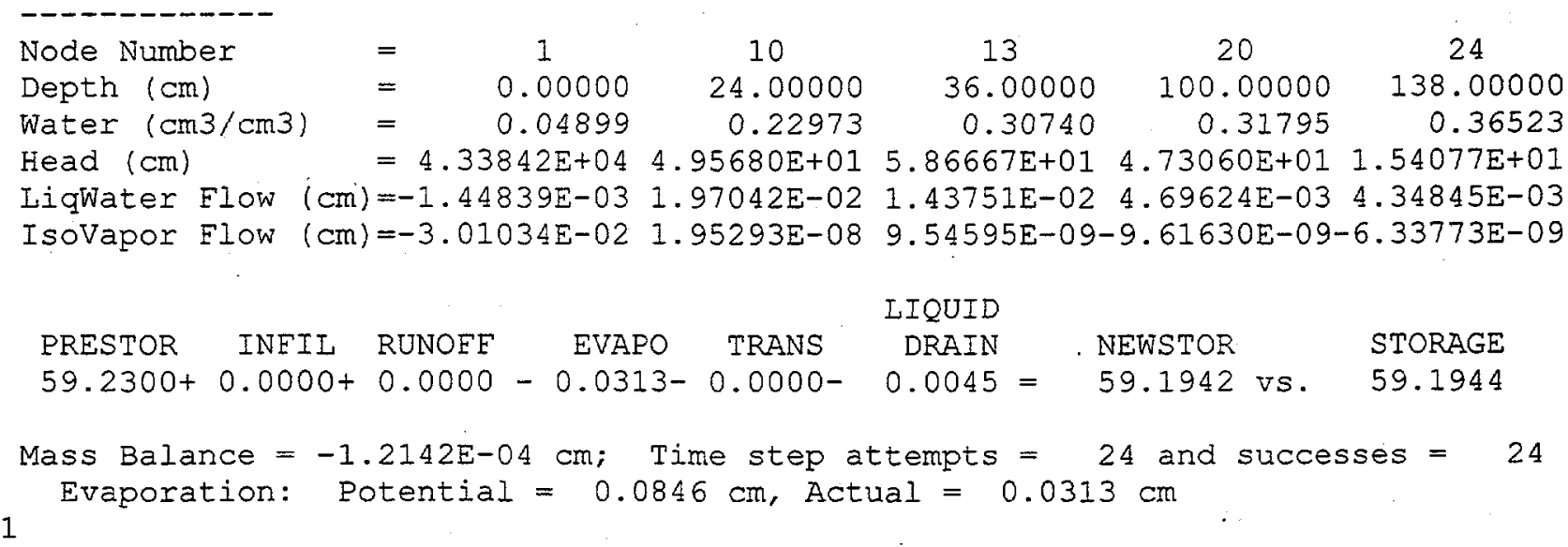

UNSAT-H Version 3.00

SIMULATION SUMMARY

Title:

N62NP: test of evaporation from unvegetated barrier using polys

Transpiration Scheme is:

Potential Evapotranspiration

Potential Transpiration

Actual Transpiration

Potential Evaporation

Actual Evaporation

Evaporation during Growth

Total Runoff

Total Infiltration

Total Basal Liquid Flux (drainage)

Total Basal Vapor Flux (temp-grad) =

Total Applied Water

Actual Rainfall

Actual Irrigation

Total Final Moisture Storage

Mass Balance Error

Total Successful Time Steps

Total Attempted Time Steps

Total Time Step Reductions

$=$

(DHMAX)
$=$

$=1.6109 \mathrm{E}+02$

$=0.0000 \mathrm{E}+00$

$=0.0000 E+00$

$=1.6109 \mathrm{E}+02$

$=1.2848 E+01$

$=0.0000 E+00$

$=0.0000 E+00$

$=1.5392 \mathrm{E}+01$

$=1.6618 \mathrm{E}+00$

$=0.0000 E+00$

$=1.5392 \mathrm{E}+01$

$=1.5392 \mathrm{E}+01$

$=0.0000 E+00$

$=5.9194 \mathrm{E}+01$

$=4.9125 \mathrm{E}-02$

$=.14959$

$=\quad 17641$

$=$ [cm]

[cm]

[cm]

[cm]

[cm]

[cm]

[cm]

[cm]

[cm]

[cm]

[cm]

[cm]

[cm]

[cm]

[cm]

\section{B. 21}


Total Changes in Surface Boundary = Total Time Actually Simulated
7175

$=3.6500 E+02 \quad$ [days]
Total liquid water flow $(\mathrm{cm})$ across

\begin{tabular}{rrrrrr}
\multicolumn{1}{c}{ DEPTH } & FLOW & DEPTH & \multicolumn{1}{c}{ ELOW } & DEPTH & FLOW \\
\hdashline 0.000 & $2.5441 \mathrm{E}+00$ & 0.050 & $8.5402 \mathrm{E}+00$ & 0.150 & $5.3046 \mathrm{E}+00$ \\
0.350 & $3.5926 \mathrm{E}+00$ & 0.750 & $2.5473 \mathrm{E}+00$ & 1.500 & $2.4840 \mathrm{E}+00$ \\
3.000 & $2.4831 \mathrm{E}+00$ & 6.000 & $2.4744 \mathrm{E}+00$ & 12.000 & $2.4471 \mathrm{E}+00$ \\
20.000 & $2.3513 \mathrm{E}+00$ & 26.000 & $2.1940 \mathrm{E}+00$ & 30.000 & $2.0666 \mathrm{E}+00$ \\
34.000 & $1.9735 \mathrm{E}+00$ & 40.000 & $1.8456 \mathrm{E}+00$ & 48.000 & $1.7237 \mathrm{E}+00$ \\
56.000 & $1.6409 \mathrm{E}+00$ & 65.000 & $1.5776 \mathrm{E}+00$ & 75.000 & $1.5347 \mathrm{E}+00$ \\
85.000 & $1.5105 \mathrm{E}+00$ & 95.000 & $1.4986 \mathrm{E}+00$ & 105.000 & $1.4941 \mathrm{E}+00$ \\
115.000 & $1.4934 \mathrm{E}+00$ & 125.000 & $1.4944 \mathrm{E}+00$ & 134.000 & $1.4958 \mathrm{E}+00$ \\
140.500 & $1.4970 \mathrm{E}+00$ & 145.000 & $1.4979 \mathrm{E}+00$ & 148.000 & $1.4987 \mathrm{E}+00$ \\
150.000 & $1.4993 \mathrm{E}+00$ & 152.000 & $1.4996 \mathrm{E}+00$ & 155.000 & $1.5000 \mathrm{E}+00$ \\
161.000 & $1.5008 \mathrm{E}+00$ & 173.000 & $1.5029 \mathrm{E}+00$ & 200.500 & $1.5083 \mathrm{E}+00$ \\
250.000 & $1.5248 \mathrm{E}+00$ & 310.000 & $1.5463 \mathrm{E}+00$ & 390.000 & $1.5768 \mathrm{E}+00$ \\
490.000 & $1.6281 \mathrm{E}+00$ & 540.000 & $1.6618 \mathrm{E}+00$ & &
\end{tabular}


Figure B.13. Input File for Layered Soil with Heat Flow Simulation

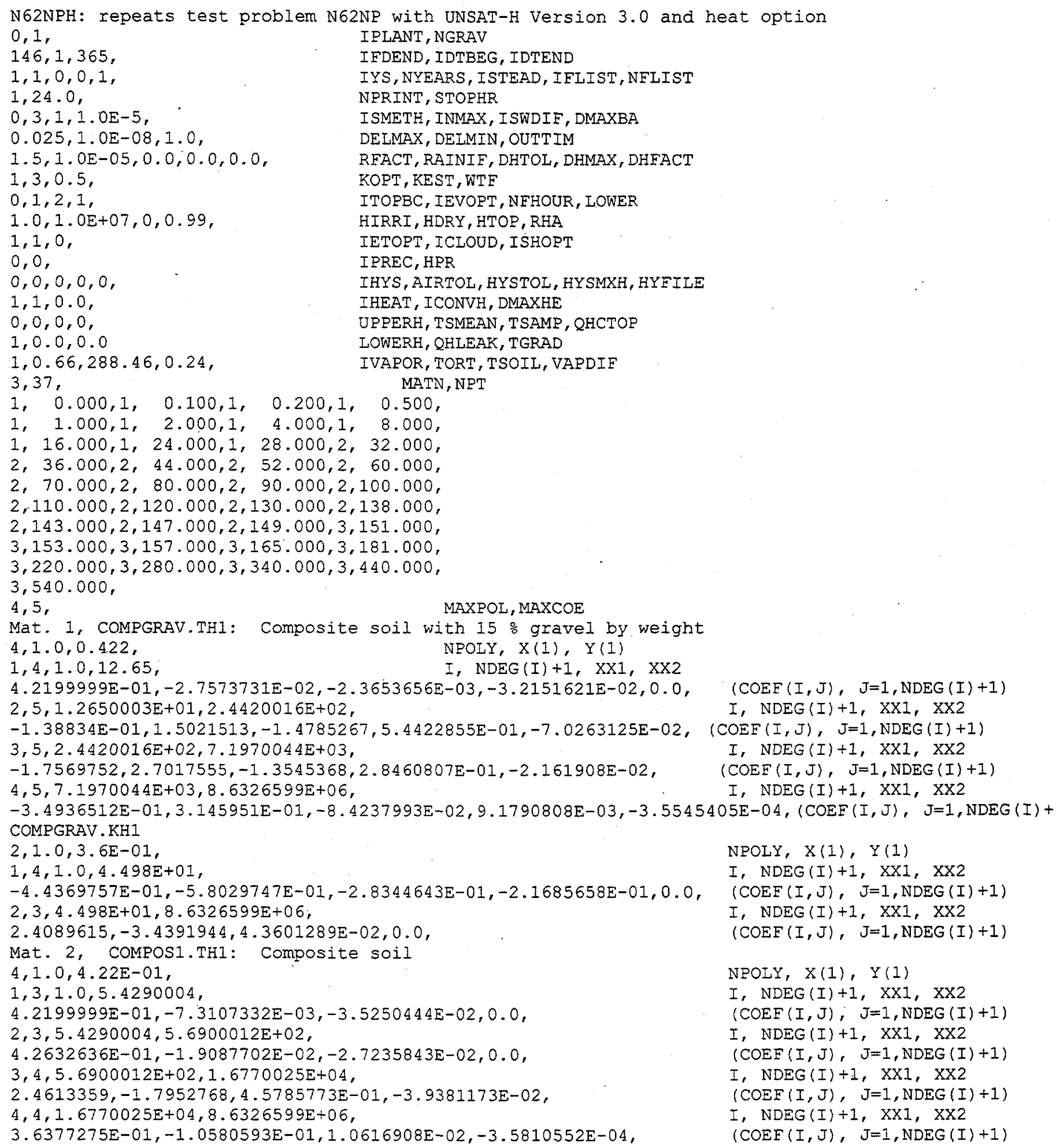

$(\operatorname{COEF}(I, J), \quad J=1, \operatorname{NDEG}(I)+1)$

$I, \operatorname{NDEG}(I)+1, \mathrm{XX} 1, \mathrm{XX} 2$

$(\operatorname{COEF}(I, J), J=1, \operatorname{NDEG}(I)+1)$

I, NDEG (I)+1, $\mathrm{XX1}, \mathrm{XX} 2$

$(\operatorname{COEF}(I, J), J=1, \operatorname{NDEG}(I)+1)$

$I, \operatorname{NDEG}(I)+1, \mathrm{XX1}, \mathrm{XX} 2$

NPOLY, $X(1), Y(1)$

I. $\mathrm{NDEG}(I)+1, \mathrm{XX} 1, \mathrm{XX} 2$

$(\operatorname{COEF}(I, J), J=1, \operatorname{NDEG}(I)+1)$

$I, \operatorname{NDEG}(I)+1, \quad \mathrm{XX} 1, \quad \mathrm{XX} 2$

$(\operatorname{COEF}(I, J), J=1, \operatorname{NDEG}(I)+1)$

NPOLY, $X(1), Y(1)$

$I, \operatorname{NDEG}(I)+1, \mathrm{XX1}, \mathrm{XX2}$ $(\operatorname{COEF}(I, J) ; J=1, \operatorname{NDEG}(I)+1)$

I, $\mathrm{NDEG}(I)+1, \quad \mathrm{XX1}, \mathrm{XX2}$

$(\operatorname{COEF}(I, J), J=1, \operatorname{NDEG}(I)+1)$

$I, \operatorname{NDEG}(I)+1, \mathrm{XX1}, \mathrm{XX} 2$

$(\operatorname{COEF}(I, J), J=1, \operatorname{NDEG}(I)+1)$

$I, \mathrm{NDEG}(I)+1, \mathrm{XX1}, \mathrm{XX} 2$

$(\operatorname{COEF}(I, J), J=1, \operatorname{NDEG}(I)+1)$ 
$3,1.0,1.080002 \mathrm{E}-01$

$1,4,1.0,1.3260002 \mathrm{E}+03$

$-9.6657562 \mathrm{E}-01,-1.0965506,5.8941185 \mathrm{E}-02,-1.2111266 \mathrm{E}-01,0.0$,

$2,4,1.3260002 \mathrm{E}+03,7.1970044 \mathrm{E}+03$,

$-6.3407219 E+01,6.0421951 E+01,-2.0131914 E+01,2.0865219,0.0$,

$3,4,7.1970044 \mathrm{E}+03,8.6326599 \mathrm{E}+06$,

$-9.5900745,1.8411379,-6.0871047 \mathrm{E}-01,2.465306 \mathrm{E}-02,0.0$,

Mat. 3, GRAVEL1.TH1: Gravel 0.6-1.3 cm diameter

$4,9.9999998 \mathrm{E}-03,4.19 \mathrm{E}-01$,

$1,3,9.9999998 \mathrm{E}-03,7.743001 \mathrm{E}-02$,

$2.9529411 \mathrm{E}-01,-9.5835656 \mathrm{E}-02,-1.6991356 \mathrm{E}-02,0.0$,

$2,3,7.743001 \mathrm{E}-02,2.7829993 \mathrm{E}-01$,

$-2.0774645 \mathrm{E}-01,-1.0013254,-4.2446923 \mathrm{E}-01,0.0$,

$3,5,2.7829993 \mathrm{E}-01,1.2920002 \mathrm{E}+01$,

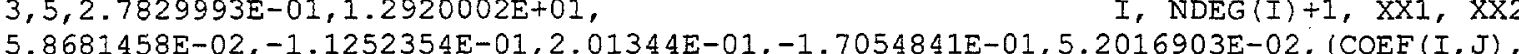

$4,5,1.2920002 \mathrm{E}+01,8.7777891 \mathrm{E}+06$,

$4.5875967 \mathrm{E}-02,-2.2514086 \mathrm{E}-02,6.2657609 \mathrm{E}-03,-7.9328578 \mathrm{E}-04,3.5441328 \mathrm{E}-05$, (COEF (I, J) GRAVELI. KH1

$4,9.9999998 \mathrm{E}-03,1.2600005 \mathrm{E}+03$,

$1,4,9.9999998 \mathrm{E}-03,2.7829993 \mathrm{E}-01$,

NPOLY, $X(1), Y(1)$

I, $\operatorname{NDEG}(I)+1, \mathrm{XX1}, \mathrm{XX} 2$

$-2.7429957,-1.0566543 E+01,-6.7793403,-1.4784553,0.0,(\operatorname{COEF}(I, J), J=1, \operatorname{NDEG}(I)+1)$

$2,3,2.7829993 \mathrm{E}-01,4.6420007$,

$-1.3305095,-5.0247631,-5.5922753 \mathrm{E}-01,0.0$,

$3,3,4.6420007,1.6680004 \mathrm{E}+01$

$1.8869209 \mathrm{E}-01,-9.5821028,2.8585794,0.0$,

$4,4,1.6680004 \mathrm{E}+01,8.7777891 \mathrm{E}+06$

$I, \operatorname{NDEG}(I)+1, \mathrm{XXI}, \mathrm{XX} 2$

$(\operatorname{COEF}(I, J) ; J=1, \operatorname{NDEG}(I)+I)$

$I, \mathrm{NDEG}(I)+1, \mathrm{XX} 1, \mathrm{XX} 2$

$\{\operatorname{COEF}(I, J), J=1, \operatorname{NDEG}(I)+1\rangle$

$I, \mathrm{NDEG}(I)+1, \mathrm{XX} 1, \mathrm{XX} 2$

$-3.7477951,-3.1739995,2.7821976 \mathrm{E}-01,-2.2469539 \mathrm{E}-02,0.0, \quad(\operatorname{COE} \mathrm{S}(I, J), J=1, \operatorname{NDEG}(I)+1)$

Mat. \#1, Silt Loam and Gravel Thermal Conductivity Parameters

$0.6,0.8,4.5,0.22,6.0,2.39$,

Mat. \#1, Silt Loam and Gravel Enhancement Factor Parameter

1.0,0.0,0.0,1.0,4.0,

Mat. \#2, Silt Loam Thermal Conductivity Parameters

$0.6,0.8,4.5,0.22,6.0,2.39$,

Mat. \#2, Silt Loam Enhancement Factor Parameters

$1.0,0.0,0.0,1.0,4.0$,

Mat. \#3, Gravel Thermal Conductivity Parameters

$0.6,0.7,8.0,0.26,3.0,1.36$,

Mat. \#3, Gravel Enhancement Factor Parameters

$1.0,0.0,0.0,1.0,3.0$,

143, NDAY (toss.out file for day $1.43000 \mathrm{E}+02$ ) Ver 3.00

$6.5292052 \mathrm{E}+01,6.4366785 \mathrm{E}+01$,

$5.6602297 \mathrm{E}+01, \quad 5.2304426 \mathrm{E}+01$,

$7.3783091 \mathrm{E}+01, \quad 8.0073890 \mathrm{E}+01$,

$8.1522638 \mathrm{E}+01,7.7905266 \mathrm{E}+01$,

$6.5810905 \mathrm{E}+01,6.0610858 \mathrm{E}+01$,

4. $0368980 E+01,3.2022959 \mathrm{E}+01$,

$1.0636506 \mathrm{E}+01, \quad 6.7075684 \mathrm{E}+00$,

$2.9159699 \mathrm{E}+00,2.9140662 \mathrm{E}+00$,

$2.9460494 \mathrm{E}+00,2.9708545 \mathrm{E}+00$,

$2.8941301 \mathrm{E}+00$

$6.3212998 \mathrm{E}+01$

5. $2471584 \mathrm{E}+01$,

$8.2884990 \mathrm{E}+01$,

$7.4203456 \mathrm{E}+01$,

5. $4695782 \mathrm{E}+01$

2. $3032104 \mathrm{E}+01$,

$4.7287791 \mathrm{E}+00$,

$2.9215843 E+00$,

$2.9873244 \mathrm{E}+00$,

$6.0252090 \mathrm{E}+01$

7. $3034711 \mathrm{E}+01$,

8. $3005400 E+01$,

7. $0535103 \mathrm{E}+01$,

$4.7950573 \mathrm{E}+01$,

1. $5479480 \mathrm{E}+01$,

$2.9137480 \mathrm{E}+00$

$2.9218399 \mathrm{E}+00$,

$2.9460487 \mathrm{E}+00$,

$289.1,289.1,289.1,289.1$,

$289.1,289.1,289.1,289.1$,

$289.1,289.1,289.1,289.1$,

$289.1,289.1,289.1,289.1$,

$289.1,289.1,289.1,289.1$,

$289.1,289.1,289.1,289.1$,

289.1,289.1,289.1,289.1,

$289.1,289.1,289.1,289.1$,

289.1,289.1,289.1,289.1,

289.1 , 
$0.00049,0.00049,0.914,15.24,0.0,46.57$

$1.0,33.0,26.0,28.9,41.4,2.0,10.0,0.00$,

$\mathrm{ZH}, \mathrm{ZM}, \mathrm{ZT}, \mathrm{ZU}, \mathrm{D}, \mathrm{LAT}$

$2.0,32.0,30.0,30.3,48.6,2.4,10.0,0.00$,

3.0, 54.0, 29.0, 33.9.105.6, 6.5, 8.1, 0.08,

< similar lines deleted >

$143.0,58.0,51.0,47.1,195.0,5.3,10.0,0.21$,

$144.0,54.0,49.0,49.1,66.6,4.1,10.0,0.51$,

$145.0,65.0,49.0,48.3,427.8,2.5,9.3,0.00$,

$146.0,74.0,46.0,48.2,616.2,2.0,4.6,0.00$,

$147.0,81.0,55.0,47.2,654.6,7.8,3.4,0.00$,

< similar Iines deleted >

$363.0,46.0,39.0,32.4,30.6,5.5,10.0,0.00$,

$364.0,52.0,37.0,35.0,14.4,8.0,10.0,0.00$,

$365.0,55.0,36.0,36.9,138.0,2.8,5.0,0.00$,

$$
\text { 62, NWATER (Total for } 1962=15.3924 \mathrm{~cm} \text { ) }
$$

3, 1, 2,1.000,

$0.0,0.2032$,

$2.0,0.0000$

$6,1,2,1.000$,

$14.0,0.0762$,

$15.0,0.0000$,

< similar lines deleted >

143. 1, 4,1.000,

$3.0,0.4318$,

$7.0,0.0000$,

8.0, 0.1016 ,

$10.0,0.0000$,

144, $1,6,1.000$,

$3.0,0.1524$,

$5.0,0.0000$,

$6.0,1.0668$,

$13.0,0.0000$,

$15.0,0.0762$,

$17.0,0.0000$,

$154,1,2,1.000$

$12.0,0.0254$,

$13.0,0.0000$,

< similar lines deleted >

351, 1, 4, 1.000,

$9.0,0.1524$,

$11.0,0.0000$,

$13.0,0.0254$,

$14.0,0.0000$,

$352, \quad 1,2,1.000$,

$13.0,0.0508$,

$15.0,0.0000$.

353, 1, 2, 1.000,

$2.0,0.1270$,

$4.0,0.0000$, 
Figure B.14. Output File for Layered Soil With Heat Flow Simulation

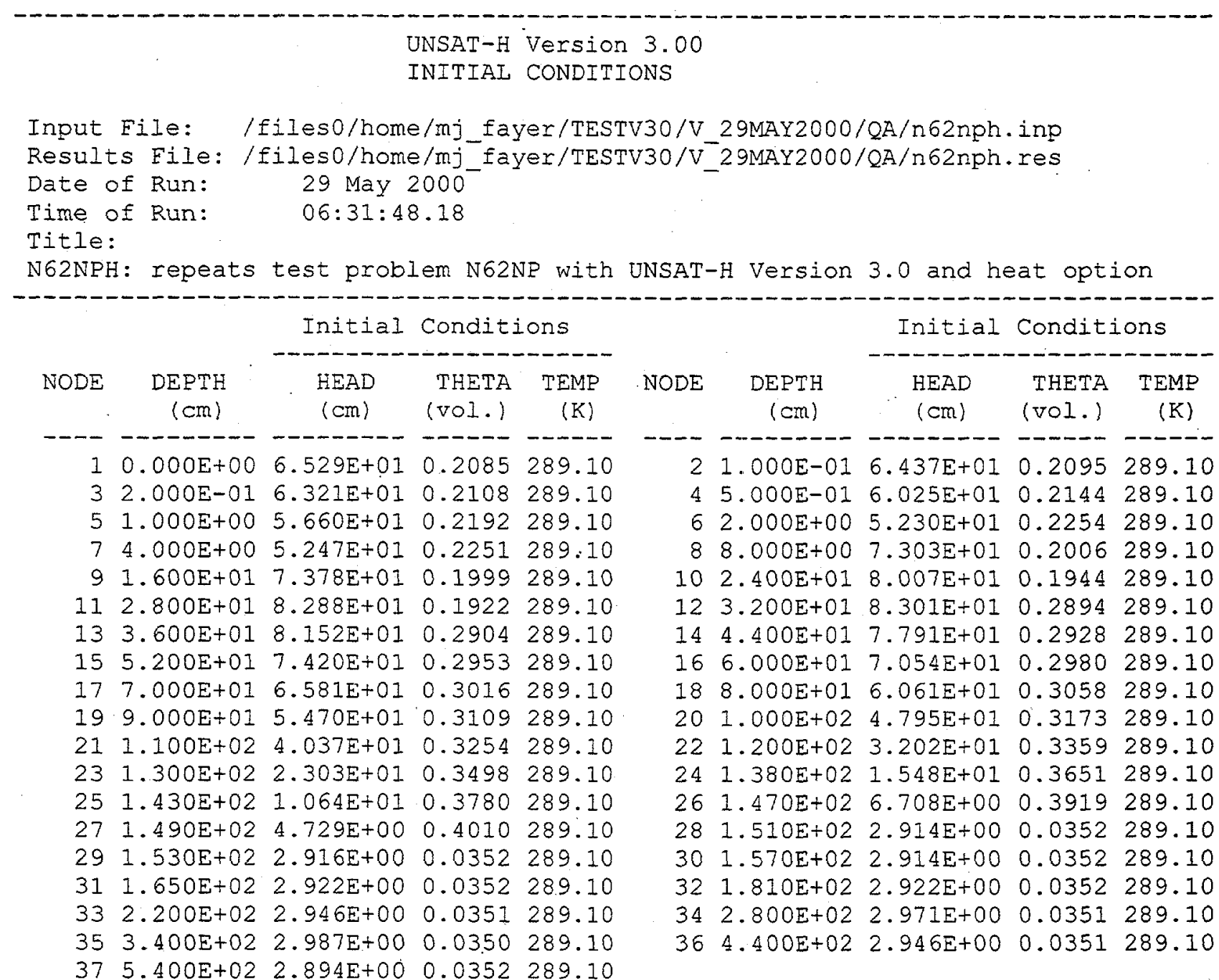

Initial Water Storage $=58.2248 \mathrm{~cm}$

DAILY SUMMARY: Day $=144$, Simulated Time $=24.0000 \mathrm{hr}$

$\begin{array}{llrrrrr}\text { Node Number } & = & 1 & 10 & 13 & 20 & 24 \\ \text { Depth }(\mathrm{cm}) & = & 0.00000 & 24.00000 & 36.00000 & 100.00000 & 138.00000 \\ \text { Water }(\mathrm{cm} 3 / \mathrm{cm} 3) & = & 0.31384 & 0.19469 & 0.29039 & 0.31730 & 0.36507 \\ \text { Head }(\mathrm{cm}) & =1.91395 \mathrm{E}+01 & 7.97661 \mathrm{E}+01 & 8.14697 \mathrm{E}+01 & 4.79483 \mathrm{E}+01 & 1.54779 \mathrm{E}+01 \\ \text { LiqWater Flow }(\mathrm{cm})= & =1.23598 \mathrm{E}+00 & 4.07325 \mathrm{E}-03 & 2.83395 \mathrm{E}-03 & 4.12915 \mathrm{E}-03 & 3.98979 \mathrm{E}-03 \\ \text { IsoVapor Flow }(\mathrm{cm}) & =-5.34182 \mathrm{E}-08 & 2.15181 \mathrm{E}-08-7.88358 \mathrm{E}-09-1.04033 \mathrm{E}-08-6.61384 \mathrm{E}-09 \\ \text { ThermVap Flow }(\mathrm{cm}) & =-2.45536 \mathrm{E}-04-7.58636 \mathrm{E}-05-1.52155 \mathrm{E}-05-1.43855 \mathrm{E}-08-4.26512 \mathrm{E}-11 \\ \text { Temperature }(\mathrm{K}) & =2.84977 \mathrm{E}+02 & 2.88357 \mathrm{E}+02 & 2.88747 \mathrm{E}+02 & 2.89099 \mathrm{E}+02 & 2.89100 \mathrm{E}+02 \\ \text { Heat Elow }(\mathrm{J} / \mathrm{cm} 2) & =-1.42415 \mathrm{E}+02-2.53018 \mathrm{E}+01-1.04597 \mathrm{E}+01-1.33201 \mathrm{E}-02-8.55975 \mathrm{E}-05\end{array}$

B.26 


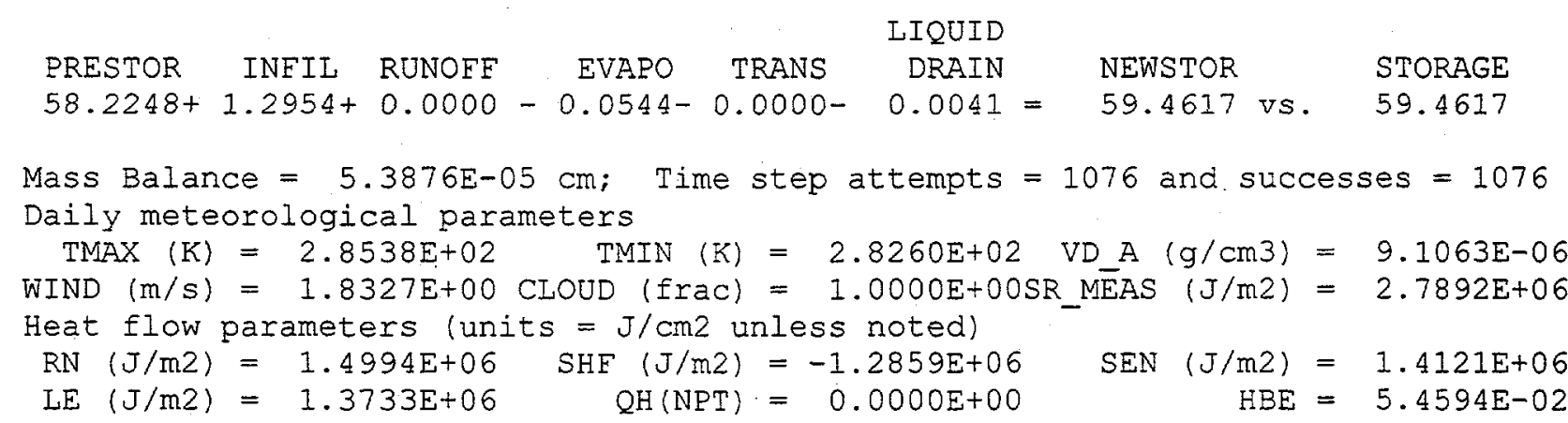

DAILY SUMMARY: DaY $=146$, Simulated Time $=24.0000 \mathrm{hr}$

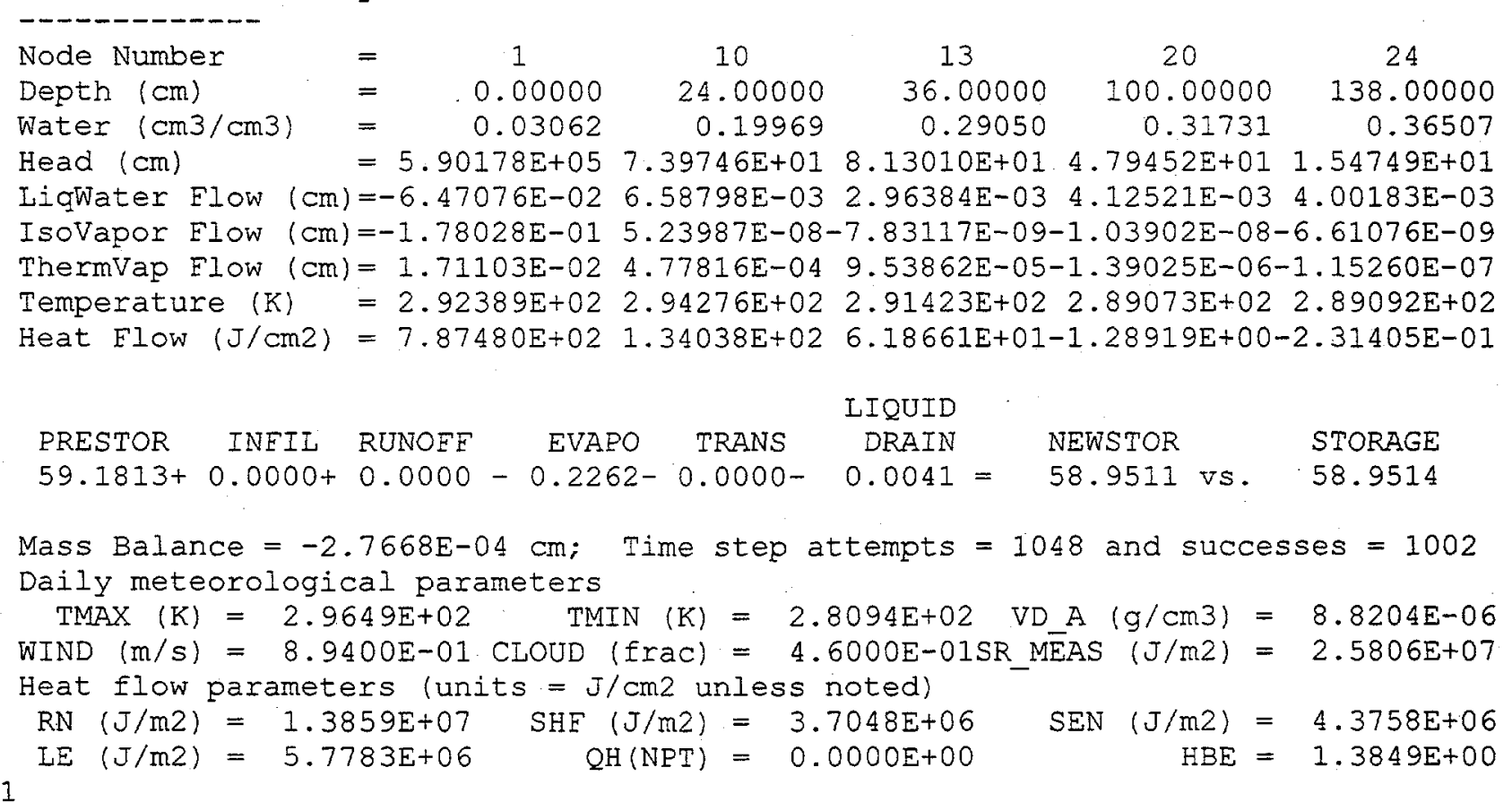

UNSAT-H Version 3.00

SIMULATION SUMMARY

Title:

N62NPH: repeats test problem N62NP with UNSAT-H Version 3.0 and heat option

Transpiration Scheme is:

Potential Evapotranspiration

Potential Transpiration

Actual Transpiration

Potential Evaporation

$\begin{array}{lll}=0 & \\ =0.0000 E+00 & {[\mathrm{~cm}]} \\ =0.0000 E+00 & {[\mathrm{~cm}]} \\ =0.0000 E+00 & {[\mathrm{~cm}]} \\ =0.0000 E+00 & {[\mathrm{~cm}]}\end{array}$

\section{B.27}


Actual Evaporation

Evaporation during Growth

Total Runoff

Total Infiltration

Total Basal Liquid Flux (drainage) =

Total Basal Vapor Flux (temp-grad) =

Total Applied Water

Actual Rainfall

Actual Irrigation

Total Final Moisture Storage

Mass Balance Error

Total Successful Time Steps

Total Attempted Time Steps

Total Time Step Reductions (DHMAX)

Total Changes in Surface Boundary

Total Time Actually Simulated.

Total Net Radiation

Total Soil-Surface Heat Flow

Total Sensible Heat Flow

Total Bottom Heat Flow

Total Iatent Heat Flow

Heat Balance Error

Total Convected Heat in Infilt.

Total Convected Heat in Drainage
$=5.5697 \mathrm{E}-01$

$=0.0000 E+00$

$=0.0000 \mathrm{E}+00$

$=1.2954 \mathrm{E}+00$

$=1.2205 \mathrm{E}-02$

$=0.0000 \mathrm{E}+00$

$=1.2954 \mathrm{E}+00$

$=1.2954 \mathrm{E}+00$

$=0.0000 \mathrm{E}+00$

$=5.8951 \mathrm{E}+01$

$=-3.4355 \mathrm{E}-04$

$=\quad 3052$

$=\quad 3110$

$=$

$=$

$=$

$=$

$=$

$=$

$=$

$=$

$=$

$=$

$=$ [cm]

[cm]

[cm]

[cm]

[cm]

[cm]

[cm]

[cm]

[cm]

[cm]

[cm]

[days]

[J/m2]

[ $J / m 2]$

[ $\mathrm{J} / \mathrm{m} 2]$

[J/m2]

[ $\mathrm{J} / \mathrm{m} 2$ ]

[J/m2]

[ $\mathrm{J} / \mathrm{m} 2]$

$[\mathrm{J} / \mathrm{m} 2]$

Total liquid water flow $(\mathrm{cm})$ across different depths at the end of $3.0000 \mathrm{E}+00$ days:

\begin{tabular}{r}
\multicolumn{1}{l}{ DEPTH } \\
\hdashline 0.000 \\
0.350 \\
3.000 \\
20.000 \\
34.000 \\
56.000 \\
85.000 \\
115.000 \\
140.500 \\
150.000 \\
161.000 \\
250.000 \\
490.000
\end{tabular}

\begin{tabular}{c} 
ELOW \\
\hdashline $7.3843 \mathrm{E}-01$ \\
$8.7273 \mathrm{E}-01$ \\
$8.1381 \mathrm{E}-01$ \\
$4.6612 \mathrm{E}-02$ \\
$9.5042 \mathrm{E}-03$ \\
$1.0193 \mathrm{E}-02$ \\
$1.2347 \mathrm{E}-02$ \\
$1.2272 \mathrm{E}-02$ \\
$1.1988 \mathrm{E}-02$ \\
$1.1852 \mathrm{E}-02$ \\
$1.1773 \mathrm{E}-02$ \\
$1.0905 \mathrm{E}-02$ \\
$1.1616 \mathrm{E}-02$
\end{tabular}

DEPTH

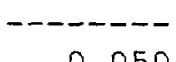

0.050

0.750

6.000

26.000

40.000

65.000

95.000

125.000

145.000

152.000

173.000

310.000

540.000

\begin{tabular}{c} 
FLOW \\
\hdashline $9.9862 \mathrm{E}-01$ \\
$8.0589 \mathrm{E}-01$ \\
$7.3679 \mathrm{E}-01$ \\
$1.5289 \mathrm{E}-02$ \\
$8.6928 \mathrm{E}-03$ \\
$1.1241 \mathrm{E}-02$ \\
$1.2436 \mathrm{E}-02$ \\
$1.2155 \mathrm{E}-02$ \\
$1.1933 \mathrm{E}-02$ \\
$1.1839 \mathrm{E}-02$ \\
$1.1680 \mathrm{E}-02$ \\
$1.0461 \mathrm{E}-02$ \\
$1.2205 \mathrm{E}-02$
\end{tabular}

DEPTH

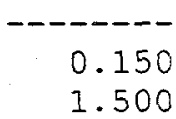

12.000

30.000

48.000

75.000

105.000

134.000

148.000

155.000

200.500

390.000
FLOW

$8.8570 \mathrm{E}-01$
$8.1646 \mathrm{E}-01$
$3.2415 \mathrm{E}-01$
$1.0824 \mathrm{E}-02$
$9.1992 \mathrm{E}-03$
$1.1991 \mathrm{E}-02$
$1.2382 \mathrm{E}-02$
$1.2058 \mathrm{E}-02$
$1.1888 \mathrm{E}-02$
$1.1817 \mathrm{E}-02$
$1.1427 \mathrm{E}-02$
$1.0660 \mathrm{E}-02$

Total heat flow $(\mathrm{J} / \mathrm{cm} 2)$ across different depths:

\section{DEPTH}

0.000

0.350

3.000
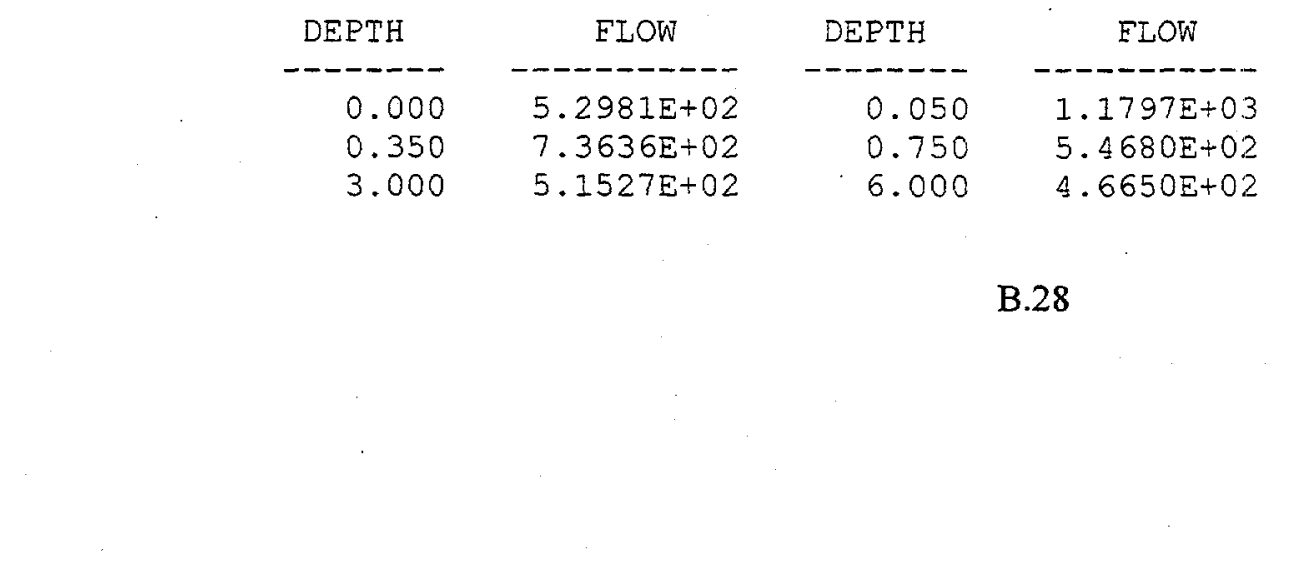

DEPTH

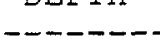

0.150

1.500

12.000
ELOW

$8.5868 \mathrm{E}+02$

$5.3683 E+02$

$3.4985 \mathrm{E}+02$ 


$\begin{array}{rrrrrr}20.000 & 2.1722 \mathrm{E}+02 & 26.000 & 1.4928 \mathrm{E}+02 & 30.000 & 1.1441 \mathrm{E}+02 \\ 34.000 & 8.2742 \mathrm{E}+01 & 40.000 & 4.6713 \mathrm{E}+01 & 48.000 & 2.0871 \mathrm{E}+01 \\ 56.000 & 7.6030 \mathrm{E}+00 & 65.000 & 3.1719 \mathrm{E}-01 & 75.000 & -2.5866 \mathrm{E}+00 \\ 85.000 & -3.0946 \mathrm{E}+00 & 95.000 & -2.6186 \mathrm{E}+00 & 105.000 & -1.8836 \mathrm{E}+00 \\ 115.000 & -1.2170 \mathrm{E}+00 & 125.000 & -7.1990 \mathrm{E}-01 & 134.000 & -4.1752 \mathrm{E}-01 \\ 140.500 & -2.6016 \mathrm{E}-01 & 145.000 & -1.6923 \mathrm{E}-01 & 148.000 & -1.1498 \mathrm{E}-01 \\ 150.000 & -7.9883 \mathrm{E}-02 & 152.000 & -6.8137 \mathrm{E}-02 & 155.000 & -5.5323 \mathrm{E}-02 \\ 161.000 & -3.5830 \mathrm{E}-02 & 173.000 & -1.4224 \mathrm{E}-02 & 200.500 & -1.5446 \mathrm{E}-03 \\ 250.000 & -5.6481 \mathrm{E}-05 & 310.000 & 1.2575 \mathrm{E}-06 & 390.000 & 1.3844 \mathrm{E}-06 \\ 490.000 & 4.4605 \mathrm{E}-07 & 540.000 & 0.0000 \mathrm{E}+00 & & \end{array}$


Figure B.15. Input File for Transpiration Simulation

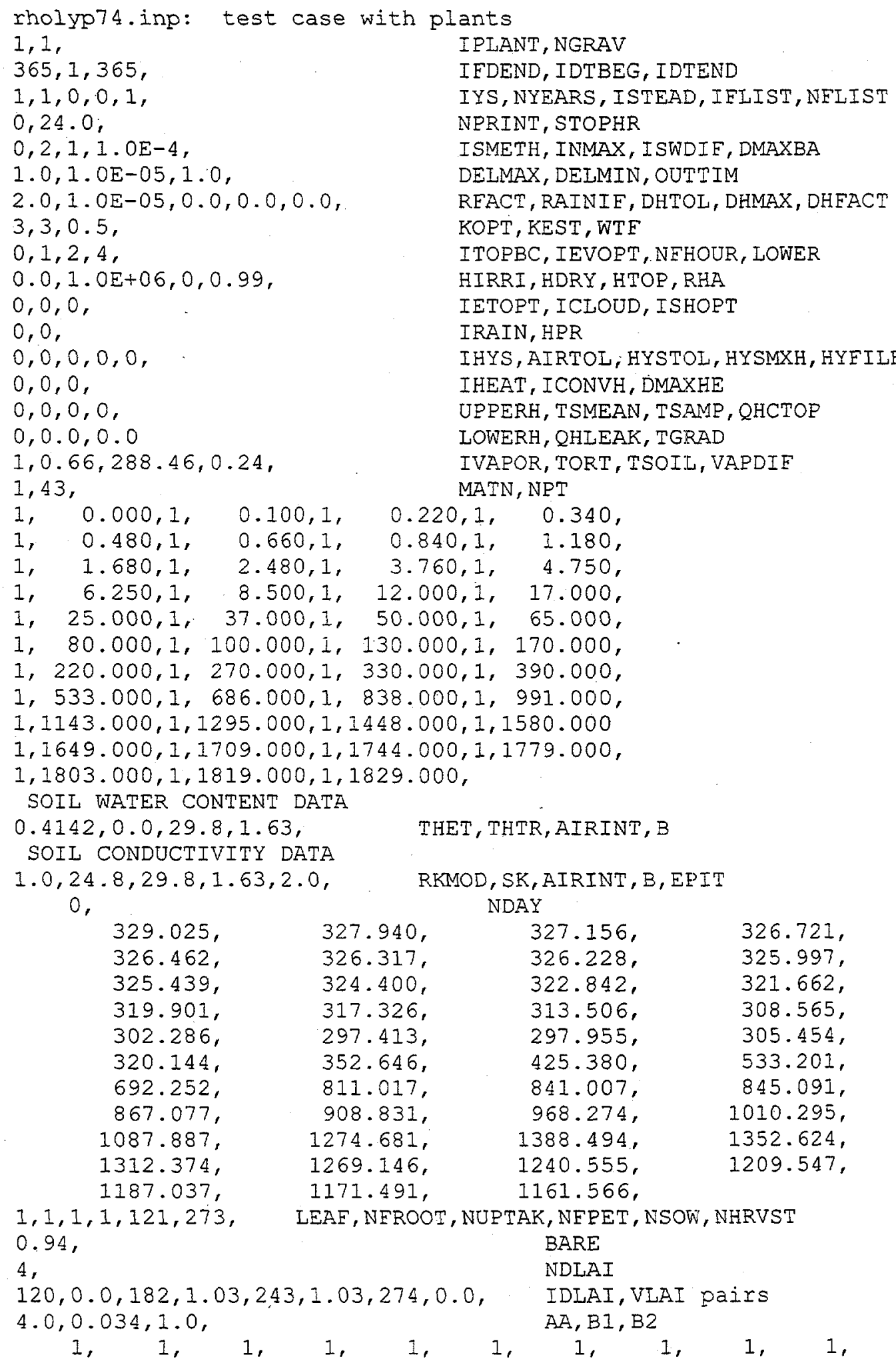




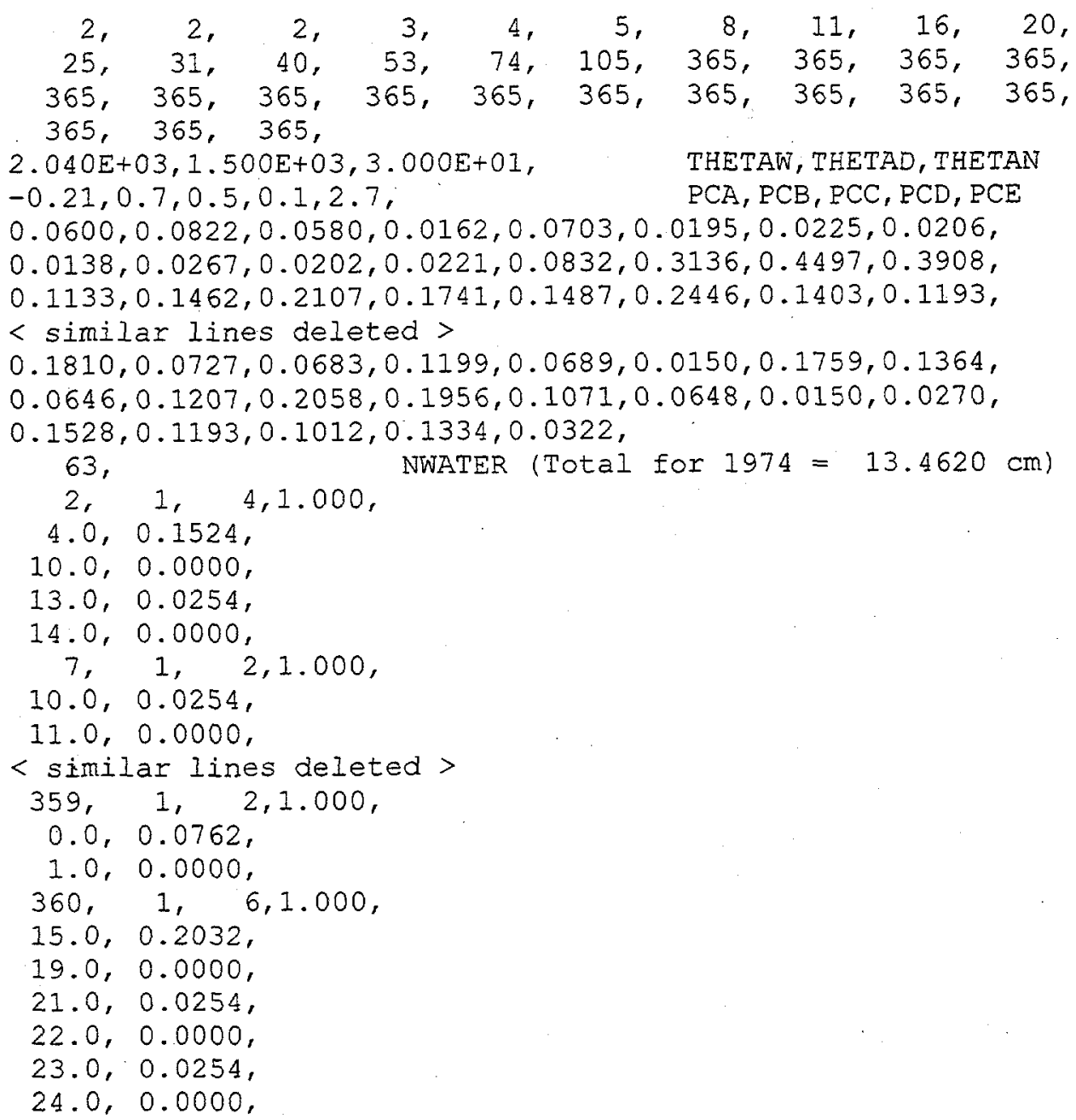


Figure B.16. Output File for Transpiration Simulation

\begin{tabular}{|c|c|c|c|c|c|c|c|c|c|}
\hline \multicolumn{10}{|c|}{$\begin{array}{l}\text { UNSAT-H Version } 3.00 \\
\text { INITIAL CONDITIONS }\end{array}$} \\
\hline \multicolumn{10}{|c|}{$\begin{array}{lc}\text { Input File: } & / \text { files } 0 / \text { home } / \mathrm{mj} \text { fayer } / \\
\text { Results File: } & / \text { files0/home/mj fayer/ } \\
\text { Date of Run: } & 20 \text { May } 2000 \\
\text { Time of Run: } & 10: 40: 30.64 \\
\text { Title: } & \\
\text { rholyp74.inp: } & \text { test case with plants }\end{array}$} \\
\hline & & Initial & Condi & & & & Initial & Condit & \\
\hline NODE & $\begin{array}{r}\mathrm{DEPTH} \\
(\mathrm{cm})\end{array}$ & $\begin{array}{l}\text { HEAD } \\
(\mathrm{cm})\end{array}$ & $\begin{array}{l}\text { THETA } \\
\text { (vol.) }\end{array}$ & $\begin{array}{r}\text { TEMP } \\
(K)\end{array}$ & NODE & $\begin{array}{l}\text { DEPTH } \\
(\mathrm{Cm})\end{array}$ & $\begin{array}{l}\text { HEAD } \\
(\mathrm{cm})\end{array}$ & $\begin{array}{l}\text { THETA } \\
\text { (VOI.) }\end{array}$ & $\begin{array}{r}\text { TEMP } \\
(K)\end{array}$ \\
\hline$--\frac{1}{1}$ & - - & $-1-1-1$ & $-x---$ & 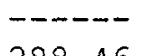 & & 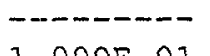 & - & $---1-1$ & \\
\hline $\begin{array}{l}1 \\
3\end{array}$ & $\begin{array}{l}0.000 E+00 \\
2.200 E-01\end{array}$ & $\begin{array}{l}3.290 E+02 \\
3.272 E+02\end{array}$ & $\begin{array}{l}0.0949 \\
0.0952\end{array}$ & $\begin{array}{l}288.46 \\
288.46\end{array}$ & $\begin{array}{l}2 \\
4\end{array}$ & & $\begin{array}{l}3.279 E+02 \\
3.267 E+02\end{array}$ & & \\
\hline 5 & 4. $800 E-01$ & $3.265 \mathrm{E}+02$ & 0.0954 & 288.46 & 6 & $6.600 E-01$ & $3.263 E+02$ & 0.0954 & \\
\hline 7 & $8.400 E-01$ & $3.262 E+02$ & 0.0954 & 288.46 & 8 & $1.180 \mathrm{E}+00$ & $3.260 E+02$ & 0.0955 & 288.46 \\
\hline 9 & $1.680 E+00$ & $3.254 E+02$ & 0.0956 & 288.46 & 10 & $2.480 E+00$ & $3.244 E+02$ & 0.0957 & 288.46 \\
\hline 11 & $3.760 E+00$ & $3.228 E+02$ & 0.0960 & 288.46 & 12 & $4.750 E+00$ & $3.217 E+02$ & 0.0962 & 288.46 \\
\hline 13 & $6.250 E+00$ & $3.199 E+02$ & 0.0966 & .46 & 14 & 8. & 3.1 & 0. & $\cdot$ \\
\hline 15 & $1.200 E+01$ & $3.135 E+02$ & 0.0978 & 288.46 & 16 & $1.700 \mathrm{E}+01$ & $3.086 E+02$ & 0.0987 &. \\
\hline 17 & $2.500 E+01$ & $3.023 E+02$ & 0.1000 & 288.46 & 18 & $3.700 E+01$ & $2.974 E+02$ & 0.1010 & 288.46 \\
\hline 19 & $5.000 E+01$ & $2.980 E+02$ & 0.1009 & 288.46 & 20 & $6.500 E+01$ & $3.055 E+02$ & 0.0993 & 288.46 \\
\hline 21 & $8.000 E+01$ & $3.201 E+02$ & 0.0965 & 288.46 & 22 & $1.000 E+02$ & $3.526 \mathrm{E}+02$ & 0.0910 & 288.46 \\
\hline 23 & $1.300 E+02$ & $4.254 E+02$ & 0.0811 & 288.46 & 24 & $1.700 \mathrm{E}+02$ & $5.332 \Xi+02$ & 0.0706 & 288.46 \\
\hline 25 & $2.200 \mathrm{E}+02$ & $6.923 E+02$ & 0.0601 & 288.46 & 26 & 2.70 & $8.110 E+02$ & 0 & 288 \\
\hline 27 & 3. $300 E+02$ & $8.410 E+02$ & 0.0534 & 288.46 & 28 & $3.900 E+02$ & $8.451 E+02$ & 0.0532 & 288.4 \\
\hline 29 & $5.330 \mathrm{E}+02$ & $8.671 E+02$ & 0.0524 & 288.46 & 30 & $6.860 E+02$ & $9.088 E+02$ & 0.0509 & 288.46 \\
\hline 31 & $8.380 E+02$ & $9.683 E+02$ & 0.0489 & 288.46 & 32 & $9.910 E+02$ & $1.010 E+03$ & 0.0477 & 288.46 \\
\hline 33 & $1.143 E+03$ & $1.088 \mathrm{E}+03$ & 0.0456 & 288.46 & 34 & $1.295 \mathrm{E}+03$ & $1.275 E+03$ & 0.0414 & 288.46 \\
\hline 35 & $1.448 \mathrm{E}+03$ & $1.388 E+03$ & 0.0392 & 288.46 & 36 & $1.580 E+03$ & $1.353 E+03$ & 0.0399 & 288.4 \\
\hline 37 & $1.649 E+03$ & $1.312 E+03$ & 0.0406 & 288.46 & 38 & $1.709 E+03$ & $1.269 E+03$ & 0.0415 & 288.4 \\
\hline 39 & $1.744 E+03$ & $1.241 E+03$ & 0.0420 & 288.46 & 40 & $1.779 E+03$ & $1.210 E+03$ & 0.0427 & 288.4 \\
\hline 41 & $1.803 E+03$ & $1.187 \mathrm{E}+03$ & 0.0432 & 288.46 & 42 & $1.819 E+03$ & $1.171 \mathrm{E}+03$ & 0.0435 & 288.46 \\
\hline
\end{tabular}

Initial water Storage $=93.8557 \mathrm{~cm}$

NOTE: There are no temperature data when plants are modelled.

DAIIY SUMMARY: Day $=1$, Simulated Time $=24.0000 \mathrm{hr}$

\begin{tabular}{|c|c|c|c|c|c|c|}
\hline $\operatorname{sic}$ & $=$ & 1 & 19 & 22 & 29 & 41 \\
\hline th $(\mathrm{cm}$ & $=$ & 0.00000 & 50.00000 & 100.00000 & 533.00000 & 03 \\
\hline ter $(\mathrm{cm} 3 / \mathrm{cm} 3)$ & $=$ & 0.09176 & 0.09871 & 0.09190 & 0.05238 & \\
\hline
\end{tabular}

B.32 
Head $(\mathrm{cm})$

$=3.47669 \mathrm{E}+02 \quad 3.08665 \mathrm{E}+02 \quad 3.46814 \mathrm{E}+02 \quad 8.67064 \mathrm{E}+02 \quad 1.18701 \mathrm{E}+03$

LiqWater Flow $(\mathrm{cm})=-5.98420 \mathrm{E}-02 \quad 1.05816 \mathrm{E}-01 \quad 1.09368 \mathrm{E}-01 \quad 1.65334 \mathrm{E}-03 \quad 1.23728 \mathrm{E}-05$

IsoVapor Flow $(\mathrm{cm})=-9.63501 \mathrm{E}-08 \quad 1.49752 \mathrm{E}-08 \quad 9.98989 \mathrm{E}-08 \quad 1.30047 \mathrm{E}-08-4.73607 \mathrm{E}-08$

Plant Sink $(\mathrm{cm})=0.00000 \mathrm{E}+00 \quad 0.00000 \mathrm{E}+00 \quad 0.00000 \mathrm{E}+00 \quad 0.00000 \mathrm{E}+00 \quad 0.00000 \mathrm{E}+00$

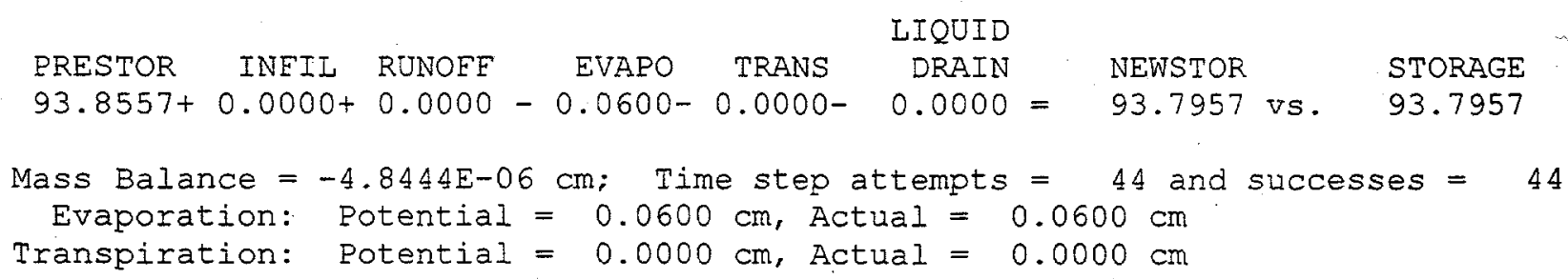

DAILY SUMMARY: Day $=365$, Simulated Time $=24.0000 \mathrm{hr}$

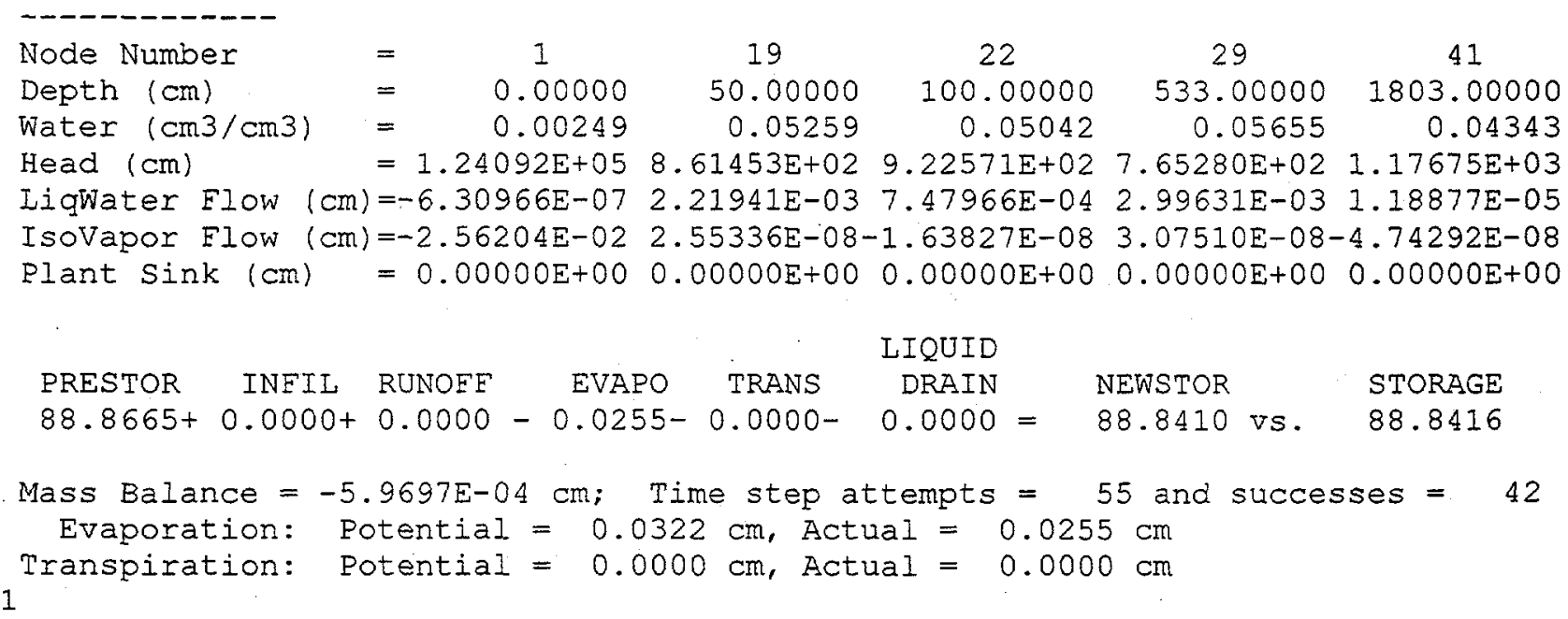

UNSAT-H Version 3.00

SIMULATION SUMMARY

Title:

rholyp74.inp: test case with plants

Transpiration Scheme is:

Potential Evapotranspiration

Potential Transpiration

Actual Transpiration

Potential Evaporation

Actual Evaporation

Evaporation during Growth

Total Runoff

Total Infiltration

Total Basal Liquid Flux (drainage) =

Total Basal Vapor Flux (temp-grad) =

$\begin{array}{lll}=1 & \\ =1.7494 E+02 & {[\mathrm{~cm}]} \\ =2.7426 E+00 & {[\mathrm{~cm}]} \\ =2.4068 E+00 & {[\mathrm{~cm}]} \\ =1.7220 E+02 & {[\mathrm{~cm}]} \\ =1.6042 E+01 & {[\mathrm{~cm}]} \\ =3.7537 E+00 & {[\mathrm{~cm}]} \\ =0.0000 E+00 & {[\mathrm{~cm}]} \\ =1.3462 E+01 & {[\mathrm{~cm}]} \\ =0.0000 E+00 & {[\mathrm{~cm}]} \\ =0.0000 E+00 & {[\mathrm{~cm}]}\end{array}$

B.33 
Total Applied Water

Actual Rainfall

Actual Irrigation

Total Final Moisture Storage

Mass Balance Error

Total Successful Time Steps

Total Attempted Time Steps

Total Time Step Reductions (DHMAX)

Total Changes in Surface Boundary

Total Time Actually Simulated
$=$

$=$

$=$

$=$

$\begin{array}{cc}1.3462 \mathrm{E}+01 & {[\mathrm{~cm}]} \\ 1.3462 \mathrm{E}+0] & {[\mathrm{cm}]} \\ 0.0000 \mathrm{E}+00 & {[\mathrm{~cm}]} \\ 8.8842 \mathrm{E}+01 & {[\mathrm{~cm}]} \\ 2.7345 \mathrm{E}-02 & {[\mathrm{~cm}]} \\ 18344 & \\ 22984 & \\ 0 & \\ 8555 & \\ 3.6500 \mathrm{E}+02 & {[\text { days }}\end{array}$

4

Total liquid water flow $(\mathrm{cm})$ across different depths at the end of $3.6500 \mathrm{E}+02$ days: -

\begin{tabular}{r}
\multicolumn{1}{c}{ DEPTH } \\
\hdashline 0.000 \\
0.280 \\
0.750 \\
2.080 \\
5.500 \\
14.500 \\
43.500 \\
90.000 \\
195.000 \\
360.000 \\
762.000 \\
1219.000 \\
1614.500 \\
1761.500 \\
1824.000
\end{tabular}

FLOW
$-2.5800 \mathrm{E}+00$
$4.5134 \mathrm{E}+00$
$1.4356 \mathrm{E}+00$
$-1.2040 \mathrm{E}+00$
$-1.9634 \mathrm{E}+00$
$-1.9259 \mathrm{E}+00$
$-1.0462 \mathrm{E}+00$
$6.1801 \mathrm{E}-01$
$2.7586 \mathrm{E}+00$
$2.0658 \mathrm{E}+00$
$5.7145 \mathrm{E}-01$
$3.4906 \mathrm{E}-01$
$4.6511 \mathrm{E}-02$
$1.5488 \mathrm{E}-02$
$1.2199 \mathrm{E}-03$

\begin{tabular}{r}
\multicolumn{1}{|c}{ DEPTH } \\
\hdashline 0.050 \\
0.410 \\
1.010 \\
3.120 \\
7.375 \\
21.000 \\
57.500 \\
115.000 \\
245.000 \\
461.500 \\
914.500 \\
1371.500 \\
1679.000 \\
1791.000 \\
1829.000
\end{tabular}

\begin{tabular}{c} 
ELOW \\
\hdashline $7.3153 E+00$ \\
$3.5521 E+00$ \\
$6.6549 E-01$ \\
$-1.6475 E+00$ \\
$-2.0265 E+00$ \\
$-1.7409 E+00$ \\
$-5.5352 E-01$ \\
$1.4307 E+00$ \\
$2.7389 E+00$ \\
$1.4292 E+00$ \\
$4.3253 E-01$ \\
$1.9109 E-01$ \\
$3.2576 E-02$ \\
$8.9277 E-03$ \\
$0.0000 E+00$
\end{tabular}

DEPTH

$-\cdots-\cdots$

0.160

0.570

1.430

4.255

10.250

31.000

72.500

150.000

300.000

609.500

1067.000

1514.000

1726.500

1811.000

FLOW
$-5.8761 E+00$
$2.4286 \mathrm{E}+00$
$-2.4081 \mathrm{E}-01$
$-1.8736 \mathrm{E}+00$
$-2.0644 \mathrm{E}+00$
$-1.4527 \mathrm{E}+00$
$-8.2349 \mathrm{E}-03$
$2.2454 \mathrm{E}+00$
$2.3880 \mathrm{E}+00$
$8.1194 \mathrm{E}-01$
$3.8474 \mathrm{E}-01$
$7.8259 \mathrm{E}-02$
$2.2887 \mathrm{E}-02$
$4.3016 \mathrm{E}-03$

Total plant water uptake $(\mathrm{cm})$ at different depths:

\begin{tabular}{rr} 
DEPTH & WATER UPTAKE \\
\hdashline 0.000 & $0.0000 \mathrm{E}+00$ \\
0.340 & $9.4469 \mathrm{E}-05$ \\
0.840 & $3.0951 \mathrm{E}-04$ \\
2.480 & $3.0899 \mathrm{E}-03$ \\
6.250 & $1.9701 \mathrm{E}-02$ \\
17.000 & $1.3950 \mathrm{E}-01$ \\
50.000 & $1.8325 \mathrm{E}-01$ \\
100.000 & $2.0078 \mathrm{E}-01$ \\
220.000 & $2.5893 \mathrm{E}-01$ \\
390.000 & $0.0000 \mathrm{E}+00$ \\
838.000 & $0.0000 \mathrm{E}+00$ \\
1295.000 & $0.0000 \mathrm{E}+00$ \\
1649.000 & $0.0000 \mathrm{E}+00$ \\
1779.000 & $0.0000 \mathrm{E}+00$ \\
1829.000 & $0.0000 \mathrm{E}+00$
\end{tabular}

\begin{tabular}{rr} 
DEPTH & WATER UPTAKE \\
\hline 0.100 & $-1.6593 \mathrm{E}-0.5$ \\
0.480 & $1.3563 \mathrm{E}-04$ \\
1.180 & $6.1783 \mathrm{E}-04$ \\
3.760 & $5.7976 \mathrm{E}-03$ \\
8.500 & $4.1294 \mathrm{E}-02$ \\
25.000 & $2.0286 \mathrm{E}-01$ \\
65.000 & $1.6005 \mathrm{E}-01$ \\
130.000 & $2.4697 \mathrm{E}-01$ \\
270.000 & $2.0472 \mathrm{E}-0$. \\
533.000 & $0.0000 \mathrm{E}+00$ \\
991.000 & $0.0000 \mathrm{E}+00$ \\
1448.000 & $0.0000 \mathrm{E}+00$ \\
1709.000 & $0.0000 \mathrm{E}+00$ \\
1803.000 & $0.0000 \mathrm{E}+00$
\end{tabular}

DEPTH

0.220

0.660

1.680

4.750

12.000

37.000

80.000

170.000

330.000

686.000

1143.000

1580.000

1744.000

1819.000
WATER UPTAKE
$7.7425 \mathrm{E}-05$
$1.8635 \mathrm{E}-04$
1. $2850 \mathrm{E}-03$
9. $1241 E-03$
7. $9159 \mathrm{E}-02$
2.0379E-01
1. $6120 \mathrm{E}-01$
2. $8381 E-01$
$0.0000 E+00$
$0.0000 E+00$
$0.0000 E+00$
$0.0000 E+00$
$0.0000 E+00$
$0.0000 \mathrm{E}+00$ 
Figure B.17. Input File for Multiyear Simulation

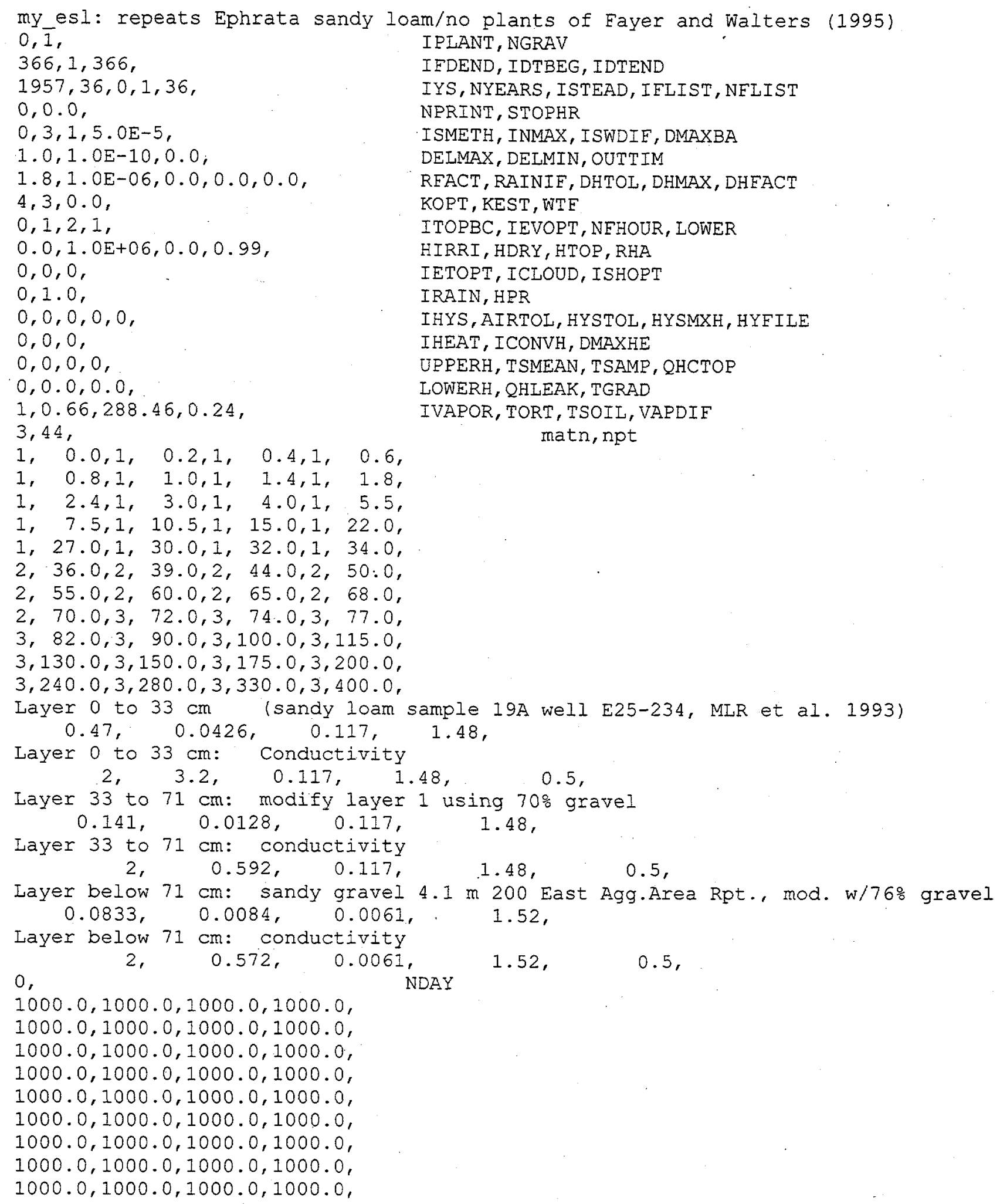


$1000.0,1000.0,1000.0,1000.0$,

$1000.0,1000.0,1000.0,1000.0$,

$\sim /$ hms/dayv30/

pet

pen_u7

$\sim /$ hms/dayv30/

rain

dat 
Figure B.18. Output File for Multiyear Simulation

\section{UNSAT-H Version 3.00}

INITIAI CONDITIONS

Input File: /files0/home/mj_fayer/TESTV30/V_29MAY2000/QA/my_esl.inp Results File: /files0/home/mj_fayer/TESTV30/V_29MAY2000/QA/my_esl1957.res

Date of Run: 20 May 2000

Time of Run: $\quad 11: 39: 59.84$

Title:

my_esI: repeats Ephrata sandy loam/no plants of Fayer and Walters (1995)

\begin{tabular}{|c|c|c|c|c|c|c|c|c|c|}
\hline \multirow[b]{2}{*}{ NODE } & \multicolumn{6}{|c|}{ Initial Conditions } & \multicolumn{3}{|c|}{ Initial Conditions } \\
\hline & $\begin{array}{c}\text { DEPTH } \\
(\mathrm{cm})\end{array}$ & $\begin{array}{l}\text { HEAD } \\
(\mathrm{cm})\end{array}$ & $\begin{array}{l}\text { THETA } \\
\text { (VOI.) }\end{array}$ & $\begin{array}{r}\text { TEMP } \\
(\mathrm{K})\end{array}$ & NODE & $\begin{array}{c}\text { DEPTH } \\
(\mathrm{cm})\end{array}$ & $\begin{array}{l}\text { HEAD } \\
(\mathrm{cm})\end{array}$ & $\begin{array}{c}\text { THETA } \\
\text { (vol.) }\end{array}$ & $\begin{array}{r}\text { TEMP } \\
(\mathrm{K})\end{array}$ \\
\hline & & & & & & & & & \\
\hline 1 & $0.000 E+00$ & $1.000 E+03$ & 0.0860 & 288.46 & 2 & $2.000 \mathrm{E}-01$ & $1.000 E+03$ & 0.0 & 288. \\
\hline 3 & $4.000 E-01$ & $1.000 E+03$ & 0.0860 & 288.46 & 4 & 11 & $00 E+03$ & 0.0 & 288 \\
\hline 5 & $8.000 E-01$ & $1.000 \mathrm{E}+03$ & 0.0860 & 288.46 & 6 & $1.000 E+00$ & $1.000 E+03$ & 0.0860 & 288.46 \\
\hline 7 & 1. $400 E+00$ & $1.000 E+03$ & 0.0860 & 288.46 & 8 & $1.800 E+00$ & $1.000 E+03$ & 0.0860 & 288.46 \\
\hline 9 & $2.400 \mathrm{E}+00$ & $1.000 E+03$ & 0.0860 & 288.46 & 10 & $3.000 E+00$ & $1.000 E+03$ & 0.1 .0$. & 288.46 \\
\hline 11 & $4.000 E+00$ & $1.000 E+03$ & 0.0860 & 288.46 & 12 & $5.500 \mathrm{E}+00$ & $1.000 E+03$ & $0.8-1.30$ & 288.46 \\
\hline 13 & $7.500 E+00$ & $1.000 E+03$ & 0.0860 & 288.46 & 14 & $1.050 E+01$ & $1.000 E+03$ & 0.0 & 288.46 \\
\hline 15 & $1.500 E+01$ & $1.000 E+03$ & 0.0860 & 288.46 & 16 & $2.200 E+01$ & $1.000 E+03$ & 0.0860 & 288.46 \\
\hline 17 & $2.700 \Xi+01$ & $1.000 \mathrm{E}+03$ & 0.0860 & 288.46 & 18 & $3.000 E+01$ & $1.000 E+03$ & 0.0860 & 288.46 \\
\hline 19 & $3.200 E+01$ & $1.000 E+03$ & 0.0860 & 288.46 & 20 & $3.400 E+01$ & $1.000 E+03$ & 0.0 & 288.46 \\
\hline 21 & 3.60 & $1.000 E+03$ & 0.0258 & 288.46 & 22 & +01 & $1.000 E+03$ & 0.0 & 288.46 \\
\hline 23 & $4.400 E+01$ & $1.000 \mathrm{E}+03$ & 0.0258 & 288.46 & 24 & \pm+01 & $1.000 E+03$ & 0. & 288.46 \\
\hline 25 & $5.500 E+01$ & $1.000 E+03$ & 0.0258 & 288.46 & 26 & $6.000 E+01$ & $1.000 E+03$ & 0.0 & 288.46 \\
\hline 27 & $6.500 E+01$ & $1.000 E+03$ & 0.0258 & 288.46 & 28 & $6.800 E+01$ & $1.000 E+03$ & 0.0258 & 288.46 \\
\hline 29 & $7.000 E+01$ & $1.000 \mathrm{E}+03$ & 0.0258 & 288.46 & 30 & $7.200 E+0 I$ & $1.000 E+03$ & 0.0370 & 288.46 \\
\hline 31 & $7.400 E+01$ & $1.000 E+03$ & 0.0370 & 288.46 & 32 & $7.700 E+01$ & $1.000 E+03$ & 0.0 & 288.46 \\
\hline 33 & $8.200 E+01$ & $1.000 E+03$ & 0.0370 & 288.46 & 34 & $9.000 E+0 I$ & $1.000 E+03$ & 0.0370 & 288.46 \\
\hline 35 & $1.000 E+02$ & $1.000 E+03$ & 0.0370 & 288.46 & 36 & 1. $150 E+02$ & $1.000 E+03$ & 0.0370 & 288.46 \\
\hline 37 & $1.300 E+02$ & $1.000 \mathrm{E}+03$ & 0.0370 & 288.46 & 38 & $1.500 \mathrm{E}+02$ & $1.000 E+03$ & 0.0370 & 288.46 \\
\hline 39 & $1.750 E+02$ & $1.000 E+03$ & 0.0370 & 288.46 & 40 & $2.000 E+02$ & $1.000 E+03$ & 0.0370 & 288.46 \\
\hline 41 & $2.400 E+02$ & $1.000 E+03$ & 0.0370 & 288.46 & 42 & $2.800 E+02$ & $1.000 E+03$ & 0.0370 & 288.46 \\
\hline$\neq 0$ & $3.300 E+02$ & $1.000 \mathrm{E}+03$ & 0.0370 & 288.46 & 44 & $4.000 E+02$ & $1.000 E+03$ & 0.0370 & 288.46 \\
\hline
\end{tabular}

Initial Water Storage $=16.1265 \mathrm{~cm}$

DAILY SUMMARY: Day $=1$, Simulated Time $=24.0000 \mathrm{hx}$

Node Number

Depth $(\mathrm{cm})$

Water $(\mathrm{cm} 3 / \mathrm{cm} 3)$

Head $(\mathrm{cm})$

Liqwater Flow $(\mathrm{cm})=1.94331 \mathrm{E}-06 \quad 3.59533 \mathrm{E}-073.23057 \mathrm{E}-03 \quad 3.74461 \mathrm{E}-03 \quad 3.74488 \mathrm{E}-03$

IsoVapor Flow $(\mathrm{cm})=-2.60821 \mathrm{E}-12$ 6.91520E-14-8.15460E-10-4.13565E-13-1.10499E-17 


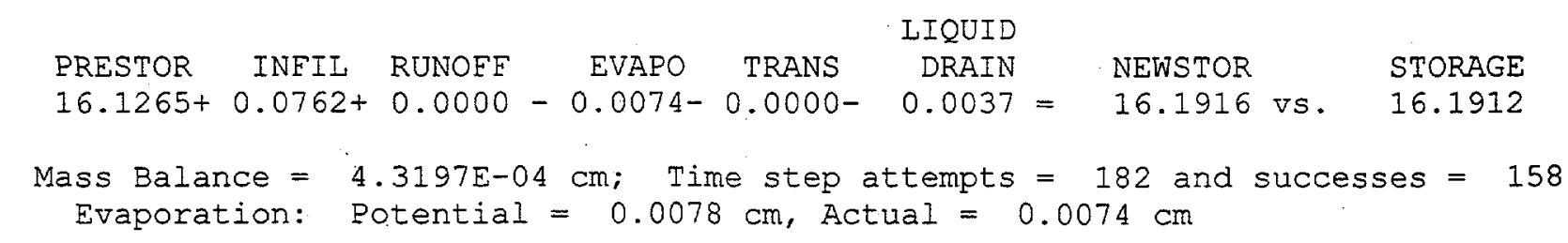

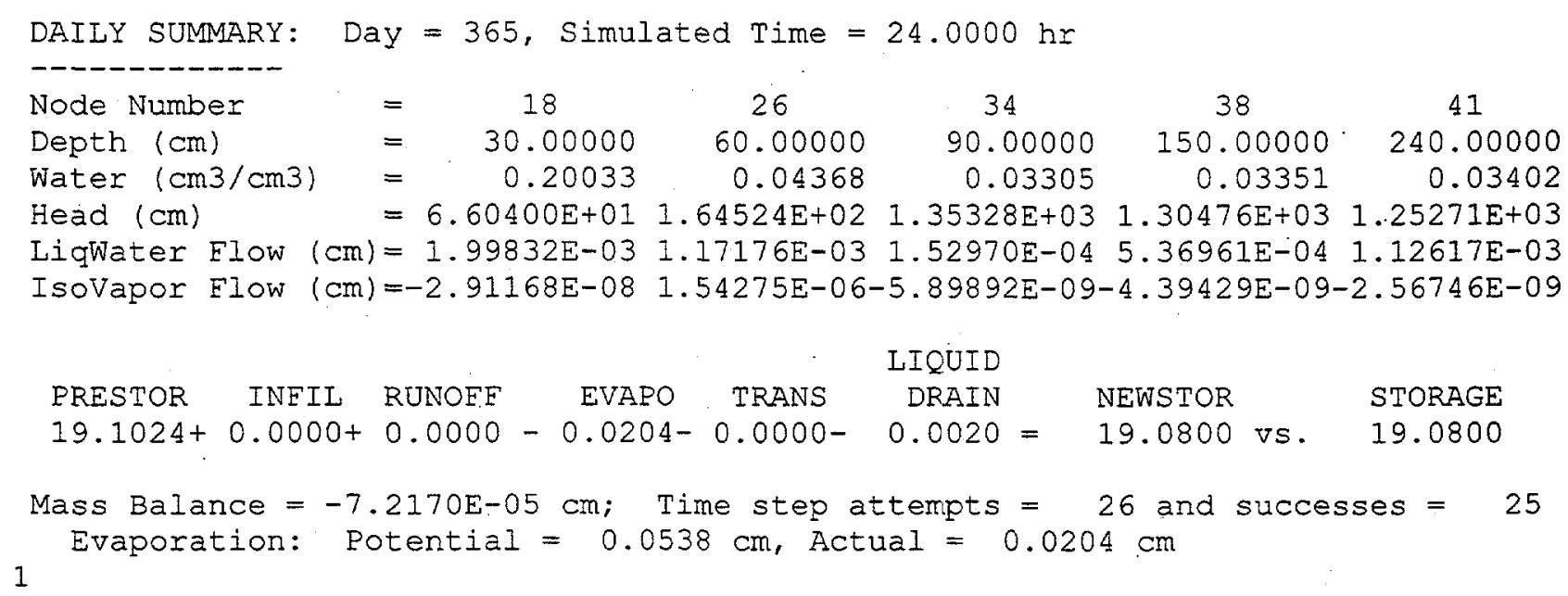

UNSAT-H Version 3.00

SIMULATION SUMMARY

Title:

my_esl: repeats Ephrata sandy loam/no plants of Fayer and Walters (1995)

$\begin{array}{llcl}\text { Transpiration Scheme is: } & = & & \\ \text { Potential Evapotranspiration } & =1.6642 \mathrm{E}+02 & {[\mathrm{~cm}]} \\ \text { Potential Transpiration } & =0.0000 \mathrm{E}+00 & {[\mathrm{~cm}]} \\ \text { Actual Transpiration } & =0.0000 \mathrm{E}+00 & {[\mathrm{~cm}]} \\ \text { Potential Evaporation } & =1.6642 \mathrm{E}+02 & {[\mathrm{~cm}]} \\ \text { Actual Evaporation } & =1.6833 \mathrm{E}+01 & {[\mathrm{~cm}]} \\ \text { Evaporation during Growth } & =0.0000 \mathrm{E}+00 & {[\mathrm{~cm}]} \\ \text { Total Runoff } & =2.9421 \mathrm{E}-01 & {[\mathrm{~cm}]} \\ \text { Total Infiltration } & =2.0762 \mathrm{E}+01 & {[\mathrm{~cm}]} \\ \text { Total Basal Liquid Flux (drainage) } & =1.0467 \mathrm{E}+00 & {[\mathrm{~cm}]} \\ \text { Total Basal Vapor Flux (temp-grad) } & =0.0000 \mathrm{E}+00 & {[\mathrm{~cm}]} \\ \text { Total Applied Water } & =2.1057 \mathrm{E}+01 & {[\mathrm{~cm}]} \\ \text { Actual Rainfall } & =2.1057 \mathrm{E}+01 & {[\mathrm{~cm}]} \\ \text { Actual Irrigation } & =0.0000 \mathrm{E}+00 & {[\mathrm{~cm}]} \\ \text { Total Final Moisture Storage } & =1.9080 \mathrm{E}+01 & {[\mathrm{~cm}]} \\ \text { Mass Balance Error } & =-7.0611 \mathrm{E}-02 & {[\mathrm{~cm}]} \\ \text { Total Successful Time Steps } & = & 23968 & \\ \text { Total Attempted Time Steps } & = & 32145 & \end{array}$

\section{B.38}


Total Time step Reductions (DHMAX) = Total Changes in Surface Boundary = Total Time Actually Simulated
$=$

$=$
0

10004

3. $6500 \mathrm{E}+02$ [days]

Total liquid water flow $(\mathrm{cm})$ across

different depths at the end of $3.6500 \mathrm{E}+02$ days:

1

\begin{tabular}{r} 
DEPTH \\
\hline 0.000 \\
0.500 \\
1.200 \\
2.700 \\
6.500 \\
18.500 \\
31.000 \\
37.500 \\
52.500 \\
66.500 \\
73.000 \\
86.000 \\
122.500 \\
187.500 \\
305.000
\end{tabular}

\begin{tabular}{cr} 
ELOW & \multicolumn{1}{c}{ DEPTH } \\
\hdashline $3.9296 E+00$ & -1.100 \\
$9.6912 E+00$ & 0.700 \\
$6.4692 \mathrm{E}+00$ & 1.600 \\
$4.7997 \mathrm{E}+00$ & 3.500 \\
$3.9226 \mathrm{E}+00$ & 9.000 \\
$2.6533 \mathrm{E}+00$ & 24.500 \\
$1.2839 \mathrm{E}+00$ & 33.000 \\
$7.2670 \mathrm{E}-01$ & 41.500 \\
$2.3303 \mathrm{E}-01$ & 57.500 \\
$3.0222 \mathrm{E}-03$ & 69.000 \\
$1.7376 \mathrm{E}-02$ & 75.500 \\
$7.0331 \mathrm{E}-02$ & 95.000 \\
$2.1157 \mathrm{E}-01$ & 140.000 \\
$4.3918 \mathrm{E}-01$ & 220.000 \\
$7.9237 \mathrm{E}-01$ & 365.000
\end{tabular}

FLOW
$-1.5010 E+01$
$8.4109 E+00$
$5.5885 E+00$
$4.5841 E+00$
$3.5434 E+00$
$2.0155 E+00$
$1.0516 E+00$
$5.8627 E-01$
$1.0154 E-01$
$5.1011 E-03$
$2.7665 E-02$
$1.0615 E-01$
$2.7576 E-01$
$5.4369 E-01$
$9.5470 E-01$

DEPTH

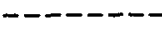

0.300

0.900

2.100

4.750

12.750

28.500

35.000

47.000

62.500

71.000

79.500

107.500

162.500

260.000

400.000

\begin{tabular}{c} 
FLOW \\
\hdashline $1.1536 \mathrm{E}+01$ \\
$7.4028 \mathrm{E}+00$ \\
$5.1832 \mathrm{E}+00$ \\
$4.2514 \mathrm{E}+00$ \\
$3.2118 \mathrm{E}+00$ \\
$1.5696 \mathrm{E}+00$ \\
$8.1588 \mathrm{E}-01$ \\
$4.0127 \mathrm{E}-01$ \\
$1.2309 \mathrm{E}-02$ \\
$9.1057 \mathrm{E}-03$ \\
$4.4025 \mathrm{E}-02$ \\
$1.5487 \mathrm{E}-01$ \\
$3.5510 \mathrm{E}-01$ \\
$6.6417 \mathrm{E}-01$ \\
$1.0467 \mathrm{E}+00$
\end{tabular}




\section{Distribution}

No. of

\section{Copies}

\section{OFFSITE}

B Albright

Desert Research Institute

2215 Raggio Parkway

Reno, NV 89512

B Andraski

USGS

333 West Nye Lane

Carson City, NV 89706

M Ankeny

D.B. Stephens and Associates 6020 Academy NE

Suite 100

Albuquerque, NM 87109

C Benson

Univ. of Wisconsin-Madison

2214 Engineering Hall

1415 Engineering Drive

Madison, WI 53706

B. Scanlon

Bureau of Economic Geology

University of Texas at Austin

University Station

Box X

Austin, TX 78713

M Young

Desert Research Institute

755 Flamingo Road

Las Vegas, NV 89119
No. of

Copies

\section{ONSITE}

\section{Fluor Federal Services}

R Khaleel

B4-43

FM Mann

HO-22

RJ Puigh

B4-43

38 Pacific Northwest National Laboratory

CR Cole

K9-36

JL Downs

K6-85

MJ Fayer (20)

K9-33

GW Gee

K9-33

LH Gerhardstein

K7-28

CT Kincaid

K9-33

RR Kirkham

K9-33

RJ Lenhard

K9-33

PD Meyer

BPO

GP Streile

K9-33

JK Tarantino

K9-41

AL Ward

K9-33 